\title{
Common standards via the backdoor : the domestic impact of asylum policy coordination in the European Union
}

Citation for published version (APA):

Engelmann, C. (2015). Common standards via the backdoor : the domestic impact of asylum policy coordination in the European Union. [Doctoral Thesis, Maastricht University]. Datawyse / Universitaire Pers Maastricht. https://doi.org/10.26481/dis.20150320ce

Document status and date:

Published: 01/01/2015

DOI:

10.26481/dis.20150320ce

Document Version:

Publisher's PDF, also known as Version of record

Please check the document version of this publication:

- A submitted manuscript is the version of the article upon submission and before peer-review. There can be important differences between the submitted version and the official published version of record.

People interested in the research are advised to contact the author for the final version of the publication, or visit the DOI to the publisher's website.

- The final author version and the galley proof are versions of the publication after peer review.

- The final published version features the final layout of the paper including the volume, issue and page numbers.

Link to publication

\footnotetext{
General rights rights.

- You may freely distribute the URL identifying the publication in the public portal. please follow below link for the End User Agreement:

www.umlib.nl/taverne-license

Take down policy

If you believe that this document breaches copyright please contact us at:

repository@maastrichtuniversity.nl

providing details and we will investigate your claim.
}

Copyright and moral rights for the publications made accessible in the public portal are retained by the authors and/or other copyright owners and it is a condition of accessing publications that users recognise and abide by the legal requirements associated with these

- Users may download and print one copy of any publication from the public portal for the purpose of private study or research.

- You may not further distribute the material or use it for any profit-making activity or commercial gain

If the publication is distributed under the terms of Article 25fa of the Dutch Copyright Act, indicated by the "Taverne" license above, 


\section{COMMON STANDARDS VIA THE BACXDOOR THE DOMESTIC IMPACT OF ASYLUM POLICY COORDINATION IN THE EUROPEAN UNION}

CLAUDIA ENSEELMANIN
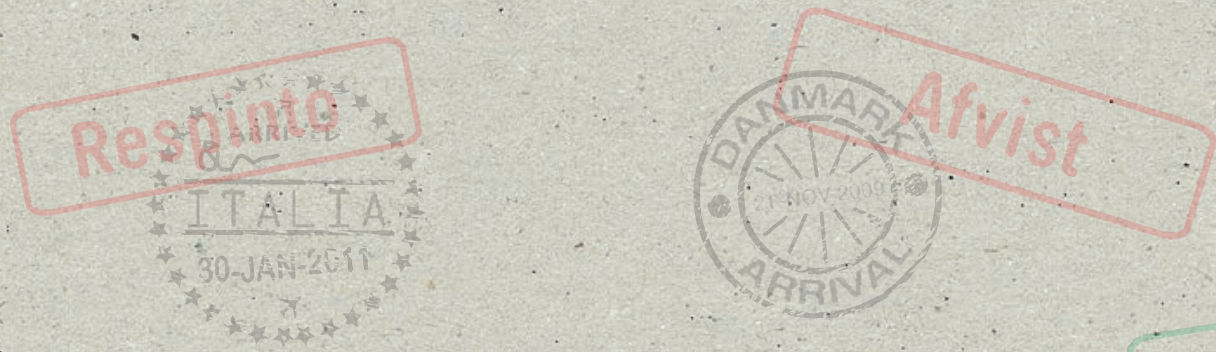
Production: Datawyse / Universitaire Pers Maastricht

(C) Copyright, Claudia Engelmann, Maastricht 2015

ISBN 9789461594204 


\title{
Common standards via the backdoor The domestic impact of asylum policy coordination in the European Union
}

\author{
DISSERTATION \\ to obtain the degree of doctor at Maastricht University, \\ on the authority of the Rector Magnificus, Prof. dr. L.L.G. Soete, \\ in accordance with the decision of the Board of Deans, \\ to be defended in public \\ on Friday, 20 March 2015 at 12.00 hours \\ by \\ Claudia Engelmann
}

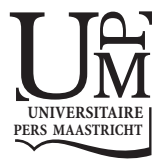




\section{$\underline{\text { Supervisors }}$}

Prof. dr. T. Christiansen

Prof. dr. M. P. Vink

Assessment Committee

Prof. dr. C. Neuhold (chair)

Prof. dr. T. Conzelmann

Prof. dr. K. Koser

Dr. K. M. Kyrieri (European Institute for Public Administration)

Dr. E. Thielemann (London School of Economics and Political Science) 


\section{Table of contents}

Acknowledgements $\quad 9$

List of tables 11

List of figures 12

List of boxes 12

List of abbreviations 13

1. Introduction 15

1.1. The human story 15

1.2. Setting the scene: international refugee law 16

1.3. The evolution and nature of asylum governance in Europe 18

1.3.1. First phase of the Common European Asylum System 19

1.3.2. Second phase of the Common European Asylum System 20

1.4. Beyond legal harmonisation $\quad 21$

1.5. Research questions 24

1.6. Research on EU asylum governance and its domestic impact 25

1.6.1. EU asylum governance 25

1.6.2. Domestic impact 27

1.7. Outline of study 29

2. Setting up the puzzle: safe country of origin policies across Europe 31

2.1. Introduction 31

2.2. The notion of safe country of origin 32

2.3. European cooperation on safe country of origin policies 35

2.3.1. The start of intergovernmental cooperation on safe countries of origin $\quad 35$

2.3.2. EU policy and the Asylum Procedures Directive 36

2.3.3. The proposed EU-wide common list on safe countries of origin 38

2.4. The national regulation of SCO policies $\quad 39$

2.4.1. Data 40

2.4.2. Introduction of SCO policies 40

2.4.3. Introduction of SCO lists and number of designations $\quad 42$

2.4.4. The content of national SCO lists 45

2.4.5. Some normative concerns 50

2.5. Conclusion $\quad 52$ 
3. Theoretical and analytical framework $\quad 55$

3.1. Introduction 55

3.2. European level cooperation 57

3.2.1. Transnational communication as a mechanism explaining convergence 58

3.2.2. Intensive transgovernmentalism and policy coordination 59

3.2.3. Deliberative intergovernmentalism 61

3.2.4.. Informal governance 62

3.2.5. Analytical framework I: operationalising policy coordination 64

3.3. Catalysts for domestic change 66

3.3.1. Logic of consequences 67

3.3.2. Logic of appropriateness 70

3.3.3. Analytical framework II: operationalising the two logics of action $\quad 74$

$\begin{array}{ll}\text { 3.4. Conclusion } & 76\end{array}$

$\begin{array}{ll}\text { 4. Methodology } & 79\end{array}$

$\begin{array}{ll}\text { 4.1. Introduction } & 79\end{array}$

4.2. Research design $\quad 79$

4.2.1. Case selection $\quad 82$

4.2.2. Background on cases $\quad 87$

4.3. Data collection 93

4.3.1. Primary sources $\quad 95$

$\begin{array}{ll}\text { 4.3.2. Secondary sources } & 96\end{array}$

4.4. Interviews as a data source $\quad 97$

$\begin{array}{ll}\text { 4.4.1. Selecting interviewees } & 97\end{array}$

4.4.2. Conducting interviews $\quad 99$

$\begin{array}{ll}\text { 4.5. Data analysis } & 100\end{array}$

$\begin{array}{ll}\text { 4.6. Conclusion } & 101\end{array}$

5. Coordinating asylum policies and information in Europe: cooperation on country of origin information 103

5.1. Introduction 103

5.2. Collecting country of origin information in the national context 104

5.2.1. About country of origin information 104

5.2.2. Structure and functioning of COI units 106

$\begin{array}{ll}\text { 5.2.3. Pressure on COI units } & 110\end{array}$

5.3. Cooperation on country of origin information $\quad 114$

5.3.1. COI cooperation in policy perspective 114

5.3.2. The spectrum of COI cooperation $\quad 116$

5.4. Informal cooperation on country of origin information 117

$\begin{array}{ll}\text { 5.4.1. Some general observations } & 118\end{array}$ 
5.4.2. Intergovernmental Consultations on Migration, Asylum and Refugees serving an early need for global COI exchange

5.4.3. CIREA - an informal start at the EC level

5.4.4. Bilateral COI cooperation - the informal end of the scale

5.5.1. Towards formalising COI cooperation: the role of the European Commission

5.5.2. The EU as a laboratory of COI cooperation

6. Strategic policy transfer: domestic change following a logic of consequences

6.1. Introduction

6.2. Domestic preferences - why have a safe country of origin rule?

6.3. Domestic constraints

6.3.1. Relation between executive and legislative $\quad 150$

6.3.2. Role of national courts 155

6.3.3. Role of civil society 159

6.4. Engagement in transnational asylum policy coordination for the purpose of acquiring information on other countries' policies

$\begin{array}{ll}\text { 6.5. Justifying legitimacy of action } & 169\end{array}$

$\begin{array}{ll}\text { 6.6. No change of preferences } & 174\end{array}$

$\begin{array}{lr}\text { 6.7. Conclusion } & 179\end{array}$

7. Coping by copying: domestic change following a logic of appropriateness

7.1. Introduction

7.2. Domestic conditions preceding policy coordination 184

$\begin{array}{ll}\text { 7.2.1. Newness of the policy issue } & 185\end{array}$

$\begin{array}{ll}\text { 7.2.2. Few cognitive priors by the decision-maker } & 187\end{array}$

7.3. Asylum policy coordination in epistemic communities $\quad 189$

$\begin{array}{ll}\text { 7.3.1. A knowledge-community } & 190\end{array}$

7.3.2. A shared understanding of work, of problems and solutions 192

7.3.3. Informal set-up and insulation from political pressure 196

7.4. A Europe-wide consensus on safe country of origin policies 200

7.4.1. The emergence of a safe country of origin norm 200

$\begin{array}{ll}\text { 7.4.2. The adoption of an appropriate norm } & 202\end{array}$

7.5. Indeed social learning? Domestic conditions when downloading 206

$\begin{array}{ll}\text { 7.5.1. Domestic institutions facilitating consensus } & 207\end{array}$

$\begin{array}{ll}\text { 7.5.2. Political culture } & 208\end{array}$ 
7.5.3. Conclusion

7.6. Summary of findings for each of the cases

7.6.1. Germany

7.6.2. UK

7.6.3. Luxembourg

8. Conclusion

8.2. Answering the research questions

8.2.1. Do safe country of origin policies become more similar or more diverse?

8.2.2. How can we conceptualise and theorise recent forms of European asylum cooperation?

8.2.3. How does policy coordination in the field of asylum policy, and cooperation on country of origin information in particular, work?

8.2.4. What is the role of COI cooperation in the domestic policy-making process relating to safe country of origin policies?

8.3. Bridging both logics: consequences and appropriateness

8.4. The future of the Common European Asylum System

8.4.1. Convergence vs. divergence

8.4.1. Policy coordination and the role of EASO

8.5. The normative dimension

8.5.2. Cooperation on country of origin information

Annex I: List of interviews and email communication

Annex II: Provisions from Directive 2013/32/EU relating to the SCO notion

Annex III: National provisions regulating the safe country of origin notion in the four countries selected 


\section{Acknowledgements}

This book would not have been possible without Thomas Christiansen and Maarten Vink. It was their idea to come up with a $\mathrm{PhD}$ proposal together, and I am grateful that they invited me to implement that idea. I thank Thomas for always being able to see the bigger picture and for always giving me the impression that I can finish the project. I thank Maarten for many hours of closely reading my manuscripts, for inviting me from day one to work and write together, and for always being accessible. My personal and professional development in the last five years, this book, and staying sane throughout (most of) the process is greatly attributed to both of you.

Starting the $\mathrm{PhD}$ adventure is to a big extent owed to Anna Würth from the German Institute for Human Rights. While working for and with her, I learned how to do research and to trust in my own abilities. I also owe thanks to Margaret Bedggood at Oxford University and Almut Todorov at the University of Konstanz for their guidance and inspiration.

A big part of the $\mathrm{PhD}$ project was about talking to people. I am grateful to all my interview partners for having taken the time to explain the ins and outs of their work to me. Some helped me to gather data much beyond what their job would require, including Stefan Kessler, Anouk Kirpach, Giacomo Orsini, Gabriele Wecker and the staff of the Westminster Archive. For translations and language editing, I thank David Frank Barnes, Steffi de Jong, Nigel Mifsud, Tina Schmidt and Ruben Wiggers.

The Faculty of Arts and Social Science at UM was my professional home during the $\mathrm{PhD}$ process. From the very start, I felt I was at the right spot in the right moment. Some people helped me with theory, methodology or the pain of substance; others supported me in finding my place within academia without losing my mind. They include: Alexandra, Alexander, Aneta, Barbara, Christoph, Christine N., Elissaveta, Esther, and Marieke. I thank Sophie for her support and for being a role model for many of us female PhDs. I also owe thanks to Joke, Sabine, Jacqueline, Dianne and Lidwien, who helped me navigating through all administrative hurdles. Research has only been one part of my job description at FASoS. In fact, I soon became equally (if not more) excited about teaching. This is also due to some colleagues who gave me the space and inspiration to grow as a teacher, including Thomas, Petar and especially Heidi. Beyond FASoS, colleagues from other faculties and universities provided me with invaluable feedback, including Jasper Krommendijk, Will Lowe, Ingo Rohlfing and Natascha Zaun. 
Not being trained as a political scientist, I substantially profited from training provided by the Netherlands Institute of Government. I also owe thanks to the FASoS Graduate School as well as colleagues I met during conferences and workshops of the European Consortium for Political Research, the University Association for Contemporary European Studies and the ODYSSEUS Network.

A completed PhD not only needs good supervision, training and feedback from colleagues but also friends, distraction and good coffee. For the latter, I owe thanks to the Banditos crew. I also thank Anna H., Constance, Eefje, Eliza, Eva, Joan, Judith, and Maarten for being friends and being there; Marijke for sharing sweets, wedding excitements and many hours of happiness and frustration concerning the thesis; Tessa for constantly turning a short coffee into an enjoyable 2 hour-long break full of laughter; and Ilse for sleep-overs and Indonesian dinners. Talking of friends, the biggest thank you goes to Natasja. Thank you for being a great companion from day one of my time in Maastricht.

Lastly, this book would have not been possible without the unconditional support of my parents and Torsten. Thank you for keeping me grounded. 


\section{List of tables}

3.1: A typology of informal institutions

3.2: Overview of indicators for describing and explaining policy coordination

3.3: Overview of conditions for policy-making following a logic of consequences

3.4: Overview of conditions for policy-making following a logic of appropriateness

4.1: Distribution of cases across the spectrum of engagement in informal asylum policy coordination

4.2: Distribution of cases for hypothesis 1

4.3: Distribution of cases for hypothesis 2

4.4: Overview of SCO regulations in countries selected for case studies

4.5: Overview of field trips conducted

5.1: COI units in the EU-27, Norway and Switzerland

5.2: Fora facilitating country of origin information exchange (incl. scope of membership and year of foundation)

6.1: Overview of conditions for policy-making following a logic of consequences

6.2: Number of asylum seekers and recognition rates for countries proposed to be included in the German safe country of origin list in 1992

6.3: Number of recognition and refusal rates for asylum seekers from Senegal in Germany in 1994

6.4: Number of asylum seekers and recognition rates for all countries proposed to be included in the British safe country of origin list in 2002

6.5: Number of asylum seekers from countries designated as safe in Luxembourg, as of 2011

6.6: Number of asylum seekers in 2003 and 2004 for countries included in the Maltese safe country of origin list

7.1: Overview of conditions for policy-making following a logic of appropriateness

7.2: Year of introducing SCO provision in national asylum law in 2004 and 2007 accession countries

7.3: $\quad$ Proposed EU-wide SCO list and Maltese SCO list 


\section{List of figures}

2.1: Introduction of SCO notion in domestic asylum law (source: own compilation)

2.2: Presence of SCO lists in EU-27 (source: own compilation)

2.3: Total number of SCO designations in EU-27 (source: own compilation)

2.4: Number of EU member states that have designated Western Balkan countries as safe (source: own compilation)

2.5: Number of EU member states that have designated Benin, Ghana and Senegal as safe (source: own compilation)

2.6: Percentage of countries of origin designated as SCO by one or more EU member states in 2013

3.1: Levels of analysis

4.1: Cross-case level and within-case level of empirical analysis

4.2: Number of asylum-seekers per 1 million inhabitants in 2013 (source: Eurostat)

9.1: Example of tweet contributing to current asylum debate in Europe

\section{List of boxes}

5.1: The importance of country of origin information for assessing the case of Mr. Bavol from Serbia

5.2: Fact-finding missions: common legal requirements as one prerequisite for informal COI cooperation

6.1: $\quad$ The Javed 2001 Case

6.2: The Independent Advisory Group on Country Information

6.3: Strategic learning from other countries: the practice of the German Federal Office for Migration and Refugees

6.4: Other means to achieve the same ends - the example of Serbian asylum seekers in Germany

7.2: Fact-finding missions as a means of generating common knowledge

7.3: Changing attitudes towards asylum policy coordination

7.4: An illustration of COI cooperation as epistemic community 198

7.5: The consensual designation of Serbia as a safe country of origin 


\section{List of abbreviations}

BAMF Bundesamt für Migration und Flüchtlinge, Federal Office for Migration and Refugees

BMI Bundesministerium des Inneren

C.

Column, columns

CAHAR Ad hoc Committee of Experts on the Legal Aspects of Territorial

Asylum, Refugees and Stateless Persons

CDU Christlich Demokratische Union Deutschlands

CEAS Common European Asylum System

CIREA Centre for Information, Discussion and Exchange on Asylum

COI

CSU

Country of origin information

Christlich-Soziale Union

CSFR

Czech and Slovak Federal Republic

EASO European Asylum Support Office

EC

European Communities

ECS

European Country Sponsorship

ECJ

European Court of Justice

EMN

European Migration Network

ExCom

Executive Committee of UNHCR

EU

European Union

$\mathrm{HoC}$

House of Commons

HoL

House of Lords

IAGCI Independent Advisory Group on Country Information

IGC

JHA

Intergovernmental Consultations on Migration, Asylum and Refugees

$\mathrm{n} / \mathrm{a}$

Justice and Home Affairs

NGO

Not available

NIA

Nongovernmental organisation

NSA Non-suspensive appeal

OMC

Open Method of Coordination

Par.

Paragraph

PoM

Parliament of Malta

SCO

Safe country of origin

SPD

Sozialdemokratische Partei Deutschlands

TDI

Temporary Desk Iraq

UKBA

UK Border Agency

UNHCR

United Nations High Commissioner for Refugees 



\section{Introduction}

\subsection{The human story}

The human story of asylum policy is the story of a man called Mr. Bavol. He is aged 21 and comes from a small village just outside of Belgrade, Serbia. He is a Rom. In his village, Roma families have always been met with distance and hostility. However, over the last few months, the situation has worsened. His Roma neighbours were forced to leave their houses; another neighbour's house was set on fire. Mr. Bavol lives together with his mother. They both were threatened many times over the last weeks. He was told to leave the village as soon as possible - otherwise something bad would happen to him and his mother. Mr. Bavol heard that one of his childhood-friends managed to escape to Germany and started his own business there. With a heavy heart, he leaves his mother and the village he has grown up in, and makes his way to Germany. His goal is to reach the German city of Mannheim, where his former school mate lives. Mr. Bavol has no problems crossing the border to Croatia, moving to Slovenia and into Austria. In Germany, somewhere south of Munich, he gets into a police control and tells the officers that he wants to apply for asylum.

The human story of asylum policy is also about a man called Mr. Franz. He is 45 years old, lives in the German city of Munich and has two children. He works since 20 years for the local asylum authority called Außenstelle M 2 of the Bundesamt für Migration und Flüchtlinge. For almost all of his work life, he has been a civil servant responsible for deciding on asylum applications. He knows his job by heart. Since shortly, Mr. Franz is responsible for applicants from the Western Balkan countries. This means that - together with some other colleagues - he is solely deciding on asylum applications of people coming from Serbia, Macedonia and Bosnia-Herzegovina. He is not too happy with his new country focus. In fact, he had been an expert on Latin America for most of his work-life. However, given the recent increase in asylum applications from the Western Balkan, his supervisor asked him to work on these countries instead. Mr. Franz has to check whether Mr. Bavol has a right to stay in Germany. Most of the applications ending up at Mr. Franz' desk are declined. In Mr. Bavol's case, he checks reports on Serbia and in particular on the situation for Roma living in Serbia. He also checks whether Mr. Bavol's story is correct, whether he and his family are indeed in danger and thus qualify for protection. For doing so, Mr. Franz has very limited time - too little 
time, he thinks. In fact, there is a whole pile of similar cases waiting for him to be decided by the end of this week.

Both (fictitious) stories - the one of Mr. Bavol and the one of Mr. Franz - are closely connected. They are connected via rules governing the asylum procedure. These rules regulate the rights of the refugee to be granted protection as much (or little) as they regulate the obligation of the case officer (Mr. Franz). The rules are set by international law, by European law and - in this specific case - also by German law. While Mr. Franz might have some leeway in making a decision on Mr. Bavol's case, he is also bound to a set of rules on how asylum seekers as Mr. Bavol are dealt with, especially if they come from a country like Serbia. Asylum seekers from Serbia are not very often granted protection in an EU member state - in contrast to people coming from Somalia, Iran or Afghanistan. According to policy-makers in Berlin, this low recognition rate justifies a 'special treatment' meaning an accelerated check of the asylum application with less procedural safeguards. Decision-makers argue that such an approach is justified by the generally good human rights situation in countries like Serbia, and the subsequent unlikely need for protection. Such measures are called safe country of origin (SCO) policies.

Not only the German policy-maker has specified how to deal with asylum seekers from certain countries of origin - also the Dutch, the Polish, the Maltese and many other EU member states have done so. And in fact, asylum policies across EU member states on countries of origin (like Serbia) are quite similar. Given the comprehensive set of common asylum rules developed at the EU level, this policy similarity looks like an obvious result of legal harmonisation. This, however, is not the case: several attempts to harmonise safe country of origin policies across the EU have failed. Thus, there is no common legal framework, no formal agreement on neither the existence nor the content of these policies nor specific countries (such as Serbia) to be declared as safe. And this is the puzzle driving my $\mathrm{PhD}$ thesis. How can we explain policy convergence in Europe given the absence of a common legal framework? I explore in this thesis whether informal coordination of asylum policy among EU member states accounts for policy convergence. By focusing on safe country of origin policies, I am asking how these policies come into force, and what role policy coordination between countries plays in this regard.

\subsection{Setting the scene: international refugee law}

International cooperation between states for the protection of refugees became an issue in the early twentieth century. During that time and due to the tightening of border controls, refugees and migrants were no longer allowed to cross borders without permission. Contemporary events - the Russian Revolution, the First World War and the massive refugee movements produced by the Balkan Wars - posed a problem to this closure of national borders (Lavenex 1999, p.5). Governments soon realised not only 
that some sort of legal status had to be given to people fleeing their home country, but also that the refugee problem was one of common interest for the international community.

Preceded by several other attempts to coordinate and acknowledge international responsibility of refugees, the central international organisation for the protection of refugees - the United Nations High Commissioner for Refugees (UNHCR) - was established in 1949. UNHCR prepared the 1951 Geneva Convention relating to the Status of Refugees (UNHCR 1951). The Geneva Convention is, together with its 1967 Protocols (UNHCR 1967), still the primary source of international refugee law. ${ }^{1}$ It creates minimum standards for granting not only basic protection but also rights to refugees and asylum-seekers, including the right to work and the right to education. Negotiations leading to the Geneva Convention already reflected the main tension in asylum policy: the balancing act between rights of the individual and rights of the state. A binding obligation on states to provide asylum in the form of a subjective right of the refugee to receive protection has never been established. The international refugee regime has been - and still is - based on the sovereign right of the nation state to grant asylum rather than on the right of the refugee to be granted asylum (Lavenex 1999, p.12).

Nevertheless, what has been established and is considered as a norm of customary international law today is the notion of 'non-refoulement'. Non-refoulement, in the context of the Geneva Convention, means that no state can return a refugee to his or her country of origin, when his or her life or freedom would be threatened on account of his or her race, religion, nationality, membership to a particular social group or political opinion (article 33). Non-refoulement is the central principle in asylum law, contained not only in the Geneva Convention but also in the UN International Covenant on Civil and Political Rights, the UN Convention against Torture and Other Cruel, Inhuman or Degrading Treatment or Punishment and the European Convention on Human Rights. The notion of non-refoulement is also central to this research. It lies at the heart of any single decision on an asylum application. It is also key for policy decisions on asylum matters, such as safe country of origin policies. These policies are targeted towards groups of asylum seekers originating from one country of origin, such as Serbia. Based on a general assessment of the situation in the country, the legislator assumes that asylum applicants from this country are not in need of protection and thus, can be send back to their home country. According to many critics, these policies risk violating the principle of non-refoulement (Costello 2005; Martenson and McCarthy 1998; Byrne and Shacknove 1996; Goodwin-Gill 1992).

\footnotetext{
${ }^{1}$ For a comprehensive overview of international asylum law, see Goodwin-Gill and McAdam (2007).
} 


\subsection{The evolution and nature of asylum governance in Europe}

Europe has gone a long way from the first realisation of the need for cooperation in asylum matters to the adoption of common legal standards in the form of several asylum directives. Also these developments have first and foremost been shaped by the fact that asylum issues are deeply entrenched in national political and judicial systems and are strongly related to questions of national sovereignty (Lavenex 2010, p.458). Both process and outcome of European integration are very much shaped by the prevalence of national sovereignty. However, they are also shaped by the need for cooperation between countries - and this need was early on recognised by some EU member states.

Countries in Europe realised soon that there is a need for cooperation on migration issues due to the development of a Single Market (Single European Act of 1985), the abolition of internal borders and the agreement on joint external borders (Schengen 1985 ) as well as the increasing number of asylum seekers in Western European states in the late 1980s and early 1990s. During that time, various informal ad-hoc groups were established, which soon mushroomed, institutionalised and expanded their mandates to new occurring problems (Monar 2001). Over the years, member states developed a more institutionalised and comprehensive approach to asylum and migration. While asylum cooperation in the beginning was very much an informal process, formalisation took off in the early 1990s. With the Maastricht Treaty of 1993, a formal linkage of the asylum regime to the Community process was established. Asylum policy became included in the third pillar of the European Union, and as a consequence thereof, there was now a formal institutionalised setting within which immigration and asylum cooperation occurred. Still, few agreements were made in the 1990s, mainly because the Council could only decide by unanimity. Also, there was no role for either the European Parliament (EP) or the European Court of Justice (ECJ). Intergovernmentalism prevailed (Monar 2001; Noll 2000).

With the Treaty of Amsterdam (1999), European asylum governance became more communitarised: asylum and immigration were moved from the third 'intergovernmental' pillar to the first 'Community' pillar. The move implied a potentially greater role for the Commission, the European Parliament and the European Court of Justice. However, Amsterdam was also determined by a 'formalization of flexibility' (Lavenex and Wallace 2005, p.466) establishing a number of strong intergovernmental elements in the first pillar: asylum matters would for another five years (1999-2004) be regulated by the Maastricht rules, meaning the sole right of initiative for the member states, Council unanimity voting and only consultative power for the EP. Only after that period would the Commission obtain the exclusive right of initiative and would the Council move to co-decision with the EP and qualified majority voting. The European Court of Justice 
obtained a more prominent role in EU asylum policy but would only after the entry into force of the Lisbon Treaty (2009) become fully competent to rule. ${ }^{2}$

\subsubsection{First phase of the Common European Asylum System}

During the years 1999 to 2004, EU member states adopted the first comprehensive set of legally binding rules in the field of asylum. Based on the Tampere Programme of 1999 (European Council 1999), the rules aimed at establishing a Common European Asylum System (CEAS), which first and foremost related to similar asylum standards across the EU member states. The EU-15 agreed on five measures targeted at harmonising member states' legal frameworks, including the Dublin II Regulation (Regulation 2003/343/EC), the Asylum Procedures Directive (Directive 20005/85/EC), the Reception Conditions Directive (Directive 2003/9/EC), the Qualification Directive (Directive 2004/83/EC) and the Eurodac Regulation (Regulation 2000/2725/EC). These rules represented the first phase of the Common European Asylum System. What is important to note is that these measures were adopted under the old intergovernmental rules meaning the Council decided by unanimity and there was no decision-making power for the Parliament. Also, the measures were adopted by the EU-15 only and thus just before eight new member states would join the club. Consequently, we see that - though supranational elements of decision-making had been formally agreed upon in 1999 - intergovernmental rules prevailed: what had been agreed upon amongst the governments of 15 countries with only consultation power for the European Parliament forms, until today, the basis for a common European asylum policy.

Regarding implications of the rules adopted, scholars disagree. While some argue that the acquis represents little more than minimum standards and, in some cases, is even incompatible with international obligations (Costello 2005), others stress its increasingly liberal and progressive character (Thielemann and El-Enany 2009; Kaunert and Leonard 2012). What, however, cannot be neglected is that the adoption of these measures failed to achieve one of its main goals, namely more similar asylum policies across the EU. As the Commission notes itself, the rules adopted 'have not created the desired level playing field' (European Commission 2008b, p.4). There are still wide differences among the national asylum systems of the EU member states. These differences relate to both procedural matters and the actual outcome of the asylum procedure (UNHCR 2010b; ECRE 2010; European Commission 2008b; Costello 2006). Recognition and rejection rates of applicants from the same country of origin vary greatly between member states (European Commission 2009c, annex 6). In order to further work towards harmonising standards, the European Commission proposed in its Policy Plan on Asylum several measures for the second phase of the Common European Asylum

\footnotetext{
${ }^{2}$ For a comprehensive analysis of this 'partial communautarization' see Kostakopoulou (2000).
} 
System, including a further revision of the asylum acquis and a focus on practical cooperation (European Commission 2008b).

\subsubsection{Second phase of the Common European Asylum System}

The second phase of the Commen European Asylum System saw a revision of the asylum acquis ${ }^{3}$, eventually leading to the following instruments (of 2014):

- Dublin Regulation (Regulation 604/2013/EU) regulating the country responsible for processing an asylum application

- Asylum Procedures Directive (Directive 2013/32/EU) regulating the asylum procedure, such as right to legal assistance, rights and obligations during the interview

- Reception Conditions Directive (Directive 2013/33/EU) regulating the living conditions of asylum seekers, such as housing, schooling, health care and right to education

- Qualification Directive (Directive 2011/95/EU) regulating the definition of a refugee and who qualifies for protection

- Returns Directive (Directive 2008/115/EC) setting out rules on the return of rejected asylum seekers

- Temporary Protection Directive (Directive 2001/55/EC) specifying measures to be taken in case of sudden influxes of refugees

Despite these rules having been adopted, two observations are striking: first, EU member states continue being reluctant to transfer power to the EU institutions. Thus, many decisions remain in the hands of individual countries rather than supranational institutions. We see this primarily in the setup of the Common European Asylum System: it is still a much decentralised system with agreement on only minimum norms leaving a lot of room for member states when it comes to implementing these norms. In fact, a lot of issues remain entirely in the hands of member states. Second, many differences prevail. It still makes a big difference whether someone applies for asylum in one EU member state, or in another. Given that there is no further legislation on asylum planned for the near future (Peers 2013, p.1), one wonders how asylum policies will become more similar across the EU.

Nevertheless, it is commonly acknowledged that the second phase of the CEAS was achieved by much more of a supranational decision-making process than the previous one. Not only did the European Parliament become an equal decision-maker to the Council, but also the Commission gained competence as well as the European Court of Justice (Kaunert and Leonhard 2012). There is disagreement over in how far these institutions were able to exert their newly-gained powers. It was argued that the Commission managed to establish itself as a policy entrepreneur promoting the Geneva Convention

\footnotetext{
${ }^{3}$ The term 'EU asylum acquis' refers to the accumulated asylum law adopted at the European level.
} 
(Kaunert 2009). Also the strengthened role of the European Court of Justice (ECJ) as one element of increasing judicialisation in EU asylum policy has led towards more liberal policies (Kaunert and Leonhard 2012). However, the Parliament has been unable to construct a more liberal immigration policy (Ripoll-Servent 2011).

Despite these developments at the supranational level, observers argue that governments frequently look for alternative ways of policy-making outside the formal EU structures. They do so to avoid liberal pressures stemming from communitarisation as well as obstacles faced at the domestic level (Maurer and Parkes 2007; Lavenex 2006; Guiraudon 2000). In addition, the recourse to more informal, intergovernmental modes of decision-making is explained with increasing difficulties to come to an agreement in the ordinary legislative procedure - be it because of the almost doubling of EU member states (and respective interests) from 15 to 28, because of the increasingly assertive role of the European Parliament (Lavenex 2010, p.466) or because of any other constraints faced by policy-makers. Groups of member states meet informally to coordinate their asylum policies or prepare changes eventually intended at the EU level. These groups of member states meet in fora such as the G5/G6, the Salzburg Forum or the Future Group. Evaluation of these groups are mixed: while some see their advantage in precooking decisions and subsequently increasing efficiency at the formal, EU level (Oel and Rapp-Lücke 2008; von Koppenfels 2001), others stress the deliberate aim of policymakers to circumvent official institutions of the EU and the related lack of scrutiny and transparency (Lavenex 2010).

\subsection{Beyond legal harmonisation}

There is little disagreement about the fact that asylum standards across Europe are very diverse. It still makes a huge difference whether an asylum seeker asks for protection in Italy or in Sweden, in the UK or in Poland. The asylum procedure as such, the reception conditions and most importantly, the outcome of an asylum seeker's claim can be very different: while the person asking for asylum might qualify for protection in one country, she might be sent back to her country of origin in another one. This was also acknowledged in the Stockholm Programme, the most recent multi-annual Justice and Home Affairs programme, agreed on by the European Council in 2009:

The European Council remains committed to the objective of establishing a common area of protection and solidarity based on a common asylum procedure and a uniform status for those granted international protection. While CEAS should be based on high protection standards, due regard should also be given to fair and effective procedures capable of preventing abuse. It is crucial that individuals, regardless of the Member State in which their application for asylum is lodged, are offered an equivalent level of treatment as regards reception conditions, and the same level as regards procedural arrangements and status determination. The objective should be that similar cases should be treated alike and result in the same outcome (European Council 2009, paragraph (par.) 6.2). 
Furthermore:

There are still significant differences between national provisions and their application. In order to achieve a higher degree of harmonisation, the establishment of CEAS, should remain a key policy objective for the Union. Common rules, as well as a better and more coherent application of them, should prevent or reduce secondary movements within the Union, and increase mutual trust between Member States (ibid).

In order to overcome these differences, the legal harmonisation of asylum standards is not sufficient. Instead, 'practical cooperation' has become one of the buzzwords (Commission 2006a; Commission 2006b), and seems to be the panacea towards achieving similar asylum standards in Europe. In a nutshell, the term 'practical cooperation' refers to cooperation between the actors that are involved in implementing policy. For the field of Justice and Home Affairs, this could, for example, relate to cooperation between judges, between national data protection officers or between national asylum administrations. For national asylum administrations, this would, for example, mean an exchange of practices on how to deal with asylum seekers from Serbia that belong to the Roma minority.

According to the European Commission, such an exchange would be a key tool towards making asylum standards more similar across Europe:

\footnotetext{
Practical Cooperation will enable Member States to become familiar with the systems and practices of others, and to develop closer working relations among asylum services at the operational level. This will build a basis for wider areas of collaboration, with the development of trust and a sense of mutual interest. The main goal of practical co-operation is to improve convergence in decision-making by Member States within the framework of the rules set by the Community asylum legislation (Commission 2006a, par. 4).
}

What, however, tends to be ignored is the fact that these forms of cooperation have been practiced for a long time already - though informally and between a limited number of countries. Let us stay with the example of cooperation between national asylum administrations: for instance, the German Federal Office for Migration and Refugees cooperates already since the early 1990s with its counterparts in Austria and the Netherlands. Such cooperation relates to many different aspects ranging from bilateral exchange amongst country experts on how to evaluate cases of Roma families from Serbia to highlevel policy coordination on whether safe country of origin policies should be similar across European countries. The $\mathrm{PhD}$ thesis is based on the assumption that these policy coordination processes play an important role in the formulation of domestic asylum policies.

In order to illustrate what has been called 'practical cooperation' above, I will look at the example of cooperation between national asylum authorities on country of origin information (COI). This is a prime example of an issue where some supranational rules exist (i.e. what constitutes a ground for protection, how to justify a protection refusal) 
but most of the decisions are left to the individual member states (or rather their asylum authorities). Each member state decides itself how to collect and interpret information on the situation in countries of origin. And each state does it differently. For example, whereas in one European country asylum seekers from Mogadishu might be sent back because the region is considered to be safe, another European country might decide the opposite, and grant protection to these people. It is argued that the difference in the collection and interpretation of country of origin information is still one of the main obstacles to similar standards across Europe (UNHCR 2004). One key measure for overcoming this policy divergence is cooperation between the national authorities involved in implementing the legal rules. The idea of 'practical cooperation' in the field of country of origin information has been considerably upgraded on the political agenda since the early 2000s. As one of the most recent steps, an EU agency (European Asylum Support Office, EASO) was created that is explicitly mandated to facilitate COI cooperation.

For analysing the effect of 'practical cooperation' on the domestic asylum policymaking process, I am studying safe country of origin policies. Just to be very clear about the difference between safe country of origin policies and country of origin information: the latter is necessary for determining in individual asylum applications whether or not someone is eligible to protection; however, it is also necessary for making countryspecific policies on asylum matters, such as safe country of origin policies. ${ }^{4}$ These policies exemplify the core dilemma of modern asylum administrations, namely adhering to international refugee law by thoroughly examining whether or not it is safe for an asylum seeker to go back to his or her country of origin, while at the same time thinking about strategies for processing asylum claims more efficiently. Such strains are inherent to many aspects of asylum policy. Safe country of origin policies were also selected for the analysis because they disclose a key characteristic of asylum governance in Europe: one the one side, there are national needs for cooperation; and on the other side, there is a hesitance to commit to supranational norms. Though we only observe some minimum regulation at the EU level, member states have been very active in pursuing these policies unilaterally. This aspiration did not take place in a vacuum. Governments look what other governments do before taking a policy decision. Though there might be no formal, EU forum where safe country of origin policies are discussed and decided upon, informal transnational policy coordination takes place. It is argued in this thesis that this policy coordination plays an important role in the domestic formulation of safe country of origin policies.

There are asylum policies with similar characteristics that would have been worth to investigate. Safe country of origin policies are country-specific policies meaning they are targeted towards a group of asylum seekers originating from the same country of origin. Other country-specific asylum policies relate, for example, to safe third coun-

\footnotetext{
${ }^{4} \mathrm{~A}$ more detailed account of the nature and function of country of origin information is provided in chapter 5. A more detailed discussion of safe country of origin policies is provided in chapter 2 .
} 
tries. However, while these have been studied in-depth (see for example Costello 2005; Byrne et al 2002; Thielemann 2001; Lavenex 1999; Byrne and Shacknove 1996), there is hardly any empirical analysis of safe country of origin policies and respective decisionmaking processes.

\subsection{Research questions}

Based on previous considerations, the overarching research question for this thesis is as follows:

Main research question: What is the role of transnational policy coordination in the domestic asylum policy-making process in the EU member states?

In order to study this question, a number of sub-questions were formulated:

1. Do safe country of origin policies become more similar or more diverse?

2. How can we conceptualise and theorise recent forms of European asylum cooperation?

3. How does policy coordination in the field of asylum policy, and cooperation on country of origin information in particular, work?

4. What is the role of COI cooperation in the domestic policy-making process relating to safe country of origin policies?

The thesis starts from the puzzle of how to explain policy convergence given the absence of common rules developed at the EU level. In order to make a solid statement about convergence/divergence tendencies in asylum policy, a comprehensive analysis of the development of specific policies over time is necessary. Thus, the first sub-question investigates the development of safe country of origin policies in the EU-27 between 1990 and 2013. The respective empirical analysis concludes a rather surprising amount of convergence. Given the minimum legal framework developed at the EU level, there must be other factors than legal harmonisation accounting for this similarity.

I am arguing in this thesis that European asylum governance needs to be re-thought and scholars need to focus more prominently on informal policy coordination that has been taken place between governments of EU member states since the 1980s. This policy coordination happens until today though a lot has changed: including a move from informal to formal elements of coordinating policy; but also including many actors that are traditionally neglected by asylum studies, such as national agencies that shape and implement policy. Re-thinking recent asylum governance in Europe requires a proper conceptual and theoretical framework developed in sub-question 2. 
The third sub-question empirically analyses an example of asylum policy coordination, namely the cooperation between national asylum administrations on country of origin information. Eventually, the key aim of this $\mathrm{PhD}$ thesis is to analyse and specify what role asylum policy coordination plays in the domestic decision-making process.

Consequently, the fourth sub-question and overarching question for the whole research project investigates the role of COI cooperation in the domestic safe country of origin policy-making process. Here it is important to clarify what is meant by 'role'. First of all this includes an impact analysis, in the sense that I investigate the consequences of COI cooperation for the domestic policy-making process. Yet examining the role of COI cooperation in the policy-making process also goes beyond looking at the domestic impact only, given that such processes may take place without a clearly identifiable influence on policies at the national level. In order to answer this question, I am drawing on two logics of action - one based on a cost-benefit rationale (logic of consequences) and one based on rules of appropriateness (logic of appropriateness). They are presumed to provide complementary answers to the role of policy coordination in domestic asylum policy-making. The research questions are investigated by means of a comparative case study design. Four countries are studied in detail, including Germany, the UK, Malta and Luxemburg.

\subsection{Research on EU asylum governance and its domestic impact}

Research relevant for this study can be divided along two dimensions - EU asylum governance and the effect of EU asylum governance on domestic policy-making. The thesis aims at contributing to both.

\subsubsection{EU asylum governance}

There is a wide array of literature studying the emergence and nature of asylum governance in Europe. In the past, most of it was coined as intensive transgovernmentalism (Lavenex 2001). The early years of cooperation were characterised by intergovernmental groups that operate secretively and in the absence of any parliamentary and judicial control (see for example Lavenex 2001; Bunyan and Webber 1995). The specific character of this kind of asylum cooperation meant that there was an exclusive group of interior ministry officials who could avoid domestic constraints by meeting in a privileged setting, and allowing policy-makers to agree on common interests away from nationallevel control (Thielemann 2001, pp.18-19; Monar 2001).

With the European Parliament and the Commission gaining competences via subsequent treaty changes, the Community Method moved into focus. The gradual upgrade of supranational actors in the form of gaining competences also fuelled their scholarly analysis. The success of the Community Method in asylum policy-making was analysed 
with regard to the European Commission as a supranational policy entrepreneur (Thielemann and Zaun 2013; Kaunert 2009; Ucarer 2001), the role of the European Parliament (Ripoll-Servent and Trauner 2013; Ripoll-Servent 2011) as well as the increasing role of European courts (Kaunert and Leonhard 2012; Vedsted-Hansen 2010). During the last 15 years, Justice and Home Affairs was characterised by 'a delicate compromise between intensive transgovernmental cooperation, on the one hand, and the incremental consolidation of supranational structures, on the other' (Lavenex 2010, p.460).

Next to the Community Method, also policy coordination (as defined by Wallace 2010) as a new mode of governance evolving in EU asylum policy has been taken up by respective scholars. ${ }^{5}$ The key example for Wallace's form of policy coordination is the Open Method of Coordination (OMC). ${ }^{6}$ The possible use of OMC in asylum policy was discussed by Velluti (2007) and Monar (2003). They argue that the Commission could adopt and monitor multi-annual guidelines to be implemented through national action. The potential risk of such an approach would be its inherent intergovernmental nature (Monar 2003, p.42). However, all of this stayed hypothetical and there are no signs of OMC-like governance structures in the current EU asylum system. Another governance pattern having emerged in the new century is the growth of agencies in Justice and Home Affairs. Both Monar (2006) and Thielemann (2001) acknowledge the growing demand for information exchange between law enforcement authorities and the creation of respective policy networks. Analyses on agencies in the field of Justice and Home Affairs (JHA) mushroom both with regard to the policy field in general (Carrera et al 2013; Guild et al. 2011; Rijpma 2010; Lavenex 2010; Monar 2006) but also focusing on specific agencies, such as Frontex (Carrera et al 2013; Pollak and Slominski 2010) or EASO (Comte 2010). Much of the agencies' work was conceptualised as policy coordination (Lavenex 2010). However, none of these (agency) examples are clear cases of policy coordination (as defined by Wallace 2010) because many features of intensive transgovernmentalism prevail: agencies are being criticised for adhering to opaque decision-making procedures, and for being driven by national interests with limited or no role for the Commission, the parliament (both national parliaments and the EP) or the public (Carrera et al. 2013; Pollak and Slominski 2010). Consequently, there are also scholars who place the recent operationalisation trend (i.e. the increase of agencies and cooperation between law enforcement authorities) in the realm of intensive transgovernmentalism instead (Wolff and Mounier 2012, p.4).

\footnotetext{
${ }^{5}$ Policy coordination is characterized by Wallace (2010) as the Commission being the developer of networks of experts or epistemic communities, the involvement of independent experts as promoters of ideas, the convening of high-level groups in the Council in a brainstorming or deliberative rather then negotiating mode, and dialogue with specialized EP committees (p.98).

${ }^{6}$ For more information on the OMC see Bórras and Jacobsson 2004.
} 
In sum, there are some trends in recent European asylum governance that do not seem to fit existing conceptualisations. State executives - being based in the national ministries or law-enforcing authorities - exchange asylum-relevant information and coordinate respective policies behind closed doors and outside of formal channels. The literature review shows that scholars do not only disagree about the labels (intensive transgovernmentalism, policy coordination ...) but also about the underlying mechanisms: why do these exchanges take place? Who participates and for what reason? What is the relation between these fora and the more formal decision-making processes? And how do these governance processes translate into domestic policy-making?

What also tends to be ignored by scholars is that these processes of exchanging information and coordinating policies have been going on for many years already. In fact, they are far away from being a phenomenon of the new century's asylum governance structure in Europe. State executives exchanged ideas on policy issues and coordinated their actions throughout the 1990s already - and on a very informal basis. This brings us to an important but neglected point in EU asylum governance studies: the informal nature of cooperation. Informal governance processes, particular in a European context, have been frequently attributed importance, yet received little systematic study so far (for notable exceptions, see Kleine 2013; Christiansen and Neuhold 2012; Peters 2006; Christiansen and Piattoni 2003). Also the informal nature of European asylum governance has played a surprisingly insignificant role in the academic discussion. Several authors have noted a strong presence of informal elements in European asylum governance, but few go beyond this acknowledgement. In fact, there is a persistent informal nature to asylum cooperation (Vink and Engelmann 2012; Thouez and Channac 2006). It however remains to be analysed how this looks like, why this is the case and what it means for policy-making at both the EU and the domestic level.

This thesis contributes to the literature of asylum governance by conducting an indepth analysis of what has been called the 'operational' dimension of European asylum governance. In the course of this research, it will be defined as policy coordination meaning the horizontal coordination of policy between state executives that is determined by its informal nature and the deliberative character of interactions. It does not lead to legally-binding outcomes. I will provide a theoretical contribution to the asylum governance literature by defining this form of governance, also in relation to other forms. I will further provide a comprehensive case study of this form of policy coordination unfolding its function, its form and the kind of actors involved. Most importantly, the thesis aims at analysing the effect of policy coordination on the domestic policy-making process.

\subsubsection{Domestic impact}

A key contribution of this thesis relates to the study of country-specific policies and safe country of origin policies in particular. Country-specific policies illustrate best the core 
dilemma of modern asylum administrations, namely adhering to international refugee law by thoroughly examining whether or not it is safe for an asylum seeker to go back to his or her country of origin, while at the same time thinking about strategies for processing asylum claims more efficiently. The other prominent example of this kind of policies is the safe third country notion. ${ }^{7}$ Whereas these have been studied in depth (Costello 2005; Byrne et al 2002; Thielemann 2001; Lavenex 1999; Byrne and Shacknove 1996), the analysis of safe country of origin policies remains underdeveloped. Given the growth of these policy measures over the last years, this is a considerable gap in asylum studies - and one that this research intends to close.

The thesis aims at contributing to asylum research by studying the width and breadth of safe country of origin policies in Europe, and thus helping to understand the mechanism of asylum policy-making in general. There so far exists no comprehensive overview that captures variation across member states and time since the first introduction of these policies in the early 1990s. Existing overviews at best cover a selection of member states or time periods (UNHCR 2010b; Council of Europe 2005; European Parliament 1996; Martenson and McCarthy 1998). The most recent documentation of national safe country of origin policies was compiled by the ELENA project in 2005 (ELENA 2005). Despite its significant merits this study did not cover all EU member states. Most importantly, none of the above-mentioned collections give a temporal overview of the development of safe country of origin policies, and therefore do not provide any ground for discussing possible convergence or divergence of safe country of origin policies across EU member states.

Based on the absence of such an overview, it is not surprising that authors who have discussed the convergence/divergence question regarding safe country of origin policies have come to very different conclusions. While some argue that the application of the SCO concept and national SCO lists diverge (ECRE 2010, p.49; European Commission 2009a, p.18), others observe convergence (Costello 2006, p.3; Costello 2005). Both camps provide little systematic evidence to support their claims. This disagreement illustrates the core puzzle which drives the present analysis: on the one hand, divergence might be expected because there is no formal harmonisation at the EU level; on the other hand, one might expect convergence as countries seem to orientate their own policies in line with those of others (Byrne, Noll and Vedsted-Hansen 2004). Consequently, the very first task of the researcher is to empirically analyse the safe country of origin policies of each member state in order to make a qualified statement about convergence or divergence. The thesis provides the first comprehensive overview of such kind covering an analysis of the EU-27 over a time period of 23 years (1990-2013). With

\footnotetext{
${ }^{7}$ Safe country of origin policies presume that the country of origin of the asylum seeker is safe. Safe third country policies presume that the country through which the asylum seekers has traveled is safe. 'Third' refers to the third country after the country of origin and the country of asylum (where the asylum application has been lodged).
} 
regard to the policy field in general, the question of convergence vs. divergence of asylum policies has been discussed before - however, only from a quantitative point of view (see for example Neumayer 2005; Vink and Meijerink 2003).

Finally, the thesis aims at analysing the European impact on the domestic asylum policy-making process. Naturally, one would turn to Europeanisation studies first (Vink and Graziano 2008; Börzel and Risse 2003; Börzel and Risse 2000). In the field of asylum policy, analysis on how Europe 'hits home' was conducted with relating primarily to the concept of two-level games (Putnam 1988; for an application see Post and Niemann 2007; Vink 2001; Thielemann 2001; Guiraudon 2000) and, to a lesser extent, policy learning (Checkel 2001a 2001a; for an application see Thielemann 2001). However, the difficulty to blame Brussels for domestic developments regarding asylum policy has been commonly acknowledged. Rather than a straightforward link between Europe and the domestic level, it seems to be horizontal, sub-regional dynamics driving domestic policy change (see for example Vink 2010; Byrne et al. 2004; Martenson and McCarthy 1998). The difficulty of applying the notion of Europeanisation to the field of asylum studies has been spelled out by Lavenex (2008). Given that the policy field is characterised by only minimum legal harmonisation, the classic approach seems inappropriate for studying asylum policy-making. Rather, norms might be shared horizontally via framing (ibid.). However, this idea of soft Europeanisation through framing remains unspecific and provides only few starting points for operationalisation. So far, it has only been taken up by Thielemann (2001). The thesis contributes to the Europeanisation literature by studying the impact of informal policy coordination processes on the domestic level. These processes have not received any scholarly attention so far. The study conducted also relies on the two concepts mentioned above, two-level games and policy learning. These concepts are used because they are both general and specific enough- they are general enough because they allow studying countries that look for policy solutions abroad, also beyond a strict European/EU focus; and they are specific enough because they provide tools for operationalising the effect of the transnational on the domestic. Lastly, this study also aims at contributing to the learning literature with providing the first comprehensive analysis on how learning works in the field of asylum policy (for an outline of learning in this very field, see Thielemann 2001).

\subsection{Outline of study}

The book proceeds as follows. Chapter 2 analyses in how far safe country of origin policies become more similar or more diverse. It does so by providing a longitudinal national-level analysis of these policies in the EU-27 for the time period 1990 to 2013. The chapter concludes that there is policy convergence across Europe relating primarily to the introduction of the safe country of origin notion. Also with regard to the designation of certain countries as safe, we see policies becoming more similar in EU member states. 
Chapter 3 provides the theoretical and analytical framework for this study. It thus addresses the question of how we can conceptualise and theorise recent forms of European asylum cooperation. The chapter also introduces two logics of actions - the logic of consequences and the logic of appropriateness - that will help analysing the domestic policy-making process. Chapter 4 discusses the case study design as well as sources and methods used. Chapter 5 shows how policy coordination in the field of asylum policy in Europe actually works - by drawing on the example of cooperation on country of origin information. Chapters 6 and 7 provide in-depth analyses of the role of transnational policy coordination in the domestic asylum policy-making process. Whereas chapter 6 interprets policy-making following a logic of consequences, chapter 7 analyses the same events assuming a logic of appropriateness. Finally, the concluding chapter focuses on the relevance of results in broader terms, links the two logics of action, discusses results in light of the future of the Common European Asylum Systems and addresses several normative concerns. 


\section{Setting up the puzzle: safe country of origin policies across Europe}

\subsection{Introduction}

This chapter asks whether and in how far asylum policies converge across Europe. It looks at one particular element in the field of asylum policies, namely safe country of origin policies. These policies exemplify the core dilemma of modern asylum administration, namely adhering to international refugee law by thoroughly examining whether or not it is safe for an asylum seeker to go back to his country of origin, while at the same time thinking about strategies for processing asylum claims more efficiently. The tension between national needs for cooperation and hesitance to commit to supranational norms resulted in the institutional complexity which became so familiar in many aspects of European asylum governance. In the case of SCO policies, it meant that a need for cooperation and common rules was acknowledged in the early 1990s, followed by some minimum standard legislation in the form of the original Asylum Procedures Directive (Directive 2005/85/EC), and its revised version adopted in June 2013 (Directive 2013/32/EU).

However, so far little analysis exists of what has happened at the national level. On the one hand, one might expect divergence because the EU common legal framework relates only to minimum norms and much discretion is left to the member states in how they implement these rules. This leads to some arguing that the application of the SCO concept and national SCO lists diverge (UNHCR 2010b, p.67; ECRE 2010, p.40 European Commission 2009a, p.18). On the other hand, one might expect convergence given that countries seem to orientate their policy in line with (neighbouring) countries (Byrne, Noll and Vedsted-Hansen 2004). Convergence has been noted by others (Costello 2006, p.3, Costello 2005, p.38). This disagreement is not surprising given that there exists no comprehensive overview capturing variation across member states and time since the first introduction of these policies in the early 1990s. Existing overviews cover policies in selected member states at a particular moment in time (UNHCR 2010b; ELENA 2005; Council of Europe 2005; European Commission 2002; Martenson and McCarthy 1998; European Parliament 1996). Despite their significant merits none of the above-mentioned collections give a temporal overview of the development of SCO poli- 
cies, and therefore do not provide any ground for discussing possible convergence of SCO policies across EU member states.

The current chapter aims at filling this gap. By empirically analysing the safe country of origin policies of the EU-27 over a period of time (1990-2013), it will thus allow making a qualified statement about whether or not convergence occurs. In this study, convergence is defined as 'the extent to which the policies of countries become more similar to each other over time' (Knill 2005, p.786). The chapter concludes that - despite a continuing large extent of policy divergence - there is a rather surprising amount of convergence: Governments of EU member states not only increasingly include the safe country of origin notion in their national asylum law; they also adopt more similar safe country of origin lists. For example, they agree in their safety assessment of the situation in the Western Balkan and West Africa.

Based on these findings, the subsequent chapters 3-8 investigate one particular mechanism accounting for convergence, namely transnational asylum policy coordination. Hence, the status of this chapter is a bit different than the rest of the chapters in this book. By basically introducing the puzzle, it precedes theoretical and methodological considerations as well as the empirical analysis that aims at explaining policy convergence. In what follows, data is presented that shows whether and in how far safe country of origin policies converge in Europe.

The current chapter proceeds as follows: the next section (2.2) clarifies the terms used, most importantly safe country and safe country of origin. Section 2.3 outlines the start of intergovernmental cooperation and developments at the EU level. It discusses the rules adopted in the Asylum Procedures Directive and the failed attempt to agree on an EU-wide common list of safe countries of origin. Section 2.4 presents national-level data that allows concluding on either convergence or divergence to occur. The nationallevel analysis focuses on several aspects of the SCO notion, namely its formalisation in national asylum law, the number of SCO lists and designations and the composition of SCO lists. Eventually, several normative concerns related to these policy measures are discussed.

\subsection{The notion of safe country of origin}

Safe country of origin belongs to a concept family which has existed since the early 1990s and includes a number of notions. 'Safe country' refers to 'countries which are determined either as being non-refugee-producing countries or as being countries in which refugees can enjoy asylum without any danger' (UNHCR 1991). Notions subsumed under this concept are generally dealt with through an accelerated asylum procedure, and declared manifestly unfounded or inadmissible (depending on the legal basis). All states have obligations under the Geneva Convention (UNHCR 1951) and its additional protocols (UNHCR 1967). The key principle in asylum law - and at the core of 
any safe country notion - is the principle of non-refoulement. It means that no state can return a person to her country of origin in case her life or freedom would be threatened on account of her race, religion, nationality, membership of a particular social group or political opinion (article 33 of the Geneva Convention). Due to the different administrative and judicial traditions of State parties to the Geneva Convention, it allows much discretion for states on how to shape asylum procedures (Vedsted-Hansen 2012). However, soft law, regional human rights conventions and national law spell out the obligation of states regarding asylum procedures in general, and safe country notions in particular, in much more detail. Changing migration patterns and an increase in numbers of asylum seekers have fuelled new, often contested, ways to process asylum claims. National asylum authorities (that are normally in charge of processing asylum applications) deal with a large backlog of applications. Safe country declarations arguably help to speed up the asylum procedure, and reduce administrative costs.

A safe country of origin is a country in which there is generally and consistently no risk of persecution. Definitions in national and European law are often more specific, but the core idea is the same: the situation in the country of origin in general is safe enough to presume that an asylum seeker is not entitled to international protection in another country. Normally, national asylum authorities examine an asylum claim with regard to the general situation in the country of origin and with regard to the claimant's individual grounds. When applying the safe country of origin notion, the individual part is reduced and often linked to fewer procedural safeguards (such as limited possibilities for appeal). The essence of the safe country concept is the reverse of the burden of proof. While the collection of evidence is a task normally shared between the official assessing the claim and the asylum seeker, the burden of proof is now entirely placed on the claimant. He is presumed to have arrived from a safe country and he himself has to prove that this is not the case.

Types of SCO policies vary considerably across EU member states. Comparative overviews of the procedural dimension of SCO policies - although not complete and somewhat dated - have been provided by others (Commission 2010b; ELENA 2005; Martenson and McCarthy 1998; European Parliament 1996; Hailbronner 1993a). However, a comprehensive and comparable overview (a typology, so to say) is still lacking. What follows is a general overview of how SCO policies are understood and applied in national legislation.

- General application: The SCO notion can be applied in a formal way, with a prescribed list of safe countries of origin. This list can be public (France, the UK, Germany) or confidential (Denmark, Czech Republic). There is also the possibility of applying the SCO notion on a case-by-case basis (Hungary, the Netherlands).

- Legal basis for SCO designations: SCO designations can be established by law (Austria, UK), or by the government directly through a ministerial order (Denmark, 
Germany). Several countries require parliamentary approval of the list (UK, Germany); others do not (Luxemburg, Malta).

- Scope of designation: It is possible to limit SCO designations to parts of the population and parts of the country. The latter is, for example, possible in Greece and the UK. Also, the UK as well as Luxembourg allow designating a country as safe for only parts of its population (the UK: male applicants from Malawi; Luxembourg: male applicants from Ghana).

- Criteria for considering a country of origin as safe: The criteria are generally quite similar and mirror art. 37(1) of the Asylum Procedures Directive (see annex II to this thesis). They include a functioning democracy, independence of the judiciary, a state of the rule of law, observance of the 1951 Refugee Convention, and ratification and compliance with other human rights treaties, including the European Convention on Human Rights (where relevant). Whether the number of asylum applicants in relation to the number of recognised refugees coming from the country under consideration should also be a valid criterion is contested. It is mentioned in the London Resolutions (Council 1992a and 1992b) as a factor to be taken into account when adopting such policy measures. It is also informally practiced in many EU countries, but was declared unlawful in Belgian law (Constitutional Court of Belgium 1993).

- Right of appeal: Rules on the possibility and extent of an appeal vary greatly. For example, appeals from applicants having arrived from a safe country of origin can have a suspensive effect (Latvia) or not (Austria, Germany, the UK).

- Institutional and juridical oversight: In some countries, SCO designation is not a matter for national governments alone but involves additional bodies, such as nongovernmental organisations (Denmark) ${ }^{8}$ or independent oversight bodies (UK). ${ }^{9}$ Increasingly national courts are also involved in invalidating procedural standards ${ }^{10}$ or SCO designations as such. ${ }^{11}$

Further procedural differences relate to whether or not there is a regular review of the SCO lists, information used to assess safety in a country of origin, and the standard of proof required from asylum seekers.

\footnotetext{
${ }^{8}$ The Danish Refugee Council is involved in the setup of the Danish SCO list as well as in the manifestly unfounded procedure.

${ }^{9}$ In the UK, the Independent Advisory Group on Country Information is mandated to review country of origin information on which refugee status determination is based. It is, however, explicitly not mandated to review the safe country of origin designations as such. For more information on the Group see section 5.2.4 and box 6.2 in this thesis.

${ }^{10}$ The Belgian Constitutional Court classified a rule void that would declare applications inadmissible if the applicant originated from a country which had accounted for 5\% of asylum seekers in the previous year and where less than $5 \%$ of the applicants had been granted refugee status (Constitutional Court of Belgium 1993).

${ }^{11}$ The French Supreme Court judged in 2012 that neither Kosovo nor Albania can be declared as safe countries of origin (Conseil d'Etat 2013). Similar judgements occurred in the UK (see section 6.3.2).
} 
In sum, the safe country of origin notion is applied differently in different member states. However, the main idea of SCO policies remains similar across all national legislations: there are countries that are presumed to be safe for returning asylum seekers (being citizens of the country in question); and applicants from these countries can be considered through an accelerated procedure, often with fewer procedural safeguards. The following section illustrates how difficult it was for EU member states to agree on an EU-wide common legal framework for SCO policies, and what, eventually, was agreed upon.

\subsection{European cooperation on safe country of origin policies}

This section looks at European cooperation on safe country of origin policies. It will discuss how EU member states started during the early 1990s to coordinate respective policies and come to first, intergovernmental agreements. With the EU gaining competences in the field of Justice and Home Affairs, also legally binding agreements on asylum matters came into sight. With regard to safe country of origin policies, this primarily related to some minimum norms adopted as part of the 2005 and 2013 Asylum Procedures Directive (for the most recently adopted norms, see annex II to this thesis). The content of those norms and the process leading to their adoption will be discussed. Also, the failed attempt to come to an agreement on countries to be designated as safe is subject of analysis - primarily because it was the first (and probably last) attempt to have an EU-wide agreement on the core of safe country policies, namely which countries to designate as safe.

\subsubsection{The start of intergovernmental cooperation on safe countries of origin}

The possibility of accelerated procedures was first discussed in the early 1980s by UNHCR's Executive Committee in the context of manifestly unfounded asylum applications. By then, governments acknowledged the fact that there are some asylum applications from individuals who clearly have no valid claim, so-called manifestly unfounded or abusive applications (UNHCR 1983). These applications could be processed through an accelerated procedure. Acceleration was limited to cases which are clearly fraudulent or do not relate to the grounds of international protection. However, the idea of processing some applications faster than others remained rather general and, importantly, was still very much linked to procedural safeguards (Oakley 2007, p.3). The term 'safe countries' was not explicitly mentioned in UNHCR's final document but used throughout negotiations and dropped, eventually, due to political considerations (Joly 1994).

In the early 1990s, the idea of accelerated procedures was further fuelled by a massive influx of asylum seekers in several European countries. It did not take long before the first countries (Switzerland and Belgium) picked up on the idea of accelerated pro- 
cedures and started listing so-called safe countries. In 1992, the ministers of the member states of the European Communities agreed to formalise the concept of accelerated procedures. The so-called London Resolutions presented the first European agreement on asylum-related issues (Council 1992a, Council 1992b; for a critique see Joly 1994). This set of soft rules defined manifestly unfounded applications for asylum as not meeting the substantive criteria of the Geneva Convention because 'there is clearly no substance to the applicant's claim to fear persecution in his own country' (Council 1992a, article 1). A decision on unfoundedness would be made on the basis of a general safety assessment of the country of origin. Criteria for such a safety assessment included previous numbers of refugees and recognition rates, observance of human rights, democratic institutions, and stability (Council 1992b).

With the London Resolutions, the European ministers not only stressed the possibility of an accelerated processing of asylum claims; they also emphasised the need for harmonised action: 'Member States have the goal to reach common assessment on certain countries that are of particular interest in this context' (Council 1992a, article 8). The London Resolution can be marked as the birth of cooperation on SCO policies for two reasons: on a substantive level, it is the first intergovernmental agreement (though non-binding) allowing for manifestly unfounded applications on the basis of a general assessment of the country of origin. On a procedural level, it is the first expression of a common will of EU member states to agree on such an assessment, or to work towards a common list of safe countries of origin.

\subsubsection{EU policy and the Asylum Procedures Directive}

At EU level, the first binding agreement on countries to be considered safe was made in 1999. With the Treaty of Amsterdam, member states agreed to consider all EU member states as safe countries of origin (Protocol on Asylum for Nationals of Member States of the European Union). In 2002, the JHA Council went one step further and declared all (then) accession countries as safe countries of origin from the date of signature of accession treaties. Subsequently, asylum applications from Cyprus, the Czech Republic, Estonia, Hungary, Latvia, Lithuania, Malta, Poland, the Slovak Republic and Slovenia would be considered manifestly unfounded (Council of the European Union 2002; for a critique see Statewatch 2002).

The original Asylum Procedures Directive of 2005 was the first instrument at the European level providing binding regulation on the asylum procedure in general and on the application of the SCO concept in particular. The Directive was one of several asylum-related instruments adopted between 2001 and 2005. Compared to agreements on more substantive standards (as for example in the Refugee Qualification Directive (Directive 2004/83/EC) or in the Temporary Protection Directive (Directive 2001/55/EC)), 
agreement regarding procedural standards did not go beyond minimum norms. ${ }^{12}$ The Council laid down rules for the many aspects of the asylum procedure, including grounds for designating countries of origin as safe and who is legitimised to do so.

Regarding the grounds for designation, several criteria should be taken into account, including legislation in the country of origin, observance of rights laid down in the main human rights documents, respect of the non-refoulement principle, and a system of effective remedies against violations of these rights and freedoms (annex I to Directive 2013/327EU).

Regarding procedural standards, Articles 29 and 30 of the original Directive (of 2005) foresaw two avenues for SCO designations - via an EU-wide common list and via a national list. A common list might be adopted by qualified majority of the Council, on a proposal by the Commission and after consultation with the European Parliament (original article 29). Contrary to the initial draft as suggested by the Commission, member states would have been required (instead of having an option) to adhere to that common list (Costello 2006, p.12). However, article 29 was never put into practice. Discussion on the common SCO list delayed the adoption of the original Asylum Procedures Directive (eventually adopted in 2005). As a result, the list was de-linked from the Directive and supposed to be agreed on at a later point in time. Criticism on the 2005 Directive related to many issues, also regarding the SCO notion. Nongovernmental organisations (NGOs) and international organisations pointed out that the safe country notion potentially violates the principle of non-refoulement (see for example UNHCR 2010b; ECRE 2010; Statewatch 2004; Amnesty International UK 2004; for substantive criticism, see section 2.4.1). In addition, UNHCR (2010b) as well as the European Council on Refugees and Exiles (2010) revealed significant differences in how the member states applied the criteria for designating countries of origin as safe. Also competence issues were raised: Costello (2006) stressed that the Council was only entitled to establish minimum norms, whereas the implementation of the SCO notion as such would have required some member states to lower their domestic asylum standards. Also, the attempt of establishing a common list of safe countries of origin was heavily criticised, mainly because member states considerably disagreed over the safety assessment on most countries on the proposed list (Costello 2006; Statewatch 2004).

In 2006, the European Parliament, supported by the Commission, asked the European Court of Justice for an annulment of article 29(1) of the original Directive on the Council's mandate to create such a list. The complainants argued that by agreeing on this rule the Council had adopted Community legislation and consequently the codecision procedure was applicable. The ECJ supported this argumentation and annulled article 29(1) (ECJ 2008). However, the EP appeal and the subsequent ECJ decision only

\footnotetext{
${ }^{12}$ For a discussion of the regulatory differences between the various asylum instruments, see Vedsted-Hansen 2012 .
} 
related to procedural grounds; no assessment was made on the SCO notion as such and its normative implications.

Despite the annulment of article 29 (1), article 30 of the original Directive still allowed member states to designate countries of origin as safe by national legislation. It is important to note that national designation is an optional provision, thus there was (and still is) no obligation on EU member states to adopt such a policy.

A revised version of the Asylum Procedures Directive was agreed upon in June 2013 (Directive 2013/32/EU). The recast was also explicitly targeted towards reaching more convergence on the application of SCO practices (European Commission 2009a, p.25). The recast of the Directive still includes the SCO notion as a valid case for an accelerated procedure (for a discussion, see ECRE 2010). The possibility of a common list of safe countries of origin is, however, no longer mentioned. ${ }^{13}$ If member states want to designate countries of origin as safe, they have to do so by national legislation (art. 37). Regarding the SCO notion, the following issues changed from the 2005 to the $2013 \mathrm{Di}$ rective:

- Deleted: member states may no longer apply rules (related to safe countries of origin) existing pre-2005 and setting out lower standards than those agreed upon in the Directive (previous art. 30(2) and (3))

- Deleted: possibility to have a common EU-wide list of safe countries of origin (previous art. 29)

- Deleted: possibility to designate parts of a country as safe (instead of a whole country) (previous art. 30(1))

- Included: need to regularly review the situation in countries designated as safe (art.37(2))

- Included: information required upon which to base SCO designations shall include information from the European Asylum Support Office (art. 37(3)).

Also the recast invited criticism from NGOs (see for example Peers 2013); however, not very much related to the SCO notion. ${ }^{14}$ Given the comprehensiveness of the directive in general, not a lot has changed. It is thus difficult to see how the new directive will contribute towards more convergence on SCO policies.

\subsubsection{The proposed EU-wide common list on safe countries of origin}

Although there will be no common list of safe countries of origin, the negotiations arising around that list-to-be in 2005 are interesting for this analysis. Already since 1992,

\footnotetext{
${ }^{13}$ There were several countries still proposing such a possibility, including Germany and France (European Commission 2009c, annex 2, p.10).

${ }^{14}$ During negotiations of the revised directive in 2010, ECRE criticized the maintenance of the safe country of origin concept in the recast proposal (2010, p.6, p.40).
} 
there was an interest on the part of some member states to agree on such a common list. In 1992, these attempts were abandoned because 'the majority of delegations voiced misgivings for political or diplomatic reasons, or because absence from a list might imply that the country is unsafe' (Ad Hoc Group on Immigration, in: Joly 1994, p.170). Also negotiations leading up to the Asylum Procedures Directive saw several attempts to create a common list of safe countries of origin (Statewatch 2004).

The list proposed by the JHA Council in March 2004 included the following countries: Benin, Botswana, Cape Verde, Chile, Costa Rica, Ghana, Mali, Mauritius, Senegal, and Uruguay. It was already then clear that a possible list should not be a collection of any safe country in the world but a useful list. Useful meant that there needed to be a considerable number of asylum seekers coming to the EU from the countries included. This becomes obvious when looking at the Draft Council Conclusions of the Dutch presidency: Chile, Costa Rica and Uruguay were eventually not included in the agreed list 'due to the generally small number of asylum applications of South and Central American nationals in the European Union' (Council of the European Union 2004, par.5).

Significant disagreement among the member states' assessment of the safety situation in the countries of origin accounted for the common list not being further pursued in the revised Asylum Procedures Directive. However, a closer look at the list, its proponents (Statewatch 2004), and national designations of safe countries of origin in this time period, is worthwhile: several member states (such as the Slovak Republic and Sweden) who in 2004 (and some even by 2013) had no SCO policy at all were not only in favour of a common list, but also in favour of including most of the proposed countries in that list. Thus, they would have agreed to European legislation lower than their own national standard. What was criticised by NGOs and international organisations throughout the negotiation process (Statewatch n.d.; Casciani 2004) became obvious here: adopting the provision would have resulted in lowering national standards and would thus have raised competence concerns given that the EU is only entitled to establish 'minimum norms' in this area (Costello 2006, p.12). Eventually, no common list of safe countries of origin was adopted - not only because of disagreement between EU member states on which countries to declare as safe but also because the ECJ judgment deprived the Council of the competence to solely adopt such a list. However, these developments at the EU level did not hinder member states to pursue such policies individually, as the next section shows.

\subsection{The national regulation of SCO policies}

The previous section showed that common criteria according to which countries can be designated safe were established with the adoption of the Asylum Procedures Directive in 2005, and revised with its 2013 recast. However, no attempt of achieving agreement 
regarding which countries to designate as safe was successful. It is difficult to assess whether this is a good or a bad development. On the one hand, a common EU-wide agreement on countries to be designated as safe could give a wrong signal in the sense of "normalising" a practice that is considered by many to weaken the notion of nonrefoulement (see section 2.4.5 on normative concerns). On the other hand, common designations could possibly avoid member states experimenting individually with SCO rules. The current situation is determined by developments in national asylum law and practice, despite the halt in supranational formalisation of SCO rules. This section gives an overview over safe country of origin policies in $27 \mathrm{EU}$ member states over the time period 1990-2013.

\subsubsection{Data}

The following analysis of national SCO policies is based on an extensive data collection. SCO policies for the EU-27 were collected for the time period 1990 to 2013. Data includes the legal basis for SCO designations as well as any entries and exits of countries of origin on SCO lists during this period. Data was collected by desk research and enquiries for information to national ministry officials, NGOs and other experts. A complete overview of the sources used can be found in annex IV to this thesis. Since national SCO policies are not equally formalised and accessible for each member state, some information might be incomplete. For example, in Denmark SCO lists are compiled informally and are not publicly available. The author is only in possession of two lists (2005 and 2011), whereas there might have been changes (meaning more lists) in between. However, even if the history of SCO designations cannot be verified for all states, there is one fact that makes the data rather reliable: few countries of origin ever exit any national SCO list. Thus, the limited data reliability relates solely to the year of list entry. The current data is, however, much more comprehensive (in spatial and temporal terms) than older attempts and captures the basic pattern, namely that SCO lists have grown immensely and became more similar over recent years. The data set was supplemented by interviews with ministry officials from several EU member states based in the policy directorates and thus being involved in policy-making regarding SCO policies.

\subsubsection{Introduction of SCO policies}

This part of the analysis shows that there is convergence regarding the existence of the safe country of origin notion in domestic asylum law. Figure 2.1 shows the year in which member states legally introduced the SCO notion. 


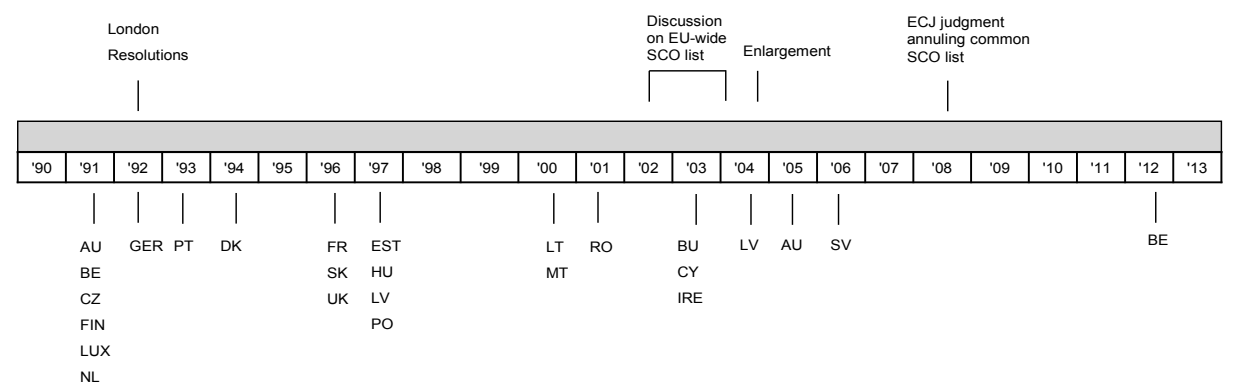

Figure 2.1: Introduction of SCO notion in domestic asylum law (source: own compilation)

The number of EU-27 countries with a safe country of origin notion in domestic asylum law has greatly increased over time. In 1991, one can by no means speak of policy convergence because only six EU member states had SCO policies in their domestic asylum law, and most of the current EU-27 countries had no reference to SCO whatsoever. In 2013, the picture has completely changed: only two EU member states had not yet legally established the possibility to adopt SCO policies (Italy and Sweden). Thus, there is a clear trend towards convergence regarding the formalisation of the SCO notion in national asylum law.

There are a number of explanations why the SCO notion has spread so rapidly in domestic asylum law. Most of the EU-15 introduced SCO notions into their national asylum law in the 1990s. At that time, the break-up of the Soviet Union and Yugoslavia led to large streams of refugees trying to claim asylum in one of the old member states. As a consequence thereof, Germany, Austria ${ }^{15}$ and the Netherlands changed their national asylum laws and also included the notion of safe country of origin. Subsequently, two parallel mechanisms can possibly account for the proliferation of the SCO rule: a European factor and sub-regional dynamics.

Let us focus on the European factor first. In addition to the London Resolutions, two further landmarks could have had an influence on the introduction of SCO notions into national asylum laws: discussions on the Asylum Procedures Directive and the 2004 enlargement. During the years 1999 to 2005, the EU-15 negotiated several asylumrelated directives, including the Asylum Procedures Directive. During these negotiations EU member states discussed which countries should be considered safe. These discussions could account for the introduction of SCO notions across Europe. One could argue that old member states (Ireland, Austria) introduced SCO during this time because $\mathrm{EU}$ negotiations sent the message that the safe country of origin notion belonged to every national asylum policy; and the new member states introduced the no-

\footnotetext{
${ }^{15}$ Austria abolished the notion in 1997, only to re-introduce it in 2005 (see Fassmann and Reger 2008).
} 
tion because they had to bring their asylum laws in line with European regulations before entering the club (Malta, Bulgaria). The latter argument will be made in much more detail for the case of Malta in chapter 6. It is important to remember that discussions at the EU level were not concerned with whether or not an SCO notion conforms with the principle of non-refoulement, but rather with how to realise such policies. Also, later analysis (chapter 7) will show that the SCO practice is an accepted part of a tool box for dealing with unwanted immigration. Its legitimacy was no longer questioned - and this signal was also sent to member states-to-be and those that had not yet introduced the notion.

However, blaming solely Brussels (or London) for national policy developments would oversimplify the matter. Several countries, including Austria, Germany and the Netherlands, introduced the SCO notion before the London Resolutions were adopted. Also other EU member states (France, the UK, Denmark, or Poland) followed long before discussions at EU level picked up speed. Rather than top-down, a bottom-up explanation seems logical. Byrne et al. (2004) indeed show that domestic and subregional dynamics also accounted for the introduction of safe country of origin policies: closely mirroring the German legislation, Poland included the SCO notion into national asylum law in 1997 (ibid., p.361). The same accounts for Hungary, which saw the introduction of safe country rules in Germany 'as a confirmatory license to introduce safe country rules' (Nagy 2002, p.165). Similar arguments could be made for Ireland and Austria, that (re-) introduced the SCO notion in 2003 and 2005 respectively as a reaction to policy changes in neighbouring countries - the UK in 1996 (for the case of Ireland) as well as Germany in 1992 and Hungary in 1997 (both for the case of Austria).

The data in figure 2.1 only shows that the possibility of applying the notion was formalised. This does not, in fact, say anything about the actual application. One could argue that this does not become an issue until there is actually practice following the law. However, most states that introduced the notion have also used it in the longer run, as the next section shows.

\subsubsection{Introduction of SCO lists and number of designations}

Many member states have designated countries of origin as safe and have thus contributed to a trend towards more lists and more designations. Figure 2.2 shows the growth in the number of lists in the EU-27.

Figure 2.2 shows that policies in the early 1990s were similar in their extent of not having safe country of origin lists. During the years to come, several countries introduced such lists and thus policies became more diverse. At the end of the 1990s, six EU member states had officially designated SCO lists (Denmark, Germany, Latvia, the Netherlands, the Slovak Republic, the UK). By 2013, the number of countries with an official SCO list had doubled to 12 out of 27 (Austria, Belgium, Czech Republic, Den- 
mark, France, Germany, Ireland, Latvia, Luxembourg, Malta, the Slovak Republic, the UK).

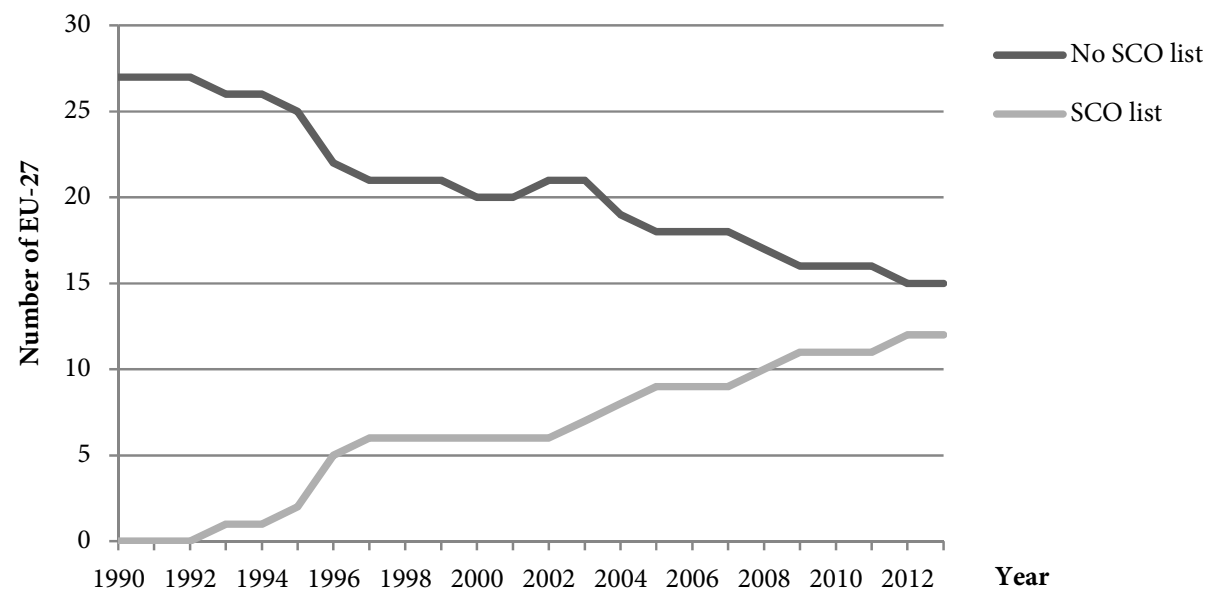

Figure 2.2: Presence of SCO lists in EU-27 (source: own compilation)

SCO lists are defined as actual designations of countries of origin as safe at the national level. In 1999 and 2002, EU member states agreed on designating all EU member states and accession countries as safe. This agreement is not taken into account in figure 2.2. The lists themselves differ regarding, inter alia, their level of formality, length and frequency of modification (and of course composition, which will be discussed in the next subsection). Most of the member states with a list of safe countries of origin have published this list (including France, the UK and Belgium). However, there are also countries that have drawn up a list, but it is not public (Denmark, Czech Republic). This already indicates an interesting puzzle: publishing the list serves first and foremost the purpose of deterring asylum seekers from the countries on this very list. If a country like Denmark does not publish its list, it must serve another purpose. Here, we already see that motivations to have countries designated as safe seem to be more diverse (than just deterrence). In addition, there are several countries presumable applying the safe country of origin notion on a case-by-case basis and thus do not formally adopt a list (UNHCR 2010a, p.66). For example, the Hungarian authorities currently do not operate a SCO list, but are presumed to process applications from some countries much faster than from others (email communication \#4). The same accounts for the Netherlands. Countries applying the SCO notion on a case-by-case basis are not shown in figure 2.2.

There are also big differences regarding the number of countries of origin designated as safe. While in 2013 the UK authorities declared 26 countries as safe, Germany had 
done so for only two. ${ }^{16}$ Germany and the UK also serve as examples when assessing the durability of the lists: the UK list is frequently changed, while the German list has not been changed since $1996 .{ }^{17}$ However, the actual number of designations is probably the most striking development. Figure 2.3 shows the total number of SCO designations for all EU member states over time.

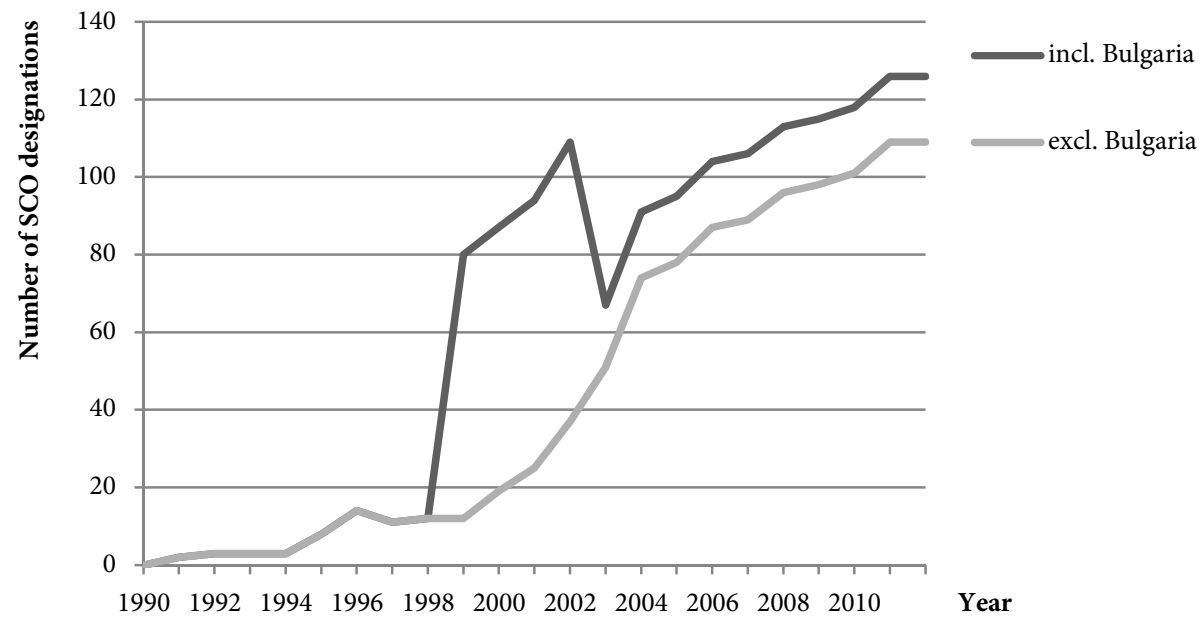

Figure 2.3: Total number of SCO designations in EU-27 (source: own compilation)

Before discussing the data shown in figure 2.3, two remarks on the scope of the data set are necessary. First, the designations counted omit certain countries, including EU member states (EU-27) as well as Croatia, Andorra, Australia, Canada, Iceland, Japan, Liechtenstein, New Zealand, Norway, San Marino, Switzerland, South Korea, and the US. These countries are excluded because there is hardly any disagreement on the safety situation in these countries. Nevertheless, some EU member states have - on a unilateral basis - also designated these countries as safe. These designations are irregular - meaning that it can be assumed that all EU member states see Iceland as a safe country of origin, although not all have declared it as such. Mapping them in the analysis would distort the results unnecessarily. Second, figure 2.3 shows the total both including and excluding Bulgaria because it weights the results in an unwanted way. During the years 2000-2003 Bulgaria had between 68 and 72 countries on its SCO list, including countries like Yemen and the Peoples' Republic of Korea. However, most of these countries were

\footnotetext{
${ }^{16}$ In 2014, the German government added three countries to the SCO list, including Serbia, Montenegro and Bosnia and Herzegovina. However, the thesis covers only the period 1990-2013.

${ }^{17}$ See previous footnote
} 
removed from the list in 2003 (between 2003 and 2004 Bulgaria cut its SCO list from 72 to 17 countries).

Figure 2.3 shows that the total number of SCO designations for all EU member states significantly increased over the last two decades. While during the 1990s it remained under 12, by 2013 it was 126. This does not mean that a total of 126 countries of origin were declared safe. Rather it shows that overall EU member states had issued a total of 126 SCO designations (with some countries of origin being on several lists and thus counting multiple times). There was a slight but steady increase in SCO designations from the mid-1990s, and dramatic growth after 2002. The increase might be explained by developments at the EU level during this time (negotiations on the original Asylum Procedures Directive and a common list). It is interesting, however, that after the stalemate at the EU level in 2005/2006 (no agreement on the list; the EP appeal before the ECJ), the growth continued.

This suggests that factors other than the European one account for policy changes. The argument by Byrne et al. (2004) was stressed before. They see sub-regional dynamics accounting for the growth of such policies. Along the same lines, Martenson and McCarthy (1998) talk of the 'copycat game'. They argue that member states copy each other's lists in order not to be the weakest link in the asylum chain. If this is indeed the underlying mechanism, it provides a worrying picture. It would lead to a race to the bottom, since no country wants to be the weakest point of entry: any SCO designation in one country would trigger similar policy changes in other countries. This could be an explanation for the tremendous growth in SCO designations shown in this section. However, we can only specify the mechanism after having studied the policy-making process in more detail. For that, let us first have a look at the content of the lists - the actual countries of origin declared safe.

\subsubsection{The content of national SCO lists}

Up to this point, the chapter discussed the bigger picture of SCO policies in Europe, the presence of such policies and lists, and the number of designations. The analysis will now zoom in on the actual composition of the SCO lists. Where these lists exist, they became more similar over time. However, they also remain being very diverse. There continues to be a large (but decreasing) number of unilateral decisions on SCO designations. Regarding the convergence matter, member states nowadays agree on their safety assessments of two parts of the world, the Western Balkans and West Africa.

What countries of origin are we actually talking about when discussing SCO policies? The simple answer to this question is nearly all countries. Almost any country one can think of - from Albania to Zambia - has been declared safe by one or several EU member states at some moment in time. The more precise answer is, of course, not that simple. There are big differences with regard to how many EU member states declared a certain country of origin as safe. For example, whereas only one state (Bulgaria) ever 
declared Zambia to be safe for a certain period of time (2000-2003), Albania has already been considered safe for some years (since 2000) by six EU members (Austria, Belgium, Bulgaria, Denmark, Luxembourg and the UK). Considerable agreement on the safety situation in countries of origin and consequently the way of handling the claims of asylum seekers from these countries can be seen for two regions: the Western Balkans and West Africa. Let us start with the Western Balkans (see figure 2.4).

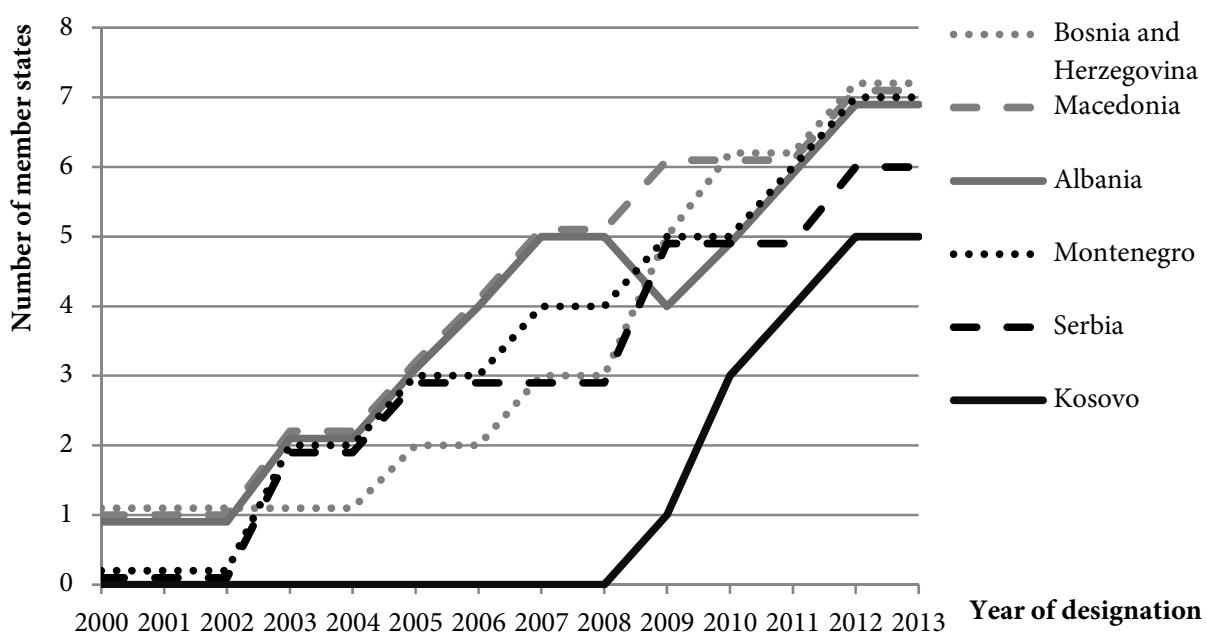

Figure 2.4: Number of EU member states that have designated Western Balkan countries as safe (source: own compilation)

Figure 2.4 shows a whole region for which EU member states share their safety assessment. All the Western Balkan countries score high for the number of member states that have designated them as safe. The situation as of 2013 looks as follows:

- Albania: Austria, Belgium, Bulgaria, Denmark, France, Luxembourg, the UK

- Bosnia and Herzegovina: Austria, Belgium, Bulgaria, Denmark, France, Luxembourg, the UK

- $\quad$ Kosovo: Austria, Belgium, Denmark, France, the UK

- Macedonia: Austria, Belgium, Bulgaria, Denmark, France, Luxembourg, the UK

- Montenegro: Austria, Belgium, Bulgaria, Denmark, France, Luxembourg, the UK

- Serbia: Austria, Belgium, Bulgaria, Denmark, France, the UK

Similar convergence is observed in three West African countries, Benin, Ghana and Senegal (figure 2.5). 


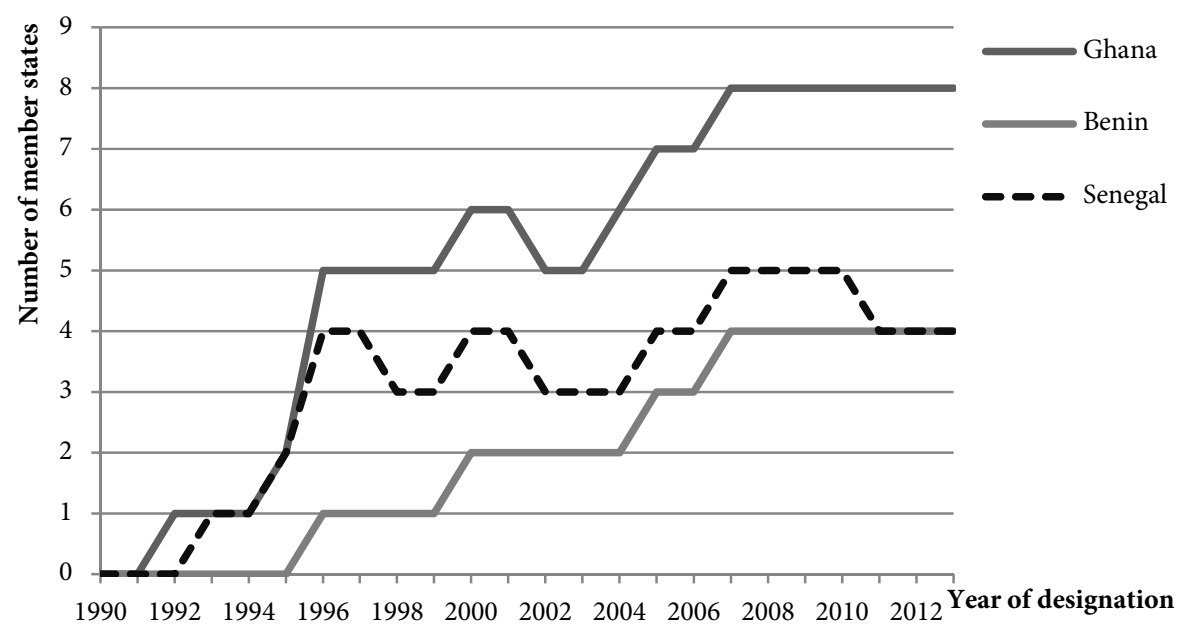

Figure 2.5: Number of EU member states that have designated Benin, Ghana and Senegal as safe (source: own compilation)

Again, figure 2.5 shows that for Benin, Ghana and Senegal EU member states share their safety assessment, and consequently adopt similar policies. The situation as of 2013 looks as follows:

- $\quad$ Benin: Denmark, France, Luxembourg, Malta

- Ghana: Bulgaria, Denmark, France, Germany, Luxembourg ${ }^{18}$, Malta, the Slovak Republic, the $\mathrm{UK}^{19}$

- $\quad$ Senegal: Denmark, Germany, Luxembourg, Malta

On Ghana, member states reach their maximum similarity in assessment. In 2013, eight member states agreed that Ghana was a safe country of origin. Now, one might say that 8 (or 4 respectively for the other countries of origin) out of 27 are not so many. But let us be reminded of the difference in applying the safe country of origin notion: out of the $12 \mathrm{EU}$ member states with a list of safe countries of origin, eight have declared Ghana as safe, and seven have declared Bosnia and Herzegovina as safe. It is fair to assume that member states with confidential lists and those applying the SCO notion on a case-bycase basis, share these assessments. Thus, we observe a considerable amount of policy convergence.

There are a number of explanations possibly accounting for this convergence. They are just briefly mentioned here because an in-depth analysis is provided in the subsequent chapters of the $\mathrm{PhD}$ thesis. The most obvious mechanism accounting for policy convergence is harmonisation. However, this is not a convincing explanation for the

\footnotetext{
${ }^{18}$ Designation only applies to male asylum seekers.

${ }^{19}$ Designation only applies to male asylum seekers.
} 
field of safe country of origin policies. According to article 37(1) of the Asylum Procedures Directive, the introduction of national SCO policies is optional, thus no requirement for member states when implementing the directive. Nevertheless, all but two of them have done so (see section 2.4.2). In addition and as noted previously, there is no common EU-wide agreement on which countries to designate as safe. Though there were several attempts to establish such a common list of safe countries of origin, it was not successful (see section 2.3.3).

Another explanation for policy convergence could be imposition (Holzinger and Knill 2005) or transfer of policies (Dolowitz and Marsh 2005): countries feel pressured to adopt whatever their neighbouring countries are doing, because they fear being the weakest point of entry to the EU. According to this logic, Luxembourg would declare Ghana as safe (in 2007) because its bigger neighbour France had done so in 2005; the Netherlands would declare Senegal as safe (in 1995) because Germany had done so in 1993 (see Vink 2002 for this latter example). Assuming such a 'copycat game' (Martenson and McCarthy 1998) would require from governments a close observation of (intended) policy changes in other countries. To a certain extent, it would also require coordinating policies with other countries because nowadays, no policy decision is taken in a vacuum. However, it is difficult to believe that safe country of origin policies are only a reaction to similar policy changes in neighbouring countries. If that would be the case, we would need to see much more convergence than observable now.

Domestic level considerations presumably play an important role too. One is quick to assume that Serbia, Bosnia and Herzegovina or Montenegro are declared as safe by so many EU member states because they produce large numbers of asylum seekers (arguably) not being in need of protection. Thus, the ratio of numbers of asylum seekers coming from a certain country of origin to the actual acceptance rate (i.e. how many claimants are granted protection) seems to play an important role too. Following the launch of the visa liberalisation process for the Western Balkans in 2008, high increases of asylum seekers from these countries were anticipated and subsequently led to safe country of origin designations (Austria and France in 2009, Luxembourg in 2011, Belgium in 2012). There are also other domestic level factors that possibly play a role when designating countries of origin as safe, such as historical or cultural links to the country of origin or foreign policy considerations. However, given the peculiarities of each and every EU member states, we would expect policy divergence rather than convergence to follow from this. And, in fact, data confirms that.

The final figure of this section illustrates the high level of divergence remaining in the field of safe country of origin policies, and in particular with regard to which countries to designate as safe. Figure 2.6 shows in how far EU member states agree on their SCO designations in 2013. 


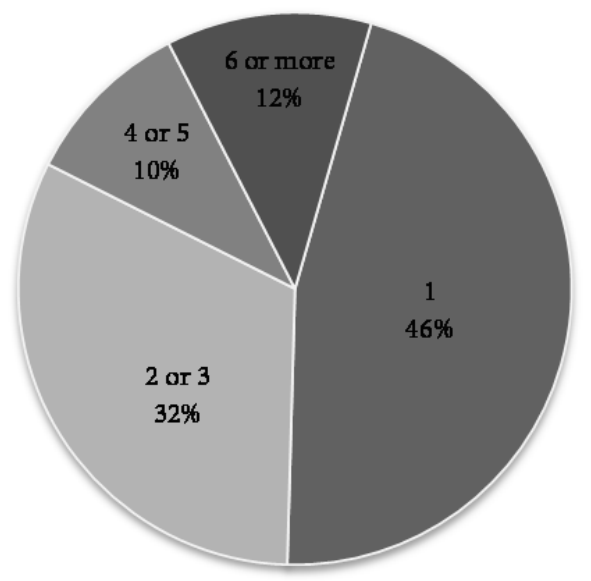

Figure 2.6: Percentage of countries of origin designated as SCO by one or more EU member states in 2013

In 2013, a total number of 50 countries of origin were designated as safe by one or several EU member states. ${ }^{20}$ Almost half of them are designated as safe by just one member state. For example, Uruguay is only designated as a safe country of origin in Malta; Ecuador is only considered a SCO by the UK; China only by Bulgaria. Thus, these countries of origin show on only one of the SCO lists in all EU member states. Almost half of all SCO designations in 2013 are such single-country designations. In contrast to that, only $12 \%$ of all countries of origin declared as safe (resembles 6 countries of origin) are agreed on by 6 or more EU member states. These countries of origin are Ghana, Bosnia and Herzegovina, Macedonia, Albania, Montenegro and Serbia.

The pie chart provides a snapshot of 2013. Looking at earlier years, an even greater percentage of countries of origin are singular SCO designations, reflecting a divergent approach among EU member states on the safety situation in countries of origin. Consequently, figure 2.6 puts my findings on convergence in perspective. It shows that despite a high level of policy convergence with regard to the introduction of the SCO notion, as illustrated previously in section 2.4 - SCO policies continue to be diverse with regard to the application of the notion of safe country of origin.

In sum, we observe a certain level of policy convergence regarding safe country of origin policies. This relates primarily to the introduction of SCO notions and, to a lesser extent, to the designation of certain countries of origin as safe. How can we explain this? Here, the present analysis comes in. The key argument of this $\mathrm{PhD}$ thesis is that informal asylum policy coordination plays an important role in domestic policy-making and the formulation of safe country of origin policies in particular. In the following chapters,

\footnotetext{
${ }^{20}$ The data set excludes a number of countries, such as EU member states, Croatia, Andorra, Australia and others (as discussed earlier).
} 
this argument will be specified theoretically, the term 'informal asylum policy coordination' is conceptualised and empirically studied; and two perspectives for the role of policy coordination in the domestic policy-making process are empirically investigated. Safe country of origin policies serve as the key example for this analysis. Before starting with the actual analysis, the next section provides a normative discussion of these policies. Given that they are met with a constant and high level of criticism, it would be irresponsible to not thematise these concerns.

\subsubsection{Some normative concerns}

Safe country of origin policies have always invited criticism - independent of the context and country where they were adopted. This section gives an overview over these normative issues. In its assessment of the implementation of the 2005 Asylum Procedures Directive, UNHCR stressed that it does not oppose the safe country of origin notion as such

(... ) as long as it is used as a procedural tool to prioritize and/or accelerate examination of an application in carefully circumscribed situations. It is critical that each application is examined fully on its merits in accordance with procedural safeguards; each applicant has an effective opportunity to rebut the presumption of safety of the country of origin in his/her individual circumstances; the burden of proof on the applicant is not increased, and the applicants have the right to an effective remedy against a negative decision (UNCHR 2010, p.65).

What is stressed by UNHCR here points to the core of criticism: applying the notion of safe country of origin risks violating international refugee law - and the notion of nonrefoulement in particular (see also Costello 2006). To recall, non-refoulement means that no state can return a person to her country of origin in case her life or freedom would be threatened on account of her race, religion, nationality, membership of a particular social group or political opinion (article 33 of the Geneva Convention). It is also questionable whether this policy is consistent with the Convention's article 3 providing for access to asylum procedures without discrimination as to race, religion or country of origin. UNHCR (2010b) also revealed great differences in how the existing rules (in the form of the Asylum Procedures Directive) are applied in the EU member states. Some states fall short of adhering to the norms agreed upon, such as including mere ratification (rather than observance of the 1951 Convention) as a criteria for designating a country as safe (see UNHCR 2010b for further criticism on the implementation of the Directive).

Critics also frequently stress that the safe country of origin practice rests upon several controversial assumptions in the asylum determination procedure, such as the availability of sufficient and verified information (Byrne and Shacknove 1996, GoodwinGill 1992). It is argued that information available on the situation in the countries of origin can never be sufficient and verified enough to presume general safety in the coun- 
try for everyone originating from there. This relates, for example, to the naturally biased information provided by foreign ministries (on which these policies are mostly based). It also relates to the fact that information on which such an assessment is based often reflects the situation in major cities rather than rural areas (Byrne and Shacknove 1996, p.196). Also, it is doubted whether the information - after being filtered through many instances (from the diplomatic mission to the foreign ministry to various levels of the ministry of interior) - is still sufficiently current when reaching the determining case officer (Byrne and Shacknove 1996, p.195). These issues with data availability and reliability are well-known (see sections 5.2.1 and 5.2.2 on country of origin information). They are also only avoidable to a certain extent. However, according to critics, they make it even more dangerous to assume safety for an entire country of origin.

Furthermore, there are frequent voices stressing that the policy is dangerously susceptible to political, economic and foreign policy considerations (UNHCR 2010a, p.66; Byrne and Shacknove 1996, p.223). Martenson and McCarthy (1998) stress that there is a high risk that such SCO policies are adopted which aim at pleasing close allies and important trading partners by including their country on the list (p.305). It was already argued in 1998 that East European countries about to join the EU were declared as safe countries of origin to a surprisingly similar extent by old EU member states. This behavior suggested 'an inclination of the EU to ignore current human rights abuses and reach a consensus that any serious human rights violations in this region disappeared with the end of communism' (Martenson and McCarthy 1998, p.310). The same concern could be stressed regarding the Western Balkans nowadays. The countries showing up on most if not all SCO lists drawn up by EU member states are either candidate countries to the EU (Macedonia and Montenegro) or listed as potential candidate countries (Albania, Bosnia and Herzegovina, Serbia, Kosovo). This is a worrying development, not only because it could help governments in the region to whitewash their human rights records, but also because it tends to downplay the human rights problems of these countries in the long term. Further analysis will show that politicians from the Western Balkans and beyond have an interest in seeing their own country on European SCO lists, and have explicitly asked to do so. A similar argument can be made for other countries, such as Benin, Ghana and Senegal (see figure 2.5 in this chapter), which are high on the development aid agenda of many EU member states. However, what contradicts this line of argumentation is the continuing lack of transparency regarding safe country of origin lists of some EU member states, such as Denmark. It seems to be the case that the political susceptibility of SCO lists encourages some countries to publish these lists, whereas it discourages others.

Finally, a major point of criticism relates to the intended effect of SCO designations: in many, if not most cases, the safe country of origin notion was introduced as a measure to deter asylum seekers from countries that are considerably safe. By declaring them as safe, policy-makers want to make sure that, if these asylum seekers enter the 
territory of the state of asylum, they can be processed faster than their 'more genuine' counterparts from, e.g., Somalia, Afghanistan or Iran. What, however, tends to be ignored is the fact that pull factors, and restrictive policy measures in particular, play only a limited role in determining the asylum seeker's choice of country of host (Thielemann 2006). It can also be doubted whether SCO designations indeed speed up the refugee status determination procedure. In fact, this was questioned by several of my interview partners too (interview 12; interview 13; interview 15). They argued that it only postpones a more thorough check of the asylum application to the appeals stage. No data exists on the success of appeals of SCO cases. However, the growing case law relating to safe country of origin designations in general, may suggest that SCO designations do not speed up but prolong the asylum procedure. ${ }^{21}$

In sum, the safe country of origin notion has fuelled profound criticism. Since the very first appearance of these policies, NGOs and UNHCR have criticised the concept as such as well as the way it has been applied by governments in Europe. Much of the analysis in the upcoming chapters will not relate to any of these normative concerns. It is, however, important to keep in mind that in no country the application of the SCO notion went unnoticed; and that it was always accompanied by harsh criticism from both NGOs and international organisations.

\subsection{Conclusion}

This chapter discussed European and national developments regarding safe country of origin policies. It showed that the governance pattern at the European level is symptomatic of other asylum issues too. Starting with intergovernmental cooperation between those states being pressured by large influxes of asylum seekers, the discussions soon reached the European level. European countries acknowledge a need to adopt a common approach towards SCO policies in order to avoid a potpourri of 27 different SCO practices. However, commitment did not follow cooperation. SCO regulations in the revised Asylum Procedures Directive remain general and with little practical relevance. Member states continue to have much discretion regarding the implementation of such policies. The leeway relates to procedural aspects but it especially relates to the content of these policies - namely which countries of origin to designate as safe.

Parallel to this reluctant and cumbersome process at the European level, something interesting happened at the domestic level. Most European countries pursued national policies on safe countries of origin. A high level of convergence regarding the existence of SCO notions in national legislation was observed. All but two countries have adopted

\footnotetext{
${ }^{21}$ Throughout Europe, national courts both confirmed and rejected the designation of specific countries of origin as safe. Respective case law exists in Austria, Belgium, France, Germany and the UK, The latter two examples are discussed in section 6.3.2.
} 
such a notion and do thus have the possibility to designate countries of origin as safe. Policy similarity also occurs when it comes to the actual designations of countries of origin from two regions, namely the Western Balkans and West Africa.

Having concluded on a certain level of policy convergence raises several questions the most important one being how come? How can we explain that all but two EU member states have introduced the SCO notion in domestic asylum law though there is no legal obligation to do so? How can we explain convergence regarding the safety assessment in several countries of origin given the absence of a common legal framework on which countries to designate as safe? Several explanations were touched upon, including imposition or policy transfer aimed at not being the weakest link in the (sub-) region. Whereas these mechanisms indeed seem to explain part of the policy convergence, they also create new puzzles. It not only seems to matter what neighbouring countries do, but, of course, domestic level factors also play a role. They include, for example, national foreign policy consideration or simply how many asylum seekers are coming, and from where they originate. Given the peculiarities of each and every member states, such factors speak for policy divergence rather than convergence. We thus also observe that many differences between EU member states' SCO policies remain existent. In any case, it is expected that - despite the absence of legally binding rules - European countries coordinate their policies with and on each other. It is argued in this thesis that this informal asylum policy coordination plays an important role in the domestic formulation of safe country of origin policies. The next chapter presents a theoretical and analytical framework allowing to test this claim. 



\section{Theoretical and analytical framework}

\subsection{Introduction}

The previous chapter concluded with an interesting puzzle: safe country of origin policies in Europe converge despite the absence of a common legal framework. Several attempts to come to such a common agreement at the EU level failed. There are two reasons for this failure: first, the European Court of Justice supported the Commission and the Parliament in their view that an EU-wide list of safe countries of origin could not be decided by the Council on its own. However, apart from the disagreement about the legal competences, there is a second, very practical, reason for not coming to a common decision: member states could simply not agree on which countries of origin to declare as safe. Now what is surprising is that despite this disagreement, there is a considerable amount of policy convergence regarding this very issue: almost all EU member states applying a SCO policy declared the Western Balkan countries as safe; also a majority of countries agrees in their safety assessment of certain West African countries, including Benin, Ghana and Senegal. It is difficult to argue that this policy convergence is pure coincidence. Rather, there must be other factors than legal harmonisation accounting for policy convergence.

The central argument of this $\mathrm{PhD}$ thesis is that transnational policy coordination between state executives ${ }^{22}$ accounts for convergence. The aim of this chapter is to provide a theoretical and analytical framework as a basis for testing this claim. In doing so, the chapter primarily addresses the second and the fourth sub-question: how can we conceptualise and theorise recent forms of European asylum cooperation; and what is the role of asylum cooperation in the domestic policy-making process relating to safe country of origin policies.

The key factor accounting for convergence is 'practical cooperation'. This is the core argument of the thesis, and needs further conceptual and theoretical examination. 'Practical cooperation' is, in general terms, described as transnational cooperation between state executives being involved in setting up or implementing asylum policy. The term 'practical cooperation' is not an intuitive one. The chapter starts with this term because it is very much used in recent political speech related to European asylum poli-

\footnotetext{
${ }^{22}$ The term state executives relates to persons being based in either the national ministry or the national asylum administration and being involved in shaping safe country of origin policies. They can be either officials or elected politicians.
} 
cy. The European Commission defines it as 'the establishment of appropriate structures involving the national asylum services of the Member States' (European Commission 2006a, par.1). According to the Commission, the core aim of 'practical cooperation' is to facilitate

(...) practical and collaborative cooperation towards three main objectives: achieving an EU wide Single Procedure; the joint compilation, assessment and application of Country of Origin Information (COI); and how Member States can better work together to address particular pressures in asylum systems or reception capacities resulting from factors such as geographic location (European Commission 2006a, par.1).

We see that this term continues to be rather vague and is thus not useable for an indepth analysis. Instead, throughout this thesis I will use another term, which is analytically sharper and better suited for an academic discussion: policy coordination.

Policy coordination is conceptualised as the horizontal coordination of policy or policy-relevant information between state executives. It is determined by its informal nature and the deliberative character of interactions. Policy coordination does not lead to legally-binding outcomes and in that sense, is understood in this analysis as standing in opposition to other modes of governance, most prominently the Community Method. The key factor making policy-makers turn to policy coordination is their dependency on each other's policy choices. This interdependence leads to a willingness to cooperate, however without commitment. There are similar coordination challenges in other policy fields as well, such as Common Foreign and Security Policy, employment or monetary policy. However, the concepts and explanations developed in this chapter are specifically applicable to asylum policy.

Regarding the setup of the analysis, figure 3.1 visualises two different levels, including the EU level and the transnational level.

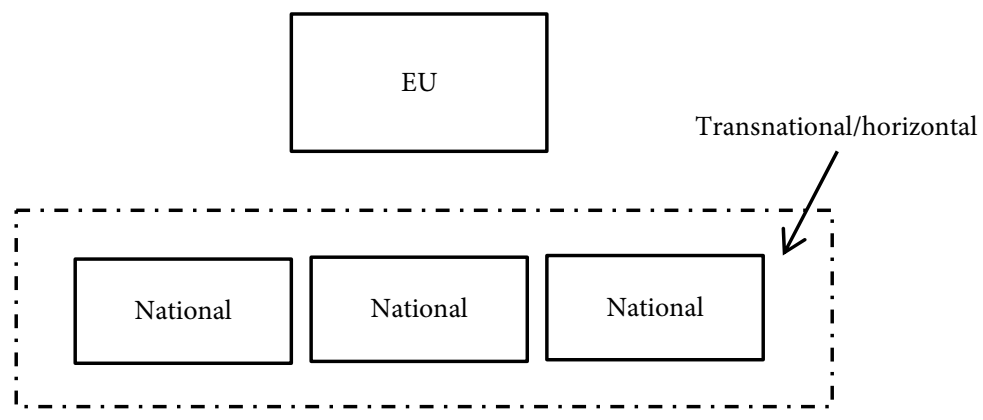

Figure 3.1: Levels of analysis 
The EU level relates to the formal EU structures. As discussed previously, with regard to the specific policies looked at, there is no or only minimum legal harmonisation at the EU level. Policy coordination primarily takes place at the transnational level. By transnational, I mean horizontal inter-state cooperation that is not embedded in the formal EU structures. However, it is still EU countries (and non-EU countries) that are the key players at the transnational level. The main difference between the transnational and the EU level is that the latter relates to the formal EU structures whereas the former primarily takes place informally.

The current chapter first focuses on the transnational level. Policy coordination is discussed as a distinct governance mode. However, we need to specify this term further. Thus, the first part of this chapter (section 3.2) conceptualises policy coordination by drawing on related concepts from the convergence literature, EU studies and the informal governance discussion. These concepts contribute to the conceptualisation of policy coordination. These contributions will be discussed and combined in an analytical framework. The analytical framework provides tools for empirically studying the actors (who), the function (why) and the form (how) of policy coordination (chapter 5).

In the second part of the theory chapter (3.3), the interaction between the national and the transnational moves into focus. Two distinct logics for domestic policy change influenced by transnational policy coordination are discussed: one based on a costbenefit rationale and another one based on a social constructivist argument. Both logics are theoretically placed and subsequent discussions feed into the development of an analytical framework. This framework is eventually applied in chapters 6 (logic of consequences) and 7 (logic of appropriateness).

\subsection{European level cooperation}

The aim of this section is to discuss the various concepts that inspired the definition of policy coordination. As a reminder, policy coordination was conceptualised as the horizontal coordination of policy between state executives. It is determined by its informal nature and the deliberative character of interactions. It does not lead to legally-binding outcomes.

What follows is an overview of concepts being closely related to what has been identified here as policy coordination. These concepts include transnational communication (Holzinger and Knill 2005), intensive transgovernmentalism (Wallace 2010), policy coordination (Wallace 2010), deliberative intergovernmentalism (Puetter 2012a, 2012b) and informal governance (Christiansen and Neuhold 2012; Helmke and Levitsky 2004; Christiansen et al. 2003). These concepts were studied in detail because they helped me in conceptualising and operationalising policy coordination - and in particular regarding three aspects: 
- Actors: Who is involved in policy coordination?

- Function: Why does policy coordination take place?

- Form: How does policy coordination look like?

In what follows, all concepts and their relevance in specifying these aspects are discussed in more detail.

\subsubsection{Transnational communication as a mechanism explaining convergence}

Because my key puzzle is about (unexpected) convergence, it is the most obvious choice to turn to the convergence literature first. Holzinger and Knill (2005) identify several mechanisms possibly accounting for convergence. These mechanisms include imposition, international harmonisation, regulatory competition, transnational communication and independent problem-solving. They serve as a driving force for policy adjustment, and can lead, in varying degrees, to domestic change and cross-national convergence. For example, it is argued that a coercive governance pattern (requiring compliance) is unlikely to result in domestic change and cross-national convergence. A competitive and a communicative governance pattern, although very different, both can lead to strong convergence and are likely to result in domestic change (Holzinger and Knill 2005).

For this analysis, transnational communication as one of the mechanisms leading to policy convergence is of particular relevance. According to Knill and Lenschow (2005), it relates to 'communication between regulatory agents across national levels arranged in an EU legal or institutional framework' (p.584). In that sense (and as opposed to the other mechanisms based on compliance or competition) nothing but information exchange and communication between countries explains cross-national convergence (Holzinger and Knill 2005, p.783). The governance mode is characterised by the absence of any legally-binding institutional/or policy model for domestic compliance. Instead, it stimulates information exchange and mutual learning between national policy-makers, and is thus purely based on communication. Whereas communication might also play a role in the case of harmonisation or regulatory competition, here it is the main factor accounting for convergence (Holzinger and Knill 2005, p.783). However, the specification of the mechanism at work does not go any further than that. ${ }^{23}$

Consequently, the convergence literature is only of limited help. It notes the presence of a mechanism solely based on communication, and contrasts it to competition-

\footnotetext{
${ }^{23}$ Several related terms were used to capture this mode of governance, including lesson-drawing, transnational problem-solving, emulation or policy-promotion (Holzinger and Knill 2005, p.783). Whereas the precise definition of these concepts might depend on the scholar using them, the actual theoretical expectations are similar: The voluntary nature of communication and its openness to policy suggestions leaving a broad leeway for interpretation are likely to stimulate cross-national lesson-drawing, eventually leading to policy transfer (p.789).
} 
and compliance-driven mechanisms. However, it provides no explanation of what this governance mode as such entails. What is still missing is a conceptualisation of the $a c$ tors, function and form of the governance mode at stake. What is actually meant by transnational communication? Who is involved, and for what reason? And how does it look like? Before discussing its impact and likelihood for domestic level change, these questions need to be answered first.

\subsubsection{Intensive transgovernmentalism and policy coordination}

Aiming to shed more light on the actual nature and function of policy coordination (as defined by me), this section now turns to the EU governance literature. Policy-making in the EU can be distinguished in several policy modes. This argument and the subsequent distinction were prominently put forward by Helen Wallace (2010). She identifies five variants of the EU policy process, including the traditional Community method, the EU regulatory mode, the EU distributional mode, policy coordination and intensive transgovernmentalism. Wallace's differentiation is helpful because it allows further specifying the difference between what I understand as policy coordination and related governance modes. The two modes of particular relevance for this analysis are intensive transgovernmentalism and policy coordination (as defined by Wallace). The former is characterised by the active involvement of the European Council in setting the overall direction of the policy, a predominance of the Council of Ministers, no role for the Commission, European Parliament and European Court of Justice, and an opaque decision-making process (Wallace 2010, p.101). The latter, policy coordination, is characterised by Wallace as the Commission being the developer of networks of experts or epistemic communities, the involvement of independent experts as promoters of ideas, the convening of high-level groups on the Council in a brainstorming or deliberative rather than negotiating mode, and dialogue (sometimes) with specialised committees in the EP (Wallace 2010, p.98). Wallace identifies both governance modes by specifying the actors involved (Council vs. Commission) as well as the form (opaque vs. open; deliberative vs. negotiating). This differentiation (actors, form) will be taken over for the analytical framework developed in this chapter (with function to be added). However, in what follows we will see that Wallace's typology does not sufficiently capture the mode of governance that is of interest to this analysis.

Whereas there is no disagreement among asylum scholars that previous and recent asylum cooperation was determined by a high level of intensive transgovernmentalism (see for example Lavenex 2001; Thielemann 2001; Monar 2001; Bunyan and Webber 1995), other policy modes become increasingly important too, including the Community Method. Respective analyses relate to the role of the European Commission (Thielemann and Zaun 2013; Kaunert 2009; Ucarer 2001), the role of the European Parliament (Ripoll-Servent and Trauner 2013; Ripoll-Servent 2011) as well as the increasing role of European courts (Vedsted-Hansen 2010). Recent forms of EU asylum governance were 
also labeled as policy coordination (as defined by Wallace 2010). Scholars have, for example, discussed the hypothetical use of the Open Method of Coordination in asylum policy (Velluti, 2007; Monar 2003) but also the growth of agencies in the field of Justice and Home Affairs (see for example Carrera et al. 2013; Pollak and Slominski 2010; Lavenex 2010; Rijpma 2010; Comte 2010; Monar 2006) as well as the need for cooperation between law enforcement agencies (Monar 2006; Thielemann 2001). These developments were put into Wallace's policy coordination-box. However, there are considerable flaws with this classification. My analysis will show that neither agencies nor cooperation between law enforcement authorities is a clear case of policy coordination (as defined by Wallace 2010) because many features of intensive transgovernmentalism prevail: Agencies are being criticised for adhering to opaque decision-making procedures, and for being driven by national interests with limited or no role for the Commission, the parliament (both national parliaments and the EP) or the public.

Eventually, it becomes clear from this discussion that Wallace's differentiation between the five variants is only of limited help for our analyses. It is too rigid and does not reflect contemporary governance in the field of asylum policy. ${ }^{24}$ In particular, it does not capture the horizontal, informal policy coordination that is of interest to this analysis. In addition, it is not only difficult to clearly differentiate between Wallace's governance modes (policy coordination and intensive transgovernmentalism), but also their relation to each other remains unclear. This is a crucial point because policy coordination originally was nothing more than a transition mode towards the Community Method (Wallace 2010, p.99). While today it clearly is a governance mode in its own right, the relation between, for example, policy coordination, intensive transgovernmentalism and the Community Method remains unclear. However, this relation between the various governance modes is important for the present analysis. I argue at a later point that policy coordination has gained prominence at the expenses of other forms of governance, and the Community Method in particular. In order to understand why policymakers prefer one mode of governance over the other and in how far one has gained importance at the expense of the other, one need to study their relation to each other.

Concluding on the relevance of Wallace's model for this analysis, one has to say that much of recent European asylum governance cannot be clearly conceptualised in terms of her five policy modes. The types are too rigid to allow for describing the mode of governance that is of interest to this analysis. Most of recent asylum governance modes lie very much between policy coordination (as Wallace understands it) and intensive transgovernmentalism. Also the relation between these types is not further specified. The growing importance of policy coordination in asylum somehow seems to be related to the evolvement of the Community Method - but how remains unclear. The subsequent section, discussing deliberative intergovernmentalism, sheds light on this.

\footnotetext{
${ }^{24}$ It has to be acknowledged though that also Wallace talks about ideal types and stresses that they might not appear in their 'pure' form in any policy field.
} 


\subsubsection{Deliberative intergovernmentalism}

Puetter's (2012a, 2012b) concept of deliberative intergovernmentalism aims at bridging different governance types and puts them in relation to each other. By doing so, it provides ideas on how my concept of policy coordination (assumingly) works - namely by deliberation.

Puetter (2012a) refines the classical understanding of intergovernmentalism by introducing the concept of new intergovernmentalism. It is viewed as an alternative form of governance in opposition to the classic Community Method, and responsible for fundamental changes in mainly two policy fields: economic governance and foreign and security policy. These fundamental changes occur because of an integration paradox: on the one hand, member states are very reluctant to further transfer power to the supranational level; however, on the other hand, they notice that cooperation is crucial because of mutual interdependences. For this reason, cooperation between countries is facilitated by specific mechanisms and routines allowing member states to remain in constant dialogue with each other over policy decisions (ibid., p.57). Both the European Council and the Council of Ministers play a key role in this form of cooperation.

Because political cooperation focuses on the creation of consensus via political deliberation, Puetter labels this form of governance 'deliberative intergovernmentalism':

The consensus dependency of EU policy-making in economic governance and in foreign and security policy is internalized by the key actors. They endorse and actively search for institutional settings which are conducive towards consensus-oriented intergovernmental policy dialogue (ibid., p.59).

The existence and level of deliberation depends on two factors, the setting and the policy content: The potential for deliberation is high, if the setting is informal, there is a recurrent dialogue and regular meetings, and if actors are socialised 'into the practice of open and consensus-oriented debate as well as collegial behaviour' (Lewis 1998, in: Puetter $2012 \mathrm{~b}, \mathrm{p}$.165). Other factors matter too, including technical knowledge and group composition as well as duration and frequency of meetings (ibid.). Next to the setting, also the policy content determines the level of deliberation. It thus plays an important role whether or not the policy issue is understood as a common problem, and the level of uncertainty attached to it is high (ibid.). By determining these conditions, deliberative intergovernmentalism provides a theoretical framework for assessing whether intergovernmental cooperation is likely to be driven by policy deliberation.

What is key to deliberative intergovernmentalism is its relation to the Community Method: both policy fields in which deliberative intergovernmentalism is prevalent (economic governance and foreign and security policy) will not be governed by supranational competences in the foreseeable future (Puetter 2012a, p.62). This is of course a big difference to asylum policy. Asylum policy is, to a large extent, already governed by supranational rules. However, the 'integration paradox' (ibid.) is inherent to asylum 
policy too: there is a principle resistance towards further transferring power to the supranational level, while at the same time actors are aware of the necessity to cooperate and act collectively. In that sense, there is also a high level of interdependency between the member states. However, because in asylum policy supranational institutions do have quite a lot of competences already, the decision-making power is not reserved to top-level representatives of the EU member states (i.e. the European Council and the Council of Ministers), as in the case of deliberative intergovernmentalism. Other actors come into play as well. Nevertheless, the trend towards more cooperation (without commitment at the supranational level) fits very much my understanding of policy coordination. Along the lines of Puetter's analysis, it can be argued that - because of the integration paradox - policy coordination developed as an alternative to the Community Method.

Closely linked to this point is the level of politicisation of issues discussed. Because economic governance and Common Foreign and Security Policy are highly politicised topics (p.59-60), alternative modes of governance (alternative to the Community Method) are needed. The same could be argued for the field of asylum policy. Reluctance towards further strengthening the Community Method can be explained by the highly politicised nature of the subject. At the same time, reluctance towards more supranational decision-making does also explain the informal nature of cooperation (see for example Vink and Engelmann 2012). In sum, deliberative intergovernmentalism is helpful in conceptualising and operationalising policy coordination because it helps specifying actors (homogenous group composition), the form of governance (informal, recurrent) and the presumed mode of interaction (deliberation). These factors will reappear in the analytical framework.

\subsubsection{Informal governance}

In the previous sections, several concepts were identified that are helpful in conceptualising policy coordination: it stands in opposition to other governance modes, mainly the Community Method; the issues to be coordinated are of sensitive nature and highly politicised (relating closely to intergovernmentalism, deliberative intergovernmentalism); and it is expected to be driven by deliberation rather than a cost-benefit rationale. Moving beyond the sheer conceptualisation of policy coordination, it is worthwhile to ask $w h y$ it actually takes place (i.e. its function). Given that the governance processes of interest are very much determined by their informality (see also Oelgemöller 2011; Pollack, Wallace and Young 2010; Puetter 2004), this section turns to studies on informal governance (Christiansen and Neuhold 2013; Kleine 2013; Christiansen and Neuhold 2012; Helmke and Levitsky 2004; Christiansen et al. 2003).

The term 'informal' has been used to study three separate issues - informal frameworks or arenas within which decisions are taken (organisations, governments or networks), informal processes or procedures that guide decision-making (politics, ar- 
rangements, activities), or the informality of an outcome of any such process (rules, norms agreements) (Christiansen and Neuhold 2013, p.2). My focus is on the first one, meaning informal arenas, fora or institutions in which policy decisions are taken. Informal institutions are understood as 'socially shared rules, usually unwritten, that are created, communicated, and enforced outside of officially sanctioned channels' (Helmke and Levitsky 2004, p.727). Informal governance, following Christiansen et al. (2003, p.7), is thus identified by two core elements: non-codified exchange and lack of public sanctioning. First, non-codified exchange means there are no codified or written rules regulating the behaviour of actors involved. Second, informal exchanges usually take place behind closed doors, in a setting which is not accessible to the general public and has no public authority with sanctioning power. Notwithstanding, private sanctioning mechanisms might exist, for example peer pressure, reputation or retaliation (ibid.). It is assumed that policy coordination is governed by these principles (non-codification and lack of public sanctioning) too. The different bodies in which policy coordination takes place can be seen as informal institutions.

Besides defining informal institutions, it is important to understand why they are created. Most prominently, the existence of informal institutions is explained by its juxtaposition to formal institutions. Helmke and Levitsky (2004) propose a fourfold typology putting informal institutions in relation to their formal counterparts. ${ }^{25}$ The typology is based on two dimensions: the degree to which the outcome of formal and informal institutions converges and the effectiveness of the formal counterpart (table $3.1)$.

Table 3.1: A typology of informal institutions (Helmke and Levitsky 2004, p.728)

\begin{tabular}{lll}
\hline \multicolumn{1}{c}{$\begin{array}{c}\text { Effectiveness } \\
\text { Outcomes }\end{array}$} & Effective formal institutions & Ineffective formal institutions \\
\hline Convergent & Complementary & Substitutive \\
Divergent & Accommodating & Competing \\
\hline
\end{tabular}

A typology of four informal institutions emerges:

- Complementary informal institutions fill in gaps by addressing issues that are not dealt with by the formal institution or by facilitating goals within the formal institutional framework. They might also serve as foundation for formal institutions in the sense of creating incentives to comply with the more formal rules that otherwise might only exist on paper (p.728).

- Substitutive informal institutions concur with complementary institutions in the sense that they aim for similar outcomes as their formal counterparts. However,

\footnotetext{
${ }^{25}$ Christiansen and Neuhold (2013) add to this typology by applying it to the interplay between formal and informal arrangements in the EU's context, and providing respective examples for each type.
} 
here the formal institutions are not effective, meaning formal rules are not enforced: 'substitutive informal institutions achieve what formal institutions where designed, but failed, to achieve' (p.729).

- Accommodating informal institutions 'create incentives to behave in ways that alter the substantive effects of formal rules, but without directly violating them; they contradict the spirit, but not the letter, of the formal rules' (p.729). They are often created because actors dislike the outcome of the formal institution or are unable to change/openly violate their rules (ibid.).

- Competing informal institutions combine ineffective formal rules and divergent outcomes. These institutions create incentives incompatible with the formal rules: to follow one rule, actors have to violate another (Helmke and Levitsky 2004, p.729). ${ }^{26}$

For the present analysis, this typology is helpful because it allows analysing why (informal) policy coordination fora were set up - by relating them to their formal counterparts. It thus allows studying the 'why' (the function) of policy coordination.

In case no formal counterpart exists, Helmke and Levitsky (2004) provide two further explanations of why informal institutions were created. They, first, argue that their creation might be the second-best strategy for actors who prefer but cannot achieve formal solutions. Informal cooperation can thus be a way out of institutional dilemmas arising from reluctance of national governments to move towards further transfer of formal decision-making capacities to a supranational level (Puetter 2003). Informal governance thus facilitates the pooling of expertise, for example in a sensitive policy field such as foreign policy, because it allows for a limited number of actors to exchange information (Justaert and Keukeleire 2012, p.446). And secondly, informal institutions were created (in the absence of formal counterparts) because they help pursuing a goal that is not yet publicly acceptable (Helmke and Levitsky 2004, p.730). Linked to European governance, this argumentation basically stresses the informal element in the twolevel game logic (see section 3.3.1). In sum, this section looked at the informal governance literature because most of policy coordination in the field of asylum policy tends to be informal. The respective literature helped to specify the form (how) and the function (why) of policy coordination.

\subsubsection{Analytical framework I: operationalising policy coordination}

Until now, the chapter tried to make analytical sense of what the Commission vaguely labeled 'practical cooperation'. I took the Commission's idea of 'practical cooperation' to an analytical level and defined it as policy coordination. Policy coordination means

\footnotetext{
${ }^{26}$ A somewhat similar differentiation was developed by Tatenhove et al. (2006) who distinguish between informal institutions created because of cooperative strategies (facilitating the formal process) and informal institutions created because of opposition strategies (aimed at changing or circumventing formal practices).
} 
the horizontal coordination of policy between state executives. It is determined by its informal nature and the deliberative character of interactions. It does not lead to legallybinding outcomes.

Policy coordination was conceptualised by relying on a number of concepts, including transnational communication (Holzinger and Knill 2005), policy coordination (Wallace 2010), intensive transgovernmentalism (Wallace 2010), deliberative intergovernmentalism (Puetter 2012a; 2012b) and informal governance (Christiansen and Neuhold 2013; Helmke and Levitsky 2004; Christiansen et al 2003). Both the convergence literature and EU studies were helpful in putting policy coordination in its place by relating it to other modes of governance, such as the Community Method. Also the informal governance literature was helpful in this regard because it allows analysing why policy coordination takes place by juxtaposing the (dominant) informal nature of policy cooperation with its more formal counterparts (i.e. institutions under the Community Method). Next to its informality, the form of policy coordination was further specified (addressing the how-question), including its secretive nature as well as the uncertainty and high political value attached to the topics discussed. The nature of these topics is closely interlinked with the (presumed) deliberative character of policy coordination. Both can be best analysed with drawing on Puetter's (2012) deliberative intergovernmentalism.

These various streams of literature were compiled in an analytical framework, focusing on the actors involved (who), the function of policy coordination (why), and its form (how) (table 3.2). This framework will help analysing specific instances of policy coordination, and cooperation on country of origin information in particular (chapter 5).

Table 3.2: Overview of indicators for describing and explaining policy coordination

\begin{tabular}{ll}
\hline Aim of the analysis & Indicators \\
\hline Actors - who is involved in policy coordination? & Function of actors \\
Function - why does policy coordination take place? & If formal counterpart exists: \\
& - Complementing \\
& - Substitutive \\
& - Accommodating \\
& - Competing \\
& Otherwise: \\
& - Second-best strategy \\
Form - how does policy coordination look like & - Pursuing goals otherwise unachievable \\
and how does it work? & Informal /formal \\
& High level of routine \\
& Duration and frequency of meetings \\
& Deliberation \\
\end{tabular}


In what follows, a brief description of actors, function and form of policy coordination is given.

About the actors involved: actors involved in policy coordination have - on purpose - been defined rather openly as state executives being involved in the policymaking process of interest. ${ }^{27}$ Whereas concepts such as intensive transgovernmentalism (Wallace 2010), policy coordination (as defined by Wallace 2010) or deliberative intergovernmentalism (Puetter 2012a, 2012b) focus rather narrowly on one type of actors, such as ministers or experts, the function of the person involved in policy coordination might vary. What, however, is important for policy coordination is that there are commonalities between the actors involved. The group is rather homogenous. In the course of the analysis, we will see whether it is possible to further specify the actors involved.

About the function of policy coordination: given the informal nature of the governance mode of interest, the analysis of why these fora emerged relies on informal governance literature. More specifically, the creation of informal institutions is explained with juxtaposing them to their formal counterparts (Helmke and Levitsky 2004). It is important to remind the reader that this aspect is not about individual countries' motivation to engage in policy coordination. Instead, it looks at the emergence of policy coordination (fora) from an institutional perspective. The domestic level - meaning single countries' motivation to engage in policy coordination - is theoretically discussed in the next section of this chapter.

About the form of policy coordination: finally, the form of policy coordination is specified by relying on both the informal governance literature (Christiansen and Neuhold 2013; Christiansen et al 2003) and Puetter's deliberative intergovernmentalism (2012a, 2012b). The latter identifies a number of conditions related to the setting and the policy issue as such. What thus matters is the informal nature of policy coordination but also a high level of routinization of dialogue, duration and frequency of meetings as well as a homogenous group composition. If all these conditions are given, deliberation is likely to occur.

The remaining part of the chapter moves away from the transnational level towards the interaction between the transnational and the national level (see figure 3.1). What role does policy coordination play in the domestic asylum policy-making process?

\subsection{Catalysts for domestic change}

The second part of this chapter deals with the possible effect of transnational policy coordination on domestic policy-making processes. The key question being asked is

\footnotetext{
${ }^{27}$ To remind the reader, the term 'state executives' relates to persons being based in either the national ministry or the national asylum administration and being involved in shaping safe country of origin policies. They can be either officials or elected politicians.
} 
what role does policy coordination play when it comes to the formulation of domestic policies? I am planning to answer this question by drawing on two different logics of action: the logic of consequences and the logic of appropriateness. In consequence, there are two ways to interpret domestic change being influenced by transnational asylum policy coordination: either it is understood as a strategic move among self-interested actors; those actors have entered policy coordination with pre-set preferences and leave the exchange without preferences having changed. Or preferences have been formed while coordinating policies and exchanging knowledge with other countries. In the first case, preferences are formed exogenous to policy coordination; in the second case, they are formed endogenously. The analysis starts from the assumption that both logics may not be mutually exclusive but rather co-existent (March and Olsen 2009; Goldmann 2005; Börzel and Risse 2003; March and Olsen 1998). Theory discussion and empirical data on both logics are viewed separately and in distinct chapters. The final chapter will then show in how far the two logics are complementary rather than competing and thus discuss how the two interact. In what follows, both logics of action are discussed in more detail leading to the setup of an analytical framework as a basis for studying - from both perspectives - the role of policy coordination in the domestic policy-making process.

\subsubsection{Logic of consequences}

The logic of consequences sees human action driven by a cost-benefit rationale (March and Olsen 2009; March and Olsen 1998; March and Olsen 1993; March and Olsen 1989). The section introduces the logic of consequences and two mechanisms through which it manifests itself, including two-level games (Putnam 1988) and learning (Checkel 2001a and 2001b). Based on the theoretical discussion, an analytical framework operationalising the logic of consequences will be developed.

The core idea of a rational logic of action is that it is based on a cost-benefit rationale and strategic behaviour. Such behaviour anticipates consequences and is based on given preferences. A logic of consequences treats actors as rational, goal-oriented and purposeful. Based on fixed preferences, they engage in strategic negotiations aimed at utility-maximization. Thus, 'human actors choose among alternatives by evaluating their likely consequences for personal or collective objectives, conscious that other actors are doing likewise' (March and Olsen 1998, p.949). The respective litany for action asks the following questions: first, what are my alternatives; second, what are my values; third, what are the consequences of my alternatives for my values; and finally, which alternative to choose that has the best consequences (March and Olsen 1989, p.23). According to the logic of consequences, actors' preferences are external to the institutional context in which they find themselves. Institutions, however, affect the strategic opportunities for achieving these preferences (Immergut 1998). In what follows, two mechanisms are specified through which the logic of consequences manifests itself. 


\section{Two-level games}

The logic of consequences has informed most of European integration studies (Garrett and Tsebelis 1996; Moravscik 1993). To quote one of its key agents, Moravcsik, 'the unique institutional structure of the EC [European Community] is acceptable to national governments only insofar as it strengthens, rather than weakens, their control over domestic affairs, permitting them to attain goals otherwise unachievable' (1993, p.507). According to Moravscik (1993), the European Union strengthens governments in two ways: it increases their efficiency in interstate bargaining; and it strengthens the autonomy of national leaders vis-à-vis certain groups within their domestic polity (p.507). Here, the classic two-level game comes into play (Putnam 1988), which explains the politics of international negotiations as follows:

\footnotetext{
At the national level, domestic groups pursue their interests by pressuring the government to adopt favorable policies, and politicians seek power by constructing coalitions among those groups. At the international level, national governments seek to maximize their own ability to satisfy domestic pressures, while minimizing the adverse consequences of foreign developments. Neither of the two games can be ignored by central decision-makers, so long as their countries remain interdependent, yet sovereign (Putnam 1988, p.434).
}

Thus, the European level can provide substantive support to domestic policy-makers. They can let themselves be pushed into a policy they privately favour, but would have found too costly or difficult to impose without indirect support from the European level. Common policies adopted with other member states provide national governments with legitimacy and credibility, and thus enhance their autonomy at the domestic level.

Given the logic of two-level games, it is crucial to understand not only the European level but also the national level, and the domestic determinants for European policy in particular:

National interests are [...] neither invariant nor unimportant, but emerge through domestic political conflict as societal groups compete for political influence, national and transnational coalitions form, and new policy alternatives are recognized by governments (Moravcsik 1993, p.481).

According to Moravcsik (1993), governments first define a set of interests, followed by bargaining amongst themselves to realise these interests. Politics needs to be studied first - which relates to much more than just executive officials and institutional arrangements, but also to parties, social classes, interest groups, legislators, public opinion and elections (Putnam 1988, p.432; see also Börzel and Risse 2003).

\section{Policy transfer and learning}

Apart from two-level games, there are other mechanisms presuming a logic of consequences, including policy learning and policy transfer. Both are often used to describe similar phenomena. This will not be further discussed here but the interested reader is advised to consult Bennett and Howlett (1992) who try to differentiate between these 
terms - however, only to come to the conclusion that also the literature on learning/transfer has been overtheorized and underapplied.

Policy transfer (Bennett and Howlett 1992; Rose 1991; Dolowitz and Marsh 2000) is defined as a 'process in which knowledge about policies, administrative arrangements, institutions and ideas in one political setting (past or present) is used in the development of policies, administrative arrangements, institutions and ideas in another political setting (Dolowitz and Marsh 2000, p.5).' In the European context, one differentiates between vertical and horizontal transfer. Vertical transfer relates to minimum European legislation that might be binding or non-binding, but with no coercive power to make states adapt to it. It nevertheless can prepare the ground for domestic policy change. According to Radaelli (2000), this kind of minimum or soft legislation can do so by providing additional legitimacy to domestic reformers in search for justifications, by 'inseminating' possible solutions in the national debate, and by altering the expectations about the future (p.18).' It thus very much follows a two-level game logic (see above). There is also the possibility of horizontal policy transfer. In this case, policies travel from one country to another with Brussels providing the opportunity structure for civil servants to exchange best practices. Again, the same logic is at hand providing policymakers with new options and a wider margin of maneuver within their domestic opportunity structure, as discussed above in the light of two-level games.

Coming to the definition of learning, Checkel (2001a) distinguishes between simple and social learning (the latter is discussed in the next section). Simple learning refers to processes where '... actors acquire new information as a result of interaction. Actors then use this information to alter strategies, but not preferences, which are given [in contrast to social learning] (Checkel 2001a, p.561).' Theorising learning in that way means that communication and language are just cheap talk of agents with fixed interest and identities (ibid.). Simple learning can be facilitated via the establishment of exclusive networks allowing for policy transfer. It suggests that even in the absence of binding EU regulation, European integration can facilitate learning.

In essence, and what is important for this analysis, is that the logic of consequences can not only manifest itself in the two-level game, but can also be disclosed in a mechanism that is here called simple learning. There are not necessarily constraints at the domestic level that make policy-makers look for alternative venues to achieve pre-set preferences. It might also be simply the case that policy-makers carry some pre-defined interests and preferences, and turn to other countries in order to find out how they deal with certain issues. Whatever has been learned is then applied in the own, domestic setting to achieve these pre-set preferences. In the course of this thesis, the term policy learning (or simple learning if relating to a logic of consequences) will be preferred over the term policy transfer. In what follows, the second logic of action and the related mechanism is specified. 


\subsubsection{Logic of appropriateness}

The logic of appropriateness sees human action driven by rules of appropriateness (March and Olsen 2009; March and Olsen 1998; March and Olsen 1993; March and Olsen 1989). After the logic of consequences, it is the second perspective through which asylum policy-making will be interpreted. This section introduces the logic of appropriateness and one mechanism through which it manifests itself, namely social learning (Checkel 2001b).

According to the logic of appropriateness, behaviour of human beings is driven by what is considered as appropriate or exemplary behaviour, organised into institutions (March and Olsen 2009). Instead of maximising and pushing for preferences (as suggested by the logic of consequences), actors are 'guided by collectively shared understandings of what constitutes proper, i.e. socially accepted behaviour in a given rule structure' (Börzel and Risse 2000, p.7). The term 'rules' refers to

(...) routines, procedures, conventions, roles, strategies, organizational forms, and technologies around which political activity is constructed [...]; [but also] beliefs, paradigms, codes, cultures, and knowledge that surround, support, elaborate, and contradict those roles and routines (March and Olsen 1989, p.22).

Rules are followed because they are viewed as natural, rightful, expected and legitimate (March and Olsen 2009). Thus, the respective litany for action asks the following questions: first, what kind of situation is this; second, who am I; third, how appropriate are different actions for me in this situation; and finally, do what is most appropriate (March and Olsen 1989, p.23).

The structure or institution in which actors are embedded plays a crucial role here. March and Olsen (2009) speak of a 'social collectivity' to which actors belong. This collectivity makes them '.. seek to fulfill the obligations encapsulated in a role, an identity, a membership in a political community or group, and the ethos, practices and expectations of its institutions' (March and Olsen 2009, p.3). Whereas in the logic of consequences, institutions primarily served the achievements of pre-given preferences, now they are key in the formation of preferences:

\footnotetext{
Institutions are organizational arrangements that link roles/identities, accounts of situations, resources and prescriptive rules and practices. They create actors and meeting places and organize the relations and interactions among actors. They guide behavior and stabilize expectations. Specific institutional settings also provide vocabularies that frame thought and understanding and define what are legitimate arguments and standards of justification and criticism in different situations (Mills 1940) (March and Olsen 2009, p.5).
}

Thus, preferences are formed endogenous to institutions, while actors are exposed to the institutional structure. What is considered appropriate action is prescribed by rules formed in the institutional structure. These rules of appropriateness tell actors where to 
look for precedents and what are the key interpretive traditions (March and Olsen 2009, p.7).

\section{Social learning}

In order to study the processes and dynamics of the logic of appropriateness, one can turn to different mechanisms, including normative isomorphism, learning, policy transfer, problem-solving and lesson-drawing. This section will not go into a detailed discussion of what is meant by each of the concepts. Social learning (Checkel 2001b) was considered most helpful for this analysis primarily because it presents the most hands-on approach in deriving an analytical framework from social constructivist ideas.

Following Checkel's (ibid.) understanding of social learning, actors acquire new interests or preferences while interacting with others. They do so in the absence of any obvious material incentives. Instead, argumentative persuasion plays a crucial role. It means that attitudes change without coercion. One rather assumes 'an activity or process in which a communicator attempts to induce a change in the belief, attitude or behaviour of another person ... through the transmission of a message in a context in which the persuadee has some degree of free choice' (Perloff 1993, in Checkel 2001a, p.562). It is important to note that learning can also be associated with a more rational understanding, often referred to as simple learning. In this case, agents acquire new information, alter strategies, but then pursue given, fixed, interests (Checkel 2001b, p.53; see section 3.3.1). However, this section is about social learning which involves a process of argumentative persuasion (as opposed to manipulative persuasion in a logic of consequences calculation).

There are a number of conditions that make social learning in policy-making likely to occur. They range from conditions at the domestic level (such as novelty of the issue or institutions facilitating social learning) to conditions related to the institution in which learning occurs (often epistemic communities). These conditions are discussed in detail below.

\section{The learning community: policy networks and epistemic communities}

Norm-entrepreneurs play a crucial role in social learning. There are several understandings of what these norm- and idea-promoting agents are, ranging from epistemic communities (Haas 1992) to advocacy networks (Börzel and Risse 2003, Keck and Sikkink 1998) to policy networks (Stone 2001). Both epistemic communities and policy networks are relevant for this analysis. I discuss the term policy network because it is broader than epistemic communities, and thus allows capturing a wider array of policy coordination fora.

Policy networks are broadly defined as 'having a shared problem on which there is an exchange of information, debate, disagreement, persuasion and a search for solutions and appropriate policy responses' (Stone 2001, p.9). These networks facilitate social learning by creating infrastructures, such as newsletters, databases or conferences. By 
these means, agents become aware of policies adopted elsewhere, and have the opportunity to evaluate the relevance of such policies in their own, national context (ibid.). As a result, policy networks add to

(...) a soft, informal and gradual mode for the international diffusion and dissemination of ideas and policy paradigms. Networks enable actors to operate beyond their domestic context and networks are the means by which organisations individually and in coalition can project their ideas into policy thinking across states and within global or regional fora (Stone 2001, p.14).

However, the concept of policy networks remains rather general. This is an important point for the present analysis because much of what will be discussed as policy coordination (in chapter 5) would fall under this more general term. But there are also instances of policy coordination that resemble a much closer, informal and specific exchange, and thus can be seen as epistemic communities.

Epistemic communities are one example of policy networks in which the conditions are particular good for social learning to occur. They are defined as networks '.. of professionals with recognised expertise and competence in a particular domain and an authoritative claim to policy-relevant knowledge within that domain or issue-area' (Haas 1992, p.3). Professionals in these networks are primarily connected via their common knowledge. However, they also share a common understanding of their work, a set of normative principles and beliefs, causal beliefs, a notion of validity and a common policy enterprise (ibid., pp. 16-20). Often, these communities operate informally. The more informal these networks and the more alike the actors involved in it, the more likely it is that social learning will occur. Other conditions further facilitating social learning (and are known for occurring in epistemic communities) include frequent meetings of the group and high density of interaction among participants but also insulation of the group from direct political pressure and exposure (Checkel 2001b, p.54)

\section{Domestic conditions facilitating social learning}

Next to characteristics related to the transnational level (engagement in policy networks and epistemic communities), also the domestic level plays an important role. In order for policy-makers to be open to social learning (and to bring what they learned transnationally into national policies), four further issues are important.

First, the history of policy-making in the policy field under review matters: social learning is likely to occur when there is uncertainty because the issue is new at the domestic level - that is a new policy field that has not or hardly been dealt with before (Checkel 2001a; Haas 1992; see also March and Olsen 1989). ${ }^{28}$

Second, next to the general history of the policy in the country-context, also the individual level matters: a decision-maker is likely to be prone to social learning when she

\footnotetext{
${ }^{28}$ Domestic change in this thesis is thus not only viewed as actual change of policy but also as change from no policy to any policy.
} 
has no preconceived views and beliefs. The more established patterns of behaviour are, the more unlikely that decision-makers are open to argumentative persuasion (Checkel 2001a; Haas 1992). Both the first and the second condition are linked by one important aspect, namely uncertainty. While uncertainty is a general feature of asylum policy, it is particulary strong in cases (countries) where the policy issue is new and/or involved actors have never dealt with these issues beforehand (Checkel 2001a). In such a situation, (policy) choices must be made without adequate information about the situation at hand. Also, facing a situation of novely means that there is no previous experience on the consequences of policy decisions possibly (not) taken (Haas 1992). This uncertainty creates a need for information, which is why actors are likely to turn to others and learn from them.

Third, the domestic institutional structure plays an important role. Social learning is likely to occur (and lead to domestic change) if the domestic institutional structure facilitates these processes. In particular, there must be political and/or administrative institutions conducive to consensus-building (Börzel and Risse 2003). The existence of such an institutional structure helps overcoming veto points by rendering their use of inappropriate for actors. It also allows for sharing adaptational costs between 'winners' and 'losers' of domestic change rather than shifting these costs upon the latter (ibid., p.68).

Coming to the fourth condition, political culture plays an important role. Political culture generally refers to the 'meaning attributed to politics' (Aronoff 2001, p.11640), and is defined as 'the set of attitudes, beliefs and sentiments that give order and meaning to a political process and which provide the underlying assumptions and rules that govern behavior in the political system' (ibid.). If the political culture of a country facilitates processes of social learning, domestic change is likely to follow from it. The third and the fourth conditions - institutional setting and political/administrative culture - are closely related. Political and administrative culture determine how domestic institutions (and eventually how policy) looks like.

In order to specify the political culture argument further, I am turning to the discussion on nation-state identity (Marcussen et. al 2001). The idea of nation-state identity assumes pre-existing collective identities (social groups) that define themselves on the basis of ideas to which its members can relate positively. These ideas define the group in a positive way (what/who is the group) but also in a negative one (what/who is not the group). This latter aspect is important: nation-state identity does not only define the 'ingroup' but also one or several 'out-groups' (ibid., p.102). These ideas (on who belongs to the group and what makes the group) can be expressed in two ways, either '... directly in the discourse of the members and in their ways of interacting and communicating, or indirectly through the application of common symbols, codes or signs' (ibid.). I am using this concept of nation-state identity in order to explain whether social learning is likely to occur in the domestic policy-making process, or not. It is argued that the na- 
tion-state identity, as perceived by government and party elites, plays an important role in whether or not government officials are prone to social learning and whether they can implement what they have learned. What matters is the identity-construction in relation to other countries. To give two examples: Country $\mathrm{X}$ might have a sense of nation-state identity that is very much focused on 'being special' and 'being different from other countries'. This could be explained by ethnicity, geographical location or any other factor illustrating that there is country X, and there are the other countries. Policymakers from such a country $\mathrm{X}$ might be unlikely to become convinced of arguments by others (policy-makers from other countries) because they believe being too special/unique to adopt policies from elsewhere. Another example would be country A: This country defines itself as very much being part of a trilogies community with countries B and C. Country A will be open to learn from countries B and C because of its history of cooperation. For A, it might just be the most rightful and socially accepted thing to do, to turn to $\mathrm{B}$ and $\mathrm{C}$ when looking for new ideas on how to tackle certain policy issues. A will, naturally, turn to these countries (and not to any country D-Z that is outside of this community) because the decisive policy-makers of A have always done so, and perceive their country as being part of the network A-B-C. These two stylised examples illustrate that nation-state identity can take very different forms. What, however, matters is that policy-makers are more or less prone to argumentative persuasion because of how they perceive their country in relation to others.

Summing up this and the previous section, two logics of action through which asylum policy-making is interpreted in this thesis were discussed: first, the logic of consequences and two related mechanisms (two-level games and simple learning); and second, the logic of appropriateness and social learning as the respective mechanism. In what follows, the theoretical discussions on both logics are translated into an analytical framework.

\subsubsection{Analytical framework II: operationalising the two logics of action}

\section{Logic of consequences}

Based on the conditions identified above, an analytical framework was developed. Table 3.3 provides an overview of these conditions as related to policy-making as a costbenefit calculation (logic of consequences).

There are a number of conditions under which policy-making can be expected to follow the logic of consequences. The mechanism at play can relate to two-level games or a simple learning process. The analytical framework inhibits a time dimension. Thus, one expects the conditions to be present one after the other. First, policy-makers need to have clearly identifiable preferences prior to entering the exchange with other countries. 
Table 3.3: Overview of conditions for policy-making following a logic of consequences

\begin{tabular}{ll}
\hline Level & Conditions \\
\hline Domestic & Preferences regarding safe country of origin policies \\
& Constraints faced \\
& - Executive vs. legislative \\
& - National courts \\
& - Civil society \\
& Engagement in asylum policy coordination for the purpose of acquiring \\
Transnational & information on other countries' policies \\
& Justifying legitimacy of action \\
Domestic & No change of preferences \\
\end{tabular}

Assuming a two-level game logic, they must also be constrained by one or several domestic actors in achieving these preferences, such as the legislative, national courts or civil society. Second, the transnational policy coordination is then used to achieve these pre-set preferences and (if a two-level game logic is at play) to circumvent domestic constraints. Thus policy-makers engage in exchanges with other countries for the purpose of acquiring information on (intended) policies. Third, policy-makers leave these coordination exercises without preferences having changed. Instead, whatever was learned from other countries is used to justify own, pre-set preferences. However, none of these conditions can be viewed as being sufficient to induce domestic change as a result of two-level games or learning. Rather, they are all facilitating factors making - in combination - two-level games or learning likely to occur.

\section{Logic of appropriateness}

Based on the theory discussion above, also an analytical framework for the logic of appropriateness was set up. Table 3.4 provides an overview of the conditions as related to policy-making as a result of socially accepted behaviour (logic of appropriateness).

Table 3.4: Overview of conditions for policy-making following a logic of appropriateness

\begin{tabular}{ll}
\hline Level & Conditions \\
\hline Domestic & Uncertainty \\
& - Newness of the policy issue \\
& - Few cognitive priors \\
& Presence of an epistemic community \\
Transnational & - United by common knowledge \\
& - Shared understanding of work, of problems/solutions \\
& - Informal setup and insulation from political pressure \\
& Emergence of EU-wide norm \\
& Institutions facilitating consensus \\
Domestic & Political culture/nation-state identity \\
\hline
\end{tabular}


There are a number of conditions making social learning likely to occur. Also here they are connected via a time dimension. First, there are two conditions at the domestic level making social learning likely to occur: a short (or non-) history of policy-making regarding the issue at stake and few cognitive priors of the decision-makers involved. Both conditions create a situation of uncertainty in which policy-makers are likely to turn to others in order to learn (and become convinced) of their (policy) solutions. Second, there are two conditions at the transnational level that make social learning likely to occur: the first one is the presence of an epistemic community. Such a community manifests itself by several characteristics, including its members being connected by common knowledge (and the generation thereof), a shared understanding of how their work should be conducted as well as common problems and solutions, and an informal setup of the group which also insulates it from political pressure. Second, next to the presence of an epistemic community, social learning can also occur at the transnational level because a norm evolved which became commonly accepted amongst EU member states. Finally, domestic level factors come into play again. What was learned during transnational policy coordination can only be implemented if domestic conditions allow doing so. These conditions include institutions facilitating consensus as well as a political culture prone to social learning. Again, none of these conditions can be viewed as being sufficient to induce domestic change as a result of social learning. Rather they are all facilitating factors making - in combination - social learning likely to occur.

\subsection{Conclusion}

This chapter developed a theoretical and analytical framework for the empirical analysis to follow. It addressed two major issues: first, conceptualising and theorising the mode of asylum governance that is of interest to this research; and second, providing a theoretical basis for studying the role of this governance mode in the domestic policymaking process.

Policy coordination was conceptualised as the horizontal coordination of policy or policy-relevant information between state executives. It is determined by its informal nature, the deliberative character of interaction, and it does not lead to legally-binding outcomes. In order to further theorise upon policy coordination, several related concepts were studied, including transnational communication (as defined by the convergence literature: Holzinger and Knill 2005), intensive transgovernmentalism and policy coordination (both as defined by Wallace 2010), deliberative intergovernmentalism (Puetter 2012a, 2012b) and informal governance (Christiansen and Neuhold 2013; Helmke and Levitsky 2004; Christiansen et al. 2003). These concepts proved helpful in developing an analytical framework that forms the basis for studying policy coordination in more detail. It addressed the actors (who is involved), the function (why has it been established) and the form (how does it look like and how does it work) of policy 
coordination fora, and it provides the basis for the respective empirical analysis in chapter 5 .

The second part of the chapter prepared the ground for answering the main question of the thesis, namely what role does policy coordination play in the domestic policy-making process. In order to answer this question, two distinctive logics of actions are applied: one assuming consequence-driven behaviour (logic of consequences) and one assuming rules-based behaviour (logic of appropriateness). The former uses a two-levelgame logic or policy transfer as the key mechanism explaining the role of policy coordination in the domestic decision-making process. The latter manifests itself in social learning. The respective parts of the framework will be empirically tested in chapters 6 and 7. In what follows, some further groundwork for the analysis is conducted. The next chapter discusses the methodological choices made, including the case study design, data collection and data analysis. 



\section{Methodology}

\subsection{Introduction}

This chapter discusses the methodological choices made for answering the research questions. In particular, two levels of analysis are covered: the transnational/European level, answering the question how does policy coordination in the field of asylum policy, and on country of origin information in particular, work; and the interaction between the transnational and domestic level asking what is the role of COI cooperation in the domestic policy-making process relating to safe country of origin policies?

The transnational/European level analysis is more comprehensive in the sense of including an analysis of all EU member states' engagement in policy coordination, and cooperation on country of origin information in particular. In contrast, the member state level analysis is more in-depth and will focus on four countries in particular by means of a comparative case study design. Because the latter question is the key research question of the $\mathrm{PhD}$ thesis, its methodology is also discussed more prominently in this chapter than the transnational/European level analysis. The same methods are applied and similar types of sources have been used for both levels of analysis, unless indicated otherwise.

The chapter proceeds as follows: it starts by spelling out the research design, including discussions on the type of case study analysis conducted, the scope of the population, criteria for case selection and some background information on the four countries selected (all section 4.2). Furthermore, the data collection is described, including a discussion of primary and secondary sources as well as a detailed discussion of the interview-method (section 4.3). Finally, the way of analysing the data is explained, including a discussion of the process-tracing approach (section 4.4).

\subsection{Research design}

Given the focus of the research, there were several possibilities for research designs. Analysing convergence, it would have been possible to conduct a medium-scale quantitative analysis determining the level and scope of policy convergence (Knill 2005; Holzinger and Knill 2005). However, the focus of the analysis is on the role of policy coordination in the domestic policy-making process. This analysis thus goes beyond correla- 
tional observations on cause and effect (which would have been possible to conduct quantitatively as well). Instead, I am interested in causal mechanisms and 'peer[ing] into the box of causality to the intermediate causes lying between some cause and its purported effect' (Gerring 2004, p.348). In this analysis, the key focus is on the causal relationship between policy-makers' engagement in transnational policy coordination, and the subsequent effects of this engagement on decisions taken in the national context. This is first and foremost an analysis of decision-making processes and actors' motivations. These cannot be uncovered by quantitative methods but require in-depth qualitative analysis, and a case study design in particular.

The analysis is understood as a theory-centered case study. Whereas in the literature (Rohlfing 2012), there is a clear-cut differentiation of how this advancement could look like - either hypothesis-generating or -testing or -modifying - it is much more difficult to do this in practice. This is mainly due to the different streams of theory literature that are relevant for this thesis (chapter 3). Relating to the informal governance discussion, the analysis is hypothesis-testing because it applies existing ideas to a new policy field, namely asylum. It, however, is also hypothesis-generating because it explicitly looks in how far informal governance at the transnational level translates into domestic policies (which has not been done so far). Looking at EU governance studies, the analysis is hypothesis-modifying because existing concepts (policy coordination, intensive transgovernmentalism both as defined by Wallace 2010) are advanced in their understanding and their effect on the domestic level. Relating to convergence studies, the analysis is also hypothesis-modifying because the mechanism in question (transnational communication, Holzinger and Knill 2005) is further specified and its effects are spelled out. And finally, drawing on the general logics of consequentialism and appropriateness the analysis can be viewed as theory-testing. It tests two hypotheses: one assumes that policy coordination is used in the domestic formation of safe country of origin policies because of constraints faced by policy-makers at the national level; and the other one assumes the use of this information because of appropriateness considerations of involved policy-makers. Since testing the logic of consequences and the logic of appropriateness is the most prominent part in the $\mathrm{PhD}$ thesis, it has the most influence on case selection (as discussed in section 4.2.1). Consequently, this analysis is primarily hypothesis-testing.

Looking at the level of analysis (the level of theoretical interest, not the level on which the empirical analysis is located, Rohlfing 2012, p.12), I intend both a cross-case and a within-case analysis. Relating to the within-case level, the analysis attempts to identify the intervening causal process between the independent variable and the outcome of the dependent variable (George and Bennett 2005, p.206). In order to establish the causal chain between the two, process-tracing is applied (see section 4.4). As well as looking in detail into the causal mechanisms and causal processes in each case (within- 
case level), also the overall causal effect in the different cases is of interest (cross-case level). The difference between the two levels of analysis is illustrated in figure 4.1.

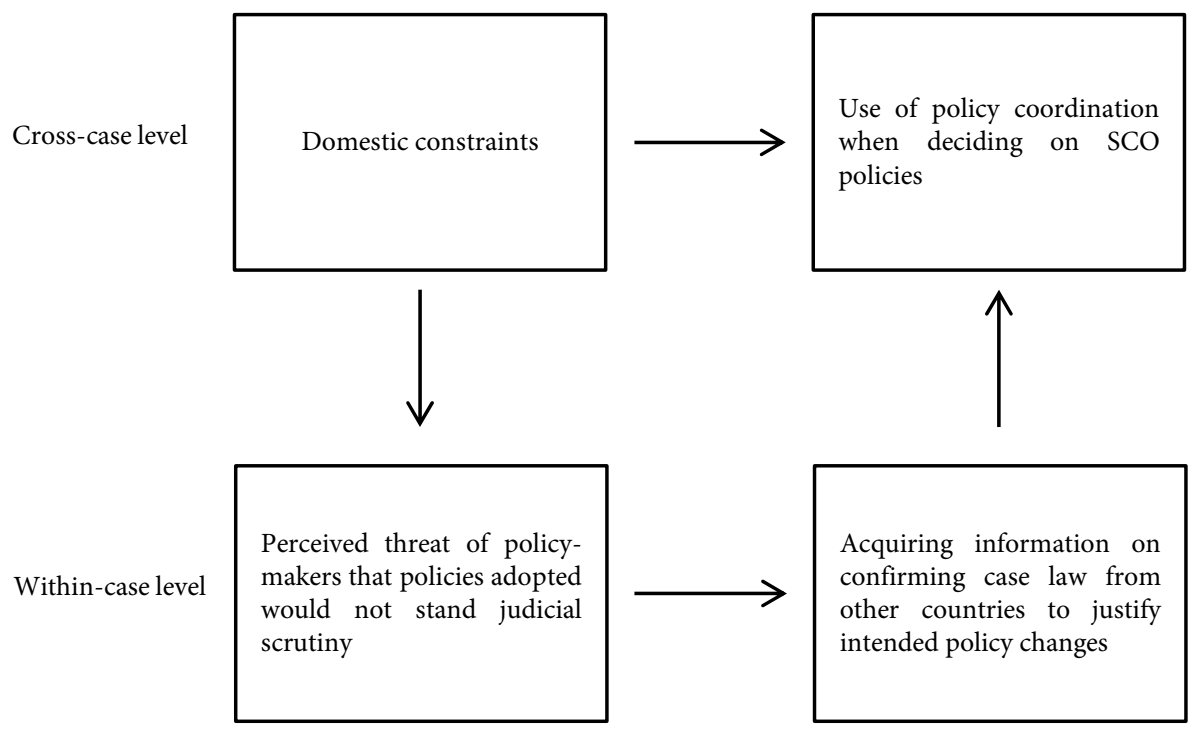

Figure 4.1: Cross-case level and within-case level of empirical analysis

Figure 4.1 illustrates both levels of analysis relevant for this research. Relating to the cross-case level, it is theorised that domestic constraints lead policy-makers to use policy coordination when deciding on SCO policies. Thus the cross-case analysis stays rather general and looks at the relationship between the independent and dependent variable from a comparative perspective. On the within-case level, the different factors are studied that lead from domestic constraints to a strategic use of policy coordination in the policy-making process. The chain of events could include: first, strong courts prevent the government from adopting a certain policy; the government wants to create sustainable policy solutions, that would stand (potential) court scrutiny; it looks for policy solutions from other countries dealing with similar constraints at the domestic level; such information from other countries (such as case law) is then used to justify own decisions; eventually, the government adopts the originally intended policy. In that sense, the within-case analysis is much more in-depth and aims at reconstructing the causal chain of events.

The present analysis is concerned with anticipated rather than realised processes. The difference between the two is that the latter 'has the cause as the starting point and the outcome as the end point of a process that was realised empirically' (Rohlfing 2012, p.154) (emphasis added). Anticipated processes are defined as follows: 
A hypothesis explaining an outcome with anticipated processes focuses on the considerations that actors make before coming to a decision and/or committing a specific action. The consequences that actors expect will unfold if they take a specific action then account for their performing the action that results in the outcome (ibid.).

For example, a government might decide to not pursue a certain policy change if anticipating strong domestic constraints, such as a challenge by courts. It is the role of the researcher to also think these processes through and make theoretically informed assumptions why certain actions have been taken, and why they have not. Based on the differentiation between realised and anticipated processes, a remark on data is in order: when studying realised processes, the actual process is the subject of analysis. When studying anticipated processes one focuses on the decision-making process accounting for the outcome (Rohlfing 2012, p.156). As regards the subject of this thesis, the decision-making process on safe country of origin policies is the focus of analysis. In what follows, case selection is discussed as well as some background on the countries selected is provided.

\subsubsection{Case selection}

In order to justify the case selection, the reader needs to be reminded of the different layers of the analysis. Four sub-questions matter in the context of answering the main question: First, do safe country of origin policies become more similar or diverse; second, how can we conceptualise and theorise recent forms of European asylum cooperation; third how does recent European asylum cooperation work; and fourth, what is the role of cooperation on country of origin information in the SCO policy-making process? All four questions are inter-related but different. They serve the purpose of answering the main research question: What is the role of transnational policy coordination in the domestic asylum policy-making process in the EU member states?

In order to do justice to the complexity of the project, one would need to select cases separately for each of the sub-questions. This is, however, not feasible for the time and scope given to this $\mathrm{PhD}$ project. Instead, there is an attempt to select a set of cases that would be relevant and add to the findings of all four questions simultaneously. Whereas the first question (convergence yes or no) requires a cross-case analysis anyway, the second and third already call for a deliberate selection of few cases as of course does the fourth one.

Before being able to conduct a thorough case study, a larger cross-case analysis and subsequent assumptions about the broader population are necessary to make (Gerring 2007, p.90). Consequently case selection presented in this section was preceded by a large-scale analysis of the complete population of safe country of origin policies in EU member states (Engelmann 2014a; chapter 2). In addition, a number of exploratory interviews with experts on national and European asylum policy were conducted. In 
what follows, first the population is discussed, and then criteria for case selection are explained.

\section{About the population}

A case is a 'bounded empirical phenomenon that is an instance of a population of similar empirical phenomena' (Rohlfing 2013, p.24). Before discussing the actual case selection, it is thus important to specify what is meant by the population in this research. Since, eventually, generalisations are aimed for, it is crucial that all cases in the population are somewhat similar. They do not have to be identical but causal homogeneity should be presumed, which means that cause-effect relationship is, on average, expected to hold true for the cases within the population (Collier et al 2004, p.29 in Rohlfing 2012, p.24). For my population this means that all cases in the population should, to some extent, be involved in asylum policy coordination and should this involvement somehow take into account when making national asylum policies. This is presumed for all cases.

The population of reference for this analysis is the EU-27. The focus on EU member states is explained by the role of the EU in the policy coordination process, and its effect on the domestic level: from entire absence in the 1990s to a driver for formal policy coordination nowadays. The time frame 1990 to 2013 was chosen because transnational policy coordination started taking off in the early 1990s, and the first countries adopted safe country of origin policies by then. However, for practical reasons, the group of countries from which one can select cases needs to be narrowed down - namely to all EU member states that have (had) safe country of origin policies and respective lists of countries designated as safe during the time 1990 to 2013. These countries are Austria, Belgium, the Czech Republic, Bulgaria, Denmark, Finland, France, Germany, Ireland, Latvia, Luxembourg, Malta, the Netherlands, the Slovak Republic and the UK. Considering the research question - in how far policy coordination plays a role in the national designation of safe countries of origin - it would have also made sense to include countries in which the decision was taken to designate no countries of origin as safe. Given that nearly all European countries engage in transnational policy coordination, it is very likely that this coordination has also led to negative decisions (meaning a deliberate non-introduction of the policy in question). However, noting the difficulties in getting access to data (see sections 4.3 and 4.4 in this chapter), it was more likely to obtain data on countries where a positive decision was taken.

Also because of data accessibility, several countries having SCO policies were unsuitable for the analysis: Denmark as well as the Czech Republic has a confidential list and data is hardly accessible; Belgium, the Netherlands as well as Finland had SCO designations for only a very limited timespan. ${ }^{29}$ Eventually, the following four countries

\footnotetext{
${ }^{29}$ In Belgium, SCO policies existed before 1993, and again since 2012. Finland had SCO policies and lists in the early 1990s before they were abandoned in 1998. The Dutch used a SCO list between 1995 and 2001.
} 
were selected: Germany, the UK, Malta and Luxembourg. In what follows, the case selection will be further explained as well as introductions to all four cases are given.

\section{Criteria for case selection}

It has been stressed above that there was a deliberate attempt to select cases that would do justice to all four research questions. Whereas the focus of analysis is on question 4, and this question consequently had the biggest influence on the cases selected, also the other questions were taken into account. Relating to question 2 and 3, it was important to get an overview how policy coordination takes place, and who is involved. Eventually, in order to study the variety of policy coordination in the field of asylum policy, countries were selected that are to varying degrees involved in policy coordination. Table 4.1 provides an overview over the case distribution.

Table 4.1: Distribution of cases across the spectrum of engagement in informal asylum policy coordination

\begin{tabular}{llll}
\hline $\begin{array}{l}\text { Involvement in asylum } \\
\text { policy coordination }\end{array}$ & Strongly involved & Moderately involved & Less (or not) involved \\
\hline Countries & $\begin{array}{l}\text { Austria, Denmark, } \\
\text { Germany, Luxembourg, } \\
\text { the Netherlands }\end{array}$ & $\begin{array}{l}\text { Belgium, Finland, France, } \\
\text { Ireland, Poland, Sweden, } \\
\text { the UK, }\end{array}$ & $\begin{array}{l}\text { Czech Republic, Estonia, } \\
\text { Greece, Hungary, Italy, } \\
\end{array}$ \\
& & $\begin{array}{l}\text { Latvia, Lithuania, Malta, } \\
\text { Portugal, Romania, the } \\
\text { Slovak Republic, Slovenia, } \\
\text { Spain }\end{array}$ \\
\end{tabular}

The analysis assumes the involvement of all EU-27 member states in asylum policy coordination - however, to varying degrees: The informal years of policy coordination in the 1990s saw primarily the old member states from Western and Northern Europe engage in transnational cooperation. Since the adoption of Dublin II and the 2004 enlargement, also the new member states as well as the Southern European ones are involved in transnational asylum policy coordination (chapter 5). It is assumed that all EU member states take this policy coordination in account when deciding on the (non-) introduction of safe country of origin policies. Again, though the case selection was primarily focused on research question 4 , cases were picked that vary on the spectrum of policy coordination as illustrated above.

Regarding question 4, the analysis was set up in order to test two hypotheses: first, strong domestic constraints make policy-makers turn to policy coordination when deciding on SCO policies (two-level games; logic of consequences); and second, high uncertainty leads policy-makers using policy coordination for SCO decision-making (social learning; logic of appropriateness).

Hypotheses-testing research enables three types of case studies: crucial, most-likely and least-likely case studies (Rohlfing 2012, p.84). Crucial cases are cases in which the 
hypothesis is very certain to be confirmed or disconfirmed (ibid.). Given these high demands on crucial cases, there is little applicability to them in the social sciences. Consequently, also this study looks for most-likely and least-likely cases. They are defined as follows: 'A most-likely case has a relatively high probability of confirming the proposition under scrutiny, while a least-likely case goes hand in hand with a comparatively low probability' (ibid.). For both hypotheses, most-likely and least-likely cases were selected. Both hypotheses and the respective distribution of cases are visualised in tables 4.2 and 4.3.

Table 4.2: Distribution of cases for hypothesis 1

\begin{tabular}{lcc}
\hline Cases & Strong domestic constraints & $\begin{array}{c}\text { Use of policy coordination in } \\
\text { deciding on SCO policies }\end{array}$ \\
\hline Germany (most likely) & + & + \\
UK & + & + \\
Luxembourg & - & + \\
Malta (passed least-likely) & - & + \\
\hline
\end{tabular}

Table 4.3: Distribution of cases for hypothesis 2

\begin{tabular}{lcc}
\hline Cases & Uncertainty & $\begin{array}{c}\text { Use of policy coordination in } \\
\text { deciding on SCO policies }\end{array}$ \\
\hline Germany (passed least-likely) & - & + \\
UK (passed least-likely) & - & + \\
Luxembourg & + & + \\
Malta (most-likely) & + & + \\
\hline
\end{tabular}

Both hypotheses are based upon the assumption that policy coordination plays a role when domestic decisions on SCO policies are taken. However, hypotheses 1 and 2 test two different causes for the outcome to be explained. Consequently, the research objective does not focus on the outcome of the dependent variable, but on the role of the independent variable (George and Bennett 2005, p.80).

According to the first hypothesis (table 4.2), policy-makers face domestic constraints and use transnational policy coordination to achieve goals (i.e. SCO policies) otherwise unachievable (two-level games). Domestic constraints are the determining factor in this regard. Most likely to use policy coordination in the domestic SCO decision-making process are the UK and Germany because in both countries, policy-makers face strong domestic constraints. Malta has no incentive to do so because domestic constraints are weak to absent. However, the country still uses policy coordination when 
deciding on safe country of origin policies. This constitutes a puzzle and makes Malta a passed least-likely case. A passed least-likely case is a case where there is a relatively low probability of confirming the proposition under scrutiny, which still proves to be confirmed (Rohlfing pp.84ff). The Maltese case thus represents a puzzle because it deviates from the established assumptions. In studying such cases, one can refine and sharpen existing hypotheses (Lijphart 1971, p.692). Luxembourg falls into the same type; however, it is not as strong as Malta.

In the second hypothesis, the driving force for policy-makers to turn to policy coordination (and use it in the national designation of SCO) is uncertainty. Uncertainty can relate to different factors, for example inexperience by the authorities, failed policies or unexpected events. Malta is a most-likely case for this hypothesis because policymakers were in a very short time confronted with many challenges, including the adoption of the EU asylum acquis, first-time responsibility for processing asylum applications (previously done by UNHCR) and occasional huge influxes of asylum seekers. To a lesser extent and for different reasons (but also linked to uncertainty), Luxembourg can be viewed as a most-likely case. Although Luxembourgish authorities are experienced with asylum institution-building, their system came under a lot of pressure during the last years (again, sudden huge influxes of asylum seekers and no resources to deal with it). In addition, Luxembourg always favoured a European (SCO list) over a national solution and was suddenly confronted with having to adapt to what the neighbouring countries already had in place. Much less uncertainty can be expected on part of the UK and Germany because of the long history of asylum policy-making, a clear interest to not have an EU-wide SCO list (not taken by surprise when the common list failed, in contrast to Luxembourg) and policies in place that already dealt with the SCO issue (expertise was there). However, both countries do rely on policy coordination when making decisions on SCO matters. In that context, again, they constitute puzzles and thus represent passed least-likely cases for hypothesis 2 .

To summarise, the first hypothesis was based on the assumption that policy-makers turn to and use policy coordination because they aim for goals otherwise unachievable (due to domestic constraints). The second hypothesis presumes that policy-makers undergo a process of social learning while coordinating policies with other countries, which eventually influences their domestic SCO policies. The determining factor here is uncertainty. The hypotheses are tested by analysing four countries - Germany, the UK, Luxembourg and Malta - which either represent most-likely or passed least-likely cases. These cases were also selected on the premise to have as much as possible variance on the engagement in policy coordination (table 4.1). ${ }^{30}$

\footnotetext{
${ }^{30}$ The four countries selected vary along additional axes, for example large vs small and old vs new member states. This variation was not decisive for the case selection, but does offer additional possibilities for inference about the differences in involvement and use of COI cooperation (see also concluding remarks in section 8.2.4).
} 


\subsubsection{Background on cases}

This section provides the necessary legal, institutional and substantial information on the cases selected: institutional relates to the setting of the asylum system; legal to the rules on safe countries of origin; and substantial to the actual practice related to the policy. ${ }^{31}$ The section presents information only as so far as it is essential for understanding the analysis. Table 4.4 provides an overview of the key features of SCO policies in the four selected countries

Table 4.4: Overview of SCO regulations in countries selected for case studies

\begin{tabular}{|c|c|c|c|c|}
\hline & Germany & The UK & Luxembourg & Malta \\
\hline $\begin{array}{l}\text { Introduction of } \\
\text { SCO rule }\end{array}$ & 1993 & 1996 & 2006 & 2000 \\
\hline $\begin{array}{l}\text { First SCO } \\
\text { designations }\end{array}$ & 1993 & 1996 & 2007 & 2004 \\
\hline $\begin{array}{l}\text { Countries } \\
\text { designated as } \\
\text { safe as of } \\
\text { December } 2013\end{array}$ & $\begin{array}{l}\text { Ghana, } \\
\text { Senegal }\end{array}$ & $\begin{array}{l}\text { Albania, Jamaica, Macedonia, } \\
\text { Moldova, Bolivia, Brazil, } \\
\text { Ecuador, South, Africa, } \\
\text { Ukraine, India, Mongolia, } \\
\text { Ghana (men), Nigeria (men), } \\
\text { Bosnia-Herzegovina, Gambia } \\
\text { (men), Kenya (men), Kosovo, } \\
\text { Liberia (men), Malawi (men), } \\
\text { Mali (men), Mauritius, } \\
\text { Montenegro, Peru, Serbia, } \\
\text { Sierra Leone (men), and } \\
\text { South Korea }\end{array}$ & $\begin{array}{l}\text { Albania, Benin } \\
\text { (men), Bosnia and } \\
\text { Herzegovina, Cape } \\
\text { Verde, Croatia, } \\
\text { Ghana (men), } \\
\text { Kosovo, Macedonia, } \\
\text { Montenegro, } \\
\text { Senegal and Serbia }\end{array}$ & $\begin{array}{l}\text { Benin, Botswana, } \\
\text { Brazil, Cape Verde, } \\
\text { Chile, Costa Rica, } \\
\text { Gabon, Ghana, } \\
\text { India, Jamaica, } \\
\text { Senegal, Uruguay } \\
\text { and the US }\end{array}$ \\
\hline
\end{tabular}

Before discussing the background for each of the cases individually, let us first have a comparative look at the numbers of asylum seekers coming from these four countries (as of 2013): Germany 126,995; the UK 30,110; Luxembourg 1,070 and Malta 2,245 (Eurostat). However, looking at the relative numbers of asylum seekers, the picture looks entirely different (figure 4.2).

\footnotetext{
${ }^{31}$ For all four countries, legal provisions relating to SCO policies are included in annex III to this thesis.
} 


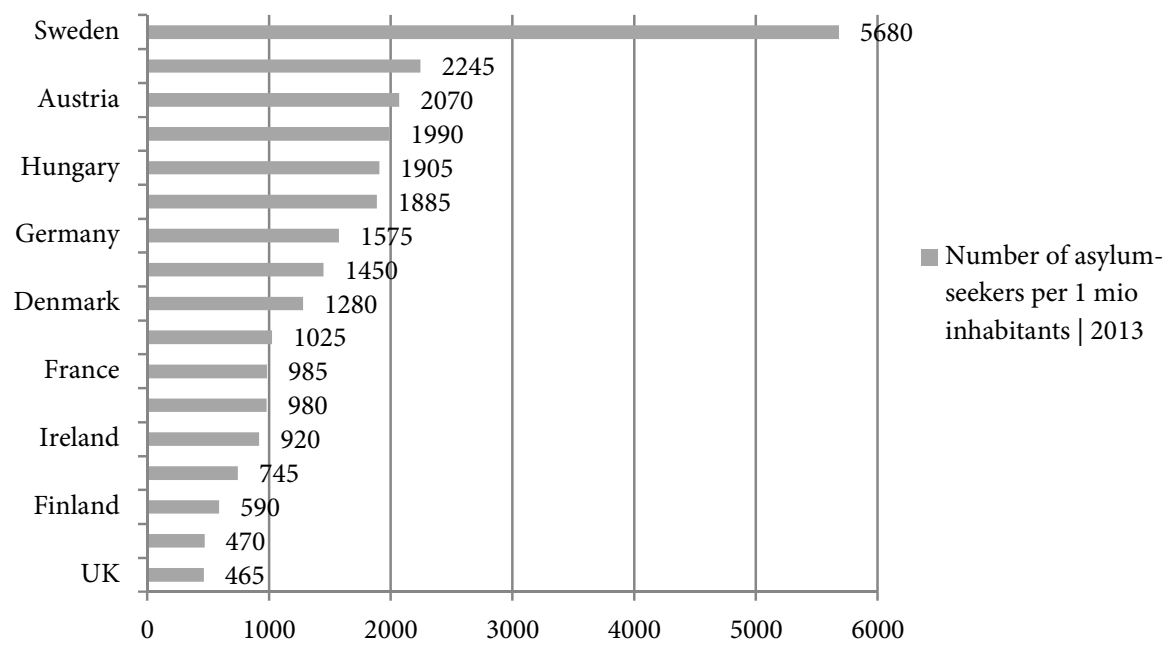

Figure 4.2: Number of asylum-seekers per 1 million inhabitants in 2013 (source: Eurostat)

Figure 4.2 shows the relative number of asylum applications lodged in the EU member states. We see that Malta ranks second if the number of applications is put in relation to the number of inhabitants. Also Luxembourg and Germany are in the 'top 10', whereas the UK only ranks $17^{\text {th }} .{ }^{32}$ In what follows, some more background is provided on each of the four cases studied in detail.

\section{Germany}

The German case was chosen because Germany has a safe country of origin policy as well as a list of countries of origin declared as safe. Germany is strongly involved in asylum policy coordination, and cooperation on country of origin information in particular. The country was also chosen because policy-makers face strong domestic constraints in the field of asylum policy. It is thus a most-likely case for the logic of consequences, and the two-level game in particular. It is assumed that strong domestic constraints make decision-makers use information obtained during transnational policy coordination in order to achieve preferences otherwise unachievable.

The main actor in the field of asylum in Germany is the Federal Ministry of the Interior (BMI). It is responsible for drafting legislation and for overseeing the Federal Office for Migration and Refugees (BAMF), which is the central operative authority. The BAMF is a superior federal authority among several subordinate authorities of the BMI and fulfills various tasks, the most important one (and also most relevant for this analysis) being the conduct of asylum procedures in Germany. ${ }^{33}$ Legislative competenc-

\footnotetext{
${ }^{32}$ For presentation reasons, the figure only shows the ranking until the lowest-ranked country selected as a case study (the UK).

${ }^{33}$ For a more detailed account of the history and work of the BAMF, see Kreienbrink 2013.
} 
es are split between the Federal Government and the 16 state governments. The latter may adopt laws in any area in which the Federal Government does not hold the sole law-making authority. In practice, this means that most migration-related issues are legislated by concurrent legislation. However, looking at asylum in particular, all overarching legislation concerning refugee-matters was adopted by the Federal Government (EMN Germany 2013, p.15).

The key laws related to the safe country of origin notion include the Basic Constitutional Law (Grundgesetz) granting politically persecuted persons a right to asylum; and the Asylum Procedures Act (Asylverfahrensgesetz) regulating the asylum procedure. The legal basis for safe country of origin designations is article 16a (3) of the Basic Constitutional Law in combination with section 29a of the Asylum Procedures Act (see annex III to this thesis). By 2013, Ghana and Senegal are the two countries declared as safe by German law.

Regarding the decision-making process, the German legislator in consent with the Federal Council (Bundesrat) can specify countries in which 'neither political persecution nor inhuman or degrading punishment or treatment exists' (article 16a (3) Basic Constitutional Law). According to the Federal Constitutional Court, only a country as a whole can be declared as safe - not parts of a country or specific populations within a country (Bundesverfassungsgericht 1996). The German threshold for declaring a country as safe is thus stricter than SCO notions in, for example, Luxembourg or the UK. ${ }^{34}$ Applications of foreigners from countries of origin declared as safe can be turned down as manifestly unfounded (section 29a Asylum Procedures Act). Negative decisions on asylum claims can be appealed before an administrative court. The appeal has no suspensive effect.

The SCO rule was introduced in 1993 and part of a comprehensive and highly contested reform of the German asylum law - the so-called Asylkompromiss (asylum compromise). By then, a number of contentious issues were included in the law, such as the concept of safe third countries and the airport procedure. As of 2013, Ghana and Senegal are designated as safe countries of origin. Since 1993, there were no changes to the German list. ${ }^{35}$ The reason for that is unclear and its investigation will be part of the analysis. In 2014, the German government added three further countries to the list (Bosnia and Herzegovina, Macedonia and Serbia; see Bundestag 2014); however, this is beyond the time frame for this analysis.

\section{The UK}

The British case is in many regards similar to the German one. It was chosen because the UK has a safe country of origin policy as well as a list of countries declared as safe.

\footnotetext{
${ }^{34}$ In both countries, it is possible to declare a country of origin as safe for specific parts of the population (such as men).

${ }^{35}$ Only Gambia had been removed from the list in 1995.
} 
Also in the UK, policy-makers face strong domestic constraints in the field of asylum policy. However, the constraints are different from the German ones because here it is the judiciary potentially constraining policy-maker. The UK thus also serves as a mostlikely case for the logic of consequences, and the two-level game in particular. In contrast to Germany and Luxembourg, the UK is only moderately involved in asylum policy coordination. It, however, has by far the most active safe country of origin policy amongst the EU member states.

Regarding the institutional setting, the UK has a rather troubled history of institutions being in charge of asylum matters. Immigration was always part of the Home Office's mandate. The creation of an executive agency in 2007 - the UK Border and Immigration Agency - was the result of a radical change after several scandals in the immigration system (Casciani 2013). In 2008, this agency was replaced by the UK Border Agency (UKBA), which was until very recently the institution in charge of processing asylum claims. UKBA was thus responsible for all aspects related to the reception of asylum seekers, the return of rejected asylum seekers and the integration of recognised refugees and beneficiaries of other forms of international protection (IGC 2009, p.365). However, in 2013 the UKBA was abolished (Casciani 2013), and its tasks returned to the Home Office.

The key legal document for asylum matters in the UK is the Nationality, Immigration and Asylum Act (NIA Act) of 2002. It regulates any issues relating to nationality, accommodation and support for asylum seekers, detention and removal as well as the asylum procedure and the immigration procedure. The current legal basis for safe country of origin designations is section 94 of this Act (see annex III to this thesis). As of December 2013, the following countries of origin are declared as safe: Albania, Bolivia, Bosnia-Herzegovina, Brazil, Ecuador, Gambia (in respect of men), Ghana (in respect of men), India, Jamaica, Kenya (in respect of men), Kosovo, Liberia (in respect of men), Macedonia, Malawi (in respect of men), Mali (in respect of men), Mauritius, Moldova, Mongolia, Montenegro, Nigeria (in respect of men), Peru, Serbia, Sierra Leone (in respect of men) South Africa, South Korea, and Ukraine. The list may be changed by the Secretary of State by order (article 5 of section 94). An order is a statutory instrument which is the principal form in which delegated or secondary legislation is made in the UK. In the case of SCO designations, these instruments are discussed by both houses and need their approval.

These (Asylum Designated States) Orders were issued many times over the last years. In that respect, the UK is not only the country with the longest safe country of origin list in Europe but also the one with the most frequent changes to that list. A state as well as parts of a state may be added to the list. Also a designation might be issued for a whole population or parts of a population. Thus, designation as safe for many countries on the list only applies to men (Ghana, Nigeria, Gambia, Kenya, Liberia, Malawi, 
Mali, and Sierra Leone). The most recent order is from 2010 and added Kosovo and South Korea to the list (Asylum Order 2010).

The SCO notion was introduced in 1996. By then, SCO designation was linked to a fast track procedure and a limited time for appeals (10 days) (1993 Asylum and Immigration Act, par. 5 of schedule 2). Since the 2002 NIA Act, the implications for asylum seekers from designated countries have changed. Nowadays, SCO designation of a country results in the claim being unfounded with no possibility for appeal within the $U K$. Thus, issuing an appeal has no suspensive effect but the asylum seeker is immediately returned to her home country. That is why SCO cases are called non-suspensive appeal (NSA) cases in the UK. However, for the sake of clarity, the term safe country of origin is also used for the UK in this thesis (as it is for the other three countries studied in detail). Any appeals of negative asylum application decisions are heard by the Asylum and Immigration Tribunal.

\section{Luxembourg}

Luxembourg was chosen as a case study because it has a safe country of origin policy as well as a list of countries of origin declared as safe. The Luxembourgish authorities are, as the German ones, strongly involved in asylum policy coordination, and cooperation on country of origin information in particular. However, in contrast to both Germany and the UK, Luxembourg faces hardly any domestic constraints in the national asylum policy-making context. Regarding hypothesis 1 , it thus constitutes a passed least-likely case worth examination. Due to several reasons (sudden high influx of asylum seekers; strong favour for but no success in achieving an EU-wide common list of safe countries of origin), Luxembourg is prone to uncertainty and thus likely to engage in policy coordination in order to formulate own positions and learn from other countries. It thus represents a most-likely case for the logic of appropriateness hypothesis.

In Luxembourg, the Ministry of Foreign Affairs is responsible for the processing of asylum applications. The key legislation regarding asylum is the Law on the Right of Asylum and to Complementary Forms of Protection of 19 May 2011 modifying the Law of 5 May 2006. The safe country of origin notion is regulated in its articles 20 and 21 (see annex III to this thesis). The possibility to designate countries of origin as safe exists since 2006. The first list was adopted in 2007. As of 2013, the Luxembourgish list of safe countries of origin includes Albania, Benin (only male), Bosnia and Herzegovina, Cape Verde, Croatia, Ghana (only male), Kosovo, Macedonia, Montenegro, Senegal, Serbia and Ukraine. The appropriate instrument for designation would be a Grand-Ducal regulation (règlement grand-ducal), which is an execution document. ${ }^{36}$ A Grand-Ducal regulation can be issued without consultation of the parliament. Four such regulations

\footnotetext{
${ }^{36}$ With regard to safe countries of origin, it would be an execution of article 21 of the Asylum Law which relates to safe country of origin designation.
} 
were issued so far (from 21 December 2007, 1 April 2011, 11 April 2011, 19 June 2013) altering the existent safe country of origin list.

Article 20(1) of the law specifies that claims of applicants coming from a country of origin considered as safe can be processed in an accelerated procedure, which takes normally about two months (article 20(2)). However, it has to be noted that during the years 2009 to 2011 no cases were processed in an accelerated procedure. The reason is that the original Asylum Law of 2006 allowed no claim against the decision (of the authorities) to process someone's case in an accelerated procedure (article 20(5) of the Law of 5 May 2006 on the Right of Asylum and to Complementary Forms of Protection). The question whether this would be compatible with European directives had been conferred to the European Court of Justice in an interlocutory question brought by the Administrative Tribunal (ECJ 2010). The ECJ issued an answer only in 2011 (ECJ 2011). Thus, during the period waiting for the ECJ reply, the accelerated procedure was suspended (for 1.5 years). In April 2011, the Luxembourgish government changed the asylum law, deleting article 20(5) and thus allowing claims against the referral of a case to an accelerated procedure.

For the case of Luxembourg, one further remark on numbers of asylum applications is in order: such numbers were always comparatively moderate. However, the year 2011 marked a major change. The number of applicants skyrocket (from 786 in 2010, to 2,164 in 2011) - with far-reaching consequences: public debate was very heated (i.e. anti-refugee) and decision-makers were in desperate search for solutions. The sudden influx of asylum seekers created so much pressure on the authorities that the Luxembourgish asylum office had to temporarily close for ten days in October 2011 (Luxemburger Wort 2011). In the beginning of 2012, the European Asylum Support Office provided emergency support to the Luxembourgish authorities (EASO 2012b).

\section{Malta}

Malta was chosen as a case study because the Maltese authorities established a safe country of origin policy as well as a list of countries of origin declared as safe. However, as Luxembourg, Malta faces hardly any domestic constraints in the national asylum policy-making process. Regarding hypothesis 1 , it thus constitutes a passed least-likely case worth examination. Being a novel actor in the field of refugee status determination, being a new EU member state and facing a disproportional high burden of asylum seekers, Malta is (as Luxembourg) prone to uncertainty and thus likely to learn from others' experiences. It is assumed that policy coordination is used to form own, domestic preferences, and subsequently alter/introduce safe country of origin policies. The country thus represents a most-likely case for the logic of appropriateness hypothesis. In addition, from the countries selected for the case study analysis, Malta is by far the one least involved in asylum policy coordination, and cooperation on country of origin information in particular. 
In Malta, the Ministry for Justice and Home Affair is responsible for any asylum matter. Within the Ministry, the Office of the Refugee Commissioner deals with decisions on first instance asylum claims. It was established in 2002. By then, responsibility on refugee status determination was passed on from UNHCR to the Maltese government (EMN Malta 2008). The rather late responsibility take can be explained by the low to non-existent numbers of asylum seekers reaching the island prior to 2002. Though the ministry has only been taken on this responsibility in 2002, it has been dealing with asylum issues since 1998. By then, its main taks was the preparation of asylum legislation, also in light of accession to the EU in 2002. The key legislation regarding any asylum matters is the Refugees Act of 2000, which is also the first specific asylum legislation ever enacted in Malta.

The current legal basis for SCO designations in Malta is part V, art. 24 (1i) of the Refugees Act of 2000 (see annex III to this thesis). The current list comprises 13 countries, including Benin, Botswana, Brazil, Cape Verde, Chile, Costa Rica, Gabon, Ghana, India, Jamaica, Senegal, Uruguay and the US. The list was introduced in 2004 and amended twice (2005 and 2008). The Minister for Home and Parliamentary Affairs is responsible for amending the SCO list by regulation (art. 24(3)). There is no role for the parliament in this process. Apart from that, the Refugees Act remains rather unspecific on how to make such a safety assessment. No reference to sources to be consulted or to criteria for designating a country as safe is made. ${ }^{37}$ According to articles 23 and 24, an application issued by someone from a safe country of origin can be declared both manifestly unfounded and inadmissible (interview 28). Any of the two lead to an accelerated procedure. The Refugee Appeals Board is responsible for reception and determination of appeals lodged against negative decisions issued by the Refugee Commissioner.

In the case of Malta, it has to be stressed that the safe country of origin notion and list has no implication for the asylum applicant. The asylum authorities do not make use of the list. However, this does not matter for the analysis as it focuses on the political decision-making process, and not on the implication of the policy.

\subsection{Data collection}

Many of the processes studied in this thesis are informal, and thus undocumented. The challenge of studying informal governance was formulated before:

Empirical research on informal governance is often not only about gathering data, but actually about defining the kind of data that is to be collected. The ultimate test then becomes the access to information

\footnotetext{
37 The original (2001) version of the Refugees Act states a number of criteria for designating a country of origin as safe (art.2 of the $2001 \mathrm{Act}$ ). However, these assessment criteria are not mentioned in later versions of the Act.
} 
about developments that are undocumented and are generally lacking transparency (Christiansen and Neuhold 2013, p.8).

The process of data collection and analysis as well as challenges faced is explained in the remainder of this chapter.

The data collection took place between November 2009 and December 2013. It includes primary sources (such as parliamentary proceedings), secondary sources and interviews. In addition, one participant observation took place. ${ }^{38}$ Table 4.5 provides an overview of the field trips conducted during that time.

Table 4.5: Overview of field trips conducted

\begin{tabular}{ll}
\hline Time & Location \\
\hline 30 March-2 April 2011 & Vienna, Austria \\
19-30 September 2011 & Luxembourg \\
18-27 March 2012 & London, UK \\
29 April-11 May 2012 & Valetta, Malta \\
11-25 June 2012 & Nuremberg and Berlin, Germany \\
Throughout the project & travels to Brussels (Belgium) and The Hague (The \\
& Netherlands) \\
\hline
\end{tabular}

The field trips not only served the purpose of meeting with interview partners but also to access information otherwise unavailable. For example, it was of great help for the data collection to speak in person to employees from the Westminster Archive in London, the UK. Also, in the German case, the actual visit to the parliament archive allowed access to many more documents than what would have been available remotely. Often interview partners also had paper documents to share with me, especially in the German case where the events of interest (almost) precede the internet era (early 1990s).

The thesis triangulates sources in order to avoid both the source coverage problem and a source coverage bias. The goal of this research is to acquire a picture of the decision-making process that is as complete as possible. This is done by collecting and analysing relevant sources. However, the source coverage problem is one that all researchers are confronted with meaning that 'every source covers only a certain fraction of the relevant empirical evidence' (Rohlfing 2012, p.169). Reliance on a single source would leave the picture incomplete. Next to that, sources are also biased. One needs to be aware of the fact that a primary source, be it an interview or a transcript of a meeting, is not a neutral piece of evidence. An interview partner shares only the information she is

\footnotetext{
${ }^{38}$ Participant observation was conducted during a conference of COI experts, judjes and asylum lawyers aimed at coordinating country of origin information on Afghanistan.
} 
willing to share, and a meeting transcript might deliberately exclude certain information while emphasising others. The source coverage problem and bias make clear that no source is superior over another (ibid.).

Triangulating sources can help overcoming both problems. Instead of only relying on one type of sources and a small number of sources, information about the decisionmaking process was derived from as many and as diverse sources as possible. For example, the decision-making process leading to the inclusion of Senegal in the German list of safe countries of origin was reconstructed by conducting interviews with people at different levels and in different functions (policy-makers, NGO representatives, lawyers) but also by reading parliamentary proceedings, documents from the Foreign Office and by observing the media coverage at this point in time.

\subsubsection{Primary sources}

The primary sources used in this research include:

- Legal texts

- Meeting proceedings

- Written records of parliamentary debates, and supportive documents to these debates

Legal texts played a major role in the first part of the research. Assessing whether safe country of origin policies in Europe become more similar or not, required a large-scale analysis of safe country of origin policies in all EU member states. In order to do so, the respective domestic asylum laws were studied for the EU-27 over time (1990-2013). For the third sub-question (how does policy coordination work), proceedings of meetings were analysed. Such proceedings relate mainly to records or reports of COI exchanges. It, however, has to be stressed that these were only few documents because either there was no record (due to the informal nature of the exchange) or it was not available. The main sources of data for question three were interviews.

Regarding sub-question 4 (what is the role of policy coordination in the domestic policy-making process), parliamentary debates were the main primary source in reconstructing the decision-making process. They are also one of the most valuable sources because they 'continue to provide a strong institutional locus for researching political positioning among the political elite over time' (Huysmans and Buonfino 2008, p.766). Parliamentary debates and supporting documents were analysed for all four cases. They were selected as follows: I was interested in all debates related to the introduction or a change in the domestic safe country of origin policy. This meant, for example, that for the case of the UK, all parliamentary debates were analysed whenever a country was supposed to be added to the list of safe countries of origin. Given the complexity of the British safe country of origin list (changes have occurred more than 10 times over the last 15 years; and have often been debated in both houses), the UK was by far the most 
time-intense case analysis regarding parliamentary proceedings. Similar debates in the German Bundestag only took place over a time period of one year (1992/1993), the same goes for Malta (2000). Luxembourg is somewhere in between.

How did I gain access to these debates? In the first place, they were searched for online. Via Hansard, most of the UK debates could be found. Reading parliamentary debates for Germany, Malta and Luxembourg as well as accessing any additional documents referred to in the debates (such as country assessment reports by the Foreign Office) required first-hand contact with the Parliament Archive. Consequently, the following institutions were visited for research purposes: archive of the German Bundestag, archive of the German Federal Office for Migration and Refugees, and archive of the UK Houses of Parliament. The archives of the Maltese and the Luxembourgish parliament were contacted via email and phone. Respective emploees were also helpful in researching the necessary documents.

There is a clear advantage of primary sources over other sources because they are first-hand information, and less filtered than secondary sources. For example, written records of parliamentary debates do not leave out anything said but are a minute detailed record of the debate in the house. These sources were of great value for the researcher. The same goes for accompanying documents, which is documents submitted in support (or in opposition) to the issues on the house's agenda.

However, there are also disadvantages to this kind of data, most prominently their accessibility. As the researcher experienced herself, access to parliamentary proceedings (and to supportive documents in particular) is rather selective. This is mainly due to the sensitivity of the topic of interest. For example, it would have been of great interest for this analysis to access the country assessment reports from the Foreign Offices relating to the countries of origin that are intended to be included in the national SCO list. These documents have, obviously, been available to the MPs in preparation for the debate, and were frequently cited during parliamentary debate. It was, however, impossible for the author to access these documents. They are still qualified as confidential (though some of the debates happened 20 years ago) and no request with involved persons led to the wished result (i.e. the wished document). In that regard, interviews proved unexpectedly useful. Not only were they a valuable source for triangulating data but often interviewees - once they gave a detailed account of their story - were also willing to share copies of confidential material that would have otherwise stayed inaccessible to the researcher.

\subsubsection{Secondary sources}

Given the long history of safe country of origin policies in some EU member states, there are several secondary sources available. Especially in the British but also in the German case, analyses conducted by others were used. Examples include reports from the UK Home Office and the German Ministry of Interior but also studies compiled in the framework of the European Migration Network, reports by NGOs or evidence com- 
piled by various observers of the legislative procedure leading to a SCO designation. The respective policies in Luxembourg and Malta were also studied by others, however to a much lesser extent. Here, secondary sources were limited to few policy reports compiled in the framework of the European Migration Network (EMN Luxembourg 2012; EMN Malta 2008) and very few academic papers.

\subsection{Interviews as a data source}

Interviews are discussed in a separate section because they make up a large part of the data collected. In what follows, I discuss the selection of interviewees and the way interviews were conducted. In total, 42 interviews took place during July 2010 and July 2012. They were conducted in the following locations: Berlin (4 interviews), Brussels (4), The Hague (2), London (5), Luxembourg (7), Maastricht (1), Nuremberg (2), Valetta (9) and Vienna (4). Four interviews took place via phone. Annex I provides an overview of interviews conducted in the framework of the analysis. It, however, only lists the number of the interview, the date and place where it was conducted. This format was chosen because most interviewees did not want to be quoted by name. They did also not want their name to be mentioned in a summary in the book.

Interviewees included policy-makers, members of parliament, employees of the national asylum administration (in administrative or executive functions), employees in Permanent Representations, officials of the European Commission, employees of the European Asylum Support Office, lawyers and NGO representatives. Several persons were interviewed on various functions. For example, employees of EASO and Permanent Representations tend to come from a background in their national asylum administration meaning they not only know how the agency or the Permanent Representation works, but can also provide valuable insights into the work of their national asylum administration.

\subsection{1. $\quad$ Selecting interviewees}

Generally speaking, there are three goals when researchers conduct elite interviews: '(1) gathering information from a sample of officials in order to make generaliseable claims about all such officials' characteristics or decisions: (2) discovering a particular piece of information or getting hold of a particular document; (3) informing or guiding work that uses other sources of data' (Goldstein 2002, p.669). For this analysis, the use of interviews served the latter two purposes. On the one hand, I was interested in particular information, which allowed me to reconstruct the decisions-making process leading to safe country of origin designations. On the other hand, I was also using interviews to inform and guide findings derived from other sources, mainly parliamentary proceedings. In that sense, interview selection did not aim at generalising from one interview 
partner to an entire population. Rather, potential interviewees were explicitly selected based on their involvement in the policy-making process of interest.

Two kinds of interviews were conducted: exploratory expert interviews and systematised expert interviews (Bogner and Menz 2009, p.46). Exploratory expert interviews served the purpose of establishing an initial orientation in the field of interest, and helped developing a clearer idea of the research problem. One example would be an interview conducted in the framework of a country of origin cooperation workshop on Afghanistan. One of the conference organisers was interviewed in order to learn about country of origin cooperation in general, to establish relevant problem statements, and to make field contacts.

Systematised expert interviews are aimed towards accessing knowledge exclusively possessed by the expert (Bogner and Menz 2009, p.46). This relates first and foremost to knowledge about the policy-making process on safe countries of origin. I explicitly searched for persons having been involved in the process of interest. However, interviewees were also selected if they have not been directly involved but where confronted with it in another way. For example, a lawyer who - in the course of defending a claimant from Serbia - challenges the inclusion of Serbia in the national list of safe countries of origin, might not be an expert on the policy-making process, but can still provide valuable information about the domestic SCO practice and respective decision-making procedures in the national asylum authority. Potential interviewees were identified via web research and the snowball effect (Goldstein 2002, p.671).

A key problem in making potential interviewees agree to meet was confidentiality. Asylum policy and safe country of origin policies in particular, are very sensitive topics. Policy-makers are frequently confronted with criticism (at the least) if not hostility. This might bring potential interviewees easily in a situation where they feel that they have to defend themselves and/or are afraid of being misunderstood (and misquoted). For example, the UK safe country of origin policy (and asylum policy in general) is severely criticised by academics and NGOs. Less strong but similar reservations were noted in the other countries too. Given these problems, a high nonresponse rate and/or refusal rate was to be expected. However, my actual experience was rather positive (with certain sacrifices in the UK case, see further down in this section). In what follows, the process of selecting and contacting interviewees is described as well as efforts to avoid justmentioned fears of potential interviewees.

Prospective interviewees were contacted via email and asked for an interview. In the course of the $\mathrm{PhD}$ project, I made the experience that asking for an interview is not the best way to go. The reason is that the word 'interview' is associated with media (and bad publicity). Rather potential interviewees were asked about 'an informal chat' or 'input for the research project' because it sounds less official and more informal. ${ }^{39}$ It was

\footnotetext{
${ }^{39}$ Nevertheless, there was a clear agreement between interviewer and interviewee whether and in how far the data obtained would be used afterwards.
} 
also made very clear to the interviewees that my role is not a judging but an understanding one. I was not talking to them in order to find out whether the right or wrong decisions were taken, but to understand who played what role in the decision-making process. In hindsight, few of the interviewees contacted refused to meet. One of the reasons might have been that, if possible, the first contact always started with a reference to someone familiar to the addresser. ${ }^{40}$ If they did not want to meet, they always referred me to someone else better suited to answer my questions. Consequently, non-response was not a serious problem in this analysis.

However, there were some challenges in the process of identifying potential interview partner. In the UK, one issue frequently trouble-making during the set-up of the interviews, was the high turnover of staff in the national asylum administration. Responsibilities for asylum had been shifted several times between divisions (Casciani 2013), which made it difficult to get hold of the right people. Politics also stood in the way: having identified the person in charge often meant this person did not want to talk about any decisions taken in the past (in official terms: in order not to exceed one's competences). ${ }^{41}$ In the case of Germany, time was an issue. Policy decisions of interest dated back to the early 1990s when the much contested and biggest change in the German asylum system took place. It proved to be a challenge to find policy-makers that are still alive and willing to talk about these times. Identifying and talking to the relevant people in both Malta and Luxembourg was no problem at all. The smallness of the countries was a clear advantage for the data collection: the few people involved were quickly identified and contacted. Also, given the limited genuine interest from outside how policy-making in these two countries work, interviewees and other contacts were very willing to share their knowledge and data with me.

\subsubsection{Conducting interviews}

Interviews were conducted for two purposes. First, the interviewer wanted to learn in how far and why civil servants of a particular country are involved in country of origin cooperation. The second purpose (sometimes with the same, often with different interviewees) was to learn why and in how far information gained from this cooperation was used in the decision-making process leading to the (non-)designation of certain countries of origin as safe. In order to learn as much as possible about these two issues, semistructured interviews with open-ended questions were conducted. Open-ended questions were asked because they 'have the virtue of allowing the subjects to tell the interviewer what's relevant and what's important rather than being restricted by the re-

\footnotetext{
${ }^{40}$ Such as 'Person $\mathrm{XY}$ advised me to contact you on this matter'

${ }^{41}$ In the case of the UK, the limited access to potential interviewees and the limited success of interviews conducted had implications for the conclusions made on this country-study, as discussed in sections 7.6.2 and 8.3 .
} 
searcher's preconceived notions about what is important' (Berry 2002, p.681). It proved to be helpful to conduct prior research. Though the (possible) knowledge of processes was not necessarily revealed to the interviewee (in order not to influence her), it allowed to pose targeted, well-informed questions.

A recorder was used in case of consent of the interviewee. About half of the interviews were tape-recorded though most of the government representatives, especially from the UK and Germany did not want to be put on record. In these cases, notes were taken during and after the interview. In case the interview was recorded, I also conducted a transcript of record. Four interviews were telephone-based.

\subsection{Data analysis}

This final section discusses the way data was analysed. A specific focus is thereby on the process-tracing method. In chapter 3, an analytical framework was developed. This framework served as the key tool to analyse the collected data. Data analysis was therefore primarily based on relying on theoretical propositions. Based on the theory discussion, the analytical framework spelled out in detail what conditions need to be fulfilled in order to make the observation fit the tested claims. For example, the social constructivist explanation to research question 4 assumes that policy-makers are especially open to social learning if they find themselves in a novel and uncertain environment. This situation can be generated by different reasons, such as the newness of the issue. Having this proposition in mind helped the researcher to focus on certain data during the collection stage.

Given the setup of the $\mathrm{PhD}$ project, it comes as no surprise that the project follows a process-tracing approach. This method has been described by Rohlfing (2012) as follows:

Gathering and evaluating evidence on the within-case level is similar to assembling a jigsaw puzzle; every piece is more or less different from every other piece, but when put together, they deliver a full picture of the phenomenon of interest, which consists of the causal process and the constitutive intervening steps (p.30).

The process-tracing method is defined as an attempt to identify the intervening causal process - the causal chain and causal mechanism - between an independent variable (or variables) and the outcome of the dependent variable' (George and Bennett 2005, p.206). As process-tracing is indispensable for theory-testing, it is also indispensable for this study. I tested in how far two hypotheses - one based on rational choice logic and another one based on social constructivist logic - lead to a common outcome, namely the use of policy coordination in the domestic asylum decision-making process. This is best done by identifying the causal process between causes (based on either of the two 
logics) and the dependent variable. The setup of the thesis sees the two hypotheses not as mutually exclusive but rather as complementary. There is a high chance that both independently could lead to the expected outcome. Thus, there is a high possibility of equifinality. Using process-tracing as a method encourages the researcher to be sensitive to the possibility of equifinality (George and Bennett 2005, p.215) and is in that sense an appropriate tool for studying this form of causation (ibid.).

There are several varieties of process-tracing ranging from a (descriptive) detailed narrative to more analytical forms (George and Bennett 2005, p.210). This thesis focused on the latter aiming for an analytical causal explanation embedded in theory. Rather than giving a minute, detailed tracing of a causal story, the analysis aimed at more general explanations involving a 'higher level of generality and abstraction' (George and Bennett 2005, p.211). This more general explanation is normally done for two reasons: either the data or the theory necessary for a very detailed explanation is lacking. In my case, the theory is precise enough. For example, it was argued that domestic constraints make policy-makers turn to other venues more favourable to their end. This venue-shopping argument is spelled out quite explicitly in the asylum governance literature (see for example Guiraudon 2000), and consequently would allow for a minute, detailed tracing of a causal story. However, the respective data is missing. As was shown in section 4.3, the data is not available to an extent that would allow this very detailed process-tracing approach. Instead, I was aiming for describing more general patterns of what the causal process entails.

\subsection{Conclusion}

The chapter set out the research design applied in this analysis. A case study approach was chosen with a focus on testing two hypotheses. The selected cases include Germany, the UK, Malta and Luxembourg. For all four cases, some background information was provided. Also, the various sources used were discussed, including primary and secondary sources as well as the challenges during data collection. A specific focus was set on describing the preparation and the conduct of interviews. Finally, process-tracing as the main data analysis method was discussed. 



\section{Coordinating asylum policies and information in Europe: cooperation on country of origin information}

\subsection{Introduction}

The chapter presents a case study on asylum policy coordination, namely the cooperation between national asylum authorities on country of origin information (COI cooperation). By doing so, it provides an answer to the third sub-question, namely: how does policy coordination in the field of asylum policy, and cooperation on country of origin information in particular, work? If one looks at the website of the European Commission, cooperation on country of origin information has often been labeled 'practical cooperation' (Commission 2006a; Commission 2006b). However, it was argued in section 3.1 that this term is rather vague, analytically not sharp enough and thus not useable for an empirical analysis. Instead, this form of cooperation was conceptualised as policy coordination. By policy coordination, I mean the exchange of policy-relevant information between state executives. It is determined by its informal nature and the deliberative character of interactions. It does not lead to legally binding outcomes.

Drawing on several related concepts (including transnational communication, intensive transgovernmentalism, deliberative intergovernmentalism and informal governance), an analytical framework was set up (section 3.2.5). In this chapter, it is used to empirically analyse specific instances of policy coordination in the field of asylum policy. Analysis will focus on the transnational level (see figure 3.1) - that is inter-state horizontal cooperation not embedded in formal EU structures (but still with EU and nonEU countries as key players). Actors involved in fora facilitating policy coordination as well as the function and form of these fora will be analysed. Also, the change from informal towards formal cooperation is discussed. In contrast to the empirical chapters 6 and 7 , analysis in this chapter does not focus on specific countries but includes data from all countries involved in informal asylum policy coordination. It is thus not about individual countries' motivation to engage in asylum policy coordination (see chapters 6 and 7) but on the institutional setting in general.

The chapter proceeds as follows: It will start with an introduction into the case study. The term country of origin information is explained and put into perspective. 
Also, the institutional context is presented: the role of national country of origin information units (and their role within a country's national asylum administration) is discussed as well as the increasing pressure faced by these institutions (section 5.2). What then follows is a general overview of transnational cooperation on country of origin information including both a contextualisation in the wider European asylum governance framework as well as an overview of the most important fora for COI cooperation (section 5.3). The core of the empirical analysis is on informal asylum policy coordination between a few, likeminded countries (section 5.4). By using three examples of coordination-fora, I will illustrate the actors, function and form of policy coordination, and cooperation on country of origin information in particular. One of the findings relates to the increasing formalisation of COI cooperation post-2000, which is then discussed in section 5.5 .

\subsection{Collecting country of origin information in the national context}

Chapter 2 concluded with a puzzle: how can we explain policy convergence in the absence of legally binding rules on (asylum) policies? It was assumed that policy coordination plays an important role in this regard: member states engage in non-binding coordination of their policies, exchange information and make - on the basis of information received - domestic policy choices. We do not (yet) discuss the domestic level implications but rather investigate the transnational, institutional level in more detail. The empirical focus is on coordination of country of origin information. ${ }^{42}$

\subsubsection{About country of origin information}

'Country of Origin Information' is crucial for refugee status determination. In the asylum process, the necessary authorities have to determine whether the applicant for asylum falls under the "principle of refoulement". This core principle in international refugee law states that no person might be send back to a country, where she has to fear persecution. This rule was determined in the 1951 Refugee Convention (UNHCR 1951), its 1967 Protocols (UNHCR 1967), in many regional human rights treaties and in national legislation. It is considered customary international law. ${ }^{43}$ Assessing whether an applicant for asylum can or cannot be send back to her country of origin (or country of transit) requires information on this very country. This information is not only crucial for the national asylum authorities deciding on the case but also for the asylum seeker as such, her lawyer as well as courts (second and further instances). One of the core com-

\footnotetext{
${ }^{42}$ For a more elaborate explanation why COI cooperation and safe country of origin policies were selected for this analysis see section 1.4 .

${ }^{43}$ For a more detailed discussion of the non-refoulement principle see section 1.2.
} 
petences of national asylum authorities is it to operate, on different scales, country of origin units to collect such information. Information needed includes general country information, topical information (e.g. on marriage practices, prison conditions) as well as information related to the individual case of the asylum seeker (ICMPD 2006, p.910). Box 5.1 illustrates the need for country of origin information by using the example introduced at the very beginning of this analysis - the story of Mr. Bavol.

Box 5.1: The importance of country of origin information for assessing the case of Mr. Bavol from Serbia

During the asylum procedure, Mr. Bavol is interviewed by the German BAMF. He tells his story and why he decided to flee from Serbia to ask for protection in Germany. Mr. Franz has to check whether Mr. Bavol would indeed fear persecution if returned to Serbia. If yes, the German authorities would need to grant him protection in Germany. In assessing his case, Mr. Franz consults country of origin information. He needs to check whether Roma are indeed a persecuted minority in Serbia, whether the authorities in Belgrade are known to evict people and whether they have any effective measures in place to make sure that Roma are not discriminated against. Mr. Franz also has to check the individual case of the applicant: does Mr. Bavol indeed belong to the Roma, was he indeed evicted from his house, and did he personally have a valid claim to fear persecution because of these events? In order to make such a judgment, Mr. Franz has the following documents at hand: the transcript of the interview that was conducted with Mr. Bavol, some documents provided by Mr. Bavol himself and information collected by experts on the situation in Serbia, so-called country of origin information. This information includes reports from the German Foreign Office, reports from nongovernmental organisations as well as information on Serbia collected by asylum authorities from other EU member states.

Country of origin information is not only necessary for individual refugee determination but also for policy-making, including return and resettlement policy, safe country of origin policy or safe third country policy. These policies are made for groups of persons coming from a certain country of origin (or country of transit). Because safe country of origin policies are key to this analysis, they also serve here as an example to illustrate the importance of country of origin information in policy-making: In 2011, the Luxembourgish authorities declared Serbia as a safe country of origin. This means that anyone from Serbia applying for asylum in Luxembourg will be processed in an accelerated procedure. This is because the Luxembourgish authorities presume that the situation in Serbia is safe enough for these asylum seekers to not be entitled to protection. Such a safety assessment is based on country of origin information. Thus country of origin information is not only necessary for the individual refugee status determination (processing an individual application for asylum) but also for policies on countryspecific populations, such as safe country of origin policies. 


\subsubsection{Structure and functioning of COI units}

All countries collect country of origin information. However, this process can look very differently. On one end of the scale, it could be that an individual person employed by a national asylum authority has to decide about an asylum application and conducts in this context a cursory online research on the country of origin; on the other end of the scale could stand a fully-fledged research unit with people specialising in certain countries of origin, keeping elaborated and regularly updated files about the situation in these countries and providing these information to a different unit solely responsible for deciding on asylum applications. What follows is an overview of similarities and differences between COI units across Europe.

Normally, COI units are based in the country's national asylum administration. Some examples of such units include the German Information Centre for Asylum and Migration (as part of the Federal Office for Migration and Refugees), the Dutch Country and Language Information Unit (as part of the Immigration and Naturalization Service) or the French Division for Information, Documentation and Research (as part of the Office for the Protection of Refugees and Stateless Persons). Where COI units exist, their mandate is quite similar: they collect information on the situation in the countries of origin. They do so by consulting national and international sources, public and restricted ones, governmental and nongovernmental ones. Whereas some countries (like Germany, Denmark or the Netherlands) have the capacity to collect country of origin themselves, for example by conducting fact-finding missions, others (such as Luxembourg) rely entirely on information provided by others.

Table 5.1 provides an overview over country of origin information units in all EU member states (EU-27) as well as Norway and Switzerland. 
Table 5.1: COI units in the EU-27, Norway and Switzerland ${ }^{4445}$

\begin{tabular}{|c|c|c|c|c|}
\hline Country & $\begin{array}{l}\text { Name of COI unit (if } \\
\text { existent) }\end{array}$ & $\begin{array}{l}\text { Ministry, in which } \\
\text { COI unit is placed }{ }^{46}\end{array}$ & $\begin{array}{l}\text { COI unit exists } \\
\text { since ... }\end{array}$ & $\begin{array}{l}\text { Number of staff in } \\
\text { COI unit (year of } \\
\text { reference) }\end{array}$ \\
\hline Austria & Staatendokumentation & Interior & 2005 & $20-22(2012)$ \\
\hline Belgium & $\begin{array}{l}\text { Center for Documentation } \\
\text { and Research }\end{array}$ & $\begin{array}{l}\text { None (independent } \\
\text { government agency) }\end{array}$ & $\mathrm{n} / \mathrm{a}^{47}$ & 46 (2009) \\
\hline Bulgaria & $\mathrm{n} / \mathrm{a}$ & Interior & $\mathrm{n} / \mathrm{a}$ & $\mathrm{n} / \mathrm{a}$ \\
\hline Czech Republic & $\begin{array}{l}\text { Unit for International } \\
\text { Relations and COI }\end{array}$ & Interior & 1993 & $2(2014)$ \\
\hline Cyprus & No & Interior & - & - \\
\hline Denmark & $\begin{array}{l}\text { Country of Origin } \\
\text { Information Division }\end{array}$ & Justice & 1996 & $10(2011)$ \\
\hline Estonia & No & Interior & - & - \\
\hline Finland & $\begin{array}{l}\text { Legal and Country } \\
\text { Information Unit }\end{array}$ & $\begin{array}{l}\text { Independent } \\
\text { decision-making } \\
\text { agency }\end{array}$ & 1998 & $\mathrm{n} / \mathrm{a}$ \\
\hline France & $\begin{array}{l}\text { Division of Information, } \\
\text { Documentation and } \\
\text { Research }\end{array}$ & Interior & before 2005 & $13(2006)$ \\
\hline Germany & $\begin{array}{l}\text { Information Centre for } \\
\text { Asylum and Migration }\end{array}$ & Interior & before 2000 & $100(2006)$ \\
\hline Greece & Yes & $\begin{array}{l}\text { Public Order and } \\
\text { Citizens Protection }\end{array}$ & 2013 & $4(2014)$ \\
\hline Hungary & Documentation Centre & Interior & 1998 & $8(2014)$ \\
\hline Italy & No & Interior & - & - \\
\hline Ireland & $\begin{array}{l}\text { Refugee Documentation } \\
\text { Centre }\end{array}$ & Independent service & 2000 & $13(2014)$ \\
\hline
\end{tabular}

\footnotetext{
${ }^{44}$ Norway and Switzerland are included because they are very much involved in some of the transnational (non-EU) cooperation fora.

${ }^{45}$ Where the information on COI units was not available via secondary sources, the author contacted the respective ministry or the EMN National Contact Point.

${ }^{46}$ If there is no specific COI unit, the ministry is listed within asylum issues are dealt with.

${ }^{47} \mathrm{~N} / \mathrm{a}$ (not available) indicates that the respective information could not be obtained.
} 


\begin{tabular}{|c|c|c|c|c|}
\hline Country & $\begin{array}{l}\text { Name of COI unit (if } \\
\text { existent) }\end{array}$ & $\begin{array}{l}\text { Ministry, in which } \\
\text { COI unit is placed }{ }^{46}\end{array}$ & $\begin{array}{l}\text { COI unit exists } \\
\text { since } \ldots\end{array}$ & $\begin{array}{l}\text { Number of staff in } \\
\text { COI unit (year of } \\
\text { reference) }\end{array}$ \\
\hline Latvia & No & Interior & - & - \\
\hline Lithuania & No & Interior & - & - \\
\hline Luxembourg & No & $\begin{array}{l}\text { Foreign Affairs and } \\
\text { Immigration }\end{array}$ & - & - \\
\hline Malta & No & Foreign Affairs & - & - \\
\hline Netherlands & $\begin{array}{l}\text { Country and Language } \\
\text { Information Unit }\end{array}$ & $\begin{array}{l}\text { Interior and } \\
\text { Kingdom Relations }\end{array}$ & $\mathrm{n} / \mathrm{a}$ & $24(2012)$ \\
\hline Norway & Landinfo & Justice and the Police & 2006 & $16(2014)$ \\
\hline Poland & $\begin{array}{l}\text { Country of Origin } \\
\text { Information Unit }\end{array}$ & Interior & 2001 & $9(2014)$ \\
\hline Portugal & No & $\begin{array}{l}\text { Internal } \\
\text { Administration }\end{array}$ & - & - \\
\hline Romania & $\begin{array}{l}\text { Department for Country of } \\
\text { Origin Procedures and } \\
\text { Information }\end{array}$ & $\begin{array}{l}\text { Administration and } \\
\text { Interior }\end{array}$ & 2000 & $7(2014)$ \\
\hline Slovak Republic & $\begin{array}{l}\text { Department of } \\
\text { Documentation and } \\
\text { International Cooperation }\end{array}$ & Interior & 2001 & $4(2014)$ \\
\hline Slovenia & $\begin{array}{l}\text { Administration, } \\
\text { Naturalization and Migration } \\
\text { Directorate }\end{array}$ & Interior & $\mathrm{n} / \mathrm{a}$ & $1(2014)$ \\
\hline Spain & Documentation Unit & Interior & $\mathrm{n} / \mathrm{a}$ & $\mathrm{n} / \mathrm{a}$ \\
\hline Sweden & Legal Unit & Foreign Affairs & $\mathrm{n} / \mathrm{a}$ & $12(2009)$ \\
\hline Switzerland & $\begin{array}{l}\text { Sektion Migrations- und } \\
\text { Länderanalysen }\end{array}$ & $\begin{array}{l}\text { Federal Office for } \\
\text { Migration }\end{array}$ & 1989 & $13(2014)$ \\
\hline UK & $\begin{array}{l}\text { Country of Origin } \\
\text { Information Service }\end{array}$ & Home Office & $\mathrm{n} / \mathrm{a}$ & $18(2012)$ \\
\hline
\end{tabular}


Table 5.1 illustrates that where COI units exist, they differ in many regards. Three of the differences are discussed in detail below: the institutional setting, resources and policymaking competences.

Institutional setting: this relates primarily to the question which ministerial department is responsible for the collection of country of origin information. Migration as a policy issue in general was never confined to a single ministry and traditionally is divided between home affairs, foreign affairs, justice, interior, economic and social affairs ministries (Guiraudon 2010, p.145). For COI collection in particular, home affairs or justice ministries would seem the intuitively most plausible ministries to hold responsibility, as these usually deal with asylum policy (we see this for example in Austria, Finland or Germany). Yet, given that the collection and interpretation of information on the political and human rights situation in countries of origin requires contact with local authorities through diplomatic missions, foreign affairs ministries are indispensable. Thus, in some countries they assume responsibility for collecting country of origin information (France, Luxemburg, Sweden, Malta). In other countries, such as Belgium and Switzerland, the COI unit is not affiliated to any specific ministry.

Resources: COI units are very different with regard to the resources that are available to them. The last column of table 5.1 gives an indication of how many people work in the COI unit of each member state (subject to data availability). However, these numbers are not more than an indication. Also, several countries are listed as not having a COI unit. This does not suggest that no country of origin information is collected. It rather happens in a different manner. In Luxembourg, there is no clear division between COI researcher and decision-maker. This means that the person collecting country of origin information on a particular country or region, for example West-Africa, is also responsible for deciding on claims of applicants coming from that region. Thus, it would be misleading to talk of a COI unit because it is rather country experts being responsible for both collecting information and interpreting it during individual refugee status determination. This procedure has also been called country desk system and is usually practiced by small member states (Malta, Luxembourg) and those that only start building up COI expertise (Southern and Eastern European member states). In fact, also the countries that have nowadays specialised and much bigger COI units started once with such a system. When using a country desk system, the division of labour is much different than, for example, in Germany: the Germans have a specialised COI unit of 100 people involving 30 country researchers, 10 administrative staff and 60 persons being charged with documentation and library work (ICMDP 2006, p.16). This unit is solely responsible for collecting (and managing) country of origin information. The actual refugee status determination is done by an entirely different unit. There is thus a clear division of labour between people collecting and people interpreting country of origin information. A similar division exists in other member states with long-grown 
and considerably big national asylum administrations, such as the UK, France or the Scandinavian countries.

Policy-making competences: A rather difficult question is whether or not COI units are involved in policy-making. On paper, most of them are not. They do not provide policy recommendations. However, many are involved in preparing such recommendations (ICMPD 2006, p.20). Thus, they are part of what Versluis et al (2011) call the policy-shaping stage, meaning the preparation of such policies in one way or the other (p.133). Let us look at some examples in more detail: in Belgium, the CommissionerGeneral in consultation with the head of case workers provides policy recommendations (ICMPD 2006, p.30); in Switzerland, the COI unit can draw conclusions on the general situation in the country that might feed into policies (ICMPD 2006, p.20); in Germany, the country experts are consulted when country-specific policies are drafted. When asked whether or not the German BAMF is involved in policy-making, the interviewee replied:

Well, it [policy-making] primarily takes place at the BMI [Ministry of Interior], but [..] of course the BA [Federal Authority] contributes with its expertise and its experts; and it is also asked, for example, during the drafting of policy guidelines or handbooks; of course then we deliver crucial contributions via the relevant COI; that is of course very clear; you cant compile these [guidelines of handbooks] without fundamental information (interview 35). ${ }^{48}$

Policy-making competences are a very relevant issue for this analysis. It will become obvious throughout the empirical chapters 5, 6 and 7 that (coordinating) country of origin information is a crucial part of the policy-shaping process.

In addition to the differences mentioned, COI units also vary with regard to the following issues: scope and purpose of information collected, access to COI products granted to the public, procedures for information gathering, sources of information used, guidelines for information collected, and quality control systems for COI. A more detailed account of these differences has been provided by others (see ICMPD 2006). In what follows, we will see that the work of COI units considerably changed over time.

\subsubsection{Pressure on COI units}

Country of origin information has gained a lot of importance over the last years. There are a number of reasons for this, including growing numbers of asylum seekers, a diversification of countries of origin, more complex flight routes of refugees, and the subsequent need for COI in many more (policy-) processes rather than 'just' during the refu-

\footnotetext{
${ }^{48}$ Quote in original language: Also es [policy-making] findet natürlich weitgehend im BMI statt, aber [...] das BA trägt ja auch mit seinem Wissen und seinen Experten dazu bei und wird ja auch gefragt; und zum Beispiel wenn es um die Formulierung von Leitlinien geht und auch bei der Erstellung von Texthandbüchern liefern wir natürlich schon entscheidende Beiträge durch die relevante COI; das ist natürlich ganz klar; man kann das nicht ohne grundlegende Informationen zusammenstellen.
} 
gee determination procedure. This section will briefly outline these new demands, and discuss the institutional consequences taken by the national asylum administrations.

\section{New demands on COI units}

New demands on national asylum administrations include first and foremost an increase in the number of asylum seekers. Whereas there is a (very recent) trend towards decreasing applications for asylum, looking over a longer period of time, there is clearly a growth in numbers. More asylum seekers also mean more work for the country of origin experts as every single applicant has an individual story to tell, and this story needs to be checked against available country of origin information, and, if necessary, with the respective country of origin information experts.

Next to an increase in numbers, also asylum applications as such have become more diverse and complex - as illustrated by the example of the UK Home Office:

In 1988 the United Kingdom received approximately 4,000 asylum applications per annum from a relatively small number of countries. By comparison, almost 80,000 asylum applications were processed in 2001. At the same time the range of countries of origin has become broader and the patterns of flows less predictable. Counter-intuitive flows mean recipient countries need to be aware of social and political conditions in countries with which they have previously been less familiar. In addition asylum seekers are able to move more quickly from country of origin to country of claim making the timeliness of information increasingly important (Home Office 2003, p.1).

Asylum seekers come from many more countries and have more complex flight routes than 20 years ago. In addition, the kind of information needed is different (or rather: more complex), one of the reasons being that the legal requirements have changed. There is a growing number of such requirements arising out of the jurisprudence of the European Court of Justice and the European Court of Human Rights as well as the common asylum legislation adopted at the EU level. To give only one of many examples: Having to comply with the Qualification Directive, in 2006, the Belgian authorities needed to introduce a subsidiary status for protection. ${ }^{49}$ In order to judge whether or not someone qualifies for subsidiary protection, it might be necessary to consult medical country of origin information (ICMPD 2006, p.43). This could, for example, relate to the question whether or not a specific kind of medical treatment is available in the applicant's country of origin, and whether she can be expected to follow that treatment . Consequently, the Belgium COI unit had to start collecting information related to the availability of medical treatment in countries of origin.

Another new demand on COI experts relates to the parties requesting country of origin information. The 'obvious' requester would be the respective case officers (having to decide on the actual case of the applicant). However, other parties also increasingly request country of origin information. For example, the Danish and Swiss asylum au-

\footnotetext{
${ }^{49}$ This is a protection status for someone who does not qualify for refugee status but can nevertheless not be sent back to his country of origin/transit.
} 
thorities provide country of origin information also to the police (ICMPD 2006, p.16). In addition, many COI units face more and more inquiries by the policy level (be it the government, the ministry or the parliament). The Danish and Finish COI units, for example, note growing numbers of requests by their local government officials (ICMPD 2006, p.13). These increasing requests by the policy-making level were also stressed many times during interviews, as illustrated by the following two examples:

\begin{abstract}
More and more it [country of origin information] becomes a building bloc in policy changes; if you want to change your policy [...] you can support that wish with COI through the Ministry of Foreign Affairs (interview 3).
\end{abstract}

Every country knows how this works: you are with the minister in the meeting and the minister wants to know immediately how Germany handles this and this; and he wants to know this immediately, we all know this kind of situation: then it is good if you can pick up the phone and call Berlin or Nuremberg knowing that on the other end of the line, someone is doing everything possible to make sure that your minister gets an immediate answer; and this also works, absolutely (interview 16). ${ }^{50}$

The quotes illustrate that country of origin information is needed far beyond the individual refugee status determination. Given the tendency to adopt asylum policies for groups of asylum seekers coming from certain countries of origin, this information increasingly becomes policy-relevant. This is one of many reasons why the work of national asylum administrations became more complex over the years.

\title{
Subsequent changes in COI units' work
}

Because of these growing demands, national asylum administrations started building up resources. As stressed before, country of origin information used to be stored in an adhoc manner with the country officer (the person responsible for applicants from a certain country or region), known as the 'country desk system'. This system is still practiced in countries that only start building up COI units and small countries with limited resources (see section 5.2.3). However, for most of the key asylum destination countries, such a system is no longer feasible. They had to invest in far-reaching changes in order to cope with the increased scope and responsibility of their work. In what follows, these changes are discussed in more depth.

The most obvious change relates to a growth in size and a subsequent specialisation of staff. Today, a majority of European countries maintains a fully-fledged country of origin information unit, i.e. staff that is solely responsible for collecting and managing country of origin information, and being explicitly not involved in refugee status deter-

\footnotetext{
${ }^{50}$ Original quote: Also jedes Land kennt das, mit dem Minister im Meeting, der Minister will jetzt sofort wissen, wie handelt Deutschland das und das, und das will er jetzt sofort wissen, das kennen wir alle; dann ist es gut mal eben das Telefon in die Hand zu nehmen und Nürnberg oder Berlin anrufen zu können und zu wissen auf der anderen Seite tut jetzt jemand alles, damit dein Minister sofort eine Antwort kriegt, und das klappt auch, absolut.
} 
mination. Thus, the collection of information is entirely decoupled from its interpretation. For example, the Belgian asylum authorities created a COI unit in 1997 starting with 12 staff. In 2009, it had grown to a 46-member team only collecting and managing COI (IGC 2009, p.66). Considering the size of the country, this is an impressive development. The Belgian COI unit is one of the largest ones in Europe (IGC 2009). ${ }^{51}$

Another major change relates to the sheer amount of material produced, and its organisation. COI units produce regularly updated reports on the top countries of origin, and provide answers to single case requests (ICMPD 2006, p.16). For example, Austria, Germany, the Netherlands, Sweden and the UK produce up to 20 reports each every year on their top countries of origin (ICMPD 2006, p.16-17). Country reports are also produced on other countries of origin, for example on those being particularly salient to policy issues. For example, the UK publishes annual country reports on countries declared as safe countries of origin (ICMPD 2006, p.17). Next to country reports, there are also thematic reports produced, for example on topics such as military recruitment in Afghanistan, or marriage practices in Iran. All COI units produce additional information (for example fact sheets or replies to individual requests). For example, the Belgian authorities answer about 5,000 single case requests per annum, the Finnish authorities about 300 (ICMPD 2006, p.17). However, again, respective numbers are to be treated with caution: The high number for the Belgian authorities are explained by the fact that their COI unit does not produce general COI reports as such (arguing that all general COI is publicly available by other sources) but only produce information on demand (that means responses to individual requests) (ICMPD 2006, p.43). Regarding sources, the actual collecting COI is done via desk research, via embassies and liaison officers in the respective countries of origin as well as fact-finding missions. ${ }^{52}$

Another change relates to information management. Almost all national asylum administrations with a COI unit have established databases to manage the large amount of information. These electronic databases allow quick access to a very big amount of data for everyone who is entitled to it (such as people collecting/updating the information, people needing the information to judge asylum applications). ${ }^{53}$ One of the biggest databases is run by the German authorities. Whereas some of the country of origin information available in these databases is public, most of it is restricted (because it arguably is sensitive information). Few countries, including Denmark and Sweden,

\footnotetext{
${ }^{51}$ Number of staff is also influenced by the existence of a library (which is not always located within the COI unit). If the library is part of the COI unit, staff numbers are much higher (ICMPD 2006, p.16). For example, the German IZAM has about 100 employees including 30 researchers of the country (or on specific topics), 10 administrative staff and 60 documentation officers and librarians (ICMPD 2006, p.67).

${ }^{52}$ For more information on the primary and secondary sources used, see ICMPD 2006, pp.25-28.

${ }^{53}$ In fact, the newly created EU asylum agency established a super-database connecting most of the national COI databases with each other (Penisson 2012). For an overview of countries having (no) COI database see EMN 2010.
} 
made all their country of origin information publicly available (ICMPD 2006, p.16, p.20).

In addition, some countries have introduced control systems, meaning someone else is checking the country of origin information produced (for example: the report on the situation in Serbia). This, however, can relate to very different things: in most countries, it is the head of unit or another peer scanning a country report produced by someone else. In contrast, Austria, Germany and the UK have formal advisory boards (ICMPD 2006, p.29), whereas the British Independent Advisory Group on Country Information is by far the most elaborated. The Group was set up in 2002. It is mandated to monitor the accuracy of country of origin information as produced by the Home Office's Country of Origin Information Service (which is the British COI unit). The Group reviews country of origin reports and provides recommendations to the Home Office on its improvement. For example, in 2013, the Group reviewed country of origin reports on Pakistan, Albania, Iraq, Afghanistan, Iran, Algeria and Bangladesh (IAGCI 2013b). In that sense, it is a unique body in Europe because none of the other European countries has an independent body checking on country of origin information (see also box 6.2). And finally, COI units reacted to the growing demand on their work by heavily engaging into cooperation with their counterparts in other countries. This is the focus of the next section.

\subsection{Cooperation on country of origin information}

This section analyses cooperation on country of origin information. It thus provides an empirical example of asylum policy coordination in Europe. The focus will be on informal COI cooperation processes at the global, European and sub-regional level. It will be shown that informal asylum policy coordination is characterised by few, like-minded countries heavily exchanging country of origin information and related policies. However, before doing so, COI cooperation is discussed in the bigger (policy) context: since 2000, the EU has put such cooperation highly on the political agenda. It is briefly explained why and - at the end of the section - the move torwards formalisation is further analysed.

\subsubsection{COI cooperation in policy perspective}

In 1999, EU member states agreed to the Tampere Program (European Council 1999), which most importantly related to agreement on a Common European Asylum System. Such a System would result in member states having a shared responsibility over asylum applications and each application being processed in a fair and similar manner. This means that it would make no difference whether the asylum application is filed in Germany or Poland, in Spain or Sweden. Procedures would be similar and the outcome 
would be the same. In order to achieve this goal, member states agreed between 2001 and 2005 on a number of legal instruments regulating the responsibility for asylum determination (Dublin Regulation 2003/343/EC), the reception conditions (Directive 2003/9/EC), the asylum procedure (Directive 2005/85/EC), and the definition of a refugee (Directive 2004/83/EC).

Cooperation during this time was clearly intergovernmental: the Council of Ministers was the deciding body, the European Parliament had to be consulted (but not listened to) and the European Court of Justice had no ruling power over asylum matters. The picture changed with the Treaty of Lisbon and the introduction of co-decision in asylum policy. Since 2009, the EP is the co-legislator and the European Court of Justice has gradually gained competences. By June 2013, all asylum directives were renegotiated and agreed upon by both bodies, the Council and the European Parliament. ${ }^{54}$

Despite the adoption of the directives, the Common European Asylum System is not even close to completion. It was acknowledged early on that common legal instruments alone are not sufficient to achieve similar asylum standards across Europe. As a consequence, asylum cooperation has been shifted towards more operational aspects (Lavenex 2010, p.472), that is cooperation between domestic law-enforcement authorities. The Commission labels these activities 'practical cooperation', and defines it for the field of asylum as 'the establishment of appropriate structures involving the national asylum services of the Member States' (Commission 2006a, par.1). 'Practical cooperation' aims at achieving (amongst others) the joint compilation, assessment and application of country of origin information (Commission 2006a, par.1). The main reason why the European Commission is so keen on 'practical cooperation' is simple: the adoption of legislative instruments has not led to the hoped level of harmonisation - mainly because the asylum acquis does not go beyond common minimum standards. As a consequence, big differences remain in how EU member states process asylum applications. Thus, the outcome of the determination procedure is not independent of the country where it is conducted. Consequently, the main goal of 'practical cooperation' is to work towards harmonisation not only of legislation but of practice in order 'to improve convergence in decision-making by Member States within the rules set by the Community asylum legislation' (Commission 2006a, par.3-4).

As in other fields of Justice and Home Affairs, an agency was created aimed at facilitating this form of cooperation. The European Asylum Support Office was established in 2010 and is mandated to facilitate country of origin information exchange between the national asylum authorities. A database was set up too aiming to link COI collections of national asylum authorities with each other (Penisson 2012). In this way, for example, the Dutch authorities can easily access information collected by the Austrian asylum authority. On top of that, many initiatives encouraging COI cooperation be-

\footnotetext{
${ }^{54}$ For a more detailed discussion of the development of European asylum governance, see section 1.3.
} 
tween EU member states were created or formalised (where they existed already) under the roof of EASO.

Considering these measures taken by the EU, one important aspect needs to be highlighted: the European Commission did not invent the idea of cooperation between national asylum authorities. Rather this has been practiced for many years already (see for example Vink and Engelmann 2012). Several EU (and non-EU) countries were heavily engaged in informal COI cooperation since the 1980s. Only now it has achieved political momentum because of the aim to complete the Common European Asylum System. In what follows, the long-grown and well-established informal COI cooperation system is analysed in more depth.

\subsubsection{The spectrum of COI cooperation}

This section provides an overview over existing fora that facilitate COI cooperation. This general overview is given before the next section (5.4) studies three examples of informal COI cooperation in detail. COI cooperation can take many different forms: informal or formal, ad-hoc or regular, online or offline, involving few or many countries (Vink and Engelmann 2012). Table 5.2 provides an overview of COI cooperation fora as well as their scope of membership and date of foundation.

Table 5.2: Fora facilitating country of origin information exchange (incl. scope of membership and year of foundation) (several sources; compiled by author herself)

\begin{tabular}{|c|c|c|c|}
\hline $\begin{array}{l}\text { Scope of COI } \\
\text { cooperation }\end{array}$ & Global & Europe & Sub-regional \\
\hline Fora & $\begin{array}{l}\text { Intergovernmental } \\
\text { Consultations on } \\
\text { Migration, Asylum and } \\
\text { Refugees, IGC (1985) }\end{array}$ & $\begin{array}{l}\text { Centre for Information, Discussion } \\
\text { and Exchange on Asylum, CIREA } \\
\text { (1992); European Country of Origin } \\
\text { Information Network, ecoi-net } \\
\text { (2001); European Union Network for } \\
\text { Asylum Practitioners, Eurasil (2002); } \\
\text { European Migration Network, EMN } \\
\text { (2003); General Directors' } \\
\text { Immigration Services, G-DISC } \\
\text { (2004); European Country of Origin } \\
\text { Sponsorship, ECS (2007); Temporary } \\
\text { Desk Iraq (2009); Medical COI } \\
\text { Project (2010); European Asylum } \\
\text { Support Office, EASO (2010) }\end{array}$ & $\begin{array}{l}\text { G-6 (2003); } \\
\text { D-A-CH (2006); } \\
\text { Bilateral cooperation } \\
\text {; } \\
\text { y }\end{array}$ \\
\hline
\end{tabular}


The overview in table 5.2 shows that cooperation on country of origin information can take place at very different levels, including the global, European and sub-regional. ${ }^{55}$ Also the time span of initiatives undertaken is very broad: whereas the first cooperation efforts date back to the 1980s, most of the European fora were created rather recently (since 2000). The table highlights that asylum policy with regard to cooperation on country of origin information is a highly diverse system of governance. This also emerges from the interviews: 'It happens on so many levels, in so many fora. I have been in this business for twenty years, there is not a system of COI exchange, there is no bigger picture, or I have never discovered it myself (interview 3).'

There are other differences not visible in the table. For example, some fora are more inclusive than others: the Intergovernmental Consultations on Migration, Asylum and Refugees is a forum for Western countries with relatively high numbers of asylum seeker, including amongst others Germany, the US and Australia. Membership is limited to only a handful of countries. On the other hand, the more recently established fora such as Eurasil, the European Migration Network or the European Country of Origin Sponsorship are open to all EU member states. Access for NGOs is by no means self-evident. There is some limited but strictly regulated participation within the newer fora.

Another difference between the fora relates to the mode of exchange. The European Migration Network, for example, strongly rests on an online exchange between its member countries; meaning a request for country of origin information is sent by one participating country to all others; answers are collected and distributed in a summary document. ${ }^{56}$ Other COI cooperation is much more based on a personal and face-to-face contact of few COI experts across countries.

One further difference relates to the kind of information exchanged: whereas the Temporary Desk Iraq groups experts on one country of origin (Iraq), other fora specialise in thematic exchange (the Medical COI project, where the availability of medical treatment in countries of origin is discussed) or cover a bit of everything (Eurasil). Cooperation on country of origin information can thus take many different forms. The next section discusses these different forms in a more systematic way.

\subsection{Informal cooperation on country of origin information}

This section analyses three fora of cooperation on country of origin information. It thus provides empirical examples of informal asylum policy coordination in Europe. By doing so, the analytical framework developed in section 3.2 .5 will be applied. I will thus

\footnotetext{
${ }^{55}$ Sub-regional does not relate to the in-country level (like German Länder or French provinces) but to subregions within Europe, such as German-speaking countries, Mediterranean countries or Northwest-Europe.

${ }^{56}$ For a more detailed account of the setup and functioning of the European Migration Network, see Boswell 2009, pp.190-218.
} 
focus on the actors (who), function (why) and form (how) of policy coordination in the field of country of origin information. Before discussing the three cases in detail, some general findings on informal COI cooperation are presented. They are general because they relate to all instances of informal COI cooperation, including the three examples discussed in detail.

\subsubsection{Some general observations}

Cooperation on country of origin information is determined by a large degree of informality. Before discussing three examples of COI cooperation in detail, I will present some general observations relating to the "who" and "how" of informal COI cooperation. Such cooperation has largely been limited to states with considerably welldeveloped asylum administrations, that is Northern and Western European countries. Involvement is thus not determined by EC/EU membership (as a formal institution would expect), but by common ground regarding various factors. My analysis identified the following three:

Shared problems: Countries like Germany, France or the UK face large influxes of asylum seekers for a long time already. Starting in the 1980s, these countries were forced to look into solutions on how to deal with these issues. Thus, they not only started building up national institutions, but they also started cooperating transnationally (because the EC did not provide any formal structure for asylum cooperation by then). Today, these countries have relatively well-developed asylum systems, and have built up respective COI collections. Employees working in COI units know each other for years and favour a trusted informal exchange over a formal one. Looking at the situation in Greece, Italy, Spain or any of the new member states, it becomes clear why these countries have not (and are still not) part of the informal asylum governance. They only started building up national asylum authorities when the prospect of EU membership required them to do so (in terms of implementing the asylum acquis).

Common legal requirements: COI cooperation only works if the outcome of cooperation can be used by all partners involved. This is not self-evident. Standards for asylum procedures vary to a great extent across EU member states (UNHCR 2010a). Cooperation between two countries with very different standards does not make sense, because the countries have different requirements for i.e. filing an asylum application, processing it and/or challenging an asylum decision in court. One example of COI cooperation that requires similar legal requirements, namely fact finding missions, is discussed further in box 5.2.

Common language: Whereas formal cooperation between partners speaking different languages is facilitated by translation, informal asylum cooperation allows no space for that. Consequently, countries that speak the same language are much more likely to engage in informal exchanges than others. Thus, several countries are heavily engaged in informal asylum cooperation with each other, such as the German-speaking countries 
(Germany, Switzerland, Austria and Luxembourg), the Dutch-speaking countries (Belgium and the Netherlands), the French-speaking countries (France, Belgium, and Switzerland) or the Nordic countries (Sweden, Denmark, and Norway).

However, general observations not only relate to the 'who' of informal COI cooperation but also to the 'how'. Linking the just presented findings back to the analytical framework, Puetter (2012b) suggested that deliberation is likely to occur in these fora if a number of conditions are fulfilled - including that actors involved have many commonalities, such as understanding the policy issue at stake as a common problem. Given my just presented findings valid for all instances of informal COI cooperation, one can presume that informal COI cooperation is very much driven by deliberation.

The analysis of informal COI cooperation further revealed two general rules according to which the exchange takes place:

'Give and take': This informal rule refers to the understanding and the motivation of cooperation. Participants in an informal exchange are only willing to engage in this exchange if the cooperation partner can give something in return. For example, sending out an information request by email to a colleague in another country is a common feature of informal cooperation. Yet if participants always only ask for information and are never available to provide information upon request, such informal exchange will quickly come to a halt.

'Last resort': This second rule refers to the understanding of using informal mechanisms as a last resort. Participants have a common understanding on what to ask, and what not to ask. What comes first is own research, consulting own, national databases before using the phone or email to get in touch with colleagues across the borders.

The three examples of informal COI cooperation discussed below show that the informal exchange only works as long as all actors involved can play to the rules; and that COI cooperation became formalised when several countries could not play to the rules anymore by which the informal community functioned (section 5.5).

In the next sections, three different forms of informal cooperation on country of origin information are discussed in detail. The difference mainly relates to their scope of membership (global, European and sub-regional; see table 5.2). The analysis is based on the analytical framework developed in chapter 3 (see table 3.2). It thus focuses on three questions:

- Actors: Who is involved in COI cooperation?

- Function: Why does COI cooperation take place?

- Form: How does COI cooperation look like, and how does it work?

For both actors and form, I just identified some general characteristics. In what follows, three examples of informal COI cooperation are studied in detail. 


\subsubsection{Intergovernmental Consultations on Migration, Asylum and Refugees - serving an early need for global COI exchange}

The first example, Intergovernmental Consultations on Migration, Asylum and Refugees (IGC) was picked because its scope of membership is global (table 5.2) involving (selected) countries from all over the world and because it is the earliest forum facilitating COI cooperation. IGC was created because there was no formal, institutional solution to serve the (by then) needs of participating countries. These needs mainly related to being able to discuss asylum matters in a closed setting amongst a few, like-minded countries.

The earliest proposals for transnational COI cooperation were developed in the 1980s during the Intergovernmental Consultations on Migration, Asylum and Refugees. ${ }^{57}$ Since then, the IGC provides a forum to discuss information on refugees, asylum and migration, and is generally seen as one of the key examples of informal global migration governance (Betts 2011, p.18). Until today, it is viewed by many high-level COI experts as the crucial forum for COI exchange (interview 8). The first COI-dedicated workshop in IGC was held in 1989 (UNHCR 2004, p.18). Since then and every year, many workshops related to specific countries of origin or aspects of COI work are conducted. However, country of origin information is only one of many aspects at IGC's agenda. The information that is collected and shared between member states relates to asylum applications, decision data, data on unaccompanied minors, smuggling and return (IGC 2009). Means of information exchange include a website, the issuance of country assessment reports, forum discussions and teleconferences (Citizenship and Immigration Canada 2008). According to interviewees, the two core assets of IGC meetings are its membership beyond Europe and its confidentiality. Let us focus on the actors involved first.

Membership in IGC is determined by being a Western country and by attracting a (relatively) large number of asylum seekers. Participant countries thus include Australia, Belgium, Canada, Denmark, Finland, France, Germany, Greece, Ireland, the Netherlands, New Zealand, Norway, Spain, Sweden, Switzerland, the UK and the United States. There is also some space for participation of the European Commission and two international organisations (UNHCR and IOM). Participating countries have many commonalities. According to an internal document drafted on the occasion of 20 years IGC existence, involved states are like-minded in the sense of 'they were 'destination States', with similar legal and administrative systems and similar mechanisms for responding to persons seeking asylum on their territory' (Hallam Johnston \& Associates 2005, p.8). These countries share a long history of asylum institution-building and thus cooperation on country of origin information. Germany, France or the UK but also Australia

\footnotetext{
${ }^{57}$ See Thouez and Channac (2006) as well as Hallam Johnston \& Associates (2005) for the process of setting up the IGC.
} 
and the United States face relatively large influxes of asylum seekers for several decades already. Starting in the 1980s, these countries were forced to look into solutions on how to deal with rapidly increasing numbers of asylum seekers: 'countries realised that other countries might have similar "problems", problems with people coming to their shores and claiming asylum (...) states felt that we need a place to talk among each other' (interview 3). The quote illustrates that countries participating in IGC mainly do so because they have a shared understanding of problems and look for common solutions. By doing so, the participating countries not only started to build up own, national asylum administrations but also started cooperating with each other.

Why has IGC been created? Evidence just presented showed that participating countries were united by a number of factors, including their shared need for a cooperation platform. Thus, in the 1980s and 1990s, IGC primarily served the purpose of providing a discussion forum where none existed yet. One of the hot topics at that time was the situation in Turkey (related to irregular movements of Iranians from Turkey) and in Sri Lanka (related to the return of Tamil asylum seekers to the country). These issues were the initial content of IGC Consultations in the mid-1980s (interview 3; Hallam Johnston \& Associate 2005, p.8). They were discussed in IGC a long time before the EU took an interest in them (interview 3). By then, there were only two multilateral bodies dealing with asylum matters in a broader sense; the Executive Committee of the United Nations High Commissioner for Refugees (UNHCR) (ExCom) ${ }^{58}$ and the Council of Europe's CAHAR. ${ }^{59}$ Both did not fulfill the needs of countries meeting at IGC: neither were they confidential (enough) nor did they group the 'right' participants. IGC was thus established as an institution complementary to existing ones. It filled a gap by providing an informal space for policy-makers wanting to confidentially discuss asylum issues, and the situation in certain countries of origin in particular.

A key characteristic of IGC is its informal character, its confidentiality and nonbinding way. This is explicitly stressed in the mandate ${ }^{60}$, which is

(...) $[t]$ o provide a forum for participating States, international organizations and the European Commission to exchange information on refugee, asylum and migration issues in an informal, confidential and non-binding way (IGC Management Plan 2004 and 2005, in Citizenship and Immigration Canada 2008) (emphasis added).

\footnotetext{
${ }^{58}$ The Executive Committee is the governing body of UNHCR. It was created in 1958 as a subsidiary organ of the UN General Assembly and issues (non-binding) policy recommendations on international protection matters (among other functions relating to UNHCR's budget).

${ }^{59}$ The Ad hoc Committee of Experts on the Legal Aspects of Territorial Asylum, Refugees and Stateless Persons (CAHAR) is the Council of Europe's body dealing with asylum-related issues. It issues non-binding recommendations.

${ }^{60}$ The mandate has been formulated in a document called 'Administrative Arrangements for the Informal Consultations on Asylum, Refugee and Migration Policies in Europe, North America and Australia', agreed on in 1993 (Hallam Johnston \& Associates 2005, p.9).
} 
Initially, IGC had few binding rules, there was no clear formulation of membership criteria and there were no official meeting protocols. Also, no formal decisions were taken (Hallam Johnston \& Associates 2005, p.8). Some formalisation took place over the years, including the establishment of a secretariat and the annual issuance of management plans. However, until today, there are no codified or written rules regulating the behaviour of actors involved and there is no possibility for public sanctioning. ${ }^{61}$ Also, until today, there are no formal decisions taken by IGC.

Next to informality, it is especially the confidential character and the non-binding way that was (and still is) particularly valued by participating countries. Neither CAHAR nor ExCom allowed for the wished confidentiality (Hallam Johnston \& Associates 2005, p.7). This was also stressed by interviewees: 'states and people who work for states want to have a place where they can talk to each other, not with people looking on their fingers (...)' (interview 3 ). In that sense, IGC was not only complementary to existing institutions because it covered so far un-discussed topics. It also filled a gap where no formal institutions existed yet. Of course, these two explanations are somehow contradictory (being complementary to formal institutions vs. filling a gap where no formal institution existed yet). It, however, depends on whether one sees CAHAR and ExCom indeed as formal counterparts to IGC or not. In any case, a third explanation why the informal IGC was created is more straightforward: there was an explicit aim within IGC to - informally - look for policy solutions (that are possibly not publicly accepted yet).

With this in mind, IGC is also called the 'laboratory of the EU' (Hallam Johnston \& Associates 2005, p.22). ${ }^{62}$ One of its key strength is that it 'provides a forum for listening from which ideas can be taken back to inform, and if appropriate, feed into national practice' (Hallam Johnston \& Associates 2005, p.13). The relevance for domestic level policy-making mirrors the overall aim of the analysis conducted in this thesis: showing that informal policy coordination with other countries feeds into domestic decisionmaking processes. On part of the IGC, this was confirmed by Canada, as one of the participating countries. Canadian officials stress that after attending IGC meetings

(...) Canada is more informed and effective in formulating domestic policy. [...] [Government departments] learn from others' experiences and this is reported to translate into the selection of 'best practices' in policy and program development. This type of information is often not widely shared as lessons learned are rarely openly discussed in more formal meetings or documented (Citizenship and Immigration Canada 2008).

The Canadian quotation also illustrates why one can very much assume a deliberative rather than bargaining style of interaction within IGC. Participating policy-makers are

\footnotetext{
${ }^{61}$ Both are the defining criteria of what informal governance means in this analysis (section 3.2.4).

${ }^{62}$ The term 'laboratory of the EU'was also used by Monar (2001), however, in a slightly different context. He relates it to intergovernmental cooperation in the 1990s between EU member states 'preparing' decision taken much later (adoption of the asylum acquis).
} 
not fully decided yet on issues but are willing to learn from others. This was also confirmed by observers: IGC provides a setting 'where participants are not held to account for a national position and are not in negotiating mode but are there simply to hear from and learn from others' (Hallam Johnston \& Associates 2005, p.15). Thus, deliberation is the prevailing mode of interaction. This comes not as a surprise when looking at the conditions identified previously that make deliberation likely to occur: an informal setting, many commonalities amongst participating countries, and regular meetings.

In sum, the Intergovernmental Consultations on Migration, Asylum and Refugees provide an example of asylum policy coordination at the global level. It was created to provide a private setting for like-minded policy-makers to discuss and coordinate asylum policy and policy-relevant information.

\subsubsection{CIREA - an informal start at the EC level}

Informal COI cooperation in the framework of the EC/EU can be traced back to the 1980s. By then, several working groups were created involved in discussing asylum related matters, and country of origin information in particular. The most important one was the Centre for Information, Discussion and Exchange on Asylum (CIREA). CIREA started off in the early 1990s as being explicitly informal and not anchored in the EC treaties. It became formalised and politically upgraded over the years and (its successor) is today part of the European Asylum Support Office. While CIREA had originally been an ad-hoc and informal Council working group, its powers were transferred to the Commission working group Eurasil in 2002. Already with the Amsterdam Treaty and the prospect of the EU enlargement (2004 and 2007) the European COI cooperation landscape changed completely - meaning it became very much formalised and put on the political agenda. However, these developments are discussed in more detail in section 5.5. For now, the focus is on the informal years of COI cooperation in a European context, and on CIREA in particular.

The Centre for Information, Discussion and Exchange on Asylum was set up in 1992 upon initiative of the Ad-Hoc Group on Immigration. It was a Council working group acting under the auspices of the EC Council Secretariat (Statewatch 1997, p.66). In a 'memorandum from the Dutch presidency' that led to the establishment of CIREA, it was stressed that the group 'should expressively not have a decision-making character' and it 'should not be anchored in a formal/legal way within the EC organisation' (ibid.). This ambiguity related to both the legal basis and the legal rules had been heavily criticised by the European Parliament (1996, p.25). The Dutch memorandum described CIREA as a clearing house allowing for the dissemination of asylum-related information and data from the twelve EU member states. By ways of (assumingly paper-based) exchange and regular meetings, participant countries shall take cognizance of asylum policy-related implementation practices in the other member states (ibid.), and subsequently contribute towards the harmonisation of asylum practices in the EC/EU. One of 
the key tasks had been cooperation on country of origin information. To this end, joint country reports were drawn up, for example in 1993 on the situation in Ethiopia, Eritrea and Romania. According to CIREA's activity report of 1994, such country reports 'proved very useful for the Member States [and] enabled informal consultations to be held to facilitate the coordination of asylum practices and policies' (European Council 1994). In fact, the joint reports had to indicate whether or not a country can be deemed as safe country of origin (European Parliament 1996, p.24).

Membership in CIREA was determined by a formal criterion, namely EC membership. Thus, the countries involved included the 12 member states. By then, the EC/EU community was much more coherent than nowadays. Thus, the common characteristics defining countries involved in informal policy coordination (see section 5.4.1) also apply to the example of CIREA: we talk (primarily) about countries that have undergone a similar development with regard to asylum history and asylum institution-building. Participating countries faced similar problems. However, compared to IGC (the previously discussed example), the group is already less homogenous: the differences in national asylum systems between, on the one hand, Portugal, Spain and Greece and, on the other hand, the UK, France and Germany were relatively big. Thus, one can speak of a common community that is bound by several criteria - but the main commonality being that they are EC/EU member states.

Why has CIREA been created? The key aim was to assist member states in harmonising their approaches to asylum determination (Statewatch 1997, p.66). CIREA was thus created in order to work towards convergence of asylum practices. In order to do so, it was argued in the document setting up CIREA that

(...) it is of crucial importance that the Member States have and obtain more, and structural, knowledge of the content of each other's policies with respect to asylum and right of asylum, as well as the developments which take place in that field (ibid.).

Thus, exchanging data and information on each other's policy was considered an important aspect, with country of origin information being a central part of it (ibid.).

Judging the creation of CIREA against developments in 1992, one - again - observes the need to create an (informal) institution where no (formal one) existed yet. By then, there was no possibility for EC countries to exchange information on asylum, and coordinate respective policies. A common European asylum policy was far from being in sight - as were formal institutions to work towards this. The explicit aim to not anchor CIREA in any official way in the EC treaties is thus also a sign of hesitance on parts of many member states to (formally) transfer decision-making power to the community. In consequence, the creation of CIREA can be viewed as a second-best strategy because there was no formal solution in sight. It can also be viewed as being created in order to pursue goals otherwise not publicly acceptable. Observers frequently suspected that political ideas (that would not stand public scrutiny because they are too contentious) 
were pre-formulated in CIREA, including the assessment of certain countries of origin as safe (Statewatch 1997, p.66-67).

Coming to the form of policy coordination within CIREA, it is first and foremost (again) informal. Informality relates to the legal basis. As discussed above, there was a deliberate aim to not base CIREA within the formal EC structure. The memorandum from the Dutch presidency leading to the establishment of CIREA stressed the following:

Bearing in mind the fact that the clearing house has a purely administrative function geared to the exchange of information relevant to the policy on asylum and the right to asylum, it is the Presidency's view that the setting up of a clearing house should not be anchored in a formal/legal way within the EC organisation (Statewatch 1997, p.66).

Next to the explicit informal nature, also the non-decision-making character was emphasised: '[s]uch meetings should expressively not have a decision-making character, but should serve only to allow further cognizance of the prevailing implementation practice in the EC Member States' (ibid.).

Similar to IGC, confidentiality was a key element of policy coordination within CIREA. Access to the information held by CIREA was only available to involved ministers and national authorities participating in the forum (Statewatch 1997, p.68). The clearing house was obliged to draw up a report for the Council twice a year and thus allows - in hindsight - a few insights into its work. However, the reports do not go beyond stating the topics (substantive and country-related) that were on the agenda (CIREA 1996). Bunyan and Webber (1995) stress that '[n]either its [CIREA's] databases nor its reports, briefings or conclusions are accessible to NGOs or members of the public and it is not known, therefore, what information from what sources it takes into account or how comprehensive it is'. Also the European Parliament heavily criticised the nonavailability of information regarding CIREA's work (European Parliament 1996, pp.24).

Also CIREA combined characteristics that made policy deliberation likely to occur: it was informal, participants met up frequently, there was a certain routine of work and involved countries were rather homogenous. It is, however, this last point that makes the deliberation-argument less strong for CIREA than for IGC. Eventually, countries participating in CIREA did not primarily come together because they face similar problems and look for common solutions - but because they were all part of the European Communities. They were more diverse than countries participating in IGC; and they were certainly more diverse than countries discussed in the next section. Thus, in comparative perspective, the evidence for deliberation occurring in CIREA is less compelling than for the other two fora analysed.

In sum, the Centre for Information, Discussion and Exchange on Asylum was the first institution at the EC level allowing for coordination of asylum policy between its member governments, with a particular focus on COI cooperation. Its explicit aim was 
to informally work towards harmonisation of asylum policies in Europe. In the absence of any formal decision-making power in the field of asylum policy, CIREA was created as a second-best strategy lacking a more formal solution. There is also evidence suggesting that CIREA was deliberately set up informally, in order to allow for pursuing (policy) goals not publicly acceptable (yet).

\subsubsection{Bilateral COI cooperation - the informal end of the scale}

The third example focuses on the most common form of cooperation on country of origin information, and the most informal at the same time. A large part of COI cooperation is conducted via personal networks. For example, an official in the German COI unit looks for information on a certain ethnic minority in Somalia, but cannot find this information in-house. She is most likely to pick up the phone and call a colleague in, for example, the Austrian COI unit (or send her an email) asking for this specific information. Bilateral COI cooperation can also be a bit more large-scale with COI experts visiting each other in their home departments (staff exchange) or collaborating on common fact-finding mission to countries of origin. The difference to the two previously discussed fora (IGC and CIREA) is that this section does not talk about one institution facilitating asylum policy coordination but rather many instances of a particular type. In what follows, they are presented in a general, summarised manner.

Who is involved? This example of informal COI cooperation is more than any determined by the commonalities identified in section 5.4.1: shared problems, common legal requirements and common language. A shared history of asylum institutionbuilding and a common perception of the problems connect actors involved in bilateral COI cooperation. One head of a COI unit having been involved in these exchanges for many years stressed the following:

It's an historical thing. These are the countries [involved in informal COI cooperation] that already started with a real COI unit ten, fifteen years ago; just because out of the need that they had an enormous amount of asylum seekers and they just needed this information; so we started small; we started together with a few countries (interview 8).

Some COI experts and heads of COI services have been in their positions since the early 1990s, as one interviewee stressed: 'some of them have been there forever, so they know their old colleagues' (interview 2). Personal ties between COI experts developed because they have been working in the same field for many years, sometimes even decades. They frequently meet in fora such as IGC, CIREA or any of the others mentioned in table 5.3. The above quote also illustrates that it is the perception of a common problem that brings countries together. For example, the British and the French COI units cooperate closely on Sri Lanka because both countries have a relatively large influx of Sri Lankan asylum seekers (interview 25). 
The actors involved in bilateral COI cooperation are also very much determined by another commonality, namely language. For example, there is a particularly strong cooperation on country of origin information between the German-speaking countries called D-A-CH (abbreviations stand for Germany, Austria and Switzerland). It exists since 2006 and aims at both exchanging and commonly producing country of origin information (D-A-CH, n.d.). During interviews with German and Austrian COI experts, this cooperation was valued particular high amongst all forms of COI cooperation with other countries - the main reason being the common language:

It is simply the German language that makes it easier to exchange non-English - namely German - information (interview 36: 275). ${ }^{63}$

Yes, I mean on first sight, language is of course a crucial issue; the cooperation [in the framework of DA-CH] has been existing for a really long time already; and you also see this amongst other countries that cooperate very well, such as the Netherlands and Belgium or Belgium and France - which is facilitated by the language (Interview 35: 116). ${ }^{64}$

The quotes illustrate that it is not only the German-speaking countries that have a particularly strong cooperation on country of origin information. Similar communities exist for the Nordic countries as well as the French-speaking and the Dutch-speaking countries.

Next to a shared understanding of problems and solutions and a common language, there is one further factor that heightens the chance of bilateral COI cooperation between particular countries, namely common legal requirements. In order to illustrate why COI cooperation makes sense with some countries but not with others, box 5.2 introduces one means of coordinating country of origin information, namely common fact-finding missions.

Box 5.2: Fact-finding missions: common legal requirements as one prerequisite for informal COI cooperation

Fact-finding missions are a prominent example of bilateral (or trilateral but in any case small-scale) COI cooperation. In order to acquire first-hand information on the situation in the country of origin, COI experts go on joint missions to the very country. Those fact-finding missions are initiated by COI units, normally based within the country's national asylum administration (see section 5.2.1). One example is the mission to the Democratic Republic of Congo in December 2010 conducted by the French, the Belgian and the German COI unit (Email communication \#6). Other examples are common missions by the German, Austrian and Swiss units to Ethiopia and Somaliland in January 2010 (BAMF, n.d.) or by the Danish and the Norwegian COI unit to Nairobi and Mogadishu in April 2013 (Danish Immigration Service 2013). One

\footnotetext{
${ }^{63}$ Quote in original language: Es ist einfach der deutsche Sprachkreis, der es erleichtert, Informationen auch im Nicht-Englischen, nämlich auf Deutsch auszutauschen.

${ }^{64}$ Quote in original language: Ja, ich meine vordergründig war natürlich die Sprache erstmals ein ganz entscheidender Punkt, die Zusammenarbeit [in the framework of D-A-CH] gibt es eben schon sehr lange, und das merkt man eben auch bei anderen, z.B. Niederlande und Belgien oder Belgien und Frankreich kooperieren z.B. auch sehr gut, was eben durch die Sprache erleichtert wird.
} 
key consideration on whether or not to conduct such a mission is similarity regarding procedures. Interviewees stressed that common fact-finding missions only make sense if there is agreement over the actual end-product, which is called a fact-finding report. Publishing such a report together requires first and foremost similar legal requirements regarding the publication of country of origin information. The most important aspect in this regard is whether or not sources of information need to be mentioned. For example, whereas Denmark, Sweden and the UK are required to publicly present all their material on their website, other countries are not. Thus, these three countries cannot make use of restricted material compiled by other countries (ICPMD 2006, p.31). This has been noted by the Danish as a hindrance to COI cooperation with other countries (ICMPD 2006, p.52). In fact, varying legal requirements with regard to confidentiality/publicity issues has let some countries come to the conclusion that common fact-finding missions do not make a lot of sense for them: 'we have been trying [doing common missions] different times, it just doesn't work' (interview 8).

The example of common fact-finding missions illustrates why COI cooperation makes sense with some countries, and not with others. More than in any of the previously discussed examples of informal asylum policy coordination do commonalities between the countries matter. These relate to rather specific issues such as legal requirements on fact-finding reports or on asylum procedures (interview 35: 120) but do also matter at the more general level: common history of institution-building, a common perception of problems and/or common language is the glue that holds informal asylum policy coordination together. This also becomes obvious when discussing the why and how of bilateral COI cooperation.

Why does bilateral COI cooperation take place? COI exchange via email or phone is particularly valued when other channels for acquiring country of origin information do not lead to the expected result. Often, there is no way to investigate politicallyrelevant information other than by informal and private means:

\begin{abstract}
Every country knows how this works: you are with the minister in the meeting and the minister wants to know immediately how Germany handles this and this; and he wants to know this immediately, we all know this kind of situation: then it is good if you can pick up the phone and call Berlin or Nuremberg knowing that on the other end of the line, someone is doing everything possible to make sure that your minister gets an immediate answer; and this also works, absolutely. If I know the person I am calling, it is something entirely different than not knowing him or her, then it is more stiff, more formal; but this here is really informal (interview 16$){ }^{65}$
\end{abstract}

The examples illustrate that informal bilateral COI cooperation primarily serves two needs: getting information on confidential (because policy-relevant) matters, and get-

\footnotetext{
${ }^{65}$ Original quote: Also jedes Land kennt das, mit dem Minister im Meeting, der Minister will jetzt sofort wissen, wie händelt Deutschland das und das, und das will er jetzt sofort wissen, das kennen wir alle; dann ist es gut mal eben das Telefon in die Hand zu nehmen und Nürnberg oder Berlin anrufen zu können und zu wissen auf der anderen Seite tut jetzt jemand alles, damit dein Minister sofort eine Antwort kriegt, und das klappt auch, absolut. Wenn ich die Person kenne, die ich anrufe, dann ist das was komplett anderes als wenn ich sie oder ihn nicht kenne: dann ist das viel steifer, viel formeller. Das hier ist sehr informell.
} 
ting this information on a very short notice. Interview partners acknowledge that this is not possible via the formal institutions available:

\footnotetext{
It is often easier to pick up the phone and call your colleague somewhere in Europe than go through the official channel (interview 9).
}

The contacts you get in those different fora, personal contacts are way more important, when you need to have something a la minute, which sometimes happens, (...) then you can't wait six months to put it at CIREA level and put it on paper. You have to pick up the phone (interview 3).

Thus, bilateral COI cooperation is complementary to more formal ways of COI exchange because it allows for quick and easy access to timely and possibly highly politicised information.

This third example of informal COI cooperation is the one most obviously being determined by a deliberative rather than bargaining style of interaction. Clearly, participants involved are socialised into a practice of consensus-oriented debate and collegial behaviour. The informal exchange is driven by a common understanding of 'trying to help each other as much as possible' (interview 8 ). Trust plays a crucial role in that regard:

I know if I call my colleague [in another country] or she calls me, we can exchange any information, because she knows exactly what she can and what she can't use; if she can't use it, she won't use it' [...] 'they [the COI experts involved in cooperation] know from each other what their expertise is, how to reach each other, they trust each other when they ask or get information (interview 8).

Also the similarity of actors involved, their common understanding of what constitutes a problem (i.e. to get speedy access to policy-relevant country of origin information), and the regular dialogue between the partners are conditions facilitating a deliberative style of interaction.

Thus, bilateral cooperation on county of origin information is the most informal of the cooperation fora discussed. It is complementary to more formal ways of conducting COI research by facilitating the timely collection (and interpretation) of scarcely available and often politically relevant country of origin information. These bilateral exchanges are very much based on a similarity of participants (with regard to background, problems, language...) and are rather private. From all three examples of informal COI cooperation discussed, they are by far the most informal and the one most likely being characterised by deliberation.

In sum, this section showed three examples of informal cooperation on country of origin information. The examples differed with regard to their scope of membership (global, European, bilateral) but also with regard to their level of informality, their reason for having been set up and the likelihood of deliberation to occur. The creation and existence of these informal fora was very much determined by the absence of their for- 
mal counterparts. Consequently, informal COI cooperation fulfills different roles, though the most prominent one is filling a gap where no formal institution exists (yet). Even though informal cooperation on country of origin information can take different forms, it eventually works based on similar mechanisms and rules. Actors involved have common understandings about the problems they face, and look for common solutions. Similar legal requirements and the same language family heighten the chance of informal cooperation. Based on these findings, informal COI cooperation is driven by a few, mainly Western and Northern European, states. The following section shows that there are basically two developments shaking up the well-established informal cooperation system: the EU Eastern enlargement and the upgrade of COI on the political agenda of the EU. Thus, COI cooperation in Europe became formalised.

\subsection{Formalising COI cooperation in the EU}

The current section starts from the assumption that there is a clear cut between COI cooperation pre-Amsterdam and post-Amsterdam. Whereas during the 1980s and 1990s, we only had informal COI cooperation (as discussed in the previous section), since 2000 formalisation is taking place. Cooperation on country of origin information became an important topic on the European Commission's agenda which resulted in the formalisation of many COI cooperation initiatives. Also, an EU asylum agency was created that is explicitly mandated to facilitate COI cooperation. In what follows, the growing interest and role of the European Commission in COI cooperation is analysed (section 5.5.1) and several examples of formal COI cooperation structures are given (section 5.5.2).

\subsubsection{Towards formalising COI cooperation: the role of the European Commission}

The Treaty of Amsterdam (1999) and the Tampere Program (1999) lifted cooperation on country of origin information on the agenda of the European Union, and the European Commission in particular. In the years to follow, the Commission and member states initiated many projects facilitating cooperation on country of origin information. A crucial step in this regard was the transfer of the informal Council working group CIREA (section 5.4.3) to the formal Commission working group Eurasil. In what follows, this transformation is discussed.

The transformation of the Council working group CIREA into the Commission working group Eurasil in 2002 indicated that the Commission would take a more prominent role in COI cooperation in the future. With the institutional framework having changed and more countries joining the European Union, Eurasil looked much different from its predecessor CIREA. Two changes are particularly prevalent: first, the Commis- 
sion now played a key role in COI cooperation; and second, the countries within Eurasil became more diverse. Both are discussed below.

With Eurasil taking over the functions of CIREA, the Commission became a key player in COI cooperation: From now on, it chaired the Eurasil meetings and provided secretarial functions. Along with this new role came a considerable amount of power. One interviewee went as far as stressing that 'the Commission controls Eurasil' (interview 3). For example, the secretariat - after consultation with the member states - decides on the agenda and the country-focus of the workshops conducted within Eurasil (interview 2; interview 8). Also, one of the key means of exchanging country of origin information - via email requests send to all EU member states - was now facilitated by the Commission: COI experts can send an information request to the entire group. However, the Commission (in the form of the Eurasil secretariat) acts as a kind of bottleneck deciding which requests are forwarded to the network, and which not (interview 16). This, naturally, created some discontent amongst involved COI experts. As one interviewee put it:

With Eurasil[...] it becomes a bit more formal: you have translations and you have people sitting at the table [...] and you have of course now a Commission; and it is all more political in the sense of officepolicies; it is much more ... countries don't say as much as they would in an informal setting (interview 3).

As the quote illustrates, formalisation also went hand in hand with politicisation. It suddenly mattered which countries of origin were put on the agenda. Also whether or not an information request was (politically) relevant was decided by a third party.

Next to the Commission taking a more prominent role, also the number of countries participating in Eurasil very much changed the nature of COI cooperation. Whereas within CIREA (predecessor of Eurasil) participating countries met on a somewhat equal ground (similar history of asylum institution-building, similar standards ...), the picture had now changed completely: Between 1992 and 2007, the number of EU member states more than doubled from 12 to 27 . The variety of national asylum systems became much bigger. Also the background and motivation for actors to be part of Eurasil varied a lot. This created some problems: with 27 countries sitting around the table, some are more involved than others. In fact, it was argued by some interviewees that the active countries have (hardly) changed, just the table became bigger: COI cooperation within Eurasil would still be limited to a few countries, namely those that have always been active in the informal exchange:

(...) that has always been a problem with Eurasil meetings; they were in Brussels and there were 27 countries present, and there were always 6 or 7 countries who were talking and there were countries who didn't say anything the whole day; [...] that is because COI has never been a big issue for a lot of countries (interview 8). 
However, there are other interviewees who stress that there is a lot of participation by the countries being new to COI cooperation, and by Eastern European ones in particular (interview 2; interview 25; interview 35).

The most obvious problem in COI cooperation via Eurasil is language. In fact, it was labeled by many countries as the main obstacle to COI cooperation in the future (ICMPD 2006, p.31). Interview partners acknowledged that communication within Eurasil is much more difficult than within smaller, more informal networks - simply because there are more languages and not everyone is able to follow a conversation in English (interview 3; interview 8). Thus, translation during some Eurasil meetings was introduced. These changes occurring within Eurasil indicated that COI cooperation post-2000 would start looking very different than in the 1990s: formalisation took place and more actors were involved (the Commission, more member states), which naturally created some challenges. However, the setup of Eurasil was only one of many measures taken during that time. The next section illustrates that in the years to follow the European Commission and member states experimented with many more measures aimed at facilitating the exchange of country of origin information - and thus the harmonisation thereof.

\subsubsection{The EU as a laboratory of COI cooperation}

Let us be quickly reminded of why the European Commission (and several member states) developed such a strong interest in EU-driven cooperation on country of origin information: Based on the Tampere Program of 1999 (European Council 1999), EU member states had adopted a first comprehensive set of legally binding rules on asylum matters. These rules aimed at establishing the Common European Asylum System, which first and foremost related to similar asylum standards across EU member states. ${ }^{66}$ However, the rules adopted were not sufficient to achieve this aim (Commission 2008b, p.4). Other measures were needed - including (what the Commission called) 'practical cooperation' between national authorities involved in implementing asylum rules (Commission 2006a, Commission 2006b). ${ }^{67}$

It was acknowledged soon that COI played a key role in achieving more similar asylum standards across Europe: 'more convergence on the collection and analysis of COI by asylum authorities in Member States would contribute to leveling the asylum playing field' (Commission 2006a, p.5). However, the Commission also recognised that this would not be an easy task:

The practical needs of Member States in the COI field vary greatly. Some Member States have invested heavily in this area and run sophisticated COI systems while others retain more basic systems or rely on

\footnotetext{
${ }^{66}$ For a more detailed discussion of this first phase of the Common European Asylum System, see section 1.3.

${ }^{67}$ For a detailed account of 'practical cooperation' becoming a political priority of the European Commission, see section 1.4.
} 
the services of NGOs or UNHCR. The need for all Member States to apply COI in the same way and using the same sources is inherent in the agreement of the Common European Asylum System (Commission 2006b, p.10).

The Commission acknowledged that the huge differences between COI systems in the member states would make it difficult to harmonise the approach towards country of origin information. Many projects were initiated that aimed at both: building up COI expertise in states with considerable gaps in that regard; and working towards a common interpretation of existing country of origin information. Thus, cooperation on country of origin information became a political priority in the EU's asylum policy.

A clear indicator for COI cooperation having moved up on the Commission's political agenda is the transformation from the Council working group CIREA to a Commission working group (Eurasil), as discussed in the previous section. Another indicator is the money being allocated by the Commission to respective COI cooperation projects. For example, in 2008 and 2009, four projects explicitly aimed at improving COI cooperation were funded by the European Refugee Fund (European Commission 2008a and 2009b) ${ }^{68}$ Most of the projects funded fitted very well the term of a 'laboratory' meaning they started rather ad-hoc and informally in order to find out what are promising ways to facilitate COI cooperation within the EU. In what follows, three of these initiatives are listed:

- Medical Country of Origin Information: provision of a platform for European countries to exchange information on the availability of medical treatment in countries of origin (European Commission 2011)

- Temporary Desk Iraq (TDI): provision of a secure platform for exchange of information/data related to asylum seekers from Iraq. Efforts included for example a detailed analysis of asylum seeker inflows and decisions in order to create profiles of Iraqi asylum seekers (understanding large-scale why they come, where they come from ...); or the introduction of an early-warning pilot-system possibly allowing to predict flows of asylum seekers from Iraq. ${ }^{69}$ The project was set up for 18 months and then transferred its know-how to the European Asylum Support Office (TDI 2010).

- European Country Sponsorship (ECS): member states with specialised knowledge on a particular country of origin became sponsors of that country of origin - and provide answers to asylum-related questions on this country of origin to other member states (European Country of Origin Sponsorship 2010b). For example, the Netherlands serve as a sponsor for Georgia, Iran and the Russian Federation/Chechnya (ibid.) - other COI experts and heads of COI units needing information on these countries can contact the Dutch COI unit.

\footnotetext{
68 The projects included 'COI in judicial practice', 'Temporary Desk Iraq', extension of 'European COI Sponsorship' and the "Medical COI project' (ibid.).

${ }^{69}$ Some of the tools were applied to other countries of origin too, including Russia, Afghanistan and Somalia.
} 
There are three characteristics that these initiatives (including Eurasil) have in common and that distinguishes them from informal COI cooperation pre-Amsterdam (as discussed in section 5.4): their scope of membership involving all EU member state; the key role played by the European Commission in financing and/or facilitating these COI cooperation processes; and their formalisation as part of the newly created EU asylum agency, the European Asylum Support Office.

The creation of the European Asylum Support Office is only the last step taken in order to facilitate COI cooperation amongst EU member states. The EU asylum agency was set up in 2010. According to its mandate, EASO will play a crucial role in organising, promoting and coordinating activities related to country of origin information (Regulation 439/2010, art.4). The projects mentioned previously (TDI, ECS, Medical Country of Origin Information) but also Eurasil are now part of the agency's work. And more measures were taken, including for example the setup of a Common Country of Origin Information Portal that aims at connecting all national COI databases with each other (Penisson 2012).

As of 2013, the role played by the agency with regard to COI cooperation goes beyond facilitating exchange. It also includes the formulation of common standards both related to the procedure of collecting and analysing country of origin information and the actual substance of country of origin information. With regard to procedures, EASO has published a common methodology for presenting, verifying and using country of origin information (EASO 2012a). With regard to substance, the Office started publishing country reports with the first ones being issued on Afghanistan (EASO 2012c; EASO 2012d) and the Western Balkan countries (EASO 2013). ${ }^{70}$

In sum, this section showed that with the commitment to a Common European Asylum System, COI cooperation became an important element of EU asylum governance. Not only took the Commission a lead role in facilitating and financing these processes, but also the newly created EU asylum agency focused its work prominently on COI cooperation. New projects were initiated and old (informal) ones were formalised. Thus, the main difference to informal COI cooperation of the 1990s is the formalisation, the new role of the EU bodies and the involvement of all EU member states.

\subsection{Conclusion}

The chapter analysed cooperation on country of origin information, and thus provided an empirical example of asylum policy coordination in Europe. It concluded that cooperation on country of origin information has changed from an informal, state-driven

\footnotetext{
${ }^{70}$ A brief assessment of EASO's work and its future role in the EU asylum governance system are further discussed in the conclusion.
} 
form of policy coordination to a more formal one involving all EU member states and with the European Commission playing a key role.

Before 1999, much of cooperation on country of origin information happened between a small number of countries. The Northern and Western European states coordinated their respective asylum policies in fora such as the (global) Intergovernmental Consultations on Migration, Asylum and Refugees, the (European) Centre for Information, Discussion and Exchange on Asylum as well as bilateral cooperation between two (or a few) states. Though the scope of these fora is very different (global, regional sub-regional), their form and function as well as involved actors are surprisingly similar: there are a few like-minded countries engaging informally in a deliberative policy debate; they do so because they lack any fora to confidentially exchange views, develop and/or pre-cook policy-solutions to common problems.

With the Tampere Program in 1999 and the agreement on the Common European Asylum System, cooperation on country of origin information was upgraded on the EU's political agenda. As a consequence thereof, existing COI cooperation fora were formalised and grouped under the newly created European Asylum Support Office. Next to formalisation, the main differences to the informal COI exchange is the much wider variety of national asylum systems of countries involved (all EU member states) and the Commission taking a lead role. Thus, cooperation on country of origin information became a key issue of EU asylum governance. With all these measures taken, member states and the Commission aim at achieving more similar standards across the EU. They hope that cooperating on the collection and interpretation of country of origin information would, eventually, help achieving asylum policy convergence. In fact, the same had been argued for the informal cooperation processes within CIREA, bilateral cooperation and IGC. With regard to the latter, observers stress that

[t]here is indeed a widespread view that the subsequent ongoing, informal confidential exchange of views with the IGC framework may well have resulted in what might be called a "soft policy convergence" that came about through learning what other States were doing and why they were doing it (Hallam Johnston \& Associates 2005, p.16).

It, however, remains to be analysed whether this "soft policy convergence" indeed happened. Though all fora discussed in this section eventually aimed at achieving more similar asylum standards across Europe, we lack an analysis of the actual role of asylum policy coordination (as presented in this chapter) in the domestic policy-making process. We also lack an analysis showing whether it played the role wished for - namely leading towards policy convergence. The next two chapters will shed light on these questions. 



\section{Strategic policy transfer: domestic change following a logic of consequences}

\subsection{Introduction}

This chapter interprets domestic policy-making following a logic of consequences. It is argued that policy-makers enter transnational asylum policy coordination with a clear purpose in mind, coordinate policies with other countries, and leave the exchange with the same set of preferences. Thus, preferences are formed exogenous to the institutions in which transnational asylum policy coordination takes place.

To remind the reader what is meant by asylum policy coordination: essentially, we talk about the exchange of policy-relevant information between state executives. These people could be based in either the national ministry responsible for asylum matters or in the national asylum administration. In any case, they are involved in shaping the process of safe country of origin policy-making. Asylum policy coordination is determined by its informal nature, the deliberative character of interaction, and it does not lead to legally binding outcomes. The previous chapter illustrated asylum policy coordination with the example of cooperation on country of origin information. This exchange takes place between state executives of different member states and can take various forms - from global cooperation between Western countries with large numbers of asylum seekers (Intergovernmental Consultations on Asylum, Refugees and Migration), to European cooperation aimed at coordination policies amongst EC countries (CIREA), to bilateral, small-scale cooperation between few countries sharing similar problems, languages and/or legal requirements. The previous chapter also showed that informal COI cooperation was accompanied by more formal processes of exchanging data and policy: existing fora were formalised, the Commission started taking a more active role and more (EU member) states joined the exchange.

No matter whether informal or formal, COI cooperation eventually aimed at feeding national policy decisions, and in some cases lead to policy convergence. The role of transnational policy coordination in the domestic decision-making process has, so far, remained unclear. Thus, this chapter will answer the following question: What is the role of COI cooperation in the domestic policy-making process relating to safe country of origin 
policies? This question will be answered from two different perspectives: whereas the current chapter focuses on the logic of consequences, chapter 7 views policy-making via the logic of appropriateness.

Assuming a cost-benefit rationale, the following logic appears: the safe country of origin policy of a particular European country is altered because of a strategic move among self-interested actors. Based on fixed preferences, policy-makers entered transnational asylum policy coordination in order to find out about policies in other countries. The information obtained is used to achieve pre-given preferences that have been formed at the domestic level before entering the exchange. One possibility why policymakers enter policy coordination is that they aim to achieve goals otherwise unachievable due to domestic constraints (two-level game). However, other mechanisms could also be at play: policy-makers can also enter policy coordination without facing constraints at the domestic level, and still take something back from the exchange that helps them to achieve whatever they intended to (simple learning). In any case, the key issue is that policy-makers use transnational policy coordination to achieve pre-set preferences, and leave the exchange without preferences having changed.

The chapter will show that policy-making in three of the four countries studied in detail can be very well explained by the logic of consequences. Germany, the UK and Luxembourg introduced safe country of origin policies with a clear goal in mind. They aimed at deterring asylum seekers from certain countries of origin and processing their claims faster than others. Before introducing these policies, the authorities of the three countries engaged in transnational asylum policy coordination. They did so for various reasons and to varying extents: while Germany was essentially playing a two-level game and aimed at getting a European agreement where a national one was not possible in the first place; the UK was simply interested to learn about other countries' safe country of origin policies in order to make sure that own policy is restrictive enough. Also in Luxembourg, learning from other countries served the purpose of achieving pre-defined interests. The evidence for Malta was less straightforward.

In order to operationalise policy-making following a logic of consequences, a number of conditions were identified (table 6.1). They are based on the theoretical considerations in chapter 3.

The conditions also guide the structure of this chapter. It starts by outlining the preferences of domestic policy-makers before they engage in policy coordination with other countries. Based on the two-level game, policy-makers face constraints - either on part of the legislative, national courts or civil society - when wanting to adopt the intended policy. These constraints are discussed in detail for each of the case studies. The analysis then turns to the transnational level looking at whether policy-makers engage in coordinating policies with other countries. Eventually, the focus moves back to the domestic level investigating two issues: whether information obtained during transnational exchanges are used to justify own, intended policy changes; and whether preferences 
indeed have stayed the same as before entering the dialogue with other countries. There is an inherent time dimension to this analysis: the formation of domestic preferences is followed by transnational policy coordination is followed by a legitimising discourse ... Of course, these processes do not occur in a rigid order but go back and forth many time and interact with each other. However, for the sake of a sensible chapter structure, these processes are kept separate here

Table 6.1: Overview of conditions for policy-making following a logic of consequences

\begin{tabular}{ll}
\hline Level & Conditions \\
\hline Domestic & Preferences regarding safe country of origin policies \\
& Constraints faced \\
& - Executive vs. legislative \\
& - National courts \\
& - Civil society \\
& Engagement in asylum policy coordination for the purpose of acquiring \\
Transnational & information on other countries' policies \\
& Justifying legitimacy of action \\
Domestic & No change of preferences \\
\hline
\end{tabular}

Before starting with the actual analysis, the reader is reminded of one caveat regarding the normative dimension of safe country of origin policies: much criticism was voiced over how European countries apply the safe country of origin notion. This chapter does not deal with criticising this notion in general or the very practice in the countries analysed. If mentioned, critical voices do not relate to a normative discussion but support the argument made in chapter. Consequently, this chapter solely deals with the decision-making process leading to these policies. The normative dimension of safe country of origin policies is discussed in both sections 2.4.5 and 8.5.

\subsection{Domestic preferences - why have a safe country of origin rule?}

To quickly recall the argument: Following a logic of consequences, policy-makers engage in policy coordination (and use whatever they get out of these exchanges) to achieve pre-given preferences. The preferences are thus formed exogenously to asylum policy coordination. The analysis in this chapter starts with outlining the preferences of policy-makers in the four countries under review. This is necessary in order to analyse at a later point (section 6.6) whether preferences have changed or not. 


\section{Germany}

The safe country of origin rule was introduced in Germany in 1992/1993. It was part of the so-called Asylkompromiss - which is one of the two biggest changes in German asylum legislation until today. ${ }^{71}$ The Asylkompromiss involved changing the Basic Law (equals the Constitution in other countries) and thus required the consent of a $2 / 3$ majority of members of the Bundestag. The introduction of the safe country of origin rule was one of several measures aiming for the very same: reducing the number of asylum seekers from certain countries, and accelerating their asylum procedure. ${ }^{72}$ Already between 1978 and 1992, more than ten changes to the asylum legislation had been adopted - all relating to the acceleration of the asylum procedure (Bundestag 1993c, p.13637). However, none of these measures had proven to be successful.

What was the situation back then in Germany? Whereas during the 1980s the number of asylum seekers was considerably stable between 5,000 and 10,000 per year, these numbers skyrocketed in the early 1990s. In 1992, the number of persons seeking protection in Germany was 7.5 times higher than in 1987 (from 57,379 to 438,191; Eurostat). The main reason for this increase was the fall of the Iron Curtain and the conflict in former Yugoslavia - both producing thousands of people fleeing to other countries for a better life. A key target country at that time was Germany. This large influx of asylum seekers was an overwhelming task for the German municipalities. Being in charge of accommodating asylum seekers and for processing their claims, the municipalities were not able to cope with the financial and administrative burden related to these numbers. In addition, the high number of people seeking protection in Germany coincided with a wave of right-wing extremism and violence targeted against asylum seekers: in September 1991, neo-Nazis in Hoyerswerda attacked for several days a housing for asylum seekers; in November 1992, there was an incendiary attack on two Turkish families in Mölln - to name only two of the many incidences at that time (see also Cremer 2013; Kinzer 1991). ${ }^{73}$

With introducing the safe country of origin rule, the Kohl government primarily aimed at limiting the number of asylum seekers from certain countries of origin, and accelerating their asylum procedure. This key goal was stressed by the governing Christian-Democrats (CDU/CSU) and Liberals (FDP) when the bill was introduced in 1992. The Bill aimed at

(...) continuing to provide protection and refuge to the genuinely persecuted; but to avoid an unsubstantial referral to the right to asylum; and to exclude those foreigners from the asylum procedure that

\footnotetext{
${ }^{71}$ The other one is the adoption of the Zuwanderungsgesetz (Immigration Law) in 2005.

${ }^{72}$ The other two also adopted in 1992 were the introduction of the safe third country rule and the Flughafenverfahren (airport procedure). For a comprehensive discussion of the changes, see Cremer 2013.

${ }^{73}$ A more comprehensive picture of the racist attacks at that time is provided by the documentary of Monheim (1993).
} 
are not in need of protection. In addition, the asylum procedure as well as the appeals procedure are to be accelerated (Bundestag 1993e, p.3). ${ }^{74}$

The core aim of introducing the safe country of origin notion was also confirmed by legal experts: 'It is the aim of the safe country of origin notion to profoundly shorten the procedure for asylum seekers from such countries by consolidating in a legislative decision the knowledge and experience regarding these countries (Marx 2008, p.767). ${ }^{35}$ The motivation for the German government to introduce a safe country of origin policy became also clear during negotiations in the Bundestag. The law was targeted at asylum seekers from countries with generally high application numbers and low recognition rates. It was explicitly stressed that there is no interest in creating a global list of safe countries of origin but a list of countries where low recognition rates are expected anyways:

With good reason, we abstained from compiling a complete list of countries. Two criteria determined whether or not a country was added to the list: on the one hand, a very high number of asylum applicants; and on the other hand, a very low number of recognition rates (Bundestag 1993a van Essen, p.12291; see similar statement from Minister of Interior: Bundestag 1993a, Seiters, p.12297; see also Hailbronner 1993b, p.302). ${ }^{76}$

Next to the discussion in the Bundestag, the numbers also support this core motivation. Tables 6.2 and 6.3 provide an overview of the countries proposed to be included in the German SCO list as well as their recognition rate in 1991. Senegal is listed in a separate table (6.3) because of a different source, and possibly a different counting. ${ }^{77}$

\footnotetext{
${ }^{74}$ Quote in original language: ... den wirklich politisch Verfolgten weiterhin Schutz und Zuflucht zu gewähren, aber eine unberechtigte Berufung auf das Asylrecht zu verhindern und diejenigen Ausländer von einem langwierigen Asylverfahren auszuschließen, die des Schutzes deswegen nicht bedürfen, weil sie offensichtlich nicht oder nicht mehr aktuell politisch verfolgt sind. Außerdem ist das Asylverfahren einschließlich des gerichtlichen Verfahrens weiter zu beschleunigen.

${ }^{75}$ Quote in original language: Zweck der Herkunftsstaatenregelung ist es vor allem, das Prüfprogramm für Asylsuchende aus derartigen Staaten abweichend von den sonst zu beachtenden Anforderungen wesentlich zu verkürzen, indem die Erkenntnisse und Erfahrungen im Blick auf diese Staaten gewissermaßen in einer gesetzgeberischen Entscheidung gebündelt werden.

${ }^{76}$ Quote in original language: Wir haben aus gutem Grund davon abgesehen, eine vollständige Liste dieser Staaten aufzustellen. Zwei Kriterien waren für die Betrachtung und für die Aufnahme in die Liste entscheidend: auf der einen Seite eine besonders hohe Zahl von Bewerbern und auf der anderen Seite eine besonders niedrige Anerkennungsquote.

${ }^{77}$ For problems with asylum statistics, see Hovy 2001 and Stewart 2004.
} 
Table 6.2: Number of asylum seekers and recognition rates for countries proposed to be included in the German safe country of origin list in 1992 (source: Wartenberg 1993) ${ }^{78}$

\begin{tabular}{lccccc}
\hline $\begin{array}{l}\text { Country of } \\
\text { origin }\end{array}$ & $\begin{array}{c}\text { Included } \\
\text { in the list }\end{array}$ & $\begin{array}{c}\text { Applications } \\
\text { in } 1992\end{array}$ & $\begin{array}{c}\text { Decisions taken } \\
\text { in } 1992\end{array}$ & $\begin{array}{c}\text { Protection status } \\
\text { granted in 1992 }\end{array}$ & $\begin{array}{c}\text { In \% } \\
\text { Poland }\end{array}$ Yes \\
CSFR & Yes & 2,185 & 2,747 & 1 & 0,0364 \\
Romania & Yes & 68,446 & 2,005 & 0 & 1,179 \\
Bulgaria & Yes & 16,446 & 36,701 & 66 & 0,111 \\
Hungary & Yes & 876 & 6,972 & 10 & 0 \\
Nigeria & No & 9,450 & 889 & 2 & 0,0364 \\
Ghana & Yes & 5,245 & 5,480 & 9 & 0,37 \\
Zaire & No & 5,972 & 2,401 & 1 & 0,196 \\
Liberia & No & 3,316 & 509 & 0 & 0 \\
India & No & 3,804 & 1,201 & 1 & 0,035 \\
\hline
\end{tabular}

Table 6.3: Number of recognition and refusal rates for asylum seekers from Senegal in Germany in 1994 (source: Bundesministerium des Inneren 1996, p.5)

\begin{tabular}{|c|c|c|c|c|c|}
\hline $\begin{array}{l}\text { Country of } \\
\text { origin }\end{array}$ & $\begin{array}{l}\text { Included } \\
\text { in the list }\end{array}$ & $\begin{array}{c}\text { Decisions taken } \\
\text { in } 1994\end{array}$ & $\begin{array}{c}\text { Protection status } \\
\text { granted in } 1994\end{array}$ & $\begin{array}{c}\text { Protection status } \\
\text { refused in } 1994\end{array}$ & In $\%$ \\
\hline Senegal & Yes & 897 & 0 & 748 & 0 \\
\hline
\end{tabular}

All countries proposed to be included in the German SCO list produced high numbers of applications and very low numbers of acceptance rates. Interview partners also stressed that two of the core countries to be targeted with the safe country of origin notion were Bulgaria and Romania having such a disproportionate ratio (interview 39; interview 42).

What is worth to note is that the aim to accelerate the asylum procedure, and subsequently limit the number of applications, served to tackle a number of other problems as well. First of all, the bill was framed as helping the municipalities and reacting to a public that wants less rather than more immigration. In fact, the bill was introduced as an act of national importance and something that is long sought for by the German population. The Minister of Interior stressed during debate in parliament that any failure in adopting the bill would threaten democracy in Germany:

\footnotetext{
78 The recognition rates do not refer to the same applications. Decisions taken and statuses granted relate to applications (primarily) lodged in the year before (see Hovy 2001 for a differentiation between cohort-based and period-based asylum numbers).
} 
(...) it [the bill] is overdue; it is long sought and hoped for by our cities and communities and by our people, who experience the current situation of illegal immigration to Germany as worrying and frightening. A breakdown of negotiations would be a catastrophe for democracy in our country, for the capacity to act of our state and for peoples' trust in politicians and in this parliament (Bundestag 1993c, Seiters, p.13520; see also Bundestag 1993a, Seiters, p.12297; Bundestag 1993c, Sauer, p.13657). ${ }^{79}$

In addition, the designation of countries of origin as safe was also framed as tackling the crime rates, allegedly being particularly high among asylum seekers:

More countries - also outside of Europe - have to be checked; especially those of which citizens have low recognition rates but are very active in serious and most serious crimes, such as drug trafficking (Bundestag 1993a van Essen, p.12291; for similar references see Bundestag 1993a, Marschewski, p.12284; Bundestag 1993c, van Essen, p.13531). ${ }^{80}$

Finally, the bill was introduced as aiding to stop the rise of right-wing extremism in Germany. The government argued that by reducing the number of asylum seekers, one would be able to stop the right-wing hatred that had gone through the country in the previous months and years: 'Do we first need to see the arrival of one million asylum seekers before you wake up? Or do we first need to have $20 \%$ of right wing votes before you wake up?' (Bundestag 1993c, Fuchtel, p.13606). ${ }^{81}$ In sum, we see that with the introduction of the safe country of origin rule the German government primarily aimed at reducing the number of asylum seekers from certain countries of origin. According to its logic, this was necessary for several reasons, including the inability of municipalities to cope with the administrative and financial burden arisen from the huge influx of asylum seekers, the crime rates among asylum seekers from certain countries of origin and the rise of right-wing extremism in Germany.

The UK

Also in the UK, the safe country of origin policy was all about reducing the intake of asylum applicants. In 1996, when the safe country of origin provision was introduced in the Asylum and Immigration Act, it was clearly labeled as a measure to reduce numbers of unfounded applications, and speed up the asylum procedure. The by then Home Office Minister Widdecombe stressed, that '[d] esignation will help the asylum system to deal quickly with the large number of unfounded applications we currently receive from

\footnotetext{
${ }^{79}$ Quote in original language: Er [dieser Beschluss] ist überfällig, wird seit langem erwartet und erhofft von unseren Städten und Gemeinden und von unseren Mitbürgern, die die gegenwärtige Situation der illegalen Zuwanderung nach Deutschland als besorgniserregend und beängstigend empfinden. Ein Scheitern der Verfassungsänderung wäre katastrophal für die Demokratie in unserem Lande, für die Handlungsfähigkeit des Staates und für das Vertrauen der Bevölkerung in die Politiker und in dieses Parlament.

${ }^{80}$ Quote in original language: Weitere Staaten - auch außerhalb Europas - werden zu prüfen sein, insbesondere solche, bei deren Staatsangehörigen eine niedrige Anerkennungsquote festzustellen ist, welche aber im Bereich der schweren und schwersten Kriminalität, etwa im Drogenhandel, besonders aktiv sind.

${ }^{81}$ Quote in original language: Müssen erst eine Million Asylbewerber kommen, bevor Sie klug werden? Oder müssen erst $20 \%$ rechtsradikale Stimmen kommen, bevor Sie aufwachen?
} 
countries which are, in general, safe' (HoL (House of Lords) 1996, column (c.) 1735). In the years to come, many countries of origin were added to the list and the unison reasoning of the responsible government was reducing the number of presumably unfounded asylum claims (see for example HoL 2003a, Filkin, c. 1115; HoC (House of Commons) 2003, Hughes, c. 003; HoC 2005b, Burnham, c. 7). With the adoption of the NIA Act in 2002, the legal basis and consequences for asylum seekers changed, and a new list was created.

The rhetoric in parliament resembled the actual numbers of asylum seekers asking for protection in Britain. Table 6.4 provides an overview of numbers of asylum seekers and recognition rates for countries proposed to be included in the British safe country of origin list of $2002 .^{82}$

Table 6.4: Number of asylum seekers and recognition rates for all countries proposed to be included in the British safe country of origin list in 2002 (source: Eurostat) ${ }^{83}$

\begin{tabular}{lccc}
\hline Country of origin & Application rate in 2002 & Recognition rate in 2002 & Recognition rate in \% \\
\hline Albania & 1350 & 320 & 23,70 \\
Bangladesh & 825 & 175 & 21,21 \\
Bolivia & 110 & 10 & 9,09 \\
Brazil & 65 & 0 & 0 \\
Bulgaria & 90 & 0 & 0 \\
Ecuador & 485 & 40 & 8,24 \\
Jamaica & 1445 & 30 & 2,07 \\
Macedonia & 335 & 140 & 41,79 \\
Moldova & 885 & 115 & 12,99 \\
Serbia and Montenegro & 2910 & 1245 & 42,78 \\
Sri Lanka & 3485 & 670 & 19,22 \\
South Africa & 290 & 0 & 0 \\
Romania & 2050 & 80 & 3,90 \\
Ukraine & 425 & 15 & 3,52 \\
\hline
\end{tabular}

Table 6.4 shows that designations in 2002 were to a large extent determined by the disproportionate ratio between numbers of asylum seekers from a certain country of origin

\footnotetext{
${ }^{82}$ The same logic appears for countries having been added earlier and later. However, especially for the early years (1996) it was impossible to compile reliable numbers on both application and protection rates.

${ }^{83}$ The recognition rates do not refer to the same applications. Decisions taken and statuses granted relate to applications (primarily) lodged in the year before (see Hovy 2001 for a differentiation between cohort-based and period-based asylum numbers).
} 
and their acceptance rates. For example, there were 290 asylum applications from South Africans but not a single positive decision. However, the table also shows that the ratio is rather diverse. Next to countries with a protection rate of (or close to) zero (Brazil, South Africa, Bulgaria) also countries with a much higher protection rate were added to the list (Albania: 23,7\%; Serbia and Montenegro: 42,8\%). During the years to come, the countries being added to the list were not producing huge numbers of asylum seekers anymore. For example, in 2002, Brazil produced only 65 asylum applications (for a similar observation, see also HoC 2003, c. 008). It has been argued that since the Home Office had designated all countries with high application numbers (and low acceptance rates) as safe country of origin already, they were now trying any measure to further cut the numbers. This observation was confirmed by interview partners: 'so even if large numbers aren't coming from these countries individually, designating these countries as NSA countries [...] can somehow be seen as an indicator for cutting down on asylum flows' (interview 19)..$^{84}$

The actual policy-making process in the Home Office showed that the ratio between application numbers and recognition rates was key to any safe country of origin designation. The process of potentially designating a country as safe always started with the Home Office in cooperation with the Foreign Office looking at countries of origin with a high intake of asylum seekers. After the legal test (testing whether the criteria are fulfilled for designating a country as safe according to national law) conducted by Home Office lawyers and an in-depth analysis with the Country of Origin Information Service, the responsible minister brought a draft order to parliament (interview 22). Thus, looking at the actual process of safe country of origin designation also confirms that the number of asylum seekers played a crucial role in selecting countries.

Cutting numbers of asylum seekers in the UK was, however, not only about actual numbers of asylum seekers (having entered the country already) but also about anticipated numbers: In 2003, several South American countries, including Bolivia, Brazil, Ecuador, and Jamaica were added to the list (Asylum (Designated States) (No. 2) Order 2003). Their inclusion was a preliminary measure after UK intelligence anticipated an increase in the number of asylum applications from these countries (interview 22: 107). A similar explanation accounted for South Korea being added to the list in 2010 (Asylum (Designated States) Order 2010): safe country of origin designation covers people who are legally entitled to reside in the country concerned. In this case, the actual target group was North Koreans being able to reside in South Korea because of a policy change. Thus, designation was intended to prevent the anticipated high intake of North Koreans residing in South Korea (interview 22: 113).

In European perspective, there was one further preference of British policy-makers: to not be more attractive to asylum seekers than other countries. Policy developments

\footnotetext{
${ }^{84}$ In the UK, safe countries of origin are called NSA countries (countries with non-suspensive appeals). See section 4.2.2.
} 
and intake patterns of other EU member states were closely followed (interview 21; interview 22). By doing so, one wanted to make sure that own policy is not more lenient towards asylum seekers than policy of other countries (interview 18). This, again, emphasises the key aim, namely cutting numbers of asylum seekers.

\section{Luxembourg}

In Luxembourg, the introduction of the safe country of origin notion in 2006 went hand in hand with a considerable number of law changes related to asylum issues. The Bill amending the Law on the Right of Asylum and to Complementary Protection of 3 April 1996 introduced additional protection statuses, changed the rule on detention in the country and changed the rules and grounds for accelerated procedures. The safe country of origin notion was part of the latter. For its introduction both domestic and European grounds mattered.

One the one hand, there was a clear preference to shorten the asylum procedure. In fact, the law changes intended in 2006 were already predated by several other attempts however, without success (PoL 2005, Mosar, p.161). Thus, the bill presented in 2005 was a further attempt to speed up the asylum procedure: 'we are convinced that the document will achieve its main target - namely to reduce the length of the asylum procedure' (PoL 2005, Mosar, p.162). ${ }^{85}$ By doing so, the Luxembourgish parliament aimed at deterring asylum seekers who abuse the system. The Foreign Minister Schmit stressed during debate in parliament that 'we have to react with a certain rigour to those who, for whatever reason, exploit or even abuse the right to asylum'(PoL 2005, Schmit, p.166; see also PoL 2005, Mosar, 161). ${ }^{86}$

Rather than adopting a national list, the Luxembourgish authorities were very much in favour of a common, European list of safe countries of origin: ' $t$ ] ${ }^{2}$ he Luxembourgish government does not want to put together such a list on its own (PoL 2006, Fayot, p.348). ${ }^{87}$ This was also confirmed by interviewees: '[a]s Luxembourg, we try to think very European and we anxiously waited for a European list to be adopted; that is also what we plead for in Brussels (interview 13). ${ }^{88}$ There was not only a very clear plea for a European rather than a national list amongst interviewees in the Luxembourgish ministry but also amongst members of parliament (interview 14; interview 16).

Only after it was clear that there would be no common European list, the Luxembourgish government, in 2007, decided to adopt a national list of safe countries of origin (interview 13; interview 16). And for that own, national list, the Luxembourgish prefer-

\footnotetext{
${ }^{85}$ Quote in original language: Mir sinn iwwerzeegt, datt dësen Text säin Haaptobjektiv wäert erreechen, nämlech d'Reduktioun vun der Dauer vun der Asylprozedur.

${ }^{86}$ Quote in original language: Si mussen awer gläichzäiteg mat enger gewëssener Fermetéit op déi reagéieren, déi aus welleche Grënn och ëmmer, d'Recht op Asyl wëllen hannergoen oder souguer mëssbrauchen.

${ }^{87}$ Quote in original language: D’Lëtzebuerger Regierung wëllt keng esou eng Lëscht eleng opstellen.

${ }^{88}$ Quote in original language: Als Luxemburg versuchen wir sehr europäisch zu denken und haben sehnlichst darauf gehofft, dass es zu einer europïschen Liste kommen würde; haben auch immer in Brüssel dafür plädiert.
} 
ences were very close to those of Germany and the UK. Again, the ratio between number of asylum seekers from a certain country of origin and acceptance rates played a crucial role: ' $\mathrm{w}] \mathrm{e}$ also know that according to the statistics that we got from the ministry 95\% of the applications for asylum are seen as not founded' (PoL 2005, Henckes, p.160) ${ }^{89}$ One of the persons involved in setting up the list said himself that it must be a list utile - a useful list. Useful means that the authorities must receive applications from the countries designated as safe (interview 13; interview 16), and these applications must also reach a certain number. When asked about adding the United States to the list, one interviewee replied: 'we now had one US-American; but because of a single one, you are not going to designate a country as safe' (interview 13). ${ }^{90}$ The first list adopted in 2007 included Albania, Benin ${ }^{11}$, Bosnia and Herzegovina, Cape Verde, Croatia, Ghana ${ }^{92}$, Macedonia, Mali ${ }^{93}$, Montenegro and Senegal. In 2011, Serbia was added. The latest designation concerned Kosovo in 2013. Table 6.5 shows the number of asylum seekers for all countries added to the list in 2007 as well as Serbia and Kosovo. The year of reference is 2011 .

Table 6.5: Number of asylum seekers from countries designated as safe in Luxembourg, as of 2011 (source: Eurostat)

\begin{tabular}{lcc}
\hline Country of origin & Applications in 2011 & \% in relation to all 2011 requests \\
\hline Serbia & 950 & $44,08 \%$ \\
FYROM Macedonia & 450 & $20,88 \%$ \\
Kosovo & 140 & $6,50 \%$ \\
Montenegro & 105 & $4,87 \%$ \\
Bosnia and Herzegovina & 50 & $2,32 \%$ \\
Albania & 30 & $1,39 \%$ \\
Croatia & 0 & $0 \%$ \\
Benin & 0 & $0 \%$ \\
Cape Verde & 0 & $0 \%$ \\
Ghana & 0 & $0 \%$ \\
Mali & 0 & $0 \%$ \\
Senegal & 0 & $0 \%$ \\
Others & 430 & $19,95 \%$ \\
Total & 2155 & $100 \%$ \\
\hline
\end{tabular}

\footnotetext{
${ }^{89}$ Quote in original language: Mir wëssen och, datt bei den Demandes d'asile iwwer 95\% no de Statistiken, déi mir vum Ministère kritt hunn, als net fondéiert ugesi ginn.

${ }^{90}$ Quote in original language: Wir hatten jetzt einen Amerikaner, aber wegen Einem setzt man ein Land nicht auf die Liste.

${ }^{91}$ Only male asylum seekers

${ }^{92}$ Only male asylum seekers

${ }^{93}$ Only male asylum seekers
} 
The table shows that Serbian asylum seekers made up almost half of all people claiming asylum in Luxembourg in 2011. Thus, the designation is clearly linked to the large number of applications from this country. This was also confirmed by policy-makers: 'Now that asylum seekers from Serbia are increasing a lot, we said, ok, now it is the right moment to put Serbia on the list' (interview 13). ${ }^{94}$ The fast processing of applicants from Serbia, Macedonia and other so-called safe countries was only one of several steps taken by the Luxembourgish authorities to deal with the large influx of asylum seekers. Another one was the government actively seeking cooperation with the Serbian authorities in order to avoid people leaving their country of origin in the first place (EMN Luxembourg 2012, p.117).

The number of asylum seekers coming to Luxembourg increased to such an extent, that the national asylum office had to close for several days in October 2011 (Luxemburger Wort 2011). Also Luxembourg had a very clear preference with introducing safe country of origin policies - namely to process some applications faster than others, and consequently deter asylum seekers from these countries. Rather than adopting an own, national list, the government would have preferred a common EU-wide list of safe countries of origin. Only after it was clear that such a list would not be adopted, they went for a national solution.

However, table 6.5 also shows that some countries (added in 2007) still produced very high numbers of asylum seekers in 2011 (such as Macedonia). It seems as if the measure of designating countries of origin as safe proved only of limited success. Also, there are some countries designated as safe from where no people sought protection in Luxembourg, including Benin, Cape Verde, Ghana, Mali, and Senegal. ${ }^{95}$ For now, it remains unclear why these countries were added to the list.

\section{Malta}

Identifying preferences in the case of Malta is more difficult. Whereas Germany and the UK clearly aimed at reducing the number of asylum seekers from certain countries of origin, this motivation can be excluded on parts of Maltese policy-makers. To quickly recall: the Maltese safe country of origin provision was introduced in 2000. In 2004, the following countries were designated as safe: Benin, Botswana, Brazil, Cape Verde, Chile, Costa Rica, Gabon, Ghana, India, Jamaica, Senegal, Uruguay and the United States. During a very short debate in parliament in 2004, the Minister of Interior, Tonio Borg, stressed that the policy had been adopted to avoid the abuse of the Maltese asylum system: 'I am not saying that those people [coming from safe countries of origin] may not apply, but their case will be handled much faster by the Refugee Commission in order to avoid an abuse of the system' (Parliament of Malta (PoM) 2004b, Borg, p.403). Let us

\footnotetext{
${ }^{94}$ Quote in original language: ... jetzt wo die serbischen Asylbewerber steil bergauf gingen, haben wir gesagt, ok, jetzt ist einfach der Moment, Serbien auf diese Liste draufzusetzen.

${ }^{95}$ Due to a lack of data, it is not possible to look at the respective application numbers of 2007. Thus, there might have been some applications from these countries of origin in 2007, however, most-likely just very few.
} 
have a look at the number of asylum seekers coming to Malta from the countries designated as safe (table 6.6).

Table 6.6: Number of asylum seekers in 2003 and 2004 for countries included in the Maltese safe country of origin list (source: Eurostat)

\begin{tabular}{lcc}
\hline Country of origin & Application rate 2003 & Application rate 2004 \\
\hline Benin & 0 & 0 \\
Botswana & 0 & 0 \\
Brazil & 0 & 0 \\
Cape Verde & 0 & 0 \\
Chile & 0 & 0 \\
Costa Rica & 0 & 0 \\
Gabon & 0 & 0 \\
Ghana & 0 & 10 \\
India & 0 & 0 \\
Jamaica & 0 & 0 \\
Senegal & 0 & 0 \\
Uruguay & 0 & 0 \\
US & 0 & \\
\hline & & 0 \\
\hline
\end{tabular}

Table 6.6 shows that only from one country on the list (India) Malta had received any asylum applications in the years 2003 and 2004 (10 applications in 2004, Eurostat). No applicants were recorded for the remaining 13 countries on the SCO list in either 2003 or 2004. Thus, Malta has not introduced the list to deter asylum seekers from certain countries of origin. Combatting 'abuse' of the system is clearly hypothetical.

Rather than domestic reasons, it is far more likely that European grounds were the driving force when adopting the safe country of origin list. The SCO list almost completely mirrors the EU-wide common list of safe countries of origin, as proposed in the Council of Ministers in 2004 (see chapters 2 and 7). Maltese authorities saw the need to adopt a safe country of origin policy and list when transposing the Asylum Procedures Directive into national law. Having had no experience whatsoever with asylum legislation, it was easy for Maltese policy-makers to adopt a ready-made solution provided by the EU. They did not want to do anything wrong with the first list to be created. Consequently, the list had to be a 'very, very basic list [...] a very safe list, so to speak' (interview 26), which was stressed over and over again by the respective policy-maker. Similar wording was used when the list was debated in parliament (PoM 2004c, p.17). The fact that both the list never had any practical relevance and that there had never been any 
considerations to amend the list (interview 26), is another indication for the Maltese authorities not using the list in a way done by the British, German or Luxembourgish policy-makers (namely to deter asylum seekers).

In sum, the section showed that policy-makers in three of the four countries Germany, the UK and Luxembourg - had rather clear preferences when introducing safe country of origin policies. The next section discusses whether policy-makers were constrained by domestic factors in achieving these preferences. If so, one would expect policy-makers circumventing domestic constraints by using the transnational level to achieve their preferences (two-level game).

\subsection{Domestic constraints}

The logic of consequences presumes that preferences are formed exogenously to institutions and at the domestic level (Moravscik 1993; March and Olsen 1989). The European level is then used to justify policy changes that could previously not been achieved at the domestic level (Putnam 1988). Following up on the idea of two-level games, domestic constraints limit the options of policy-makers in achieving their preferences. These constraints can take different forms. There is the possibility of a strong political opposition involving battles within or between political parties. However, domestic constraints can also relate to other actors such as courts, a strong civil society, the media or public pressure. In any case, a logic of consequences requires a close look at the domestic level, the way preferences are formed and the constraints faced by policy-makers in order to achieve these preferences (Moravscik 1993; Putnam 1988). What follows is a discussion of domestic constraints faced by policy-makers in the run-up to adopting and/or amending safe country of origin policies.

It will be concluded that both the UK and Germany were confronted with domestic constraints which made them play a two-level game. In the case of Germany, the executive was primarily constrained by a legislative not being willing to agree to the proposed changes in asylum law. In the case of the UK, courts played a strong role, and thus a potential constraint on the government aiming to adopt safe country of origin policies. In both Malta and Luxembourg, policy-makers were not constrained in their ability to adopt and/or amend safe country of origin policies.

\subsubsection{Relation between executive and legislative}

Naturally policy-making is very much determined by the relationship between the executive and the legislative. This section looks at this relationship in more detail. Based on the two- level game logic, one would assume that an executive being confronted with a constraining legislative turns to transnational asylum policy coordination in order to achieve preferences otherwise unachievable. As will be shown in this section, Germany 
is the only country (from the four countries studied) where executive policy-making was confronted with a strong legislative. This constraint was so strong, that it prevented the authorities from using the safe country provision at all. In neither the UK nor Malta nor Luxembourg provided the legislative a serious constraint on the executive.

\section{Germany}

In Germany, the biggest opposition party, the Social Democrats (SPD), had initially blocked the introduction of a safe country of origin policy. So we indeed see a legislative constraining the executive and thus, at least initially, providing a strong constraint to the governing Christian Democrats (CDU/CSU). ${ }^{96}$ Already by 1992, the German asylum law had a long history of changes. Between 1978 and 1992, not less than ten changes were adopted - all relating to the acceleration of the asylum procedure (Bundestag 1993c, p.13637). However, the biggest change took place in 1992/1993 because it aimed at changing the Basic Law as such. In order to do so, a two third majority in the Bundestag was required - meaning the Kohl government needed (parts of) the opposition for the bill to pass.

However, the opposition parties were highly divided over the proposed changes of the Basic Law. In fact, members of all opposition parties initially opposed the bill, including the Party of Democratic Socialism (Bundestag 1993c, Gysi, p.13517), the Greens (ibid., Poppe, p.13547) and the Social Democrats (ibid., Stiegler, p.13607). The Social Democrats are of particular relevance here because they were, by then, the biggest opposition party. Also their position was (amongst all opposition parties) the closest to the government, and their parliamentarians eventually provided the governing CDU/CSU/FDP with the two third majority necessary for passing the bill. Already during early discussions of the bill, Social Democrats were accused of having been bamboozled by the governing parties. A letter of a Green party member of the North RhineWestphalian Landtag stated:

I am not a Social Democrat. But if I would be one, I would be terrified in light of the self-demolition of my party as the biggest opposition in parliament and as a reformative force for which human rights and citizens' rights are not respected (Kreutz 1992)..$^{97}$

And indeed, several Social Democrat MPs stressed during the debate in parliament, how difficult it was for them to vote for the bill (Bundestag 1993c, Duve, p.13586; ibid., Lederer, p.13624; see also interview 42). Eventually, their main argument for supporting the bill was its necessity to secure political and social stability in Germany (Bundestag 1993c, Kolbow, Kastner, Wohlleben, p.13684, Lederer, p.13624). The Social Democrats

\footnotetext{
${ }^{96}$ Governing together with the Liberals (FDP)

${ }^{97}$ Quote in original language: Ich bin kein Sozialdemokrat. Aber wenn ich einer wäre, käme mir angesichts einer solchen Selbstdemontage meiner Partei als größter Oppositionspartei im Bund und als reformpolitische Kraft, für die Menschen-und Bürgerrrechte nicht zur tagespolitischen Disposition stehen, das Grausen.
} 
did not want to be perceived by the public as the party impeding the solution to a pressing problem, namely the large number of asylum seekers (interview 42). Despite the cleavages in the party, eventually there were enough party members supporting the bill, and allowing both the change of the Basic Law (1992) as well as the actual safe country of origin list to be adopted (1993).

Political opposition continued to play an important role in the further history of safe country of origin policy-making. In 1996, the SPD unsuccessfully petitioned the deletion of Ghana from the SCO list arguing that the initial information on which such an assessment had been based was insufficient (Bundestag 1996). However, the Ministry of Interior disagreed (ibid.). In fact, the legislative procedure necessary for adding countries to the list - it would always require the consent of the majority of Bundestag members $^{98}$ - was the main reason why the list was never updated, and consequently exists until today without having been used beyond 1996 (interview 36, interview 40, interview 42). ${ }^{99}$ The high majority threshold for the list to be amended was a very strong institutional constraint.

$U K$

In the UK, a safe country of origin designation takes the form of a Statutory Instrument, which is Home Office secondary legislation. For the case of SCO designations, parliamentary control over such an instrument is exercised via affirmative approval by both houses. In general, it hardly happens that such an approval is not given. As one Lord stressed:

'It is of course a longstanding convention of the House [of Lords] that although it has the power to reject orders moved by the Government, it does so only in wholly exceptional circumstances. The circumstances of this case fall below, but only just below, that level' (HoL 2003b, c. 1216).

The quote illustrates that there were some heated discussions on SCO designations in the parliament, in this case related to adding, in 2003, Bangladesh, Bolivia, Brazil, Ecuador, Sri Lanka, South Africa and Ukraine to the list. However, in practice, both the houses approved all intended SCO designations each time the list was changed.

Also in the UK, parliamentarians saw heated discussions when the SCO notion was first introduced in 1996. Compared to the cleavages in the German Bundestag, however, the British discussions were less salient. They only mirrored the expected division between Liberal Democratic party members on the one side (being opposed to the safe country of origin notion and the extension of the list) and Conservative and Labour party members on the other (some slightly opposed, most in favour). Criticism on part of the opposition related to both the substance of the law (i.e. the introduction of the

\footnotetext{
${ }^{98}$ In addition, it would also need a majority in the Federal Council (Bundesrat).

${ }^{99}$ In 2014, Serbia, Macedonia and Bosnia-Herzegovina were added to the list. However, see section 4.2.1 about the time frame of this thesis (1990-2013).
} 
SCO provision and the inclusion of certain countries in the list: HoC 1996a and HoC 1996b; for criticism on countries proposed for designation see also HoL 1996, HoC 2003) as well as the process (i.e. inadequate country reports on which the SCO designation is based; HoC 1996b, c. 712, HoL 1996, c. 1727).

The absence of a strong political opposition also becomes obvious when looking at the changes in government. After the introduction of the Asylum and Immigration Act in 1996, the government changed in 1997 from Conservative under Major to Labour under Blair. This change, however, had hardly any effect on the country's asylum policy (Bloch 2000, p.37). The Major-government had introduced the safe country of origin notion and first, Labour and Liberals opposed the notion as such. The by then Labour parliamentarian Straw even stressed that once Labour would come into government, they would not operate the list anymore (HoC 1996b, c. 198, c. 713). Straw himself served as the Home Secretary from 1997 to 2001 (also operating the SCO list during that time). With the adoption of the Nationality, Immigration and Asylum Act in 2002 (also under Labour), the implications of SCO designation changed. ${ }^{100}$ However, the overall idea and practice remained the same. This development is in line with a general observation that the two main political parties have responded to asylum issues in similar manners (see also Bloch 2000). Later changes to the SCO lists were also accompanied by opposition in the parliament. ${ }^{101}$ However, as noted before, these concerns did not go beyond the expected pro/con-debate, and is thus not comparable to the strong political opposition/constraints faced by the German government.

\section{Luxembourg}

In Luxembourg, the SCO notion was introduced in 2006. Changes to the list were made in 2007 and 2010. All measures were adopted by the governing Christian Social People's Party (in coalition with the Socialist Workers' Party). The designation of countries of origin as safe is done via an execution document (a so-called Grand-Ducal regulation) and thus without consultation of the parliament. Here we already see a major difference to both the German and the British case. In the German case, the strong role of the parliament even hindered the executive to use the SCO provision. In Luxembourg, there was no role for the parliament - at least not when it comes to designating countries of origin as safe. There is also no disagreement over the parliament not being involved in such designations. As MPs stressed themselves, given the size of the country and the

\footnotetext{
${ }^{100}$ Whereas under the Asylum and Immigration Act, his application was dealt with in a fast-track procedure (including 10 days for appeal), the 2002 NIA led to an unfounded claim with no possibility for an appeal within the UK.

${ }^{101}$ Some examples include: 2002 Nationality, Immigration and Asylum Bill: concerns/discussions of the Joint Committee on Human Rights regarding the SCO designation of ten accession states and aspirant new member states to the EU (Joint Committee on Human Rights 2002); 2007 Draft Asylum (Designated States) Order: concerns/discussions in the House of Lords regarding the 2007 inclusion of Mali (in respect of men), Mauritius, Montenegro, Peru, Serbia, and Sierra Leone (in respect of men) in the SCO list (HoL 2007)
} 
respective (huge) size of portfolios for individual MPs, this just seems to be a logical division of labour between executive and legislative (interview 14). Thus, any constraint on part of the legislative could only relate to the introduction of the SCO notion. However, also in the respective debate in the parliament, there was no disagreement about introducing the safe country of origin notion (PoL 2005). In sum, the Luxembourgish government was not constrained by the legislative in its safe country of origin policymaking.

\section{Malta}

Also the situation in Malta is representative for countries in which policy-makers face no domestic constraints in the form of political opposition. This lack of opposition is explained by a shared anti-refugee attitude across the major political groupings:

Irregular immigration and policies to meet the challenges posed by it are reported to be issues on which political parties in Malta hold substantially identical views. All political forces are also reported to use essentially similar arguments and general rhetoric concerning these issues (ECRI 2007, p.23; see also interview 32).

Consequently, there is simply 'no political will to change it [the current asylum law]' (interview 32). This lack of political will concerns the two main parties (Labour and Nationalist) but relates also to the small ones (Lutterbeck 2009, p.137) ${ }^{102}$ From 1998 to 2013, the Maltese people were governed by the Nationalist party. Consequently, also the introduction of the SCO notion and the designation of countries as safe fell under their responsibility. Opposition to the asylum law was not to be expected. If there was opposition, the opposing forces (mainly the Maltese Labour Party) were not in favour of more human rights-friendly regulations, but lobbied for even stricter asylum rules (interview 27)..$^{103}$

In sum, only in Germany did the legislative provide a constraint on the government during SCO policy-making. There were not only less cleavages between parties in the UK, Malta and Luxembourg on the safe country of origin matter, but also the law foresaw hardly any (UK) or no role (Malta, Luxembourg) for the legislative in the policymaking process.

\footnotetext{
102 The Labour Party and the Nationalist Party share also all the seats in the Maltese House of Representatives amongst themselves. Since 1966, no third party has been successful in gaining access to the Maltese parliament (Hirczy 1995, p.258).

${ }^{103}$ The last Minister of Justice and Home Affairs, Carm Mifsud Bonnici, stumbled over criticism that his policy was not strict enough. After being minister since 2008, he lost a vote of confidence in 2012 (Times of Malta 2012b).
} 


\subsubsection{Role of national courts}

Next to a strong legislative, there are other institutions potentially constraining national policy-makers. In this section, I am looking at the role of national courts. Assuming a two-level game logic, policy-makers facing strong domestic courts might turn to policy coordination with other countries in order to achieve goals otherwise unachievable. This section shows that national courts are a significant concern for British policy-makers. In fact, taking into account possible legal actions and argumentations by the court is a key factor determining whether or not a country of origin is declared as safe. Neither in Germany nor in Malta nor in Luxembourg did domestic courts provide a constraint on policy-makers - however, for varying reasons.

\section{Germany}

In Germany, the introduction of the safe country of origin principle went hand in hand with changes to the Basic Law. Thus, the respective court to look at is the German Federal Constitutional Court. From its early days onwards, this court had issued some groundbreaking judgments and continues to play an important role in 'correcting' contested (asylum) policy decisions until today. ${ }^{104}$ After the SCO notion and list were adopted in 1992/1993, many had hoped that the Court would constraint (or even abolish) these. During debates in parliament, several MPs argued that these changes would not stand legal revision (see for example Bundestag 1993c, Schmude, p.13527, p.13657). Similar hopes were raised by high-ranking ministry officials (interview 39) and nongovernmental groups. However, reality proved opponents to the law wrong: in its decision of 14 May 1996 the Federal Constitutional Court confirmed that the 1992/1993 changes to the law on political asylum complied with the German Basic Law (Bundesverfassungsgericht 1996). ${ }^{105}$ All aspects of the safe country of origin notion were confirmed, including the criteria for designating a country as safe, the inclusion of Ghana in the list ${ }^{106}$, the legislative procedure leading to the list and the procedural consequences for an asylum seeker coming from a country declared as safe (for a discussion of the ruling see Frowein and Zimmermann 1996). Beyond this judgment, the SCO notion and respective list were never legally challenged. Thus, it can be concluded that in the German case, courts did not present a domestic constraint to the policy-maker. ${ }^{107}$

\footnotetext{
${ }^{104}$ See for example the 2012 decision on benefits paid to asylum seekers according to the Asylum Seekers Benefits Act (Bundesverfassungsgericht 2012).

${ }^{105}$ In the respective case, the safe country of origin notion was only one of the three issues under scrutiny next to the accelerated airport procedure and the safe third country notion which were also judged by the court as complying with the law.

${ }^{106}$ Though there was disagreement between the judges regarding Ghana's inclusion (see dissenting opinions of the judges Limbach, Böckenförde and Sommer: Bundesverfassungsgericht 1996, bullet point E.ff).

${ }^{107}$ However, there are other asylum-related issues where the German Constitutional Court indeed imposed obligations on the authorities, and thus provided a constraint to policy-makers (Hailbronner 1999, in Thielemann 2001, p.15).
} 
The UK

When considering the role of courts as a domestic constraint, the British case is very different from the German one. In the UK, there were comparatively many court cases related to the safe country of origin provision. British policy-makers were very aware of the constraining role of national courts. Interview partners confirmed that any considerations on including a country of origin on the SCO list would go hand in hand with a detailed check in the Home Office's legal department. For particular contentious cases (countries) the legal test is even carried out at the government's Chief Legal Office. In one case, the decision whether or not the country fulfills the criteria to be declared as safe was even considered by the Attorney-General (interview 22). These considerations on part of the Home Office follow some ground-breaking rulings in the early 2000s. The most prominent case Javed 2001 relates to Pakistan (box 6.1).

Box 6.1: The Javed 2001 Case (cited as Court of Appeal 2001)

In Javed 2001, three Pakistani asylum applicants appealed against the decision to be returned to Pakistan after an expedited asylum procedure. According to the result of the asylum procedure, none of the applicants were entitled to asylum on the basis that none of them had a well-founded fear of persecution. This judgment was based on Pakistan's inclusion in the British safe country of origin list in 1996 (Asylum (Designated Countries of Destination and Designated Safe Third Countries) Order 1996). The Court of Appeal had to decide on two issues: first, whether a judge was entitled to review a decision like the Asylum Order 1996 on which basis Pakistan was declared as a safe country of origin and the asylum seekers were returned to their home country; and second, on the actual evidence, namely the decision that Pakistan was a country fulfilling the legal requirements to be declared a safe country of origin. On the first question, the Court held that it may determine the validity and review the legality of subordinate legislation, such as the order under discussion (c. 51). On the second question, the Court held the position that 'there was certainly no justification for retaining Pakistan in the Order' (Court of Appeal 2001, c. 10) after similar decisions on the situation in Pakistan had been taken in the House of Lords. The Court further stressed that ' $\mathrm{t}$ ] here is no explanation as to how he [the Secretary of State] was able to conclude, on the material before him, that there was in general no serious risk of persecution in Pakistan. Had he applied the correct test to that evidence we do not consider that he could reasonably have reached the same conclusion' (c. 73). The Javed case was one of the most prominently discussed cases in the history of UK asylum law and had implications for about 6,000 Pakistanis who were awaiting deportation by the time of the judgment (BBC 2001). All their cases had to be reconsidered.

However, Pakistan is not the only country where the British authorities faced judicial opposition. Similar stories can be told about the designation of both Bangladesh and Sri Lanka as safe countries of origin. In the case of Sri Lanka, the country was first added to the list in 2003 (Asylum (Designated States) (No. 2) Order 2003), and removed in 2006 (Asylum (Designated States) (Amendment) (No. 2) Order 2006). Already at the time of inclusion, the Refugee Council stressed the major role played by courts in the case of Sri Lankan asylum seekers (HoC 2003, c. 011). In fact, the majority of them had been recognised as refugees (or in need of another protection status) by the appeal authorities only after being refused in first instance (ibid.). The 2006 decision by the Home Office to 
take Sri Lanka of the list coincided with a hearing of a judicial review brought by a Sri Lankan refugee, who had challenged its country's inclusion on the SCO list (Doughty Street Chambers 2006). Liam Byrne, the Minister of State in the Home Department, made it sound as if the country was taken off the list due to considerations in the Home Office:

If we believe that conditions in a country are deteriorating to such an extent that we are no longer in our own minds able to satisfy the legal test that is set out in the legislation, we will not hesitate to take the country off the list. That is precisely what we did in the case of Sri Lanka. There was a general view that conditions were deteriorating, particularly in the north of the country, and that is why in December 2006 we took it off the NSA list of designated countries (HoC 2007, c. 8). ${ }^{108}$

For the researcher, it is of course not possible to investigate whether this judgment on part of the Home Office came before or after the judicial review. In fact, both go hand in hand and cannot be clearly separated from each other. This is also illustrated by the third and final example of British courts constraining the actions of policy-makers.

Bangladesh was added to the British list in 2003 (Asylum (Designated States) (No. 2) Order 2003) and removed in 2005 (Asylum (Designated States) (Amendment) Order 2005). During debate in the House of Lords, it was stressed that the country had to be removed from the list 'after the accumulation of a weight of evidence of repression and physical attacks on religious, ethnic and secular minorities ...' (HoL 2005b, c. 1805). According to interview partners in the Home Office, the decision to remove the country from the list was taken for two reasons: first, the situation deteriorated in the country; and second, there was a legal challenge combined with the advice from Home Office lawyers that this court case would not end in the favour of the Home Office (interview 22). The expected case before the High Court was about to challenge Bangladesh's inclusion in the list (HoL 2005a, c. 506). Being asked why Bangladesh is not considered a safe country of origin in the UK nowadays (2012, at the time of the interview) as it is in several other EU member states, one interview partner replied that such a (re-)inclusion would possibly not stand legal revision (interview 21). She also stressed that only if the designation would stand court scrutiny, the country would be added to the list. Again, it can be seen that the courts and also the prospective of a court decision have strong constraining effects on safe country of origin policy-making in the UK. ${ }^{109}$

\footnotetext{
${ }^{108}$ In the UK, safe countries of origin are called NSA countries (countries with non-suspensive appeals). See section 4.2.2.

${ }^{109}$ For the sake of interest, also in France domestic courts issued several judgments on the legacy of safe country of origin designations. The latest one dates from 4 March 2013. It confirms the designation of Armenia, Moldova and Montenegro as safe countries of origin; and negates the designation of Bangladesh as safe (Conseil d'Etat 2013).
} 


\section{Luxembourg}

In Luxembourg, national courts do not pose a constraint on policy-makers, at least not in the field of safe country of origin policies. The rejection of protection status in individual cases is not based on safe country of origin reasoning (interview 12). In addition, the designation of certain countries as safe was never appealed against. But similar to Malta, courts might not (yet) play a role in safe country of origin matters, but they increasingly do in asylum in general. The most far-reaching example (that is also related to safe country of origin policies) was the decision of the European Court of Justice on the lack of possibility to appeal against being placed in the accelerated procedure (ECJ 2011). The Luxembourgish law did not foresee such a possibility and while awaiting the decision of the ECJ, there were no claims processed in the accelerated procedure for almost 1.5 years (2009-2010).

What is however interesting to note in that context is that policy-makers are very well aware of the potentially constraining role of domestic courts - also in the context of safe country of origin policies. In fact, the preference for a common European list over a national one was explained with increased legitimacy before courts:

It has more weight if you can base the decision on something European rather than something national [...] it has more weight to quote Germany than to quote Lithuania - I mean when I quote this in a court (interview 16). ${ }^{110}$

It is easier to defend in court if you can say that it is supported by all countries rather than just invented in our own ministry (interview 13). ${ }^{111}$

This explanation seems surprising given that the courts in Luxembourg have - so far not provided a constraining role on policy-makers regarding safe country of origin matters.

Malta

For Maltese policy-makers, domestic courts did not constrain policy-making in any regard. ${ }^{112}$ To illustrate this, let us have a closer look at the regular appeals procedure. There are hardly any refugee status determination decisions that are overturned by the Refugee Appeals Board. In fact, between 2004 and 2008 only six decisions were overturned in total (EMN 2009, p.19). There are several explanations for this ranging from

\footnotetext{
${ }^{110}$ Quote in original language: Es hat mehr Gewicht, sich auf was Europäisches berufen zu können als auf was Nationales [...] es hat mehr Gewicht, wenn Deutschland mir eine Antwort gibt als wenn Litauen mir eine Antwort gibt - also wenn ich das irgendwo zitiere vor Gericht.

${ }^{111}$ Quote in original language: Es ist ja einfacher, leichter zu verteidigen vor den Gerichten, wenn man sagt das wird von allen Ländern getragen, nicht nur bei uns aus interner Küche ausgearbeitet.

${ }^{112}$ One explanation for the weak role of courts is the smallness of the country. Veenendaal (2013) argues that small countries (micro-states) have very strong governments vis-à-vis other institutions. Thus, institutions that are supposed to function as checks and balances to the power of the executive are weak or controlled by the government (p.221).
} 
the very good quality of decisions at first instance (interview 28) to the lack of knowledge on part of the Appeals Board (interview 27; interview 32). There are also no cases where the designation of a certain country of origin might have been contested (as it happened so many times in the British example) - which is somehow logical because the SCO notion plays hardly any role in the Maltese asylum practice (see section 4.2.2).

For now, courts do not fulfill any constraining role on parts of the asylum policymaker. However, they might do so in the future - as some promising judgments show: Lacking any other possibilities of influence, Maltese NGOs increasingly aim for strategic litigation (interview 27; interview 32). This relates not (yet) to safe country of origin policies but to asylum matters in general. For example, in July 2013 and on initiative of Maltese NGOs, the European Court of Human Rights handed the Maltese government an interim order blocking the return of 45 Somali migrants from Malta to Libya (Dalli 2013). A related judgment was issued by the Maltese Constitutional Court of Appeal confirming that the forced return of two Somali nationals in Libya in 2004 had violated their human rights (Times of Malta 2013).

\subsubsection{Role of civil society}

A further potential constraint to the policy-maker is civil society. Whereas the relation between legislative and executive is formally written in law and becomes obvious during parliamentary debates, the role of courts manifests itself in the judgments issued. The role of civil society in the policy-making process is much more intangible. The subsequent analysis shows that there was a strong role for civil society in the British and German case, which means NGOs were heard and listened to in the process of initiating and changing safe country of origin policies. It is, however, difficult to judge whether the involvement of NGOs indeed means that they have had a constraining role on policy-makers. In any case, there is a clear difference between countries where civil society has the possibility to influence safe country of origin policy-making (Germany, UK), and those where respective organisations had no possibility to do so (Malta, Luxembourg). In all four countries, the role of NGOs is of course related to the role of courts. In fact, most of the cases mentioned in the previous section were brought before courts by civil society organisations.

\section{Germany}

In Germany, there was a formal possibility for civil society to influence the policymaking process leading to the safe country of origin notion and the designation of countries as safe - namely during the expert hearings in the Bundestag. Many individual experts and NGOs were invited to express their opinion on the draft law. Their criticism related to various aspects, including the questionable competence of the legislator to designate countries as safe (Bundestag 1993b, p.54), the effectiveness of such a list in terms of cutting numbers of asylum seekers (ibid., Mohr, p.238), the expected accelera- 
tion of asylum procedures (Steinberg 1993, p.387), the disagreement between parliamentary parties on the countries proposed to be designated as safe (Bundestag 1993b; Mohr, p.238) as well as the actual countries proposed to be designated as safe (Heinhold 1993, p.407). However, there were also experts supporting the introduction and possible effectiveness of the SCO provision (Hailbronner 1993b, p.302) as well as the competence of the legislator in creating the SCO list (Preuß 1993, p.214).

On parts of civil society organisations, there was overwhelming criticism of the policy as such as well as of the intended designation of Ghana and Senegal as safe (see for example ver.di, amnesty international, both in Bundestag 1993b, p.2, p.5, pp.7-10; Amnesty International 1993). Several religious groupings, such as the Evangelical Church in Germany were not generally opposed to the idea of safe countries of origin but stressed that designations must adhere to strict criteria (Rat der Evangelischen Kirche in Deutschland, in Bundestag 1993b). Outside of the formal consultation processes, there was little possibility to influence policy-making. This primarily relates to many negotiations having taken place behind closed doors, and to many documents having been classified and thus not available (interview 42). ${ }^{113}$ Negotiations in parliament were accompanied by heavy public protests. The proportions of these demonstrations were surprising for everyone and led to a debate in parliament whether the Bannmeilengesetz prohibiting demonstrations in a certain area of government buildings, should be suspended (Bundestag 1993c).

\section{The UK}

Also in the case of the United Kingdom, civil society raised its voices during SCO policy-making. During debates in parliament, both Houses referred to criticism by several NGOs, including Amnesty International, the Law Society, the Refugee Council, the Immigration Law Practitioners Association and the Immigration Advisory Service (HoL 2003a, c.1123; HoL 2003b, c.1204, HoC 2005b, c. 9). Most of this criticism related to the designation of specific countries of origin as safe. The same applies to UNHCR (see for example HoC 2005a, c. 10). Also outside of the formal decision-making process, British asylum policy-making is under constant scrutiny of NGOs, and law changes related to safe country of origin policies are criticised by, amongst others, Statewatch (2003) and UNHCR (2010a and 2010b). However, does involvement of civil society in the policymaking process necessarily assume their constraining role on the policy-maker? No, I can only state the fact that they have been involved - and of course that they play an important role in bringing cases to the courts (section 6.3.2).

In the UK, there is one further civil society organisation that has the potential of indeed constraining policy-makers when designating countries of origin as safe: the Inde-

\footnotetext{
${ }^{113}$ In fact, the non-availability of documents (primarily related to the situations in countries proposed to be included in the SCO list) has also been a problem to the researcher - almost 20 years after decisions were taken (see also section 4.3 on data collection).
} 
pendent Advisory Group on Country Information (IAGCI). The Group is introduced in box 6.2.

Box 6.2: The Independent Advisory Group on Country Information

The Independent Advisory Group on Country Information (IAGCI) was established as part of the Nationality, Immigration and Asylum Act in 2002. Until 2009 it was called the Independent Advisory Panel on Country Information. The Group consists of civil society representatives. ${ }^{114}$ IAGCI is mandated to monitor the accuracy of country of origin information. By doing so, it makes recommendations on COI reports produced by the Home Office. The Group is explicitly not mandated to judge the inclusion or exclusion of a country of origin on the SCO list (HoL 2005a, c. 504) but only to check the accurate, balanced and comprehensive representation of the source material and country conditions. Desmond Browne, Minister for Citizenship and Immigration in 2004-2005, stressed that ' $t$ t $]$ he panel's role in connection with non-suspensive appeals [=safe country of origin cases] is not to comment on the proposal to designate a particular country, which is the responsibility of the Government and of Parliament, but to examine our country material and to provide advice on its accuracy and objectivity' (HoC 2005a, c. 7; interview 23). Though the Group is not mandated to assess whether a SCO designation is justified, the borders are not that clear. For example, it can stress that a policy does not work for cost reasons (interview 23). The IAGCI is a unique body in Europe because none of the other European countries has an independent body checking on country of origin information.

However, the question remains whether IAGCI indeed provides a constraint on British policy-makers when it comes to the designation of safe countries of origin. At least the initial idea was very much a constraining one. In fact, the establishment of the Group in 2002 was a compromise solution - the creation of an additional safeguard - after discussions on the NIA Act were stuck. According to a House of Lords debate, the Bill nearly failed and was, eventually, only passed because there was the promise to establish an independent body reviewing country of origin information (HoL 2003b, c. 1204). The Home Office minister had informally, agreed upon to always consult the Panel before designating a country of origin as safe (interview 22). As insiders stress, this commitment on parts of the minister was crucial for securing agreement in both houses on the safe country of origin designations (interview 21). In fact, also British media had frequently criticised the poor quality of country of origin information as produced by the Home Office (Prasad 2002). The establishment of the Group was thus one of many measures to rebuild public confidence in British asylum policy (interview 18).

Though the Group was initially established with the aim to constrain the work of the Home Office, it can be doubted whether it actually does so. Preliminary evidence points at policy-makers perceiving the Group as enabling rather than constraining their

\footnotetext{
${ }^{114}$ As of January 2014, its members include Laura Hammond (School of Oriental \& African Studies), Andrew Jordan (First Tier Tribunal), Blanche Tax (UNHCR Geneva), Elena Fiddian-Qasmiyeh, Patricia Daley (both University of Oxford), Harriet Short (Immigration Law Practitioners Association), Michael Collyer, Ceri Oeppen (both University of Sussex) and Heaven Crawley (University of Swansea) (IAGCI 2013a). There are also UKBA representatives present in IAGCI's meetings; however, they don't have any voting rights.
} 
work. Debates on draft SCO lists in both houses show that the Group is frequently used to legitimise intended SCO designations. For example, after being criticised for proposing India to be added to the list in 2005, the Minister for Citizenship and Immigration stressed that 'the Independent Advisory Panel found that our country information on India was essentially sound' (HoC 2005a, c. 7). The same argument was used, for example, during the debates leading to the designation of Mongolia, Ghana and Nigeria as safe countries of origin (HoL 2005b, c. 1803). These observations suggest that the Group does not constraint but rather enable policy-makers. However, a throughout impact assessment of the Group's work on the policy-making process has not been conducted so far, and is also beyond the scope of this study.

\section{Luxembourg}

In Luxembourg, the policy-making process leading to the SCO notion and respective designations saw no involvement of NGOs. NGOs were taken by surprise and were not consulted in the process of designating countries of origin as safe. They were only informed of the list once it was agreed upon (interview 10; interview 12). One NGO representative described the process as follows:

They [the government] always told us we will not adopt a national list, we are waiting for a European list; so don't worry about that, there will be a European list; so we were very surprised when we heard that there was a draft of the Reglement Grand-Ducal with these countries; and since the adoption of such an execution text of the law is faster than the adoption of a law, there was not much time to lobby them; the only thing we could do was to write them letters [...] and also to go public [...] we were aware of the draft but we didn't really have the time to react constructively to this or even have meetings with the government or any representative of the refugee board (interview 12).

Here we also see that civil society did not provide a constraint to policy-makers, at least not regarding the designation of countries as safe. In general, NGOs do play a role in the domestic policy-making process. There are several NGOs focusing on advocacy work and they are consulted in the regular law-making process, including the possibility of submitting own opinions, meeting with the relevant decision-makers and engaging in discussions (interview 12). What is, however, different in the case of SCO policies is that the designation of countries does not follow the ordinary law-making process but it is a simple execution order by the government. In these cases, the possibility for advocacy work hardly exist: 'if we hear about it, it is either because the press talks about it or either because one of the public officers was friendly to the NGOs and would tell us about it; but we hardly have the possibility to have any input into this' (interview 12). Eventually, NGOs could only react to a list that had already been agreed upon (see for example Collectif Réfugiés Luxembourg 2007). 


\section{Malta}

Also in Malta, policy-makers are not constrained by civil society. This is due to the fact that there is hardly any possibility for NGOs to lobby for their concerns. This observation goes hand in hand with the absence of political opposition and the generally very strong role of the government vis-á-vis other institutions. ${ }^{115}$ The absence of political debate in parliament (see section 6.2.1) also means that there was no political forum for NGOs, let alone support from policy-makers (interview 27; ENAR Malta 2005).

In general, the role of NGOs in Malta is quite special. They are traditionally perceived as providing services to the people (or to asylum seekers in this regard). This charity approach is deeply rooted in the Maltese culture and not only policy-makers and citizens but also many NGOs see their role as such (interview 27; interview 32). In fact, there are only two NGOs on the island doing advocacy work and being openly critical of the government's asylum policy (Lutterbeck 2009, p.136): aditus and the Jesuit Refugee Service. The latter has, for example, commented on the introduction of the SCO notion as part of transposing European Directives into Maltese law (Jesuit Refugee Service n.d.). However, these efforts were by and large ignored by policy-makers (interview 27; interview 32). Also the public is not (openly) supportive of advocaty NGOs, quite the opposite: since 2006, a number of violent acts were committed against the Jesuit Refugee Service, the main NGO supporting immigrants in Malta (Lutterbeck 2009, p.142; ECRI 2007, p.23). In addition, there is no public pressure with regard to asylum issues. One interviewee described the situation as follows:

Being a tiny, tiny island, there is a lot of fear of not wanting to stick out too much; not wanting to be too visible and not wanting to be perceived as a problem-maker [...] it is a very tiny island, and we rely on each other for everything: funds, power, resources, anything; so if you are perceived as causing problems and being different and speaking out, you could have problems, yes (interview 27).

The link between the smallness of the country and political participation was also confirmed by the literature. In fact, Veenendaal (2013, p.181) argues that the closeness and direct contact between citizens creates patterns of particularism and dependency on the government. As a result of this, political participation does not occur due to public or programmatic considerations but due to individualistic ones.

In addition, the public opinion regarding asylum matters in Malta is determined by levels of racism and xenophobia (ECRI 2007; ENAR Malta 2005). A senior ministry official stressed that the pressure on him increases with every boat that reaches Malta's shores. He is pushed to ever stricter asylum rules (interview 34). The European Commission against Racism and Intolerance (2007, p.18) argues that these public attitudes are further fuelled by newspapers and tv programs that by and large have a pattern of 'negative portrayal of members of minority groups and sensational reporting' (p.18; see

115 The smallness of the country seems to be a determining factor here. Veenendaal (2013) observed similar patterns of government's strength in other microstates. 
also ENAR Malta 2005). Also, all political forces follow such a similar (anti-refugee) rhetoric (p.23; section 6.2.1 in this chapter).

In fact, there are only few instances of public outcry in Malta, when it comes to the human rights-aspect of asylum policy. None are related to SCO policies. However, there is a change in public perception, particularly related to the country's much contested detention policy. An instance of this is what happened after the death of an asylum seeker held in custody by the Maltese policy: in July 2012, demonstrations occurred after it became public that Mamadou Kamara, an asylum seeker from Mali, died in the custody of soldiers following his escape from detention (Cooke 2012). His death was portrayed as an incident of 'institutional racism' being widespread in Malta, and amongst police officers in particular (ibid). In the aftermath of the incident, 500 people demonstrated in the city of Valletta against the country's detention policy. Such gatherings might not be noteworthy in any other European country; however, in Malta, it was an extraordinary event. What was even more special was the reaction of Maltese Church representatives. Normally being silent about the government's approach towards immigration (interview 30; Falzon 2012; Calleya and Lutterbeck 2008, p.6), after the event of July 2012, the Bishops of Malta and Gozo called for a review of the country's detention policy (Times of Malta 2012a). This was a rare incident of public outcry and, in general, there is no evidence of civil society constraining the policy-making process. If at all, the public pushes for even stricter policies than intended by the government.

In sum, this section showed that the role of civil society was very different in the countries studied. Whereas in the case of Germany and the UK, NGOs were consulted and had the possibility to give input to intended changes of the SCO policies, the same opportunity was not given to NGOs in both Malta and Luxembourg. However, in the UK, Malta and Luxembourg NGOs are active in strategic litigation (section 6.2.2). In most cases, it was difficult if not impossible to judge whether civil society provides a constraint on policy-makers. At least policy-makers did not seem to perceive it in this way.

\subsection{Engagement in transnational asylum policy coordination for the purpose of acquiring information on other countries' policies}

Until now, I showed that policy-makers aim at introducing and amending safe country of origin policies for a number of reasons - with one being particularly prominent: limiting the number of asylum seekers from certain countries of origin. In order to achieve their preferences, policy-makers in the four countries face constraints of varying degrees: whereas, for example, in Germany, the legislative played an important role in whether or not safe country of origin policies could be put in practice; policy-makers in the UK were very much constrained in their action by national courts. In both coun- 
tries, Malta and Luxembourg, safe country of origin policy-making was not constrained by either the legislative or courts or civil society.

This section takes the main argument one step further. It is argued that safe country of origin policy-making is influenced by what policy-makers learn during transnational asylum policy coordination. Based on a logic of consequences, policy-makers engage in policy coordination with other countries in order to learn about their policies, and use this information to achieve pre-given preferences. Whereas this section focuses on the pure fact that policy-makers were informed about what is going on in other countries, the next section (6.5) shows then in how far this information was used. This section concludes that all four case countries were informed about similar policies in other states, though to varying degrees. Given their long history in asylum policy coordination and their prominent role in institutionalising these exchanges (chapter 5), Germany and the UK were well informed. The same accounts for Luxembourg. Maltese policy-makers had some information on similar policies adopted in other EU member states.

\section{Germany}

When discussing the introduction of the safe country of origin policy in 1992/1993, German policy-makers were very well informed about similar decision being taken in other European countries. One of the reasons is that Germany was very active in European asylum cooperation in the 1980s and early 1990s. By then, transnational policy coordination was limited to a few countries (chapter 5) but these were already regularly engaged in exchanging views on how to deal with the large number of asylum seekers. In fact, Germany not only participated in transnational policy coordination at that time, but was also one of the driving forces regarding the inclusion of asylum and immigration in the 'third pillar' of the 1992 Treaty of Maastricht (Green 2007, p.103). It also initiated specific debates - several of them leading to the adoption of the London Resolutions in 1992 (Council of the European Union 1992a and 1992b).

During the actual discussions in parliament in 1992/1993, it became clear how wellinformed policy-makers were about similar (safe country of origin) policies adopted in other countries. MPs and invited experts frequently related to other countries' experience with these policy measures, including the UK, Austria, Switzerland and Belgium (Koiser, amnesty international, both in Bundestag 1993b; Steinberg 1993, p.387). These countries were used to either support or criticise the intended law changes in Germany.

There has been no further debate on safe country of origin policies in the Bundestag since 1992/1993. Nevertheless, other indicators point at the German policy-maker being - also today - very well informed about (safe country of origin) policy changes in other European countries: Germany has always been among the most active countries regarding transnational asylum policy coordination (chapter 5). One institutionalised way of learning about asylum policies in other European countries is illustrated in box 6.3 - the practice of installing liaison officers in countries of strategic concern. 
Box 6.3: Strategic learning from other countries: the practice of the German Federal Office for Migration and Refugees

A key source for the German Ministry of Interior (in charge of asylum policy) is the Federal Office for Migration and Refugees (Bundesamt für Migration und Flüchtlinge, BAMF). Their unit on international cooperation is responsible for observing the situation in other countries as well as collecting information on law and policy changes. This is mainly done by employing liaison officers in the respective countries of interest. In 2012, the BAMF employed such officers in Poland, Greece, Hungary, the UK, France, Belgium, Italy and the Netherlands (interview 36). For example, after the French president elections in 2012, the respective liaison officer informed the BAMF and the Ministry of Interior of expected asylum policy changes in France (interview 37). Information about any country of interest is compiled in reports and sent to the Ministry or the BAMF. The requests are handled by this respective unit who either consults their liaison officers or other sources in the country of interest (ibid.).

The example of liaison personnel provides just one of many channels for German policy-makers to be informed about policy choices made in other countries. This information is then used to achieve own policy preferences.

\section{The UK}

Also the UK was involved in European asylum policy coordination since the early 1980s. Again, the London Resolutions are the most prominent example when it comes to the notion of safe country of origin. The UK played an active role in designing these, and was very proud of this role, as the British Minister of State for Home Affairs stressed: 'That very welcome and sensible resolution [the London Resolution] was adopted under the aegis of the previous United Kingdom presidency' (House of Lords 1996, p.164). The UK was also active within other informal gatherings at the EC/EU level, one of them being the informal Centre for Information, Discussion and Exchange on Asylum, CIREA. The very first meeting of CIREA was held under the presidency of the UK (Statewatch 1997, p.71). This informal clearing house presumably played an important role in pre-cooking asylum policy decisions to be taken at the domestic level (see section 5.4.3 for a more detailed discussion of CIREA). Just as Germany, the UK was actively involved in informal policy coordination in the G-6 (Green 2007, p.104). Being involved in these exchanges, British policy-makers were able to learn about policy changes in other European countries, and use it for their own purposes. In general, the UK's engagement in European cooperation has always been rather instrumental. Geddes (2005) stressed that 'Britain has thus become a little more European in its migration management policies in the hope that Europe will become a little more British in terms of convergent policy preferences' (p.734).

It thus also comes as no surprise that when the UK introduced the safe country of origin principle in 1996 (as part of the Asylum and Immigration Bill), comparable policies from other European countries were mentioned. Members in the British House of 
Commons made clear that the 1996 Asylum and Immigration Bill and accompanying documents were very much inspired by the London Resolutions and other countries' policy choices:

I am sure that much of the clause [on the SCO notion] has been driven by European consideration. It is striking how closely the clause corresponds to the minutes of the resolutions of Immigration Ministers even as far back as 1992 [reference to London Resolutions]. It is obvious that the government has taken from the practices of other European countries (HoC 1996a, c. 185).

The debate in the House of Commons also showed that both opponents and proponents of the 1996 Bill were well-informed about safe country of origin notions in other countries. For instance, the Liberal Alton (opposed to the bill) stressed the Danish example as one where an NGO (the Danish Refugee Council) has a right of veto over the designation of countries of origin as safe. He also mentioned the German example as one were parliamentary safeguards are respected before a country is included or excluded from the list (HoC 1996a, c. 72; see also c. 157). Other opponents to the bill related to the United States, which has rejected the idea of introducing a SCO list due to concerns of damaging international relations with several countries and due to the fact the SCO notion might be illegal under the UN legislation (HoC 1996a, c. 86; HoC 1996b, c.703; see also comments from the HoL 1996, c. 1733). These examples show that British policy-makers - when considering the inclusion of the SCO notion into law in 1996 - were well aware of similar policy choices being taken in other European countries.

What is interesting to note is that related debates in the subsequent years (post 1996) hardly ever refered to other countries' policies. Thus, from looking at the debate in parliament, it is not possible to observe whether policy-makers are informed about other countries' policy choices. This does not necessarily suggest that policy-makers were not aware of these developments. It rather points at them not needing other countries' policies to justify own, intended changes (see section 6.5). This is also supported by the finding that the UK has been much less involved in asylum policy coordination in recent years. Whereas the country had been a driving force of informal asylum policy coordination in the 1990s, it participated now to a much lesser extent (see also chapter 5). ${ }^{116}$ However, during interviews with the executive, it became obvious that policymakers are still well informed about what is going on in other European countries. Respective intake numbers and policy developments are closely monitored by the Home Office (interview 21). For doing so, Home Office officials rely on a number of tools including their own intelligence, bilateral relations, the European Migration Network and EASO (for the latter three see chapter 5). The primary aim of this monitoring is to acquire information on other countries' policies (interview 21).

\footnotetext{
116 This also explains why the UK was classified as 'moderately involved' in informal asylum policy coordination (see table 4.1).
} 


\section{Luxembourg}

Just as in Germany and in the UK, policy-makers in Luxembourg were very well informed about asylum policies in other European countries. This became, for example, obvious during debates in parliament. Though the debates in parliament were rather short (compared to the German or British case), and only related to the introduction of the SCO notion, MPs did refer to similar polies in other countries - such as Switzerland, the Netherlands, France or Belgium (for example PoL 2005, Schmit, p.166). Also interviewees in the respective ministry revealed a good knowledge and understanding of SCO policies in other European countries. This comes not as a surprise given that Luxembourg is a very active country in European asylum policy coordination (see chapter 5). To give a few examples: there is a close cooperation within the Benelux countries; Luxembourg strongly coordinates its policy with the German-speaking countries (in the framework of D-A-CH); and it is very active in the more formal exchange of asylumrelated information, such as within EASO.

The actual process of acquiring data on other countries' policies was described by an involved policy-maker as follows:

At first we were looking at the lists of other EU member states, meaning France, the UK ... I don't know anymore which ones we checked; and then of course we looked at all the databases that are available to us in order to check whether the countries can really be designated as safe countries of origin in terms of the [Asylum Procedures] Directive (interview 13). ${ }^{117}$

The result of this exercise was a list of European countries, including for example Denmark, Czech Republic, Germany, France and Austria, and their respective safe country of origin designations.

\section{Malta}

In Malta, official policy documents stress the country's active participation in regional fora, such as the meeting of the Ministers of the Interior of the Western Mediterranean Forum ( $4+5$ CIMO) and the cooperation process in the Western Mediterranean Forum (Dialogue 5+5). ${ }^{118}$ Both fora aim at promoting dialogue on issues of common concern, including irregular migration (Ministry for Justice and Home Affairs 2005, p.31). Since 2002, Malta is also part of the formal EU asylum cooperation structure, which means policy-makers have access to fora in which asylum policy in Europe is exchanged and coordinated. However, during interviews, the author was under the impression that

\footnotetext{
${ }^{117}$ Quote in original language: Wir haben uns zuerst mal die Liste der anderen EU-Staaten, sprich Frankreich, UK glaube ich; wei $\beta$ nicht mehr welche wir alle durchgecheckt haben; und dann haben wir natürlich auch alle uns verfügbaren Datenbanken überprüft, ob diese Länder wirklich als safe country of origin im Sinne der Richtlinie einzustufen sind.

${ }^{118} 4+5$ CIMO is an informal gathering of 9 Western Mediterranean countries including Malta, Italy, France, Spain, Portugal, Libya, Tunisia, Algeria and Morocco. Dialogue 5+5 includes above-mentioned countries plus Mauritania.
} 
policy-makers had very varying information about what is going on in other EU member states with regard to SCO policies: while some policy-makers were very well informed, others were not. This is not to judge this but it seems to be an indication of different policy-makers attaching varying degrees of importance to related policies in other EU member states.

The debate in parliament regarding the introduction of the SCO notion showed that MPs were aware of similar policies adopted in other member states. For example, they referred to the British and the French system (PoM 2004b, Borg, p.403; PoM 2004c, Borg, p.17). Also Australia, the United States, Canada, New Zealand and France were mentioned (PoM 2004c, Borg, pp.16-17). Several interviewees in the Maltese authorities stressed that other countries' policy choices inform own policy:

We always consider what is being done by other EU member states' [...] 'so basically we also use information we obtain from other EU member states, including the UK and other countries; so that is how the list was created (interview 26; see also interview 34).

Another indication for policy-makers having been aware of SCO policies in other EU member states is the very fact that the Maltese SCO list models both the proposed EUwide common list and the UK list. Also observers note that decision-makers are aware of what is going on in other EU countries: 'we are very young as a state and vis-à-vis asylum and refugees we are still learning the way things work; so it [the government] looks at other countries to see what works and what doesn't work' (interview 27).

In sum, this section illustrated that policy-makers in all four case countries were with varying degrees - informed about SCO policies in other (European) countries. They were informed because they engage in different forms of asylum policy coordination ranging from the simple looking beyond borders to a regular consultation with other countries (see also chapter 5). However, being informed about other countries' policy choices does not tell us anything about how this knowledge was used in the own, domestic decision-making process. This is discussed in the subsequent section.

\subsection{Justifying legitimacy of action}

The previous section showed that policy-makers intending to change their safe country of origin policy were informed about similar policies in other European countries. According to the two-level game, I expect to observe that policy-makers use the information obtained during transnational asylum policy coordination, to justify their own, intended policy changes. This section shows that, indeed, all four countries refer - in the course of the policy-making process - to similar standards having been adopted in other EU member state. However, they do so to varying extents and for different reasons. 


\section{Germany}

The introduction of the safe country of origin notion in German asylum law was justified with the need to bring own, domestic law in accordance with European standards. When the Bundestag debated the bill, the Minister of Interior stressed

$\ldots$ that this system is not new. Switzerland practices such a system. The EC immigration ministers developed criteria for such a system. When designating a country of origin as safe one has to abide to a comprehensive set of criteria which is more or less based on the Conclusions of the EC immigration ministers [the London Resolutions] (Bundestag 1993a, , Seiters, p.12296; Bundestag 1993d). ${ }^{119}$

The London Resolutions featured prominently in these Bundestag debates. They served to justify the general introduction of safe country rules as well as procedural specificities. The introduction of the rule was labeled as a necessity in order to bring German law in line with what has been agreed upon at the European level. The argument went even one step further. Germany was presented as an outlier in Europe, having to end its German Sonderweg (interview 42). It was suggested that Germany is one of the few countries in Europe where these provisions have not yet been adopted and in being so, it hinders harmonisation of asylum policies:

If one wants to end the stand alone-position of Germany, one has to adapt our protection statuses to the protection statuses of the international community, as written down in the Geneva Convention. Nothing else but this adaptation is the aim of our consultation and negotiation today. [...] With adopting this provision, we adapt our protection standards to the standards of all other civilized countries, and the European ones in particular. In doing so, we aim for a fair burden-sharing in Europe. But this is only possible if we do not provide a higher protection standard than others (Bundestag 1993c, Schäuble, p.13505; see also similar statements from Glos, p.13528, Stübgen, p.13589). ${ }^{120}$

While the introduction of the safe country of origin policy was justified with having to adhere to European agreements, the actual designation of countries as safe was explained with similar developments in other (EU-) countries. Let us take Senegal as an example:

\footnotetext{
${ }^{119}$ Quote in original language: ... daß dieses System nicht neu ist. Die Schweiz praktiziert dieses System. Die EG-Einwanderungsminister haben Grundsätze für ein solches System entwickelt. Bei der Einstufung eines Staates als sicherer Herkunftsstaat ist ein umfangreicher Kriterienkatalog zugrunde gelegt worden, der sich wesentlich an dem Schweizer Katalog und den Schlußfolgerungen der EG-Einwanderungsminister orientiert. ${ }^{120}$ Quote in original language: Wer die Singularisierung der Bundesrepublik Deutschland beseitigen will, der mu $\beta$ unseren grundrechtlichen Schutz für politisch Verfolgte an das Niveau der Schutzgewähr der internationalen Staatengemeinschaft, wie es in der Genfer Konvention seinen Ausdruck findet, anpassen. Nichts anderes ist der Gegenstand der heutigen Beratung und Entscheidung. [...] Wir wollen mit unserer Regelung, mit der wir uns anpassen an das Niveau der Schutzgewähr aller anderen zivilisierten Staaten, inbesondere der europäischen Staaten, ja nichts anderes als eine faire Lastenverteilung in Europa erreichen, die wir aber erst erreichen können, wenn wir eben nicht mehr Schutz gewähren als andere.
} 
There is no political persecution in Senegal. This assessment is also shared by the diplomatic missions of all Western countries represented in Senegal, and the EU member states in particular (BMI 1996, p.4) ${ }^{121}$

An explicit reference was made to France and their implementing asylum agency with regard to a similar ratio between numbers of asylum seekers and protection quota regarding Senegalese asylum seekers (ibid.). ${ }^{122}$ Thus, the German government justified both the introduction of the SCO notion as well as the designation of countries as safe with similar decisions having been taken in other countries.

\section{The UK}

In the British case, the introduction of the SCO notion was very much justified with both the London Resolutions and similar policy developments in other European countries. When the safe country of origin rule was first introduced in 1996, the Home Affairs Minister Widdecombe stressed during debates in the House of Commons, that

The [SCO] clause develops further the concept that an effective asylum process requires arrangements for fast-tracking those cases that are clearly without foundation. That is a principle that comparable countries, including most of our European neighbours, have already adopted. It has also been endorsed in the non-binding European Union resolution of 1992 on manifestly unfounded asylum claims (HoC 1996a, c. 164; see also HoC 1996a, Kirkhope, c.64).

Beyond the London Resolutions, international experience was quoted both by the proponents and the opponents of the bill. ${ }^{123}$ When the introduction of the SCO notion was criticised by opposition party members, the Minister of State also stressed that this provision is nothing unique to the UK but has been applied in Germany, the Netherlands, Switzerland, Denmark and Finland too (HoC 1996b, c. 696; see also HoL 1996, c. 1727). Being accused of introducing provisions that are contrary to international treaty obligation, she also stressed that ' $\mathrm{i}$ ] f the creation of a designated list were against international law, why is it valid in so many countries' (HoC 1996b, c. 707).

These examples are from 1996. By then, the British government indeed justified the introduction of the safe country of origin notion with referring to other countries and European agreements. However, any debate in both houses regarding SCO designations in the following years $(2002,2003,2005,2006,2007$, and 2010) did not relate to other

\footnotetext{
${ }^{121}$ Quote in original language: Im Senegal findet keine politische Verfolgung statt. Diese Einschätzung wird auch von den Auslandsvertretungen aller im Senegal vertretenenen westlichen Staaten, insbesondere von denen der EU-Mitgliedsstaaten, geteilt.

${ }^{122}$ A comment on data availability: I only have the country reports for Senegal but for none of the other countries included or proposed to be included in the list. Most of the actual country reports (produced by the subcommittee 'human rights and humanitarian aid' of the Foreign Committee - Auswärtiger Ausschuss) assessing the safety situation in the countries were not accessible to me.

${ }^{123}$ However, only the former are of interest here because I am looking for evidence that the British government legitimized the introduction of the SCO notion by referring to other countries.
} 
countries' policy choices. The government seemed not to see the necessity of legitimising policy changes with references to similar developments in other countries.

\section{Luxembourg}

In Luxembourg, debates in parliament on safe country of origin policies were rather short. The reason for that is that the policy was only briefly discussed as part of a bigger package enhancing accelerated procedures. The actual designations, however, did not need to pass the parliament. Nevertheless, in justifying the need for more elaborate accelerated procedures, and SCO policies in particular, the Minister for Foreign Affairs Schmit frequently related to other countries. He did so in a way that is extraordinary comparing the four countries studied in detail in this thesis. He argued that the Luxembourgish changes are by far the most moderate in Europe and their introduction would thus be justified:

Because, when I look at how the procedure works in the Netherlands, in France today, in Belgium - and you have said it yourself very interestingly - if an application is admissible at all, things have gone well. Over here [in Luxembourg] every application is admissible. We do not have a preliminary question that is used to decide: your application is admissible, and yours is not. Other countries like, for example, the British have got this, other countries like, for example, the Dutch have got this; there, you are sometimes told within 48 hours whether the application that one has handed in is admissible or not. We do not have this, we have got an accelerated procedure, that is nevertheless coupled to a serious administrative analysis; that is connected to a serious recourse.... [...] In other countries they also have this! We are not a repressive country, that has invented this. In Germany, it can last up to nine months. In Austria, up to over one year. In France, we are also at one year. Thus, it's not like there would be an absolute Luxembourgish exception (PoL 2005, Schmit, p.166). ${ }^{124}$

Also the government in Luxembourg justified own, intended changes with a reference to other countries having adopted similar policies. However, in contrast to the UK and Germany, the Luxembourgish government did not engage in a race to the bottomargument. Instead, it stressed very clearly that the rules to be adopted are less strict than the rules in the Netherlands, France, Belgium, UK, Germany or Austria.

With regard to specific countries declared as safe, the legislative proposal of 2007 (not discussed in parliament) related to the practice in other countries too. The bill

\footnotetext{
${ }^{124}$ Quote in original language: Well, wann ech kucken, wéi an Holland, wéi a Frankräich haut, wéi an der Belsch d'Prozedure fonctionnéieren - an Dir hutt et selwer ganz interessant gesot -, wann do eng Demande iwwer haapt emol recevabel ass, dann ass et gutt gaang. Bei ons ass all Demande recevabel. Mir hunn net eng Question préliminaire, wou et heescht: Deng Demande ass recevabel an deng ass et net. Dat hunn aner Länner wéi zum Beispill d'Englänner; dat hunn aner Länner wéi zum Beispill d'Hollänner, wou een an e puer Stonnen, an 48 Stonnen heiansdo, gesot kritt, ob déi Demande, déi een agereecht huet, recevabel ass oder net. Dat hu mir net, mir hunn eng Procédure accélérée, déi trotz allem verbonnen ass mat enger seriöer administrativer Analys; déi verbonnen ass mat engem seriöe Recours [...] An anere Länner gëtt et dat och! Mir sinn hei net en extrem repressiivt Land, wat elo dat erfonnt huet. Däitschland kéint praktesch bis néng Méint goen. Éisträich souguer iwwer ee Joer ewech. A Frankräich si mer och bei engem Joer. Et ass also net esou, datt et hei eng absolut Exception luxembourgeoise géif ginn.
} 
included a short paragraph on the actual situation in the country of origin and a prominent reference to other European countries pursuing similar policies. Let us consider the example of Mali. After half a page of sources citing the good human rights situation in Mali, the bill stressed the following:

The Republic of Mali is considered a safe country of origin regarding the treatment of asylum seekers by France, Hungary, Ireland, Malta, the Netherlands, Portugal, the Czech Republic, the Slovak Republic and Sweden. During negotiatons at the EU level, the European Commission proposed to also include this country on the common list of safe countries of origin (projet règlement grand-ducal du 4 mai 2007, p.8). ${ }^{125}$

The bill did not only justify the SCO designation of Mali with reference to other European countries, but also with reference to the Commission and the discussed common list on safe countries of origin. Similar examples can be found for all other countries declared as safe by the Luxembourgish government in $2007 .{ }^{126}$

\section{Malta}

The Maltese parliament saw a very short debate of the SCO notion, namely related to its introduction as part of the Refugees (Amendment) Bill of 2004. A key reference was made to the UK and its successful introduction of measures to prevent abuse of the system (PoM 2004b, Borg, p.403). However, the debate did not go beyond informing members of parliament and claryfing some basic terms. In 2004, the proposed countries to be designated as safe were briefly discussed in parliament (though there is no parliamentary approval of the list necessary, see section 4.2.2). The Minister stressed that he looked at other EU member states (primarily the UK) as well as Australia, the United States and New Zealand, before making a decision on which countries to designate as safe (PoM 2004c, Borg pp.16-17). However, also this short debate was rather of an informational character. The Maltese minister did not use the evidence from other countries to justify own policy choices - primarily because there was no one to justify to. There was no disagreement in parliament on the notion as such or or countries designated as safe.

In sum, this section showed in how far policy-makers in the four countries have used information obtained during policy coordination to legitimise intended policy changes. In the German Bundestag, other countries' policies and European agreements were frequently cited in order to support the planned introduction of the SCO notion, and the designation of countries as safe. In fact, the same can be said about the UK,

\footnotetext{
${ }^{125}$ Quote in original language: La République du Mali est considérée comme pays d'origine sûr dans le cadre des traitements de demandes d'asile par la France, la Hongrie, l'Irlande, Malte, les Pays-Bas, le Portugal, la République tchéche, la Slovaquie et la Suéde. Dans le cadre des travaux au niveau européen, la Commission européenne propose également de faire figurer ce pays sur la liste européenee commune pays d'origine sûr. ${ }^{126}$ Albania, Benin, Bosnia and Herzegovina, Cape Verde, Croatia, Ghana, Macedonia, Montenegro, Senegal and Ukraine
} 
Malta and Luxembourg. The difference, however, to the German case is that in these three countries, there was much less (if any) conviction necessary on part of the government. Especially in Malta and Luxembourg, information obtained on other countries' policies served more as a piece of information rather than an argument.

\subsection{No change of preferences}

What was shown so far is that policy-makers intend to introduce or change safe country of origin policies for a specific reason. These are primarily related to cutting the number of asylum seekers from certain countries of origin. However, not always is it possible to simply introduce the intended policy change - due to domestic constraints. Policymakers then turn to transnational asylum policy coordination in order to see how other countries deal with these particular policies. What they have learned during these exchanges is, eventually, used to change own domestic policy. This chain of argumentation could be shown for the cases of Germany and the UK, and for a lesser extent, also for Luxembourg and Malta. The final step, however, is still missing: A logic of consequences presumes that policy-makers enter policy coordination with fixed preferences, and leave it with the same preferences. Thus, the preferences are formed exogenously to the exchange with other countries. In this final section, it will be shown that in both cases Germany and the UK asylum policy coordination has not led to a change of preferences. Instead, it helped respective policy-makers to pursue original intentions. Similar though less strong observations are made for the case of Luxembourg. Given that in Malta original intentions were not clear, it could also not be observed whether or not preferences have changed.

\section{Germany}

The key motivation for German policy-makers introducing the safe country of origin notion was to limit the number of asylum seekers from certain countries of origin, including Romania, Bulgaria, Ghana and Senegal. They had already been trying to achieve this goal with several policy changes in the 1980s and early 1990s (see for example Kornelius 1989). When none of these measures proved to be successful, the German government dared to touch the Basic Law, which resulted in the 1992/1993 introduction of the SCO notion. However, for amending the Basic Law, it was necessary to convince (parts of) the opposition. The opposing parties, and the Social Democrats in particular, were highly divided over the intended law changes. The German government first secured an agreement on safe country of origin policies at the European level (the socalled London Resolutions), before respective policy changes were introduced in Germany. By then, it was argued that the country would need to introduce the SCO notion in order to bring its asylum law in line with European developments. The two-level game played by the German government illustrated very clearly, that preferences before 
and after policy coordination had not changed. Instead, policy-makers managed to use the European level to achieve pre-given preferences at the domestic level. Eventually, the SCO notion was introduced and several countries were declared as safe.

However, the story does not end here. The SCO notion proved to be of limited success: the numbers did not go down to an extent as hoped for by the government; and it was very difficult to add new countries of origin to the list. To recall, designating new countries as safe would require the majority of the Bundestag (and Bundesrat) agreeing to it. This requirement was named by policy-makers and experts as the main reason why the safe country of origin notion has not actively been used in Germany - the hurdle for adding countries to the list is simply too high (interview 36; interview 38; interview 39; interview 41). Because the SCO list has no practical relevance in Germany, it was also not updated since 1996 (interview 36). In theory (or rather in law), Ghana and Senegal are still declared as safe countries of origin but - according to the Federal Office for Migration and Refugees - these designations have no implication for Ghanaians or Senegalese claiming asylum in Germany (interview 37).

So could one say that German policy-makers changed preferences? The clear answer is no. As just illustrated, not using the provision had nothing to do with what other countries did or said. Rather it was due to the high threshold for adding new countries to the list. Preferences of the German asylum authorities had not changed. Instead they found other means to achieve the same ends, namely processing claims from some asylum seekers faster than from others. The key player here is the Federal Office for Migration and Refugees which is in charge of conducting all asylum procedures in Germany (see section 4.2.2). It is a subordinate authority of the German Ministry of Interior and also mandated to issue policy-like decisions on how to treat asylum seekers from certain countries of origin. These policy guidelines (called Herkunftsländerleitsätze in German) provide guidance to the case workers (the person deciding on the asylum application) on how to treat asylum seekers from a certain country of origin. In most instances, case workers will follow the guidelines and policies set by the BAMF. ${ }^{127}$ The reason for this is pure practicability and again, efficiency: 'via administrative decisions [compared to a designation by law] one can react much quicker and more flexible' (interview 36; see also interview 39). ${ }^{128}$

Preferences of German policy-makers have thus not changed - they still aim at processing applications from certain countries of origin faster than others. However, the means to do so have been altered (from SCO policies to policy guidelines issued by the

\footnotetext{
${ }^{127}$ Case workers in the BAMF have made their decision independently from instructions until 2004. However, this has changed with the entering into force of the Zuwanderungsgesetz on 1 January 2005. They are now 'weisungsgebunden' (bound to instructions) but, in theory, still have some discretion to decide.

${ }^{128}$ Quote in original language: 'durch Behördenentscheidungen kann viel schneller und flexibler reagiert werden.'
} 


\section{BAMF). Box 6.4 illustrates this finding by looking at how the German authorities treat asylum seekers from Serbia.}

Box 6.4: Other means to achieve the same ends - the example of Serbian asylum seekers in Germany

The number of Serbian asylum seekers increased tremendously during the last years in many European countries. The main reason is the visa facilitation agreement signed between the EU and Serbia which entered into force on 1 January 2008. Since then, the numbers of Serbian asylum seekers in Germany grew from 890 applications in 2009 to 12,810 applications in 2012 (Eurostat). The authorities assume that the majority of the claimants are not in need of protection. This also shows in the protection rates: in the first (second) quarter of 2011, only eight (seven) asylum seekers from Serbia received protection equaling $0.3 \%(0.6 \%)$ of all claimants from that country (Bundestag 2011). Other European countries experience similar numbers and reacted to these by adding Serbia to their safe country of origin list. The German authorities did not do so because the SCO provision of 1992 proved to be impracticable (see text above). Instead, they found other ways to achieve similar ends. The Herkunftsländerleitsatz (policy guideline issued by the BAMF, see above) related to Serbia clearly indicated that there is in general no risk of persecution in the country. This was also confirmed by my interview partners: 'Within our control methods we indeed have possibilities [to accelerate asylum procedures for Serbian and Macedonian applicants $[\ldots]$ we conducted a certain prioritisation; because you simply assume with these countries, Serbia and Macedonia, that there is no political persecution and that the interview is not so extensive and not very complicated (interview 37; see also interview 39). ${ }^{129}$ By issuing these guidelines, Serbian asylum seekers can be treated in a procedure comparable to the SCO designation in other European countries. This also shows when looking at the average time needed for processing asylum claims. In the first half of 2011, it took the authorities 2.7 months to process an application from a claimant of Serbian origin (Iran: 7.0 months, Russian Federation 8.0, Turkey 7.2, Syria: 6.1; source: Eurostat). In 2014, the German government took initiative to designate Serbia as a safe country of origin. This intended policy change was preceded by a recognition rate close to zero. It is argued that the very low recognition rate '... is not just propaganda and populism at the expenses of the Roma - it is also part of a strategy. The Minister of Interior knows that a very low recognition rate of applicants from Serbia and Macedonia is a precondition for his intention to add these countries to the list of safe countries of origin (Waringo 2013, p.4). ${ }^{130}$ According to NGOs (Pro Asyl in Waringo 2013), the recognition rate was deliberately kept so low in order to - eventually - make this designation possible. In September 2014, these countries were indeed designated as safe.

In sum, preferences in Germany have not changed. The asylum authorities still aim at processing applications from certain countries of origin much faster than from others. By doing so, they also hope to deter certain groups of asylum seekers. By engaging in

\footnotetext{
${ }^{129}$ Quote in original language: Innerhalb unserer Steuerungsmethoden haben wir schon Möglichkeiten [Verfahren zu beschleunigen]; [...] es ist eine gewisse Priorisierung vorgenommen worden bei uns; denn man unterstellt einfach, dass bei diesen Ländern, Serbien und Mazedonien, dass es da keine politische Verfolgung gibt und dass der Sachvortrag auch nicht so ausufernd ist, dass das eventuell sehr kompliziert werden könnte.

${ }^{130}$ Quote in original language: ... ist nicht nur Propaganda und Populismus zu Lasten der Roma, es ist auch Bestandteil einer Strategie. Der Bundesinnenminister wei $\beta$, dass die lückenlose Ablehnung von Asylantragstellern aus Serbien und Mazedonien Vorraussetzung ist für seine Absicht, die Liste der sicheren Herkunftsstaaten um diese Staaten zu erweitern.
} 
transnational asylum policy coordination, the German authorities could learn about SCO practices in other countries, and use this information to pursue own preferences.

The UK

The British case reveals a similar persistency in pursuing the same ends by, if necessary, different means. In general, it can be said that restricting access to the UK as a country of asylum was key to any policy strategy of Conservative governments since the 1960s (Bloch 2000, p.33). In addition, it was always a key preference of British policy-makers to make sure that the UK is not a more attractive country of asylum than any other EU member states. This strategy was not altered with governments changing from Conservative to Labour (Bloch 2000). The safe country of origin notion was introduced in British asylum law in 1996. However, already before that time did the Home Office follow a practice of processing some claims faster than others, mainly those from countries where there presumably was no general risk of persecution (HoL 1996, c. 1724). All changes following the 1996 introduction aimed at accelerating the asylum procedure and making the UK less attractive for asylum seekers from certain countries of origin. Over the years, many countries were added to this list. With the Labour government taking office in 1997 (and changing the asylum law in 2002), the consequences of safe country of origin designation changed - to being even stricter for affected asylum seekers. ${ }^{131}$

For the years to come, the different UK governments were very active in adding more and more countries to the SCO list, having reached some 26 countries of origin designated as safe by 2013. The government argued that its key motivation in further pursuing this policy is that it has been proven successful in deterring asylum seekers from countries where there is generally no risk of persecution. During the 2007 extension of the list, the Government Spokesperson for the Home Office stressed that the list would be extended by another six countries because 'of the successful operation of the provision thus far relating to the immense drop in intake for countries that were added to the list over the previous years (HoL 2007, c. 209-210). This argument was stressed again and again when new countries were proposed to be added to the list (see for example HoL 2010, GC148). Similar to the German case, also the British authorities tried to limit the number of asylum seekers by additional means (next to SCO policies). In this regard, key targets continue to be asylum seekers from Pakistan and Nigeria. Although Nigeria was designated as a safe country of origin in 2005 (for men only), the number of asylum seekers from that country remains to be relatively high. The Home Office continuously considers alternatives to reduce this number (interview 21). The

\footnotetext{
${ }^{131}$ Whereas according to the 1996 Asylum and Immigration Act a SCO designation resulted in a fast trackprocedure with only 10 days for appeal and, if upheld, no right to appeal to the second tier Immigration Appeal Tribunal (Asylum and Immigration Act 1996, chapter 49, par.5, schedule 2); with the 2002 NIA a SCO designation immediately resulted in the unfoundedness of the asylum claim with no possibility of an appeal within the UK (NIA 2002, chapter 41, part 5, article 94).
} 
same applies for Pakistani asylum seekers. The country is currently not declared as safe. However, there is a constant aim on part of the Home Office to reduce the number of Pakistani asylum seekers, who, in 2013, made up 15\% of all people claiming asylum in the UK. ${ }^{132}$ Home Office officials argue that, while there are some groups, such as Ahmadis or women, who clearly need protection, the absolute majority - being young males - does not do so. The Home Office has been trying to cut their numbers by different means but has not been successful so far (interview 21). In sum, the analysis showed that SCO designations in the UK always aimed at limiting the number of asylum seekers from certain countries of origin and process their claims faster than others'. These preferences were pre-set and independent of what happened in other countries.

\section{Luxembourg}

Considerations for Luxembourg need to look at two points in time. At first, the government was very much in favour of a common, European solution. It aimed for a common list of safe countries of origin to be adopted at the EU level. Once it became clear that there would be no European list, the authorities in Luxembourg decided to adopt a national list. This list was primarily intended for limiting asylum seekers from certain countries of origin, and processing their claims in a much quicker way. Just as Germany and the UK, also Luxembourg had a very clear idea about which countries should be included in the list, namely those from which there are big numbers of applications and low acceptance rates. Coordinating asylum policies with other EU member states helped the government in Luxembourg to justify both the introduction of the SCO notion and the designation of countries as safe. Given that there is no need to discuss designations in parliament, the evidence is thinner than in the case of Germany and the UK. However, the Bill proposing to add some ten countries to the list (Projet Règlement grand-ducal du 4 mai 2007) very much relates to what the government had learned about other countries' safe country of origin policies: each country's designation was justified with similar policy choices having been taken in other EU member states. Thus, preferences had not changed

\section{Malta}

In the case of Malta it was difficult to identify preferences in the first place. That is why it is also difficult to see whether preferences have changed. It was argued that Maltese policy-makers face the problem of having to make up their mind about what to include in the country's first asylum law ever. They were forced to do so because having an asylum law in place is one of the conditions for soon-to-be EU member states, as formulated in the Copenhagen Criteria. ${ }^{133}$ In the process of having to decide how this law would

\footnotetext{
${ }^{132}$ In 2013, 30,110 asylum applications were issued in the UK in total, including 4645 applicants of Pakistani origin (Eurostat).

${ }^{133}$ For a more detailed account of what was required from the candidate countries before they would be able to become members of the Union, see Byrne et al. 2002.
} 
look like, Maltese policy-makers turned to other countries. Thus, one can assume that the preference for Malta had been to have any acceptable policy solution. By copypasting pre-existing lists from other countries (and the European Commission), preferences are - so to say - fulfilled. However, this line of argumentation is rather thin. None of the data consulted uncovered such a line of reasoning on part of Maltese policymakers. Consequently, one has to leave the case of Malta as primarily unexplained, for now.

\subsection{Conclusion}

This chapter aimed at providing an answer to the question in how far asylum policy coordination matters in the formulation of domestic asylum policy, and safe country of origin policies in particular. A logic of consequences was assumed. It was argued that policy-makers engage in policy coordination and use information obtained to achieve pre-set preferences. While they might learn how other countries pursue (the same or different) policies, their initial aims do not change. In that sense, the logic of consequences can manifest itself in different mechanisms; asylum policy coordination can be used in different ways: it can help in pre-cooking intended policy changes making it easier to implement them at the domestic level (two-level games); or, more general, policy-makers learn what is done in other countries and transfer what they have learned to their own, domestic context. For both Germany and the UK, safe country of origin policy-making can be explained by a logic of consequences. For both Malta and Luxembourg, the evidence has been less compelling, and puzzles remain.

In the case of Germany, policy-makers successfully played the two-level game. When introduced in 1992, the SCO notion intended to restrict the number of asylum seekers from certain countries of origin. With this preference in mind, German policymakers entered transnational asylum policy coordination. From the 1980s onwards, they engaged with other countries, became informed about their policies and preferences and were actively involved in shaping the emerging European asylum system. The German government was also key in securing an early and informal European agreement on safe country of origin policies (London Resolutions of 1992). The London Resolutions were then used to introduce a policy change long sought for. In fact, it allowed the German government to justify intended policy changes with arguing that they were needed in the spirit of Europe. Germany had to stop its Sonderweg and act more in accordance with developments in other European countries. ${ }^{134}$ Back home, these efforts

\footnotetext{
${ }^{134}$ A similar legitimisation discourse emerged with regard to the introduction of the safe third country notion. As Thielemann argues, Chancellor Kohl used Europe to legitimise the introduction of the safe third country provision arguing that it was an important precondition before Germany could fully participate in a common European asylum policy (Thielemann 2001, pp.20-21).
} 
helped the German government to secure the necessary support for introducing the SCO notion, and designating countries as safe. It helped side-playing domestic actors, such as the opposition that had opposed the intended law changes for a very long time. Thus, asylum policy coordination was, from the beginning, intentionally used to achieve pre-set preferences. However, following the years of its introduction and the designation of Ghana and Senegal as safe, the policy was not actively used in Germany anymore. Instead, the German government and the BAMF found other tools to accelerate the asylum procedure of applicants from certain countries of origin. This changed toolbox is inspired by similar measures in other countries. Thus, again, engagement in transnational asylum policy coordination follows a logic of consequences: we look for a certain solution and adapt our means after having learned about other countries' practices.

For the case of the UK, the analysis clearly showed policy-making following a logic of consequences too - though with a very different role for asylum policy coordination (compared to Germany). Also in the UK, safe country of origin policies were introduced with the aim to cut numbers of asylum seekers from certain countries of origin. Compared to all European countries (and in fact, compared to countries worldwide), the UK is by far the most active user of the safe country of origin notion. By 2013, 26 countries of origin were declared as safe, a few had to be removed, and many had been added since the notion's introduction in 1996. Both the Major and Blair government played an active role in transnational asylum policy coordination: they engaged in fora to exchange policies and ideas on how to deal with certain groups of asylum seekers; they actively shaped the informal and later formal processes of European asylum cooperation. These activities led British policy-makers to being very well informed about asylum policies in other countries, and safe country of origin policies in particular. When the SCO notion was first introduced in 1996, the British government indeed used this information to justify intended policy changes. It was argued that own law had to be brought in line with developments in other European countries. This argumentation, successfully, led to the introduction of safe country of origin policies and the adoption of respective lists. In later years, this reference to other countries was not needed anymore. There was much less opposition in parliament when new countries were added to the SCO list in the years 2002 to 2010. In fact, information on other countries' policies is still collected and Home Office officials are still well informed about what is going on elsewhere in Europe - but for a different purpose: they learn about other countries' policies, and are informed about their intake patterns, in order to make sure that British policy towards asylum seekers remains the strictest in Europe.

The policy-making process in Luxembourg could also be well-explained with a logic of consequences. Policy-makers were not successful in achieving their first priority, which was a common, EU-wide agreement on safe countries of origin. After it was clear that such an agreement is out of sight, they changed preferences and went very much in line with Germany and the UK. The introduction of an own, safe country of origin list 
was aimed at deterring asylum seekers from certain countries of origin. The usefulness of the list was a key term of Luxembourgish policy-makers, probably presenting best what is meant by a logic of consequences. The list was seen as a useful tool to potentially curb numbers of unwanted asylum seekers. Again, policy-makers engaged in transnational asylum policy coordination to learn from others, and to see how best to achieve this aim. Experiences from other countries were used to adopt an own list - best-suited to the Luxembourgish context. Thus, also here we observe simple learning.

Maltese policy-makers introduced the SCO notion in 2000, and designated 13 countries as safe in 2004. Apart from the British list, this is one of the longest SCO lists existent in the EU. However, it is difficult to see why it was created in the first place. There were no large numbers of asylum seekers from the countries declared as safe. There was no domestic pressure either for or against the adoption of such a policy. Also the transposition of the Asylum Procedures Directive into national law would have not required the Maltese authorities to set up a national list of safe countries of origin. The only explanation for the adoption of the policy would relate to a lack of resources and the need for a quick policy solution (in light of having to have asylum legislation in place before becoming an EU member state). Thus, Maltese policy-makers looked at readymade solutions provided by other countries and the European Commission. However, it was difficult to prove this explanation, and it thus remains rather inconclusive.

In sum, the chapter explained the role of transnational policy coordination in the domestic policy-making context. I showed that countries intentionally use policy coordination to achieve preferences set prior to engagement with other countries. Thus, policy coordination did not aim at harmonising policies in the first place but was targeted towards domestic goals. However, puzzles remain. I was not able to explain policymaking in Malta with a logic of consequences. Also, within the - on first sight - clear case of Germany, there are some riddles. For example, the German asylum authorities are very active in asylum policy coordination, especially in the fora being driven by mechanisms of socialisation and social learning (chapter 5). How can we then explain that German policy-makers (and partly the very same people) adopt such a cost-benefit mindset when it comes to the actual policy-making process? Whereas the overall policymaking process seemed to have followed a logic of consequences, parts of it showed strong elements inheriting notions of appropriateness and socialisation. What processes exactly are driven by a logic of appropriateness, and why? Where do the two logics come together? These are the questions that are addressed in the subsequent two chapters. Whereas the following one explains safe country of origin policy-making with a logic of appropriateness, the final one tries to bring both logics together. 



\section{Coping by copying: domestic change following a logic of appropriateness}

\subsection{Introduction}

This chapter answers the main question from a social constructivist perspective. It explores whether policy-makers adopt (or change) safe country of origin policies because they consider such measures appropriate in a certain context. The key mechanism explaining the introduction or change of safe country of origin policies is social learning. The argument is - simply put - as follows: policy-makers engage in transnational (asylum) policy coordination, become aware and convinced of how similar issues are dealt with in other countries, and respectively change domestic policy. This chapter thus presents an alternative explanation to the logic of consequences (previous chapter). The main difference to the rational choice interpretation of events is that actors follow rules of appropriateness. Their understanding of what to do is shaped by their institutional, social and cultural context. During policy coordination, policy-makers develop ideas with others and/or become convinced of how other countries deal with certain issues. They change policy because they are convinced by what they learned from others. Table 7.1 recalls the analytical framework, as developed in chapter 3.

Table 7.1: Overview of conditions for policy-making following a logic of appropriateness

\begin{tabular}{ll}
\hline Level & Conditions \\
\hline Domestic & Uncertainty \\
& - Newness of the policy issue \\
& - Few cognitive priors \\
& Presence of an epistemic community \\
Transnational & - United by common knowledge \\
& - Shared understanding of work, of problems/solutions \\
& - Informal setup and insulation from political pressure \\
& Emergence of EU-wide norm \\
& Institutions facilitating consensus \\
Domestic & Political culture/nation-state identity \\
\hline
\end{tabular}


Table 7.1 summarises the analytical framework for the present chapter. There are a number of conditions making social learning likely to occur. They are also connected via a time dimension. First, there are two conditions at the domestic level. If they are fulfilled, actors are prone to social learning: a situation of uncertainty created by a short (or non-existent) history of policy-making regarding the issue at stake; and few cognitive priors of the decision-makers involved. Second, there are two conditions at the transnational level: the presence of an epistemic community which depends on a number of factors, including shared knowledge, a common understanding of work as well as problems and solutions, and an informal setup insulated from political pressure. Next to the presence of an epistemic community, social learning can also occur at the transnational level because a norm evolved which became commonly accepted amongst EU member states. Finally, domestic level factors come into play again: what was learned during transnational policy coordination can only be implemented if domestic conditions allow doing so. These conditions include institutions facilitating consensus as well as a political culture prone to social learning (for a detailed discussion of these conditions, see section 3.3.2). In what follows, these conditions are systematically studied for SCO policy-making in Germany, the UK, Malta and Luxembourg.

As in chapter 6 , the reader is reminded of one caveat regarding the normative dimension of the analysis: much criticism was voiced over how European countries apply the SCO notion. This chapter does not deal with criticising this notion in general or the very practice in the countries analysed. If mentioned, critical voices do not relate to a normative discussion but support the argument made in this chapter. Consequently, the current chapter solely deals with the decision-making process and its determining factors. The normative discussion is part of chapter 2 and the concluding chapter.

\subsection{Domestic conditions preceding policy coordination}

The analysis starts with looking at several domestic conditions preceding policy coordination, and making social learning likely to occur. To remind the reader, all conditions are connected via a time dimension. Some are observable before the learning exercise (making it likely to be open for learning), some relate to the very learning process, and some follow after (making it likely to implement what has been learned). While this time dimension is slightly artificial - often all these processes happen at the same time for the sake of clarity they are kept separately here. This section focuses on the domestic conditions preceding the learning exercise. It is argued that actors are prone to social learning when they face a situation of uncertainty. Uncertainty leads actors having to make (policy) choices without adequate information about the situation at hand. There is not enough (or insufficient) knowledge available for assessing the expected outcome of different courses of action. Though such uncertainty is a general characteristic of asylum policy-making (Alink et al. 2001), it is particulary strong when two conditions 
are given: the policy issue is new and/or actors carry few cognitive priors (Checkel 2001a; Haas 1992). In what follows both are discussed in detail.

\subsubsection{Newness of the policy issue}

Agents are especially open to social learning if they find themselves in a novel environment. This can be generated by the newness of the issue, by a crisis or by serious policy failure. In any case, it motivates actors to analyse new information. In this section, it is argued that - in the process of SCO policy-making - government officials are particularly prone to social learning if their country has never dealt with this or similar topics beforehand. Note that there is also an individual component to this argument: policymakers are open to ideas provided by others if they individually have not dealt with this or similar issues beforehand (discussed in the next section). However, this section is about the policy issue as such, and its (lack of) history in national asylum policymaking.

The newness of the issue played the most important role in the 2004 and 2007 accession countries. Most, if not all of them, had drafted their first asylum legislation ever in the process of complying with the Copenhagen criteria. ${ }^{135}$ This also means that they had no (or hardly any) knowledge on assessing the effects of asylum policies. They thus had to act in a situation of uncertainty. The novelty made policy-makers from these countries particularly prone to social learning for two reasons: first, because they had not dealt with safe country of origin provisions beforehand, they were motivated to analyse new information on this very issue; and second, they were open to be persuaded of norms already agreed on in the club they would join very soon (the EU).

One typical case of a country operating in a novel environment is Malta. It is only since 2002 that the Maltese authorities process asylum applications themselves. Until then, all asylum claims (it were just a few) considering protection in Malta were processed by UNHCR in Italy. Malta is in that sense the poster child for a country operating in a novel environment. This was stressed by the authorities themselves: being asked why they did not directly designate countries of origin as safe when the notion was introduced in 2000 (but only four years later), one policy-maker replied:

I guess that it would be mainly related to experience; at that point [...] Malta did not yet have extensive experience on asylum; we started receiving and processing asylum applications ourselves only as from 2002; so our asylum history is very different than that of the Netherlands or Germany or some of the established or old member states; so we have to look at developments also with that frame of mind; before 2002, before the Refugees Act, asylum applications were actually processed by UNHCR; somewhat that asylum experiences at that point was rather limited, so that would explain certain delays like this (interview 26).

\footnotetext{
${ }^{135}$ For a detailed account of the process leading to the accession and the asylum law-related conditions to be fulfilled, see Byrne et al 2002 and Lavenex 1999. However, their analyses only relate to the Central and Eastern European countries that joined in 2004 (excluding Cyprus and Malta).
} 
The lack of expertise was also illustrated by the many flaws in the first-ever asylum legislation enacted in Malta. Experts continuously stress that Maltese asylum law and practice is not coherent, incomplete, and falls short of meeting international and European standards (interview 32; interview 27; ODYSSEUS 2006, pp.10, 88-89; UNHCR 2003). ${ }^{136137}$

The novelty regarding the general responsibility of asylum procedures cannot be over-estimated. In contrast to all member states on the European continent (and the UK), Maltese authorities had no experiences whatsoever with asylum policy measures. Thus, they did also not know whether certain policy measures (such as introducing safe country of origin policies) have certain effects (such as deterring asylum seekers). They thus operated in a situation of uncertainty. Given their awareness of this inexperience, they also wanted to create policies that are bulletproof, so to say. One example is the Maltese list of safe countries of origin (as adopted in 2004) being seen as a 'very safe list'. Policy-makers did not want to do anything wrong with the first list to be created. Consequently, the list had to be a 'very, very basic list [...] a very safe list, so to speak' (interview 26), which was stressed many times by the respective policy-maker (see also Bonnici: PoM 2004c, p.17). Based on this uncertainty and inexperience, Maltese policymakers were particularly open to learn from others, and become convinced of their policy solutions.

The situation described for Malta (and similarly expected for the other 2004 and 2007 accession countries) is very different from the one in the old member states, such as Germany or the UK. Policy-makers from these countries are much less likely to be prone to social learning in this context. The main reason is that the issue at stake namely SCO provisions as part of a toolbox to accelerate asylum procedures of unwanted applicants - is not at all new to them. Instead they have dealt with these and similar topics in their national (and also European) policy-making processes for many years already. Consider for example Germany: The SCO provision was introduced in German law in 1992; a respective list of safe countries of origin was adopted in the year thereafter. However, discussions on how to limit the number of asylum seekers had started in the early 1980s already. Between 1978 and 1992, not less than ten changes related to the acceleration of the asylum procedure were agreed upon in the Bundestag (Bundestag 1993c, p.13637).

The same accounts for both the UK and Luxembourg. Before introducing safe country of origin policies, both countries undertook several measures aimed at limiting the numbers of asylum seekers. Also once the policies and the initial lists were adopted,

\footnotetext{
${ }^{136}$ However, there are also voices arguing that insufficient asylum standards in Malta are not only the result of a lack of knowledge (or resources) but often a deliberate choice (interview 32).

${ }^{137}$ This criticism is in line with what was raised by Byrne et al. (2004) regarding the protection gaps in the accession countries. They argue that the implementation of the (ready-made) asylum acquis in the less developed asylum systems of candidate countries raises serious protection gaps.
} 
these lists were changed several times: in the case of the UK, the list was changed an impressive 11 times between 2001 and $2010 .{ }^{138}$ Because of the long history of policymaking, it is unlikely that policy-makers in these countries were open to new (policy) ideas and would, consequently, not at all be prone to social learning in the context of SCO policy-making. ${ }^{139}$

In sum, this section argued that policy-makers from countries with no history in (safe country of origin) policy-making are more prone to learn and become persuaded of policy measures by other countries, than those with a long respective history. If SCO provisions were debated in parliament and public for many years already, it is unlikely that policy-makers turn to other countries in order to learn and become convinced of their policy solutions. However, next to the newness of the policy issue as such, also the individual (policy-maker) and her previous engagement with the topic plays an important role. This is discussed in the next section.

\subsubsection{Few cognitive priors by the decision-maker}

Agents are especially open to social learning (and likely to turn to other countries and accept their views) if they are novice and bring few cognitive priors (Checkel 2001a, p.563; Haas 1992, p.29). Whereas the previous section discussed the novelty-argument at the general, policy-making level, this section zooms in and looks at the individual level.

Let us start with the case of Germany: interviewed policy-makers and officials were in their job for a very long time already. One person interviewed had worked with COI and COI-related policy decisions for over 20 years: 'I am already with the BA [Federal Authority] for many, many years, and also all the time with country of origin information issues [...] so I also know all the developments (interview 35). ${ }^{140}$ Also other interviewees were in their (or similar) positions for almost all of their working life. This relates to the Federal Authority (implementing agency) in particular. However, also

\footnotetext{
${ }^{138}$ Also other European countries have a comparable history of asylum policy-making, such as Austria and Belgium. Both countries introduced, abolished and re-introduced safe country of origin policies several times. In Austria, the safe country of origin rule had been introduced in 1991, only to be abolished again in 1997 (Fassmann and Reger 2008, p.24). It was then re-introduced in 2005 and has, since then, seen the designation of several countries of origin as safe (Albania in 2010 being the most recent addition). In Belgium, the SCO rule existed in 1992 and had to be abolished after a ruling of the Constitutional Court which declared part of its criteria as invalid (Constitutional Court of Belgium 1993). After long discussions, the Belgian government reintroduced the SCO notion in 2012 including a list of seven countries designated as safe.

${ }^{139}$ Of course, also in these countries the novelty of an issue (new person in job, administrative reform, change of government) may make an individual person open to social learning. However, this section looks at the country level, whereas the next one looks at the individual level.

${ }^{140}$ Quote in original language: Ich bin also schon seit sehr, sehr vielen Jahren im BA [Bundesamt] und auch die ganze Zeit in dieser Herkunftsländerdokumentation [...] und kenne insofern auch die ganzen Entwicklungen.
} 
ministry officials who had been involved in formulating the safe country of origin provisions in the early 1990s, deal with related policy issues until today (interview 39; interview 40; interview 42). These persons are thus likely to carry many cognitive priors and be not very open to new arguments (i.e. learn from others).

A similar point can be made for the UK. The person responsible in the Home Office for COI cooperation has been in his job for over 10 years, which is also almost all of his working life (interview 25). Also two interviewees having been or being responsible for policy-decisions, including SCO designations, reported about a history of working in similar positions for over 20 years already (interview 21; interview 22). Thus, they are likely to carry many cognitive priors.

A similar though less strong argument can be made for both Luxembourg and Malta. It is less strong because the history of SCO policy-making is much shorter (compared to Germany or the UK). SCO policies were introduced in Luxembourg in 2006 (with the first list to be adopted in 2007) and in Malta in 2000 (first list in 2004). In both cases, people involved in making the list were still in the same or very similar jobs in 2013.

Based on this overview, one would expect politicians and officials in all four countries to carry many cognitive priors, and consequently be not very open to become convinced of others' arguments (i.e. learn from them). However, this statement has to be qualified for two reasons.

First, state executives in both Malta and Luxembourg have - because of the smallness of the country and its asylum administration - huge portfolios. ${ }^{141}$ Let us compare the cases of Luxembourg and Germany: one person in the Luxembourgish Ministry of Foreign and European Affairs, Directorate Immigration, is responsible for the following tasks (as of the time of the interview in September 2011): first, all of European cooperation on country of origin information (including for example affiliation with EASO, European Country Sponsorship and Eurasil); second, refugee status determination for 15 countries in total, including all applicants from the Balkan countries, Somalia and several other African countries; and third, any further requests on country of origin information that cannot be answered by the country experts themselves. Now, let us look at the organisation of work in the German Federal Office for Migration and Refugees. Already the first task (COI cooperation across Europe) is divided between various units in the BAMF: unit 201 (EASO), unit 211 (EMN, European fora liaison with other countries) and unit 410 (COI library) deal with COI cooperation and COI requests that are not placed with a particular country section. In addition, an entire COI library exists, including several staff members. The actual refugee status determinations procedure is carried out in one of the 22 field offices of the BAMF. Given the size of her portfolio, the former person (from Luxembourg) can simply not develop as many and detailed cogni-

${ }^{141}$ See section 5.2 .3 on differences of country of origin information units (and their resource availability) 
tive priors as the Germans (or the British) could do - independently of how long someone has already been in the job.

Second, one could also observe big difference within the German and the British case. Whereas some interviewees were very open to learn from others, others were not however, independent of how long they had already stayed in their positions. Especially those officials, who were heavily involved in COI cooperation, seemed to be much more open to learn from others compared to those that were only occasionally involved. Thus, socialisation seems to play an important role too. This aspect will be further discussed in the next section. For now, however, one has to note that there are no generalisable findings about cognitive priors of state executives in one country. Length of the placement is not sufficient to tell us about whether or nor individuals carry cognitive priors, and, consequently, whether or not they are open to become persuaded of others' arguments (i.e. socially learn from others). Further analysis will shed more light on this question.

The current and the previous section suggested that it is Malta and Luxembourg in particular where policy-makers were open to learn from other. Due to a lack of history in asylum policy-making, a situation of uncertainty evolved (in Malta). This situation as well as the large portfolios of policy-makers in both countries made actors willing to learn from others. Also evidence in Germany and the UK suggested that policy-makers might be open to learn from others. However, these are only the conditions fulfilled before entering policy coordination with other countries. The next section will shed more light on the actual learning process.

\subsection{Asylum policy coordination in epistemic communities}

This section argues that a transnational epistemic community structure evolved in the field of asylum governance. This structure makes social learning likely to occur. Chapter 5 showed that the need for policy coordination in the field of asylum was recognised in the 1980s. By then, several countries with similar needs started looking for common solutions. They did so by creating an informal institutional structure, outside of formal processes and very much driven by the involved countries' similarities (such as similar asylum standards, similar progress in building up national asylum administrations, similar problems). While chapter 5 focused on the institutional structure as such, this section (as the entire chapter) focuses on the individual perspective of persons involved in policy coordination and SCO policy-making.

Epistemic communities are one example of policy networks in which conditions are particulary good for social learning to occur. They are crucial in limiting uncertainty. They also help defining the self-interest of a state and to formulate policy as such (Haas 1992, p.15). In what follows, I will show that epistemic communities are an essential element in European asylum governance, and that involved actors indeed perceive these communities as helpful in formulating own policy positions. 
An epistemic community was defined as 'a network of professionals with recognised expertise and competence in a particular domain and an authoritative claim to policyrelevant knowledge within that domain or issue-area' (Haas 1992, p.3). As part of the theoretical discussion in chapter 3 , several conditions were highlighted that characterise such communities, including the presence of a knowledge-community, a shared set of problem and solution-understanding and insulation from political pressure (see analytical framework in section 3.3.3). In what follows, these conditions are studied empirically in order to show that asylum policy coordination in Europe can partly be characterised as epistemic policy coordination. As a result of that, actors involved in these fora are prone to social learning. They formulate own safe country of origin policies because they became convinced of these policies' appropriateness while exchanging ideas with other countries. I also argue that such a common norm (i.e. safe country of origin policies as such; and the idea that one particular country can be declared as a safe country of origin) evolved out of epistemic asylum policy coordination.

\subsubsection{A knowledge-community}

From the early years of asylum policy coordination onwards, the generation of knowledge has been one of its key aims. For example, the first COI-related discussions in the Intergovernmental Consultations on Asylum, Refugees and Migration (IGC) in the late 1980s aimed at exchanging ideas on two countries of origin, Sri Lanka and Turkey (interview 3; Hallam Johnston \& Associates 2005, p.8). Given the considerable number of asylum seekers from these countries applying for asylum in some EC member states, decision-makers were in need of learning about the situation in these countries of origin, and about how to deal with these asylum seekers. Also during that time, informal asylum policy coordination between two (or a few) countries started to take off (see section 5.4.4). Such coordination took many forms, one of them being common fact-finding missions. Box 7.2 discusses these missions as an example of generating common knowledge on which to base domestic asylum policy.

Box 7.2: Fact-finding missions as a means of generating common knowledge

Fact finding missions include several (European) countries and aim at generating information on countries of origin. For some countries (such as Somalia, Iran or Afghanistan), this information is difficult to access due to the safety situation on-site. ${ }^{142}$ By conducting common fact finding missions, COI units of several countries go together to the country of interest and collect information that is then used in the respective national context. This knowledge can either be used for individual refugee status determination (deciding on an asylum application) or for formulating country-specific policies, such as safe country of origin policies. For example, in 2010, Germany and Austria conducted a common fact finding mission to Ethiopia and Somaliland. The mission was conducted between the respective country

${ }^{142}$ For a detailed explanation of fact finding missions, see Olesen and Olsen 2012. 
experts in the German and the Austrian national asylum administration (D-A-CH n.d.). Often the knowledge gained during such missions is also shared with countries that have not participated. This sharing takes place via informal channels meaning experts send each other the result of their missions by mail (interview 7) or more formal one, such as during Eurasil country-workshops (interview 2).

Another key means of generating knowledge in the community is the regular conduct of workshops or conferences. These are targeted towards a specific topic, often a country of origin, and aim at collecting information on this particular country. So did, for example, German and Austrian experts on Russia meet in 2009 to discuss their sources and knowledge on the country (BAMF, n.d.). Other examples are the regular countryworkshops conducted in the framework of Eurasil (now EASO). These workshops take place 8-10 times per year and focus on discussing the situation in a specific country of origin - mostly those countries producing a lot of asylum seekers. For example, in 2009 and 2010, the workshops focused on the Democratic Republic of the Congo, Syria, Iran, Sri Lanka, Kosovo and Eritrea (interview 1). Workshops on these countries take place frequently, on some countries several times a year. In between, experts meet or exchange information digitally. Time and frequent interaction play an important role here. Because experts of several European countries on, for example Afghanistan, frequently interact, they can develop a sense of community, and thus form an epistemic community.

Another example relating to Afghanistan experts of several European countries is a conference that took place in 2010 in Vienna, on invitation of the International Centre for Migration Policy Development. During this gathering involved expert included representatives from COI units but also judges and international organisations (UNHCR, IOM). While the exchange was a first-time experience for some of them (especially the judges), involved experts from national asylum administrations had known each other for a long time already. They formed a visible community before, during and after the conference and were labeled by one of the participants as 'a very exclusive club' (interview 5).

The epistemic community-like character of COI cooperation is further enhanced through the development of common standards in the group. These standards were created in the group of countries that are very active in COI/asylum policy coordination (Northern and Western European member states, see chapter 5). They relate to the processing of country of origin information (IND 2008) as well as to the conduct of joint fact finding missions (European Country of Origin Sponsorship 2010a). Also within certain COI cooperation fora, standards were developed. For example, the European Country Sponsorship started off as an informal network assigning experts from its member countries to important countries of origin. These experts could always be consulted when one member institution would need information on a particular country. In order to not overload the individual expert, formats for issuing information requests 
were developed (interview 8). Similar practices were reported from the information request system via the Commission working group Eurasil (now EASO).

In sum, we see that much of asylum policy coordination, and cooperation on country of origin information in particular, unite involved actors by their knowledge and the generation thereof. Over time, communities evolved in which actors meet on a regular basis, not only to exchange information but also to commonly generate knowledge - for example via country-specific workshops or common fact-finding missions. Also over time, standards were created on how to generate and use this knowledge. Relating the examples given to the countries studied in this thesis, we primarily see Germany and Luxembourg engaging in the transnational exchange of policy and country of origin information. The UK is involved to a lesser extent. Malta plays hardly any role, mainly because these exchanges date back to the late 1980s and early 1990s. At this time, Malta did not (yet) care about these issues. As I discussed in chapter 5 already, the old member states with well-developed asylum systems are the ones most actively engaged in these epistemic community-like fora. This engagement makes them also prone to social learning.

\subsubsection{A shared understanding of work, of problems and solutions}

Epistemic communities are primarily characterised by the similarity of their members. The previous section showed that this similarity is related to knowledge - actors involved in epistemic communities are united by their knowledge - but it is also related to other factors, including a shared understanding of how the work should be conducted as well as a shared perception of problems and solutions. This section shows such similarity, and thus supports the argument that social learning is likely to occur in these communities.

One can decide on asylum applications without knowing a lot about the country of origin of the asylum seeker. One can also decide on safe country of origin policies without having acquired in-depth information on the situation in the country concerned. And in fact, these habits seem to prevail in a lot of countries. However, what unites actors involved in coordinating country of origin information is the shared understanding of how their job should be done - namely that both refugee status determination and country-specific policies need to be based on valid, up to date and reliable country of origin information. This shared understanding of their work leads to cooperation:

\footnotetext{
During the years the $[\ldots]$ countries noticed that it was an important issue: to have the information on the country of origin, to make a good decision, to make a good judgment of the situation in relation to the story that has been told [...] by the asylum seeker (interview 8 ).
}

We do believe in a certain way of working and sharing this information, and the burden-sharing of answering those questions [in the framework of ECS] (interview 8). 
The examples illustrate that actors engaged in COI cooperation do share a common understanding of how their jobs should be conducted - namely by properly basing a decision on country of origin information. This common understanding is a long-term process and has evolved over the years. Thus, the epistemic nature of COI cooperation fora is explained by their common long-term involvement in certain fora as well as the common seriousness that participants attach to the need for country of origin information. For example, the Eurasil country-workshops exist since 1992 - first in the form of the Council working group CIREA and since 2002 as the Commission working group Eurasil. They are explained as being only attended by 'experts, not the management' (interview 9) and by 'countries who are really interested in a certain country of origin and certain topics about this country of origin' (interview 8). Both quotes illustrate that involved actors define their community not only by who belongs to it, but also who does not belong to it: experts vs. management (i.e. policy-makers) or serious vs. non-serious countries. The latter also becomes obvious in the following statement. Being asked who is (not) involved in COI cooperation, one interviewee replied:

\footnotetext{
It is more about the serious and the non-serious countries. I consider countries like the Nordics, Germany, Austria, to a certain extent the UK, they take the issues [discussed in COI cooperation] serious and they have serious systems and they take the Geneva Convention seriously and they have elaborate [asylum] systems [...] it is a costly but it is a very big system to deal with treaty obligations (interview 3 ).
}

A sense of community not only evolved by the way in which the group defines itself but also by a shared understanding of problems and possible solutions. This was already discussed in detail in chapter 5. It was shown, for example, that the Intergovernmental Consultations on Migration, Asylum and Refugees were set up because countries realised that they have similar problems, and were in need of common solutions (section 5.4.2). The same goes for the Council working group CIREA which was explicitly set up to facilitate informal asylum policy coordination between states facing similar challenges (section 5.4.3). It was also shown that - because COI cooperation is driven by a shared understanding of problems and solutions - it is mostly limited to the Northern and Western European countries, in my case Germany and Luxembourg (and partly the UK).

The idea of facing similar problems features particularly prominent in bilateral exchanges between COI experts working on similar countries (for instance experts in France, Germany and Luxembourg all working on Somalia). The following example illustrates a usual request for information to country of origin experts, and their way to respond to it:

Every country knows how this works: you are with the minister in the meeting and the minister wants to know immediately how Germany handles this and this; and he wants to know this immediately, we all know this kind of situation: then it is good if you can pick up the phone and call Berlin or Nuremberg 
knowing that on the other end of the line, someone is doing everything possible to make sure that your minister gets an immediate answer; and this also works, absolutely (interview 16). ${ }^{143}$

The example illustrates the common understanding of working methods in the COI community. The interviewee (based in Luxembourg) was asked by a colleague to provide policy-relevant country of origin expertise on short notice. Because there is a common understanding on how urgent and politically-relevant these requests are, she immediately provides the requested information. Similar examples were given by other interviewees (interview 7; interview 25). A common understanding of work and challenges faced during work as well as trust and reliance play an important role here. Because of the similar challenges faced by all members of the community, one makes an effort to quickly provide the information asked for. This might be on request (as in the example illustrated above) but also in general: within the community, it is good practice providing each other with relevant new information or results of, for example, own factfinding missions (interview 7).

The analysis showed that there is one further similarity that defines a learning community, namely language. As one interview partner stressed, ' $\ldots$ it is not only knowledge, it is also language' (interview 8). We see that asylum policy coordination is the closest (and resembles epistemic communities in the best way) if members of the community share the same language. For example, there is a particular close cooperation on country of origin information among the German-speaking countries called DA-CH. Again, the commonality of language explains this close cooperation:

There is a special cooperation between the three asylum authorities in Germany, Switzerland and Austria in the framework of D-A-CH [...] this is the result of a simple, I call it the European language fragmentation; it is simply the German language that makes it easier to exchange non-English - namely German - information (interview 36). ${ }^{144}$

Yes, I mean on first sight, language is of course a crucial issue; the cooperation [in the framework of DA-CH] has been existing for a really long time already; and you also see this amongst other countries that cooperate very well, such as the Netherlands and Belgium or Belgium and France - which is facilitated by the language (interview 35 ). ${ }^{145}$

\footnotetext{
${ }^{143}$ Original quote: Also jedes Land kennt das, mit dem Minister im Meeting, der Minister will jetzt sofort wissen, wie händelt Deutschland das und das, und das will er jetzt sofort wissen, das kennen wir alle; dann ist es gut mal eben das Telefon in die Hand zu nehmen und Nürnberg oder Berlin anrufen zu können und zu wissen auf der anderen Seite tut jetzt jemand alles, damit dein Minister sofort eine Antwort kriegt, und das klappt auch, absolut.

${ }^{144}$ Quote in original language: Es gibt eine besondere Zusammenarbeit im Rahmen der D-A-CH-Kooperation zwischen den drei Asylbehörden Deutschland, Schweiz und Österreich [...] das resultiert aus was ganz einfachem, was ich die europäische Sprachfragmentierung nennen würde; es ist einfach der deutsche Sprachkreis, der es erleichtert, Informationen auch im Nicht-Englischen, nämlich auf Deutsch auszutauschen.

${ }^{145}$ Quote in original language: Ja, ich meine vordergründig war natürlich die Sprache erstmals ein ganz entscheidender Punkt, die Zusammenarbeit [in the framework of D-A-CH] gibt es eben schon sehr lange, und
} 
Both interview partners are based in the German BAMF. The former one emphasised a 'special cooperation' with Austria and Switzerland because of the common language and the subsequent possibility to exchange information in a non-English environment. The second quote illustrates that cooperation has grown over a long period of time and that the exchange with these particular countries (Switzerland and Austria) is not only explained by language but also by the habit of meeting regulary over many years.

Time and frequent meetings play an important role here. They help generating a common sense of community, and change attitudes within that community. The following interview excerpt illustrates that over the years, asylum policy coordination, and COI cooperation in particular, has been moving away from a cost-benefit exercise to naturally helping each other in a community based on solidarity (box 7.3).

Box 7.3: Changing attitudes towards asylum policy coordination (interview 36$)^{146}$

Q: ... what is the added value for an administration like BAMF to cooperate with Luxembourg, that probably can give very little content-wise in return - just because they are such a small administration and their expertise is on a very different level.

A: We have very different ideas about efficiency. Real efficiency is efficiency of the European Community. Nobody writes about the fact that Luxembourg is a member state under equal pressure as Italy, Malta or Greece; it is a distressed country facing five times as many asylum applications compared to a year ago; they don't have the capacity to look for COI; but because we have a strong interest in constitutional and efficient procedures in all member states, it is easy for countries with more personell to support those [member states] under pressure [...] this is European solidarity because the chain is only as strong as its weakest link [ ...] As a matter of principle, this is not about national interest but

das merkt man eben auch bei anderen, z.B. Niederlande und Belgien oder Belgien und Frankreich kooperieren z.B. auch sehr gut, was eben durch die Sprache erleichtert wird.

${ }^{146}$ Quote in original language: Was hat so eine Behörde wie das BAMF von einer Kooperation mit den Luxemburgern, die inhaltlich wahrscheinlich relativ wenig zurückgeben können - einfach, weil es eine wahnsinnig kleine Behörde ist und die Expertise auf einem ganz anderen Niveua ist? A: Weil wir ganz andere Vorstellungen von Effizienz haben; Effizienz ist die Effizienz der europäischen Gemeinschaft. Luxemburg ist ein Mitgliedsstaat. Obwohl kaum jemand darüber schreibt ist es genauso unter Druck wie Italien, Malta, Griechenland, ist ein notleidender Staat, dessen Asylanträge sich verfünffacht haben binnen Jahresfrist, die haben nicht die Kapazität nach COI zu suchen; da uns aber rechtstaatliche und effiziente Verfahren in allen Mitgliedsstaaten am Herzen liegen, ist es vielleicht ein Leichtes für Staaten, denen es personell ein bisschen besser geht, anderen Mitgliedsstaaten, die unter Druck sind, unter die Arme zu greifen [...] das ist europäische Solidarität, weil die Kette so stark ist wie ihr schwächstes Glied [...] im Prinzip ist hier nicht der nationale Eigennutz, sondern die europäische Solidarität als Mitgliedsstaaten der EU. Q: Ist das eine grundsätzliche Stimmung? A: Das ist eine grundsätzliche Stimmung, so sieht sich Deutschland [...] ich glaube so ist es in Berlin gemeint. Q: Und mit grundsätzlich meine ich über Deutschland hinaus? Wird das auch von anderen, die ähnliche Kapazitäten wie Deutschland haben, so gesehen? A: Also ich kann es ja nur aus meinem Blickwinkel sagen: voll und ganz, voll und ganz; das kenne ich noch, ich bin ja Veteran; ich kenne es noch aus dem letzten Jahrtausend, da war das ein vorsichtiges Kooperieren mit dem Schauen auf den eigenen Nutzen [...] aber inzwischen ist das tatsächlich solidarisches, kooperatives Handeln, vor allem weil man feststellt, es wird ja so ähnlich überall gemacht; die Nöte und Erfolge sind überall die gleichen, die Methoden sind ähnlich, es wächst zusammen. 
about European solidarity as member states of the EU

Q: Is that a general mood?

A: That is a general mood; this is how Germany views itself [...] I think this is how it is meant in Berlin.

Q: With general I meant beyond Germany. Do other countries with similar capacities as Germany also see it that way?

A: I can obviously only tell from my point of view: yes, completely, completely; I still know it, because I am a veteran. I still know it from the last millennium, by then it was cautious cooperation with making sure to get something out of it [...] but by now it is indeed solidary and cooperative action; mainly because we realise that it is done similarly in all member states; the problems and successes are the same, methods are similar; it is growing together.

The interview partner in the German BAMF was asked why he cooperates with his Luxembourgish counterpart. Given that Luxembourg has considerably less COI expertise, what would be the added value for the Germans? The interviewee explained his help to his colleague in Luxembourg by a sense of appropriateness. It seems normal to help the weaker parts of the community though there might be no imminent benefit to it (for Germany). Equally important to the fact that he stressed the need for cooperation without an immediate benefit for him, is the process he describes: after many years of cooperation, one has arrived at a point where it becomes normal to help each other. Whereas in the 1990s, asylum cooperation was very much focused on the own benefit, nowadays participating countries perceive the group as a community in which one naturally helps each other.

\subsubsection{Informal set-up and insulation from political pressure}

Until now, I showed that several conditions for epistemic policy coordination are fulfilled. Actors are united by their knowledge and perceive themselves as part of a longgrown community. This community is connected by a similar understanding of how work should be conducted, by common problems and solutions as well as similar language. As part of the analytical framework developed, it was also argued that epistemic communities become transmitters of norms to the realm of domestic policy-making if they are placed in an informal setting and insulated from political pressure (Checkel 2001). The informal nature of COI cooperation and the recent change to more formal modes of governance was extensively discussed in chapter 5. However, I want to show here how the informal nature of COI cooperation is perceived by actors involved in these exchanges, and how it eventually makes them more receptive for social learning processes.

Experts on country of origin information - be it policy-implementing country experts or policy-making experts in the responsible ministry - consult a variety of sources when looking for COI. These range from the nowadays rather formal fora (such as EA$\mathrm{SO}$ or the European Migration Network, see chapter 5 for a more in-depth discussion) 
to very informal exchanges. It is especially the latter informal exchanges that invite processes of social learning. When asked about their most important source of external (meaning from other countries) information, almost all interviewees referred to informal contacts in other European countries:

So it has been Eurasil, IGC and a very informal network, it has always been, I think that is the most important, the informal network between different heads of COI units, then Eurasil, and then IGC (interview 8).

The informal contacts to peers in other countries was generally named as the primary source of information if own, in-country research has not led to the wished result.

However, what does 'informal' mean for the actors involved, and why are they so particularly fond of it? To recap, by 'informal' the author relates to non-codified and not publicly sanctioned exchanges. ${ }^{147}$ And these are also the features praised by interviewees who are involved in this kind of information exchanges. In their view, the informal setup is particularly linked to a lack of formal constraints and the subsequent speedy access to information, which is illustrated by the following quotes from Dutch and Luxembourgish policy-makers (see also interview 3):

It is often easier to pick up the phone and call your colleague somewhere in Europe than go through the official channel (interview 9).

In case I have an informal request from colleagues, then I don't think about it a lot, but write an email in two minutes and send it off; then I don't have to worry about format or whatever; it is written and replied to quickly (interview 16) (148 $^{14}$

If I know the person that I call [to request information] it is of course something entirely different than if I have never seen this person before; that it is more stiff, more formal; this here is very informal (interview 16). ${ }^{149}$

The quotes not only illustrate the much valued informal nature of COI cooperation; they also illustrate habits that have been developed over the years. Writing to colleagues for information requests is something done naturally without much reflection on the actual process ('then I don't think about it a lot').

\footnotetext{
${ }^{147}$ When defining informal (governance), I relate to the respective definition by Christiansen at al. (2003), who consider two elements as crucial: information exchange is based on procedures that are not codified by formal or written rules; and information exchanges are not publicly sanctioned (p.7). For a more detailed discussion see section 3.2.4.

${ }^{148}$ Quote in original language: '... hab ich eine informelle Anfrage an meine Kollegen, dann überleg ich nicht lange, hab die Email in zwei Minuten stehen und ab ist sie; da muss ich mir keine Gedanken über Form oder sonst was machen; geht schnell raus und kommt genauso schnell wieder zurück'

${ }^{149}$ Quote in original language: 'Wenn ich denjenigen kenne, den ich anrufe ist das natürlich was ganz anderes als wenn es jemand ist, den ich noch nie gesehen habe, dann ist das steifer, dann ist das formeller, das hier ist ja informell'
} 
Next to the non-codified nature of COI cooperation, also its insulation from political pressure is key for involved actors. The following quotation (from Luxembourg) shows that COI cooperation is much about personal preferences, and not politics. The interviewee describes how she acquires (country of origin) information: if own research does not bring the expected result, ' (...) then I write my colleagues; but these are some kind of cliques [...] several member states know each other; this is not so much related to the country but more about personal preferences' (interview 16). ${ }^{150}$ Political considerations hardly play a role. Information is asked for from colleagues (she even describes them as a clique, a circle of personal friends) rather than politically aligned countries.

What is, however, interesting to note in that regard is that the information asked for is, eventually, very political: country A assessing the safety situation in country $\mathrm{X}$ is highly relevant for politics because it determines country A's general asylum policy towards country $\mathrm{X}$. The political nature of country of origin information and the consequences for transnational cooperation were repeatedly stressed by the interviewees, and are illustrated in an interview excerpt below (box 7.4). The interview was conducted with a Dutch civil servant being involved in COI cooperation for many years.

Box 7.4: An illustration of COI cooperation as epistemic community (source: interview 8)

The interview started with the interviewer asking how country of origin information is gathered by the national COI unit, whether COI units in other countries are consulted, what are the most important sources and what kind of information is asked for.

Q: What kind of information do you ask for?

A: Well, it is not so much about factual country of origin information, because there is not so much confidential about it.[...] The confidentiality element is more when it becomes in how are we going to use this information in relation to our policy, what is it going to mean or what could it mean for your policy, in the way you are going to decide in a variety of cases [...] we are not policy-makers, so we have to be very careful in trying to determine before the policy is being written down, what it could mean; so that is something that we do exchange among certain countries, but not with all countries. It is very much on a trust basis. I know if [...] my Belgian colleague calls me or I call her, we can exchange any information; she knows exactly what she can use and what she can't use; if she can't use it, she won't use it; it is different if I call my colleague from Romania, because they have a completely different way of looking at things, and I am not sure if the information that I will give him or her will stay with him or her; so especially the informal cooperation network that we have amongst a few countries, it is the Scandinavian countries, it's the UK, its France, Germany and Belgium, and I think that's about it; that's the real, very close informal, that is where we, well, try to find each other in a broader way than only the exchange of factual information.

Q: Why is it these countries?

A: It's an historical thing; these are the countries that already started with a real COI unit ten, fifteen years ago; just because out of the need that they had an enormous among of asylum seekers and they just needed this information.

${ }^{150}$ Quote in original language: 'dann schreib ich mal den Kollegen an, aber das sind immer so Cliquen [...] verschiedene member states kennen sich untereinander; das hat jetzt nichts mit dem Land zu tun, sondern ich sag mal persönliche Präferenzen' 
The interview excerpt in box 7.4 nicely summarises why social learning is likely to occur in transnational COI cooperation networks: actors involved have developed a shared sense of community (sharing history, sharing understanding of problems and looking for common solutions). This community includes some actors, and excludes others. History and frequency of meetings play an important role here. Habits and rules of exchanging information have developed over a long period of time. The exchange of information was always based on common experiences, trust and was very informal. Politics is actually a key element of the cooperation - but not in the sense that participants are exposed to political pressure. Rather there is a common understanding about the political sensibility of topics and the subsequent informal nature to deal with these issues.

In sum, this section aimed to show that asylum policy coordination can lead to social learning because it resembles many features of epistemic communities. Actors of the countries studied, namely Germany and Luxembourg, perceive the exchange of country of origin information and the coordination of policies as a common enterprise driven by shared values and a notion of solidarity. Hence, one of the conditions for social learning to occur - namely the engagement in epistemic communities - is given. Similar conclusions on part of the UK cannot be drawn because of the limited data availability. ${ }^{151}$ However, for both Germany and Luxembourg, one can assume that actors being involved in asylum policy coordination were also prone to learn in these fora - and, probably, adopt what they have learned in the national policy-making process. Nevertheless, it is this very link between the two (learning and adopting what was learned) that could not be made.

A few words on Malta: It was previously argued that much of informal asylum policy coordination (and COI cooperation in particular) is linked to the old EU member states. This epistemic form of policy coordination is almost exclusively performed by the Northern and Western European countries: for example, Germany, the Netherlands, Denmark and Sweden are very active in these kinds of exchanges; whereas there is no role for Italy, Spain, Malta or Bulgaria. The reason for this 'divide' is discussed elsewhere in-depth. ${ }^{152}$ What, however, is important to ask at this point is whether social learning as the result of transnational COI cooperation is only something that can be observed in the first group of countries listed above (because only they are part of epistemic communities). The simple answer is 'no'. In what follows, I will argue that also countries not involved in COI cooperation can adopt safe country of origin policies out of appropriateness considerations.

\footnotetext{
${ }^{151}$ For a discussion of the problems with UK data and its implications, see 7.6.2 and 8.3.

${ }^{152}$ In short, informal COI cooperation has been largely limited to states with considerably well-developed asylum administrations, that is Northern and Western European countries. Involvement in these cooperation networks is not determined by EC/EU membership but by shared problems, common legal requirements and common language (see 5.4.1).
} 


\subsection{A Europe-wide consensus on safe country of origin policies}

This section shows that adopting safe country of origin policies out of appropriateness considerations does not depend on being involvement in an epistemic community. It thus provides a social constructivist explanation for SCO policy-making in those countries not part of the coordination-exercise described in the previous section. It is argued that the existence of an EU-wide consensus on safe country of origin policies made new member states considering these policies appropriate - and adopt them at the national level. By drawing on the case of Malta, it will be shown that the introduction of such policies and respective lists can be very well explained by a social constructivist framework.

\subsubsection{The emergence of a safe country of origin norm}

Chapter 2 illustrated that, by the end of the century, most EU member states had introduced the SCO notion in their national asylum law. ${ }^{153}$ Several of them had also adopted respective lists of safe countries of origin. One can thus say that, throughout the 1990s, a consensus emerged across Europe - regarding the appropriateness of such policy measures. The consensus among EU governments made new member states joining in 2004 and 2007 to introduce a SCO notion (and adopt respective lists) out of appropriateness considerations.

There are two events illustrating this consensus among EU countries. First, in 1992, the ministers of the member states of the European Communities agreed on the London Resolutions (Council of the European Union 1992a and 1992b) regarding accelerated procedures for manifestly unfounded applications. The London Resolutions can be marked as the birth of cooperation on safe country of origin policies. Second, in 2004, the discussions in the Justice and Home Affairs Council (as part of the adoption of the Asylum Procedures Directive) showed that the substance of SCO policies was still controversial, but not the SCO notion as such. Eventually, the adopted directive on asylum procedures saw some minimum norms on the safe country of origin notion but no common list of countries to be declared as safe. ${ }^{154}$

Regarding the negotiations in 2004, two issues need to be separated - the idea of safe countries as such and the countries proposed to be included in the common list. Regarding the first, there has been a consensus among governments on the legitimacy and the need for introducing the SCO policy as such. In fact, it is reported that only one country (Sweden) had opposed the general idea of safe countries of origin (i.e. the principle that a country can be safe for all asylum seekers coming from there) but later re-

\footnotetext{
${ }^{153}$ See figure 2.1 for a timeline showing the year of introduction of safe country of origin policies in all EU member states.

${ }^{154}$ For a more detailed account of both events, see chapter 2 .
} 
frained from this opposition (Statewatch 2004). Also non-state actors had not opposed the concept as such. For example, both UNHCR and the Parliamentary Assembly of the Council of Europe suggested its usage in much regulated terms (ELENA 2005, p.8; Council of Europe 2005, paragraph 8.2). ${ }^{155}$ There was a lot of disagreement in the Council on the countries proposed to be on the common list (Statewatch 2004). Eventually, no such list was adopted due to two reasons: the disagreement on the countries to be designated as safe; and a ruling by the European Court of Justice stressing that, by adopting such a list without including the European Parliament, the Council had overstepped its competences (European Parliament v. Council of the European Union, 2006). There was, however, consensual agreement amongst governments on the appropriateness of having safe country of origin policies - and this is the crucial point for the argument made in this section.

Today, such policy measures are not particularly controversial anymore. In fact, they are part of a day-to-day business of screening out early in the asylum procedure applicants from certain countries of origin. Reviewing asylum procedures in all its participant countries, the IGC stressed in 2009 that '... concepts of safe countries of origin and safe third countries have now become the norm rather than the exception in refugee status determination' (IGC 2009, p.15). There are other instances pointing at such consensus. For example the amount of criticism voiced in the course of the adoption of the original versus the recast Asylum Procedures Directive: when the SCO notion was introduced in 2004, many NGOs criticised its (intended) adoption and the accompanying common list of safe countries of origin (see section 2.3.2). However, during recastnegotiations in 2013, there was not much criticism on the (revised) SCO notion. This shall, in no way, be understood as a criticism to the advocacy work of NGOs. They also have to economise with their scarce resources and it seems as if they viewed the SCO notion as a lost battle, and rather concentrated their work on other issues. In any case, for the argument made in this section, it is confirming evidence that the SCO notion became accepted.

This consensus is most recently illustrated by the Europe-wide designation of Western Balkan countries (and Serbia in particular) as safe (box 7.5).

In sum, there is consensus among governments in Europe that the safe the country of origin notion (and respective lists) are legitimate and necessary parts of a country's asylum policy. The next section shows that the introduction of these policies in the new EU member states followed a logic of appropriateness - for the simple reason that the discourse had changed from safe country of origin policies being a contested to being an accepted norm.

${ }^{155}$ However, criticism was raised by NGOs (Statewatch 2004). 
Box 7.5: The consensual designation of Serbia as a safe country of origin

The Western Balkan presents the most recent example to illustrate that the designation of countries of origin as safe is not a contested concept anymore - quite the opposite: it is commonly accepted to use the notion as a tool to curb numbers of asylum seekers from unwanted countries, in this case from Serbia and Macedonia. The number of asylum seekers from Serbia were always relatively high but skyrocketed with the launch of the visa liberalisation process for the Western Balkans in 2008. This process had an immediate influence on asylum application numbers. Whereas in 2009, 5,325 people from Serbia claimed asylum in an EU member states, these numbers more than tripled (to 17,715) in 2010 (Eurostat). In addition, the protection rates for Serbian asylum seekers were among the lowest of all countries of origin. Consequently, there is a disproportionate ratio between (very high) application rates and (very low) acceptance rates. This ratio is a common sense reason to designate the respective country of origin as safe (Engelmann 2014a). Anticipating these increases in Serbian asylum applicant numbers, several member states added Serbia to their list of safe countries of origin, including Austria (2009), France (2009), Luxembourg (2011), Belgium (2012) and Germany (2014). ${ }^{156}$ This rapid spread of SCO designations related to a certain country (or region) shows its uncontested nature and the general consensual agreement on part of EU member states as using SCO designation as an appropriate tool to react to unwanted streams of asylum seekers.

\subsubsection{The adoption of an appropriate norm}

A change in discourse explains why the new member states joining in 2004 and 2007 have adopted safe country of origin provisions in their asylum law. While the Copenhagen Criteria (defining conditions when a country is ready to join the European Union) required Bulgaria, Cyprus, the Czech Republic, Estonia, Hungary, Latvia, Lithuania, Malta, Poland, Romania, the Slovak Republic and Slovenia to adopt the asylum acquis, they were actually not obliged to include a safe country of origin provision in their national asylum law. ${ }^{157}$ However, all of them did include it (table 7.2).

Table 7.2 shows that all 2004 and 2007 accession countries introduced safe country of origin policies before they joined the EU (except Slovenia). They did so because the SCO notion had become consensus, and consequently considered appropriate to be adopted.

\footnotetext{
${ }^{156}$ Also the UK and Bulgaria see Serbia as a safe country of origin though their designations (both in 2003) predate the visa liberalisation process.

${ }^{157}$ However, there was a requirement for member states to apply the SCO principle in national law as far as related to the common list (Statewatch 2004).
} 
Table 7.2: Year of introducing SCO provision in national asylum law in 2004 and 2007 accession countries

\begin{tabular}{ll}
\hline Country & Year of introducing SCO provision in national law \\
\hline Bulgaria & 2003 \\
Cyprus & 2003 \\
Czech Republic & 1991 \\
Estonia & 1997 \\
Hungary & 1997 \\
Latvia & 1997 \\
Lithuania & 2000 \\
Malta & 2000 \\
Poland & 1997 \\
Romania & 2001 \\
The Slovak Republic & 1996 \\
Slovenia & 2006 \\
\hline
\end{tabular}

For most of the accession countries, it can be excluded that they introduced SCO notions in order to deter certain groups of asylum seekers. First, there were no big numbers of asylum seekers in these countries by then anyways (only after they actually joined the EU and became external border countries); and second, until today, most of the accession countries do not actively make use of their SCO provision: Bulgaria introduced the policy in 2003, adopted a list in 2005 but is actually not using it at all (email communication \#1; email communication \#2); the Czech Republic is not making use of its SCO provision (email communication \#3); the same applies to Hungary (email communication \#4), Latvia (email communication \#5), Malta (interview 28) and Poland. For these countries, the safe country of origin provision is not much more than empty words on paper. This is a big contrast to the importance and strategic aim attached to safe country of origin policies by the old member states, and Germany and the UK in particular. ${ }^{158}$ Consequently, the adoption of SCO provisions in 2004 and 2007 member states did not follow the same (consequentialist) logic as in the old member states. The provisions are not used and do seem to be not more than paper tigers. This suggests that they were not adopted with a clear aim in mind but simply because it seemed appropriate to do so. Already since 1992, there were discussions at the EU level about introducing accelerated procedures, and safe country of origin provisions in particular. Inspired by the general discourse and acceptance of these policies as part of an

\footnotetext{
${ }^{158}$ In fact, the issue of SCO designations was so political that it considerably delayed the adoption of the Asylum Procedures Directive (see section 2.3.3).
} 
EU country's asylum law toolbox, the soon-to-be member states adopted SCO provisions as part of bringing their national laws in accordance with EU requirements.

In order to illustrate this argument, let us look at the case of Malta in more detail. Malta introduced the safe country of origin notion in 2000 and adopted a list of 13 countries in 2004. The Maltese list looks like an almost exact copy of the common EUwide list, as discussed in the Justice and Home Affairs Council in 2004. Table 7.3 compares the countries discussed to be included in this common list of safe countries of origin and the Maltese list.

Table 7.3: Proposed EU-wide SCO list (2004) and Maltese SCO list (2004)

\begin{tabular}{ll}
\hline Proposed EU-wide SCO list & Maltese SCO list \\
\hline Benin & Benin \\
Botswana & Botswana \\
Cape Verde & Brazil \\
Chile & Cape Verde \\
Costa Rica & Chile \\
& Costa Rica \\
Ghana & Gabon \\
& Ghana \\
Uruguay & India \\
Mali & Jamaica \\
Mauritius & Mali \\
\hline
\end{tabular}

Table 7.3 shows that the Maltese and the proposed EU-wide list are almost identical. There is no other formal SCO list adopted in any EU member states that has a comparable similarity to the proposed common list. This similarity suggests that the Maltese authorities were very much aware of the most appropriate content of such a list. Two by then - responsible ministers stressed that the Maltese list includes certain countries of origin because these countries were on the lists of the EU member states. Being asked in parliament, the responsible minister stressed that the Maltese SCO list 'must be in line with that of other European countries. For example, if Australia or Japan are safe countries of origin, and this is recognized by $25 \mathrm{EU}$ countries, why should we not con- 
sider these countries as safe countries too' (PoM 2004a, p.355). ${ }^{159}$ Note the difference to Luxembourg, Germany and the UK. There, it was explicitly stressed that the list should be useful (i.e. including countries from which there are actually applicants), and not a list of some (random) safe countries in the world. Such considerations are very different from the Maltese case. In fact, the minister went even one step further. He not only justified own designations with what is common sense in most of the member states. He also shied away from adding countries to the list where there is no such common agreement yet. Being asked why Serbia and Montenegro are on the list of other countries but not of Malta, he replied: 'I do not want to commit myself over Albania, Serbia and Montenegro before I know there are many other EU countries that accept them' (PoM 2004c, p.17). ${ }^{160}$

The quotes show that the existence and content of the Maltese safe country of origin list were explained with similar lists in other EU member states. Neither in parliament nor during interviews has there been a justification relating to the actual numbers of asylum seekers coming from the countries declared as safe. This is also confirmed when looking at the statistics: in Malta there is no link between countries declared as safe and a disproportionate ratio of (high) application rates and (low) recognition rates. In fact, only from one country on the list (India) Malta had received any asylum applications in the years 2003 and 2004 (10 applications in 2004, Eurostat). No applicants were recorded for the remaining 13 countries on the list in either 2003 or 2004 (see table 6.6 in section 6.2). In contrast to the situation in previously discussed EU countries, Malta has clearly not introduced the list to deter asylum seekers. Observers of Maltese asylum policy have stressed several times that the Maltese authorities adopt a 'copy and paste' approach when it comes to drafting or amending asylum regulations and bringing them in line with EU legislation (interview 32; interview 27). This approach can be explained by the lack of expertise (see section 7.4.1) but - equally relevant - it can be a sign of aiming for the most socially accepted policy solution.

Consequently, it was shown that Maltese policy-makers were heavily influenced by decisions taken at the EU level. One the one hand, this seems logical. In 2003/2004 when the Maltese list was discussed, Malta was about to become an EU member state. The EU can be seen as a norm-promoter playing a crucial role for the country that is about to join the club. Checkel (2001a, p.563) argued that the persuader (here the EU or the countries proposing the common list) is an authoritative member of the in-group to which the persuade (Malta) wants to belong to. Maltese authorities considered the adoption of the very list as appropriate because a list that had already been discussed (and

\footnotetext{
${ }^{159}$ Quote in original language: ... liema lista ghandha tkun in line ma' dik ta' pajjizi Ewropej ohrajn. Per eżempju, jekk 1-Awstralja jew il-Ǵappun huma safe countries of origin, u dan gie rikonoxxut fxi pajjiż mill-25 pajjiż ta' l-Unjoni Ewropea, ghaliex m'ghandniex inqisu lil dawn il-pajjiżi bhala safe countries of origin ahna wkoll?

${ }^{160}$ Quote in original language: Jiena nghid ejja nibdew b'dawn u ma nixtieqx nikkommetti ruћi fuq l-Albanija u Serbia Montenegro qabel ma nkun naf li hemm hafna pajjiżi ta' l-Unjoni Ewropea li jaćcettawhom.
} 
agreed upon) by most of the EU member states is the most socially accepted solution. Consequently, the social context (of approaching EU membership) was prone to social learning.

In sum, this section showed that safe country of origin policies (and respective lists) were adopted because policy-makers consider it the most appropriate thing to do so. There is already a consensus on the legitimacy of these policies at the EU level and, consequently, new member states adopt SCO provisions as part of a 'normal' asylum procedures toolbox. The case of Malta served as an example to illustrate this argument. What was shown in this and the previous section is that social learning occurred at the transnational level. A respective argument was made for three of the four case studies: for Germany and Luxembourg, social learning occurred within epistemic communities facilitating asylum policy coordination, and exchange on country of origin information in particular. As a result of these exchanges, one can expect policy-makers to learn and become convinced of other countries' (policy) solutions, and adopt them in their own, national context. For the case of Malta, social learning occurred as part of a broader European-wide consensus on the appropriateness of SCO policies, and the adoption of respective lists. Given that consensus, Maltese policy-makers became convinced of the appropriateness of such a policy in their own, domestic context. So far, the analysis focused on the transnational level (i.e. the exchange between the case study countries and other countries). Next to conditions at the transnational level, there are also mediating conditions at the domestic level facilitating the implementation of what has been learned. The next section looks at them in more detail.

\subsection{Indeed social learning? Domestic conditions when downloading}

What the chapter showed so far is that asylum policy coordination, and cooperation on country of origin information in particular, resembles epistemic communities. Thus, social learning is likely to occur within these coordination fora. This argument is especially valid for the cases of Germany and Luxembourg. The analysis also showed that today's understanding of safe country of origin policies is one of an ordinary part of a country's asylum legislation. This perception explains the adoption of such policies in the newer member states, including Malta. In the beginning of the chapter, I also investigated conditions at the domestic level making policy-makers prone to social learning. It was concluded that Malta and Luxembourg are more open to arguments of appropriateness (and more likely to be convinced of others' arguments) than Germany and the UK. Following the timeline of conditions established in the analytical framework (see section 3.4.2 and table 7.1 at the beginning of this chapter), this section now returns to the domestic level. It looks at in how far the institutional framework at the domestic level and respective political culture shaped the look-a-like of SCO policies and the implementation of what had been learned. 


\subsubsection{Domestic institutions facilitating consensus}

Social learning is facilitated by an institutional landscape that is conducive to consensusbuilding (Börzel and Risse 2003, p.68). In general, domestic institutions need to facilitate and be open to new ideas and, eventually, policy change (see also section 3.3.2).

Both Malta and Luxembourg have the institutional requirements for social learning-induced domestic change: in Malta, there are only two parties in the parliament who have been alternating in the government and the opposition. Though there is disagreement over many issues, both parties more or less agree when it comes to asylum policy (Lutterbeck 2009, p.136). This also becomes obvious when looking at the parliamentary debates on the adoption of the original Refugees Act (2000) as well as subsequent changes in 2005 and 2008. None of these debates saw disagreement between the parties but an overall consensus on the proposed measures to be adopted (see PoM 2000; PoM 2004a; PoM 2004b; PoM 2004c; PoM 2005a: PoM 2005b: PoM 2005c: PoM 2008). Another indicator for institutions favouring consensus is the lack of parliamentary scrutiny when it comes to designating countries of origin as safe. This accounts for Malta but also for Luxembourg, where the parliament - normally a key veto player to the government - was not involved in safe country designations. This absence of the legislative is also nothing that worried MPs, quite the opposite: given the limited resources of Luxembourgish MPs (compared to other countries), they seemed to be surprised rather than concerned about the interviewee's remark on the parliament not being involved in the policy-making process (interview 14).

An institutional landscape that is conducive to consensus-building can also relate to the role of non-state actors. In Malta, there is hardly any role for NGOs when it comes to advocating for policy. In the following example, one of two NGOs in Malta focusing on advocacy work, portrayed its efforts to influence the first asylum law ever in the country, adopted in 2000 (and introducing the SCO notion):

\footnotetext{
We asked the government to show us [...] the proposed amendments before accepting them, to give [us] enough time to comment on them; the minister gave them to us a few days before they were adopted [...]; but then they were made public anyways, so it was not a special kind of consultation; [...] we compiled detailed analysis of the draft, article by article, commenting on how the draft conforms to the [refugee] convention; which we presented to the minister; we had a meeting with the minister's legal advisor, the EU officer, and we had quite a long meeting; we really explained fundamentals and basics of refugee law; but then it [the law] was accepted as presented (laughs); we were extremely frustrated (interview 27).
}

Thus, NGOs do not represent any kind of veto points (or constraints on the government). This can also be observed in Luxembourg. Here, the list of safe countries or origin was adopted in a quick and unexpected manner, coming very much to the surprise of national NGOs, which had not been consulted at all in the decision-making process (interview 10; interview 12; see also section 6.3.3). 
The examples presented above illustrate that policy-makers aiming at introducing or changing SCO policies, are confronted with domestic institutions facilitating (instead of hindering) these intended changes. In both Malta and Luxembourg, policy-making power is concentrated in the hands of few actors which makes it easy to induce policy change. This is a big difference to the institutional setting in the other two case studies. In Germany, the parliament plays a much stronger role in the policy-making process. The necessity to agree on any designation with the Bundestag, in fact, has hindered the German government(s) from using the SCO provision (see section 6.6). Checks and balances provided by the parliament but also courts and non-state actors in both Germany and the UK suggest that whatever has been learned at the transnational level (i.e. in epistemic communities), cannot be implemented unnoticed. This was also concluded by Checkel (2001a). Studying social learning in the case of Germany, he stressed that

The Federal Republic is a robust, functioning democracy, where decision makers are subjected to daily pressures and appeals. This low degree of political insulation, which reduced the possibilities for private, in camera, interaction, worked against effective persuasion and social learning at the agent level (p.570).

This is not to suggest that the domestic institutional structure in these countries does not facilitate consensus - but it does so to a very different extent than in Malta and Luxembourg.

\subsubsection{Political culture}

Next to domestic institutions facilitating social learning, also the political culture plays an important role. In the theoretical discussion, the term nation-state identity was introduced in order to capture the political culture of a country (section 3.3.2). Nation state-identity means the way government and party elites perceive their country (Marcussen 2001). I argue that this identity construction (in particular in relation to other countries) plays an important role how safe country of origin policies look like.

Both factors - institutional landscape and nation-state identity - are closely intertwined. To illustrate that linkage, let us return to the example of Malta and its NGOs. It was stressed before that the understanding of the role of nongovernmental organisations is very different in Malta than in other European countries. NGOs doing advocacy work are hardly ever listened to (by both the public and policy-makers). The reason lies in the understanding of the Maltese nation state, in which NGOs have a very distinct role, namely providing charity rather than advocating for rights (interview 27; interview 32; interview 30). This perception also results in the government not seeing the need for listening to NGOs.

Part of the nation-state identity is the historical linkage with other countries. This linkage can explain two very different aspects of safe country of origin policies: first, it can explain what countries to turn to in the process of social learning; and second, it can 
explain the actual designation of countries of origin as safe. In what follows, both aspects are discussed.

Close ties with European countries - from whom to learn?

This section shows that the way policy-makers perceive their country in relation to other countries, tells us something about from whom to learn.

Let us consider the example of Malta again: Malta's nation-state identity is traditionally very closely linked to the United Kingdom. This comes not as a surprise given that Malta was under British command for over 150 years (from 1800 to 1964). Until today, Malta is culturally and politically closely affiliated to the UK (interview 26; interview 27) and has, as one NGO representative noted, 'a great admiration for the British' (interview 32). Maltese policy-makers stressed that they tend to orientate themselves towards the UK and Ireland when taking asylum policy decisions in an EU context:

We frequently refer a lot to legislation enacted by English-speaking countries; UK, Ireland [...] we tend to obtain information on what is being done in those countries (interview 26).

As I said, we work a lot with the UK [...] usually we make use of the information they have got but sometimes we also refer to them special cases (interview 28).

In several interviews, the British case was cited as the example on which Malta is closely oriented (interview 26; interview 27; interview 32). The UK generally is the main reference point for the Maltese government when it comes to learning about other country's policy choices. This is confirmed by the 'frequent' reference to the UK or by 'working a lot' with UK data - as the previous quotations showed. This habit of referring to the UK is based on a general understanding that 'the UK is generally doing things better than most other people [countries]' (interview 27). This also becomes clear if one looks at the debates in parliament. When the SCO notion was introduced and possible countries to be designated as safe were discussed, MPs and the minister frequently referred to the respective UK policy (PoM 2004b; PoM 2004c; see also sections 6.4 and 6.5). This close affiliation with the British is a strong part of Maltese nation-state identity, and makes policy-makers naturally turn to the UK before adopting policy. A similar argument could be made for other countries too: policy-makers in Luxembourg think very high of the Benelux-cooperation and tend to look towards the Netherlands and Belgium first, when being in search for policy solutions (interview 14).

\section{Whom to declare as safe country of origin?}

So far, the nation-state identity argument told us something about from whom the discussed countries are likely to learn. However, the way policy-makers perceive their country in relation to others also tells us about the actual composition of the safe country of origin list. Again, historical linkages play an important role. Let us consider Luxembourg and Cape Verde. Cape Verde was one of the countries designated as safe by 
the Luxembourgish authorities in 2007. Luxembourg traditionally has very close ties with Portugal. For many years, Portuguese immigrants were the largest foreign community residing in Luxembourg ${ }^{161}$ - and Cape Verde was a Portuguese colony for over 500 years. Nowadays, Cape Verde is one of the target countries of Luxembourgish development cooperation. ${ }^{162}$ According to policy observers, this also explains the designation of Cape Verde as a safe country of origin. Asked, why she thinks that Cape Verde is designated as safe, one interviewee replied: '...for Cape Verde, it is obvious because Cape Verde is a former Portuguese colony and we have a lot of Portuguese living here in Luxembourg' (interview 12). Interestingly enough, cooperation with countries of origin nowadays focuses very much on prevention strategy (EMN Luxembourg 2010, p.65). This, however, does not obscure the fact that the countries of origin are put on the list because the Luxembourgish authorities consider this as 'obvious', as appropriate, given the common history and the close ties between the countries.

What is worth to note is that these close ties and common history serve for some policy-makers as a reason to put the countries on the list, while for others it is a reason not to do so. During 2003 negotiations in the British House of Commons, the Liberal Democrat Hughes opposed the list by stressing that

\begin{abstract}
[t]he measure [extending the SCO list twice during 2003] appears to affect some of the countries with which we have the most long-standing links through both the Empire and, more recently, the Commonwealth. It appears to concern countries from which there are large communities in this country, many members of which have made a significant contribution, including those who have fled as asylum seekers from civil war and persecution (HoC 2003, c. 018).
\end{abstract}

This Member of Parliament used the Commonwealth history as a reason not to declare countries of origin as safe. Again, the perceived nation-state identity provides an argument why countries of origin are put on the list (as in the case of Luxembourg and Cape Verde), while it can also serve as reasoning for why countries should not be put on the list (UK and Commonwealth countries).

The nation-state identity not only tells something about which countries (not) to designate as safe but also when to do so - at least for the case of Luxembourg. Policymakers in Luxembourg became not tired of stressing the European and human rightsfriendly character of Luxembourgish refugee policy. Also during interviews, it became clear that policy-makers have a certain understanding of how asylum policy should (not) be conducted. Being asked why Serbia was added rather late to the SCO list - at least when compared to other EU member states - the interviewee replied:

\footnotetext{
${ }^{161}$ 1987: 30,250 Portuguese immigrants, $8 \%$ of total population; 1996: 51,500 Portuguese immigrants, $12.5 \%$ of total population (Cruz 1999, p.245)

162 One example for the focus on Cape Verde in Luxembourgish development cooperation is the fact that Luxembourg is one of only five EU member states that participate in a Mobility Partnership with Cape Verde (Reslow 2013).
} 
A: We considered including Serbia for a really long time already; and we were constantly waiting for the right moment to designate Serbia as safe; and now in this emergency situation ... we always said that we actually have to add Serbia, also probably for political reasons, but we had almost no Serbs, only Kosovars.

Q: For political reasons? Because Serbia wants to be designated as safe?

A: No. There was no reason anymore to have only Macedonia, only Bosnia and Herzegovina on the list, and not Serbia; we always sad that it would be desirable, yes; but we had almost no asylum seekers from Serbia; and now that asylum seekers from Serbia skyrocketed, we said that this is the moment to put Serbia on the list (interview 13). ${ }^{163}$

The quote illustrates that there is a certain understanding of how SCO policies should be conducted. It is only considered appropriate to designate Serbia as safe if there are indeed high numbers of asylum seekers from that country. This argumentation is quite different than from other countries such as the UK where policy-makers did not shy away from designating countries as safe that produce rather low numbers of asylum seekers. In any case, there were certain rules of appropriateness to follow for Luxembourgish policy-maker before actually designating a country as safe. Again, this is rooted in the countries self-perception as being relatively refugee-friendly and not aiming at the strictest policy in Europe. This self-perception also became obvious during debates in parliament. The introduction of (several measures allowing for) accelerated procedures explicitly related to similar measures in other European countries. However, the tenor of the argument (by the minister) was that own provisions allowing for such procedure are much more lenient than those of other EU member states - and would thus be justified (PoL, Schmit, p.166; see also section 6.5).

Summing up this section, nation-state identity helped further explaining the content of SCO listsin the countries studied. Traditionally, there a strong ties between some European countries but also between some European and non-European countries. Both these connections have been growing over years and centuries. The way policymakers perceive their own country in relation to others, helped explaining how the lists look like (which country is designated as safe and which not) but also the actual policymaking process (whom to look at). Orientating own policy decisions on others' becomes taken for granted and the right thing to do. At one point, these ideas about how asylum

\footnotetext{
${ }^{163}$ Quote in original language: A: Überlegungen gab es ständig für Serbien; und wir haben ständig abgewartet wann der richtige Moment wäre, Serbien draufzusetzen; und jetzt haben wir eigentlich aus der Not heraus bald, wir hatten immer gesagt ja, Serbien müssen wir eigentlich drauf setzten, auch aus politischen Gründen vielleicht; aber wir hatten fast keine Serben; wir hatten nur Kosovaren. Q: Aus politischen Gründen, weil Serbien das gut findet, wenn es entsprechend eingestuft wird? A: Nein, es gibt eigentlich keinen Grund mehr, wieso man Mazedonien auf der Liste hat, wieso man Bosnien-Herzegovina auf der Liste hat und wieso nicht Serbien; aber aus unseren Überlegungen heraus haben wir immer gesagt, es wäre wünschenswert, ja; aber wir haben fast keine serbischen Asylbewerber und jetzt wo die serbischen Asylbewerber steil bergauf gingen, haben wir gesagt, ok, jetzt ist einfach der Moment Serbien auf die Liste draufzusetzen.
} 
policy is made are embedded in institutions and in the country's policy-making culture. Nevertheless, the evidence collected for this argument varied. Policy-making following rules of appropriateness is assumed to occur in all four countries studied. In the present analysis, however, they could only be identified for the cases of Malta and Luxembourg.

\subsubsection{Conclusion}

In the current chapter, safe country of origin policy-making was interpreted as following a logic of appropriateness. More specifically, I showed that much of transnational asylum policy coordination and cooperation on country of origin information in particular, can be viewed as occurring within epistemic communities. For example, in CIREA but also in bilateral and small-scale cooperation networks, we observe patterns of epistemic asylum policy coordination: policy-makers come together in order to discuss whether and how to introduce SCO policies, how to construct these policies and how to realise their implementation. These cooperation networks resemble epistemic communities because involved actors are united by their common knowledge as well as a common understanding of their work. These commonalities and the private nature of exchange lead to trust and reliance amongst its members. For both Germany and Luxembourg involvement in these communities is likely to lead to social learning. Actors from these countries engage in policy coordination and become socialised. Whatever they learn during these exchanges is taken back home to the capital and, supposedly, takes shape as domestic policies.

Beyond the epistemic nature of transnational policy coordination, the chapter also showed that the discourse in Europe regarding the SCO notion has changed. Adopting such policies is nowadays considered as one of many appropriate measures in the asylum procedures tool box. Whereas these policies were, originally, introduced as a measure to deter asylum seekers from certain countries of origin (and thus followed very much a consequentialist logic), the 2004 and 2007 accession countries adopted them because of their general acceptance. There is no questioning anymore whether or not such policies should be adopted; at the most the way how to do so is contested. Consensus on the appropriateness of SCO policies was illustrated by drawing on the case of Malta. The most recent example for illustrating this consensus among governments in Europe had been the exhaustive and EU-wide designation of Serbia as a safe country of origin.

Of course, the learning environment as such does not in itself determine domestic change yet. Mediating factors come into play. Conditions at the national level - including the history of asylum policy-making, cognitive priors of policy-makers involved, an institutional setting favouring consensus and political culture - make actors receptive for policy solutions from elsewhere, and implement what they have learned. For both Luxembourg and Malta, it was shown that these domestic conditions make policymaking likely to follow a logic of appropriateness. For example, the absence of a history 
of asylum policy-making in these countries indicates that policy-makers are more open to be convinced of other countries' ideas. Also the way policy-makers perceive their nation-state identity helps explaining why they turn to particular countries to learn from them, and how the eventual list of safe countries looks like. On the one hand, the perception of relationship with other European countries explains the paths of social learning. For example, Malta turns to the UK because - as part of their colonial history - they always did so. Luxembourg turns to the Netherlands and Belgium because of the long-grown Benelux ties between them. On the other hand, the perception of relationship with countries of origin explains the look-a-like of safe country of origin lists. For example, Luxembourg has close ties with Cape Verde meaning Cape Verde somehow naturally belongs on that list.

In concluding, the analysis in the current chapter showed that policy-making in Malta seems to have followed a logic of appropriateness. For both Germany and Luxembourg, the picture is mixed. Whereas I found some evidence of policy-making being determined by rules of appropriateness, it was not possible to re-trace the full story of policy-making, and in particular the link between learning and implementing what has been learned. For the UK, one could only find traces of evidence for decisions being shaped by rules of appropriateness. The final part of this section gives a summarised account of policy-making in each of the four countries studied in detail. By doing so, it takes findings from both the logic of consequences (chapter 6) and the logic of appropriateness (this chapter) into account.

\subsection{Summary of findings for each of the cases}

The final section summarises the findings from this chapter (logic of appropriateness), and sets them in relation to the findings from chapter 6 (logic of consequences). For each of the four countries selected, I will discuss in how far the two logics haved helped explaining the role of policy coordination in domestic asylum policy-making. While this section focuses very much on the data, the conclusion (chapter 8) will discuss at a more abstract level in how far the two logics relate to each other.

\subsubsection{Germany}

The analysis showed that Germany was a key player in establishing the norm of safe country of origin at the European level. They did so for very calculated reasons: the policy measure was introduced to limit the number of asylum seekers from specific countries, including Romania, Bulgaria, Senegal and Ghana. Not being able to introduce the SCO notion in the late 1980s and early 1990s, the German government successfully played the two-level game. Once the norm was established at the European level (in the form of the London Resolutions), they downloaded it with the justification of having to 
bring domestic law in line with European law. Thus, policy coordination with other countries primarily served one purpose: to come to a European agreement on the necessity of such policy measures. This is straightforward consequentialist logic in safe country of origin policy-making (see chapter 6).

However, probing deeper into the actual process leading towards the formulation of asylum policies (and safe country of origin policies in particular) the picture becomes more nuanced: Germany has always been and still is a key player in transnational asylum policy coordination, and in particular in COI cooperation. This cooperation started among a few countries in the 1980s and continues to exist until today. While the establishment of cooperation fora might initially have followed a very consequentialist logic, over time they became perceived by involved German representatives as epistemic communities: instead of looking for one's own benefit, solidarity prevailed. Actors became socialised and perceived COI cooperation as appropriate to help their counterparts from other countries, primarily from those with less well-developed asylum (and COI) systems. They did so without expecting an immediate benefit. Thus, one can observe rules of appropriateness guiding behaviour in these communities.

Of course, strategic behaviour is not absent - also not on behalf of the German representative who previously might have helped the Luxembourgish counterpart without expecting anything in return. Consequential logic comes, for example, into play when one considers the communities connected by common language. The coordination of asylum policy among Germany, Switzerland and Austria works so well because the countries are connected via the German language. It is more efficient, cheaper and quicker to coordinate information with everyone speaking German (and publishing reports in German) - a very consequential reasoning. However, my data also showed that civil servants being involved in these German-speaking exchanges for a very long time already, are likely to argue and act following rules of appropriateness rather than a cost-benefit calculation. Time and frequency of meetings play an important role here. At one point, the Germans naturally turn to Austria and Switzerland first - not only because of the same language and efficiency matters, but also because they have always done so and see it as natural to first coordinate their (intended) policies with these countries.

Nevertheless, the implementation of a norm considered to be appropriate is an entirely different story. Even though the person involved in the exchange with other countries might have become socialised in that community - willing to learn from others, willing and able to be convinced of others' ideas - consequentialism prevailed when it came to the domestic decision-making process. Context matters here a lot. In the German domestic setting, many persons and institutions are involved in such a (policy) decision, most of them having a constraining rather than enabling function. In fact, the constraining role of the legislative, courts or civil society point towards checks and balances being in place. The person initially involved in the epistemic policy coordination 
might keep his understanding of what is appropriate (whom to consult, what norm to adopt) but cannot act accordingly in the domestic setting. Or, at least, it was not possible to show that he can.

\subsection{2. $U K$}

Asylum policy-making in the UK is very much driven by a consequentialist logic. This relates to both the initial introduction of safe country of origin policies as well as the frequent alteration of respective lists. Compared to all European countries (and in fact, compared to countries worldwide), the UK is by far the most active user of the SCO notion. By 2013, 26 countries of origin were declared as safe - a few had to be removed from the list, and many had been added since the notion's introduction in 1996. Governments in the UK had always played an active role in asylum policy coordination in Europe. Until today, coordinating policies with others lead the British policy-maker towards being well informed about asylum policies in other countries, about (expected) intake patterns, and about safe country of origin policies in particular. They thus learn from other countries. This information is then used to serve a particular purpose namely making sure that the British policy towards asylum seekers remains the strictest in Europe (chapter 6). What is nicely illustrated by the British example is the fact that though epistemic communities might exist (and I have demonstrated their existence in section 7.3 of this chapter), they are not perceived as such by all actors involved.

In the British case there was no indication of policy-making following rules of appropriateness. However, this might be due to constraints in data collection. The limited involvement of UK representatives in COI cooperation made it difficult to assess what motivates these actors and how they perceive exchanges with other countries. Despite many efforts, I was only able to access one representative from the Home Office who is regularly involved in COI exchange. Unfortunately, the interview was not too fruitful. Having found only one such person also indicates that British representatives have been much less exposed to socialisation processes than civil servants from, for example Germany or Luxembourg (being regularly involved). In addition, the interviews with politicians and officials from the Home Office did not reveal much evidence about cognitive priors or the persons' understanding of how their job should be conducted or how such a policy should look like. This is not to suggest that rules of appropriateness do not play a role in the British case. Rather data collection might have favoured a rational over a social constructivist approach (see section 8.3 on reflection of methodology).

\subsubsection{Luxembourg}

Also in Luxembourg, the designation of countries of origin as safe clearly aimed at limiting the number of asylum seekers from certain countries. The policy was introduced in 2006 and subsequent countries were added since 2007. The big difference to Germany 
and the UK is that Luxembourgish authorities clearly favoured a European over a national policy. Only after it was clear that there would be no EU-wide list of safe countries of origin, a respective national list was adopted. This list aimed at deterring asylum seekers from certain countries of origin. In 2011, Luxembourg came under immense pressure after applications from Western Balkan countries skyrocketed. In fact, the national asylum administration had to close for several days because they were unable to deal with this pressure. One measure to deal with this situation was the designation of countries of origin as safe (in this case Serbia). When setting up that list, policy-makers turned to other countries in order to learn how they had handled similar issues. Also in this case, (simple) learning served a particular purpose, namely achieving pre-set preferences (chapter 6).

However, I also showed that the policy-making process in Luxembourg was driven by appropriateness considerations. During the decision-making process, it mattered a lot how policy-makers perceived their work and their country vis-à-vis other countries. For Serbia, it was only considered appropriate to add the country to the list after the number of asylum seekers went up. At the same time, it was legitimate to add several other countries to the list that produced no (or hardly any) asylum seekers, including Benin, Cape Verde, Ghana, Mali, and Senegal. Here, a different understanding came into play: Cape Verde was added because of close cultural and historical ties with Portugal. Thus, we see that context mattered. The way Luxembourgish policy-makers perceive their country in relation to others, explains the setup of the SCO list. This selfperception became also clear when looking at how policy-makers in Luxembourg justified the introduction of the SCO notion, namely without a race to the bottom-rhetoric (and thus very different from the UK and Germany). Instead, members of parliament were assured by the responsible minister that own changes would be less strict and more in line with international refugee law obligations than similar measures taken in other countries.

\subsubsection{Malta}

Maltese policy-makers introduced the SCO notion in 2000, and adopted a list of 13 safe countries of origin in 2004 . However, the island state has no or hardly any asylum seekers recorded from any of these countries. Thus, with introducing the policy, the Maltese government clearly did not aim at cutting their number of asylum seekers. What then explains the adoption of the policy and the designation of so many countries as safe?

When Malta adopted the SCO notion and the list, a respective norm was already established at the European level. This norm was created by several old member states with Germany and the UK having been at the forefront - in order to deal with their large number of asylum seekers. Throughout the 1990s, more and more countries adopted the norm, and the discourse regarding SCO policies changed - from a contested concept to an accepted tool to accelerate asylum procedures. Any country adopting 
the notion (and respective lists) after 2000 (also) did so because it was a normal thing to do. This then also explains the existence of such a norm in other countries with low numbers of asylum seekers (such as Portugal or Finland) or in countries in which the notion is introduced but has no practical relevance whatsoever (such as Bulgaria, Czech Republic, Hungary or Malta).

Many aspects of the policy-making process in Malta indeed pointed towards appropriateness-consideration being at the forefront. Having no history of asylum policymaking and thus carrying much less (if any) cognitive priors on the issue at stake, Maltese policy-makers were prone to learn from others, and become convinced of their policy solutions. This is a big difference to, for example, German, British and even Luxembourgish policy-makers having had to decide on similar issues. Malta was not involved in the 'classic' learning fora - that is epistemic communities - to coordinate asylum policy. However, the analysis showed that Maltese policy-makers nevertheless learned from other countries, primarily from the UK. They had always naturally turned to their former colonialist when being in search of policies. Debates in parliament showed that policies are not questioned if they come from this very source. Whatever is applied in the UK was also considered appropriate in the Maltese policy context. Also: whatever has been agreed on at the EU level (a common list of safe countries of origin) was considered legitimate - and can be adopted in the own, domestic setting.

The actual implementation of what was learned from others is relatively easy in Malta. There are two reasons for that: the very strong role of the executive vis-à-vis any other actors (courts, legislative, NGOs); and the sole responsibility of the minister to designate countries of origin as safe. Consequently, many aspects of the Maltese policymaking process point towards social learning as the predominant mechanism explaining the introduction of the SCO notion and the creation of a respective list.

It, however, is difficult to neglect the issue of resources. Malta is a small island with a small administration and civil servants cover much larger portfolios than their counterparts in other countries. In 2000, the country had to adopt a complete asylum law and set up a respective administration from scratch. Downloading a norm and a list that is commonly accepted amongst EU member states is also just the most efficient thing to do in such a situation. There are no costs and the benefits of doing so are obvious: something that is accepted by all member states will not lead to any criticism (within the community of member states). However, this line of reasoning did not show during data collection.

What becomes obvious from these summaries is that one cannot view the two logics as mutually exclusive. Each can be found to have explanatory value. It is thus a key concern of the conclusion to look at the relationship between the two in more detail. 



\section{Conclusion}

\subsection{Introduction}

The thesis started by describing two short stories - the one of Mr. Bavol who fled from his village in Serbia and applied for asylum in Germany; and the one of Mr. Franz who has to make a decision on whether or not Mr. Bavol is granted protection in Germany. Throughout the analysis, the two men served as examples to illustrate the complexity of such a decision. While many rules on whether or not Mr. Bavol is granted protection are specified by international law (such as the Geneva Convention), by EU law (such as the Qualification Directive) and by national law (in this case the German Basic Law and the Asylum Procedures Act), leeway remains - not necessarily for Mr. Franz who is also bound by instructions, but for the German government. In fact, Germany - just as any other country in Europe - has a lot of freedom on how to treat asylum seekers from certain countries of origin (such as Serbia). Country-specific policies, including safe country of origin policies, are increasingly popular and throughout Europe, states adopt such policies.

These safe country of origin policies increasingly converge across EU member states. At first sight, this might not be surprising given that there is a comprehensive legal framework adopted at the EU level. By 2014, the Common European Asylum System includes an impressive set of legal rules regulating, amongst others, the state responsible for assessing an asylum claim, the criteria qualifying for protection and the asylum procedure. However, these rules are only minimum standards leaving much discretion for member states to make their own decisions - especially when it comes to country-specific policies, such as safe country of origin policies. The puzzle of the present analysis has thus been formulated as follows: How can we explain convergence if not by the presence of legal harmonisation? I argued that informal policy coordination between countries accounts for policy convergence. Thus, the main question of the $\mathrm{PhD}$ thesis was What is the role of transnational policy coordination in the domestic asylum policy-making process in the EU member states? In order to answer this question, four sub-questions were formulated. Answers to each of them are provided in the next section. 


\subsection{Answering the research questions}

\subsubsection{Do safe country of origin policies become more similar or more diverse?}

The first question set up the puzzle for the whole research project. Can we expect convergence or divergence of asylum policies, and safe country of origin policies in particular, in Europe? On the one hand, one might expect divergence because the common legal framework only provides for minimum norms, and leaves a lot of discretion for member states as to whether and how they want to apply the SCO notion. However, on the other hand, one might expect convergence given that countries seem to orientate their own policy in line with others (in order to avoid being the weakest point of entry to the EU). Asylum scholars disagree on this matter. This is no surprise given that no data set existed that would allow such inferences to be made.

In chapter 2 of this study, I analysed the development of safe country of origin policies in the EU-27 over a period of 23 years (1990-2013). This analysis significantly contributes to the scholarly discussion by providing the first comprehensive data set in both spatial and temporal terms that allows inferences on the convergence or divergence of safe country of origin policies in the EU. It was concluded that there is a surprising amount of policy convergence across EU member states. Countries in Europe (and this actually includes non-EU member states such as Norway and Switzerland) almost all introduced the safe country of origin notion in their domestic asylum law. They have thus created the legal possibility to adopt safe country of origin policies, and to designate countries as safe. While, at first sight, this might be an obvious result of EU harmonisation, this is actually not the case. There are common standards developed at the EU level relating to the SCO notion (Directive 2013/32/EU). However, they are only minimum norms that leave a lot of freedom for member states as to whether and how to apply such a policy. In addition, there is no obligation to introduce such a notion in domestic law. Given this lack of obligation, it is indeed surprising to see that all but two EU member states (Sweden and Italy) have introduced the possibility to designate countries of origin as safe.

However, policy convergence does not stop here. There is also increasing crossnational similarity regarding the actual designation of countries as safe. From those EU member states that apply a SCO list, almost all have designated the Western Balkan countries as safe. They thus agree that the situation in Bosnia and Herzegovina, Macedonia, Albania, Montenegro, Serbia and Kosovo is generally safe enough for asylum seekers originating from these countries to not be in need of protection. EU member states also agree, to a large extent, on their safety assessment regarding the situation in Ghana, Benin and Senegal. Now, one might argue that we are talking about some eight or so countries adopting similar policies - what does that say about the EU-27? 
It was also shown that countries not having formal lists still apply the idea behind the safe country of origin notion - namely processing applications from some countries (such as Serbia or Senegal) much faster than their more 'genuine' counterparts from other countries (Afghanistan, Syria, Iran). Consider for example Germany: though the German authorities did not have Serbia on their list of safe countries of origin, they applied the SCO notion informally. It was common knowledge among case workers and there were respective policy guidelines suggesting that asylum seekers from Serbia are generally not in need of protection, and cases should, preferably, be closed within days. A similar approach (towards Serbia and other countries of origin) was reported from both EU member states with formal SCO lists, and those without.

However, this policy similarity shall not obscure the fact that much divergence remains. The analysis also showed that many countries of origin were designated as safe by only one or two EU member state. SCO lists continue to look very different within the EU. Nevertheless, convergence certainly relates to the introduction of the SCO notion, and, to a lesser extent, to the safety assessment in two regions, Western Balkan and West Africa.

\subsubsection{How can we conceptualise and theorise recent forms of European asylum cooperation?}

The thesis started with arguing that existing governance terms do not capture the recent shape of asylum governance in Europe anymore. What is missing is an account of policy coordination outside of supranational decision-making. We see state executives at all levels (ministries, law enforcement agencies) meeting informally, exchanging information and coordinating policy. These dynamics are not sufficiently captured by the governance terms available. Thus, the thesis (and chapter 3 in particular) contributes to the European governance literature by conceptualising policy coordination, and by developing an analytical framework on which to base subsequent empirical analysis.

In this thesis, policy coordination was conceptualised as the horizontal coordination of policy or policy-relevant information between state executives. It is determined by its informal nature, the deliberative character of interaction, and it does not lead to legally binding outcomes. In order to avoid reinventing the wheel, several related concepts were consulted, including transnational communication as defined by the convergence literature (Holzinger and Knill 2005), intensive transgovernmentalism and policy coordination (as defined by Wallace 2010), deliberative intergovernmentalism (Puetter 2012a; Puetter 2012b) and informal governance (Christiansen and Neuhold 2013; Helmke and Levitsky 2004; Christiansen et al. 2003). These concepts proved helpful in setting up an analytical framework. It allowed studying policy coordination and three aspects in particular:

- Actors involved in policy coordination (who is involved?): these actors have, on purpose, been defined rather openly as state executives involved in the policy mat- 
ter of interest (here: COI and COI-related policies). The group is hold together by the similarity of its members.

- Function of policy coordination (why does it take place?): assuming that most policy coordination is informal, the creation of institutions facilitating such coordination was explained by juxtaposing them to their formal counterparts. Institutions facilitating policy coordination have come into existence because their formal counterparts are either absent, incomplete or goals aimed for are not publicly acceptable.

- Form of policy coordination (how does it look like, and how does it work?): next to its informality, policy coordination is driven by deliberation rather than bargaining. A number of conditions were identified making deliberation likely to occur, including homogeneity of actors involved, a high level of routine, long duration and high frequency of meetings.

Based on the framework developed, an empirical analysis of asylum policy coordination, and coordination of country of origin information in particular, was conducted.

\subsubsection{How does policy coordination in the field of asylum policy, and cooperation on country of origin information in particular, work?}

The empirical analysis of asylum policy coordination was conducted in chapter 5, by using the example of cooperation on country of origin information. Such information is key to any individual refugee status determination. Linking it back to the example from the start of the thesis, Mr. Franz needs country of origin information in order to assess whether or not Mr. Bavol faces persecution if send back to Serbia. Collecting such information is a key task of national asylum administrations, and their COI units in particular.

The analysis started with specifying the necessity and requirements for country of origin information as well as outlining the institutional setting necessary for collecting COI. The collection of COI is conducted by the national asylum authority of each EU member state and can take very different forms: from a fully-fledged COI research unit with up to 100 employees to a so-called country-desk system where the person assessing the claim is also responsible for collecting COI on the country required. The thesis (and table 5.2 in particular) considerably contributes to the study of COI systems by providing the first complete overview of COI units in the EU-27. Further on, the challenges faced by national asylum administrations in collecting COI were discussed. It was concluded that transnational cooperation on the collection and interpretation of country of origin information is one of the key tasks of asylum administrations - at least in some countries. Patterns of COI cooperation have changed from an informal, state-driven 
process to a more formal one involving all EU member states, and with the European Commission playing a key role.

The focus of the analysis was on the (solely) informal years of cooperation. Before 1999, much of COI cooperation happened between a small number of countries. The Northern and Western European states coordinated their COI and COI-related policies in fora such as the three studied in detail, namely the Intergovernmental Consultations on Migration, Asylum and Refugees (IGC), the (European) Centre for Information, Discussion and Exchange on Asylum (CIREA), as well as bilateral exchange between two (or a few) states. Though the scope of these fora is very different (global, European, sub-regional), their function and form as well as actors involved are rather similar: there are a few like-minded countries engaging informally in a deliberative policy debate; they do so because they lack any fora to confidentially exchange views, and to develop and/or pre-cook policy solutions to common problems. To name just one of many examples: in the late 1980s, several European countries faced large numbers of Tamil asylum seekers from Sri Lanka. Developing a common approach on how to deal with these had been one of the first issues to be discussed within IGC.

The analysis also showed that COI cooperation became increasingly formalised with the start of the new century. The Tampere Program in 1999 and the agreement on a Common European Asylum System rocketed COI cooperation high up on the political agenda of the member states and the European Commission. Existing COI cooperation fora became formalised (such as CIREA) and grouped under the newly created European Asylum Support Office. Next to the key role played by the European Commission and EASO, one further issue changed completely with COI cooperation becoming formalised. Not only member states with well-developed asylum systems were part of the exchange, but the newly formalised COI cooperation was explicitly targeted towards member states with less well developed (or non-existent) COI collection systems, and the Southern and Eastern European countries in particular.

After having conceptualised, theorised and empirically studied policy coordination, the next logical step was to look at its role in the domestic policy-making process. How do governments actually use the information obtained during these informal coordination exercises? This was the central question of the $\mathrm{PhD}$ project, and was analysed in the final two empirical chapters 6 and 7.

\subsubsection{What is the role of COI cooperation in the domestic policy-making process relating to safe country of origin policies?}

In answering the final and central question of this research project, two approaches were used: a logic of consequences and a logic of appropriateness (March and Olsen 2009; March and Olsen 1998; March and Olsen 1993; March and Olsen 1989). The logic of consequences was based on two mechanisms: two-level games (Putnam 1988) and (sim- 
ple) learning (Checkel 2001a; Checkel 2001b). ${ }^{164}$ At a more specific level, policy coordination is used to circumvent domestic constraints (two-level game). At a more general level, policy coordination can simply inform policy-making in the own, domestic context (learning). However, in both cases preferences were formed exogenously to the coordination exercise with other countries. Policy coordination simply aimed at achieving pre-set preferences.

Supposing behaviour driven by a logic of appropriateness, social learning (Checkel 2001a; Checkel 2001b) was the key mechanism. It was argued that preferences are not formed prior to the exchange with other countries but while policy coordination takes place (or that preferences change during that time). In any case, they were formed endogenously to asylum policy coordination. Policy-makers adopt measures because they follow rules of appropriateness. Their understanding of what to do is shaped by their institutional, social and cultural context. Both policy-making following a logic of consequences (two-level games) and policy-making following a logic of appropriateness (social learning) were operationalised by developing conditions based on a literature review (all section 3.3).

\section{Logic of consequences}

Chapter 6 explained the domestic policy-making process by actors following rules of consequences. For both Germany and the UK, policy-making could convincingly be explained as following such a logic. In the case of Germany, policy-makers successfully played the two-level game. Being unable to introduce the SCO notion at the national level in the late 1980s and early 1990s, German policy-makers first secured an agreement on safe countries at the European level (London Resolutions), before downloading the policy to the national level. Stressing that German policy has to be in line with European agreements, the Kohl government successfully convinced the opposition to agree to the introduction of the SCO notion, and respective designations of countries of origin as safe. However, the SCO notion did not prove very useful to the German government(s). Thus, in later years, other measures were sought to achieve the same preferences - processing asylum applicants from some countries much faster than from others. In doing so, inspiration was drawn from other European countries. During informal asylum policy coordination, the German government learned how to achieve its preferences - a classic case of (simple) learning.

The same argument can be made for the UK. Since the first introduction of SCO policies in the mid-1990s, the UK's involvement in transnational policy coordination served the clear purpose of achieving the government's own pre-set preferences. The key aim had always been to find means to deter asylum seekers from certain countries of origin (one tool being to accelerate their procedures), and to make sure that the British asylum policy is stricter than those of other EU member states.

\footnotetext{
${ }^{164}$ As opposed to social learning, which is the mechanism of the logic of appropriateness.
} 
Evidence for Luxembourg also pointed at policy-making being driven by a logic of consequences. The government's initial aim was to use policy coordination to come to an EU-wide common list of safe countries of origin. Once this proved impossible, preferences changed. Now, Luxembourgish policy-makers set up an own, national list aimed at designating countries as safe from which they had (too) many asylum seekers. Again, policy coordination served the purpose of learning how others legitimise these designations.

Finally, it turned out to be difficult to explain Maltese policy-making in light of a logic of consequences. The Maltese SCO list was very closely mirrored on the common list proposed in the JHA Council in 2004. One would assume that the pressure to adopt the country's first ever asylum law made the Maltese government look for and adopt a ready-made (policy) solution from other countries - thus, a clear case of simple learning. However, this was not confirmed by the data collected.

\section{Logic of appropriateness}

In chapter 7, safe country of origin policy-making was explained with a logic of appropriateness. First of all, it was shown that - throughout the 1990s - SCO policies became an accepted mean to deal with less 'genuine' asylum seekers. As many governments argued, because someone from Serbia or Ghana is generally not in need of protection, it is perfectly legitimate to apply the SCO notion to asylum seekers from these countries. I showed that this consensus exists across Europe and led many countries, especially new member states, to adopt such a notion without much thinking. Though they were not obliged to include the SCO notion in their national asylum laws, all of them did. An observation supporting this argument relates to the actual use of the SCO notion and respective lists. In most of the new member states (including Malta) the list was never made use of, and was thus clearly not introduced to deter asylum seekers from certain countries of origin.

Coming to the four countries studied in detail, many indicators pointed at policymaking in Germany following a logic of appropriateness. I demonstrated that informal asylum policy coordination resembles epistemic communities. Germany, as a very active member in these communities, was exposed to processes of socialisation and social learning. And indeed, we saw that state executives having been involved in these exchanges for many years perceive themselves as part of a community of like-minded people. For them, it is natural to help each other and to not view coordination as a costbenefit exercise. However, we did not see this logic prevailing when it came to the actual domestic policy-making process.

For the case of the UK, the evidence was much less compelling. Though British policy-makers were also involved in informal asylum policy coordination, they participated to a much lesser extent than Germany or Luxembourg. Also, it was not possible to unfold rules of appropriateness on parts of British state executives during the exchanges or in the domestic formation of policies. This might be an indication that these considera- 
tions do not play any role. However, it might also be an indication of data availability (see next section).

Luxembourg, just as Germany, was very much involved in epistemic asylum policy coordination. Respective state executives were exposed to processes of socialisation and social learning. And, in fact, what has been learned also informed the safe country of origin policy-making process. This is the main difference to Germany. There are several reasons for that, all related to a domestic setting that is more prone to social learning than in other countries: Luxembourgish policy-makers have huge portfolios compared to their counterparts in Germany or the UK (and thus few cognitive priors) - but eventually have to make the same decisions. Thus, they 'need' to learn from others and are very open to do so. Because of a very strong executive vis-à-vis other actors, they also face hardly any constraints when implementing what they have learned.

The same can be argued for Malta. Also here, rules of appropriateness played an important role in the formation of SCO policies. Though Maltese policy-makers were not involved in the informal coordination of asylum policies with other countries, there are one (or two, if including the EU) norm entrepreneurs they always turn to: when searching for policy solutions, the UK is naturally the first country to look at - because of a common history and perceived very strong links to the former colonial power. One might do so for efficiency reasons (simple learning). However, interview partners stressed that they orientate own policy on British policy because this has always been done so and it is just the most rightful and legitimate thing to do - clear appropriateness considerations. As in the case of Luxembourg, domestic level factors make it easy to implement what has been learned from the British: the executive in Malta plays a very strong role vis-à-vis other actors (legislative, NGOs, courts), and consensus drives policy-making in general.

However, these findings on Malta and Luxembourg need further discussion with regard to the factor size (of the country analysed). One is quick to judge that a key issue of the countries selected - namely their size - has not been taken into account by the researcher. Size of the country indeed played no key role when the cases were selected. Case selection was first and foremost theoretically motivated and the analysis was set up in order to test two hypotheses, one based on a logic of consequences and another one based on a logic of appropriateness. For the latter, Malta and Luxembourg presented most-likely cases, and were thus selected for analysis (see section 4.2.1). In light of the empirical analysis, the size of the country might indeed be connected to the independent variable (uncertainty). It might be the case that uncertainty is particulary high in small countries where respective policy-makers have big portfolios compared to their counterparts in larger countries (where a lot more specialisation is possible). Such big portfolios come inevitably with less cognitive priors (see section 7.2.2). 
In sum, it was shown that both logics can explain (parts of) the policy-making process in each of the four countries. The next section further specifies the relationship between the logic of consequences and the logic of appropriateness.

\subsection{Bridging both logics: consequences and appropriateness}

The co-existence of the logic of consequences and the logic of appropriateness has been observed by others before (March and Olsen 2009; Goldmann 2005; Börzel and Risse 2003; March and Olsen 1998). March and Olsen themselves note that the two models are not mutually exclusive (2009, p.19):

It is difficult to deny the importance of each of them (and others) and inadequate to rely exclusively on one of them. Therefore, a theory of purposeful human behaviour must take into consideration the diversity of human motivations and modes of behavior and account for the relationship and interaction between different logics in different institutional settings. A beginning is to explore behavioral logics as complementary, rather than assume a single dominant behavioral logic (March and Olsen 2009, p.19).

Similar observations were made by others. Checkel (2001b), for example, argues that

Much of European integration can be modeled as strategic exchange between autonomous political agents with fixed interests; at the same time, much of it cannot. Constitutive dynamics of social learning, socialization, routinization and normative diffusion, all of which address fundamental issues of agent identity and interests, are not adequately captured by strategic exchange or other models adhering to strict forms of methodological individualism (p.50).

Based on the empirical findings in this thesis, one needs to address how the two logics can co-exist. March and Olsen (2009) suggest five possible relationships between the logic of consequences and the logic of appropriateness:

- $\quad$ one logic can be subsumed under another;

- there can be hierarchy between the two;

- they can be differentiated along their prescriptive clarity;

- they can be used for different purposes;

- they can occur in a sequential logic.

The first possibility suggests that one can subsume one logic under the other. From a logic of appropriateness-perspective, this would mean that a cost-benefit decision is one of many possible rules that actors believe are exemplary for a specific social context they act in. From a logic of consequences-perspective, this would mean that following rules of appropriateness is the result of a cost-benefit calculation (March and Olsen 2008, p.20). However, such an understanding would deny the distinctiveness of the two logics, and is thus unsatisfactory (Checkel 2010; March and Olsen 2009; Jachtenfuchs 2002; March and Olsen 1998). Instead, as Jachtenfuchs (2002) argues, one should look at 'the 
conditions under which interests, ideas and identities matter respectively' (p.654). In doing so, March and Olsen (2009) suggest four further ways of how the two logics are interconnected.

The second possible relation assumes a hierarchy between the logic of consequences and the logic of appropriateness. This could, for example, mean that one logic explains major decisions, while the other minor ones; or that one logic explains behaviour of politically important actors (i.e. ministers); while the other one that of less important (i.e. public administrators) (March and Olsen 2009). March and Olsen (ibid.) reject such a stable hierarchy between the logics arguing that it is not well supported by empirical evidence.

However, already the third possible relationship between the two is closely mirrored by the empirical analysis conducted in this thesis. March and Olsen (2009) suggest to differentiate the two logics in terms of their prescriptive clarity. The main argument is that a clear logic dominates a less clear logic (p.19). Both rules of appropriateness and rules of consequences are defined with varying precision and thus provide more or less clear prescriptions - depending on the setting and situation. The prescriptive clarity of interests, preferences, alternatives and consequences following from certain actions can vary:

Even when actors are able to figure out what to do, a clear logic can only be followed when available resources make it possible to obey its prescriptions. Following rules of appropriateness, compared to predicting the future, clarifying alternatives and their expected utility, partly require different abilities and resources. Therefore, variation and change in the relative importance of the two logics may follow from variation and change in the resources available for acting in accordance with rules of appropriateness and calculated (self) interest (March and Olsen 2009, p.21).

Let us consider this suggested relationship by looking back to the empirical analysis conducted: one could observe processes of social learning in both Germany and Malta. However, such processes looked very different. In Germany, social learning occurred as part of epistemic policy coordination (for example, in the informal Council working group CIREA); in Malta, it was based on a long-grown and close relationship with its former colonial power, the UK. The result in both countries, however, was the same: state executives were willing and able to learn from others (other members of the working group resp. the UK representative) because they considered their actions as appropriate. However - and this is where the two logics and their relationship come in - only in the case of Malta, the logic of appropriateness prevailed in the actual domestic decision-making process. Setting and situation favoured following rules of appropriateness: for example, there was time pressure, uncertainty and scarce resources on parts of Maltese policy-makers which promotes rule following behaviour rather than time and resource demanding calculation of utility (March and Simon 1993, p.11); and due to the strong role of the executive vis-à-vis other actors, no one actively challenged these rules and the SCO notion adopted. 
In Germany, however, the setting and situation favoured decisions being taken with a cost-benefit mindset. We talk here about the same person that had previously been involved in epistemic policy coordination, and that learned - within the community what actions or policies are considered legitimate. However, when it came to implementing what had been learned, setting and situation at the domestic level favoured behaviour following rules of consequences: the person was not able to initiate these policies on his own but had to obey rules from above - and these rules favoured a consequentialist (as few recognitions as possible for asylum seekers from Serbia) over an appropriateness (similar standards of recognition across Europe for asylum seekers from Serbia) mindset. The case of Germany also illustrates nicely why it was of added value to analyse policy-making from two different perspectives (logic of consequences and logic of appropriateness). None of the two was sufficient to explain the whole story of policymaking. However, both provide convincing explanations of parts of the decisionmaking process. Doing such an analysis for four countries naturally comes at the expense of some analytical depth. However, we also gain something: namely, the finding that both logics have some explanatory value to the same policy-making process.

Such an understanding of the relationship between the two logics also means revisiting the case of the UK. I previously stressed that there were no signs of policy-making having followed a logic of appropriateness (section 7.6.2). Assuming prescriptive clarity, one has to refine this statement by saying that I could not unveil the evidence pointing towards a logic of appropriateness (but it might be there). Instead, data and method chosen favoured finding evidence for consequence-driven behaviour. The interview approach as such makes the researcher asking for why (which makes interviewees think about their preferences); but also the fact that all interviews captured one moment in time rather than a long-time study on changing attitudes. While for the other cases more evidence and more diverse evidence could be collected, the UK data was rather scarce and made it difficult to reveal behaviour following rules of appropriateness. ${ }^{165}$

Again, relating the two logics by their prescriptive clarity is only one of several ways to see them interconnected. Empirics of this thesis would also allow illustrating the fourth and fifth possible relationship suggested by March and Olsen (2009). Thus, it would be possible to view results from chapter 6 (logic of consequences) and 7 (logic of appropriateness) as being used for different purposes (such as making and justifying policies) or as occurring in a sequential logic. Eventually, this thesis does not aim at determining the right relationship between the two. Instead, this section concludes with confirming at least one relationship, and that is prescriptive clarity. Both logics can simultaneously co-exist but one shows stronger than the other, depending on the setting and the situation.

${ }^{165}$ Section 4.3 discusses data collection and related challenges. 


\subsection{The future of the Common European Asylum System}

What do the findings of this thesis mean for the future of the Common European Asylum System? This section relates back to the title of the thesis and 'common standards' in particular. It asks whether we can expect asylum policies in Europe to become more similar or more diverse in the future. It also looks at the EU level and provides an outlook on the asylum-institutional structure of the EU, and the European Asylum Support Office in particular.

\subsubsection{Convergence vs. divergence}

What do the results mean for the future of a Common European Asylum System? Can we expect asylum policies to converge or to diverge? As it is so often, there is no clear answer to this question. There are several factors accounting for convergence. However, there are also several factors suggesting that divergence will remain. In what follows, both are discussed.

For convergence, policy coordination is responsible. However, such coordination does not primarily serve the aim of achieving similar standards for asylum seekers across Europe. Instead, countries want to make sure that one's own policy is not more lenient than the one of other (neighbouring) countries - and consequently that the own country is not a weaker (i.e. more attractive) point of entry for asylum seekers. This logic has also been demonstrated by others for the same kinds of policies ${ }^{166}$ and for related policies. ${ }^{167}$ However, orientating own policy on what has been done by other countries also serves other (or additional) objectives, such as increasing legitimacy and room for maneuver at the domestic level (the classic two-level game as shown for Germany). Another explanation for convergence is the search for policy solutions in times of uncertainty (Luxembourg, Malta). We see that SCO lists in some countries closely mirror lists in other countries or the (failed) common list negotiated at the EU level in 2004. Here, convergence is the result of deeming other lists as legitimate enough to be adopted in the own, national context. This was shown in detail for the case of Malta, where policy-makers faced uncertainty because they were confronted with having to adopt the first ever asylum law. Maltese policy-makers dealt with their inexperience and uncertainty by copying policies (and SCO lists) from others. A similar reasoning can be expected, for example, for Bulgaria. Here the government, just as in Malta, adopted a very long list of safe countries of origin - whereas national authorities had so far never seen any asylum seekers from the countries designated as safe.

\footnotetext{
${ }^{166}$ Vink (2002) shows that the Dutch safe country of origin policy mirrors similar policy developments in Germany.

${ }^{167}$ Byrne et al (2002) show that sub-regional dynamics account for converging safe third country policies across Europe. The key aim in adopting the same policies as the neighbouring country is to not be an easier point of entry for asylum seekers than the country after which the policy is mirrored.
} 
Now, what about divergence? We see that a large amount of divergence remains, especially when it comes to the designation of countries of origin as safe. There is a simple reason for that: country-specific peculiarities determine how policies look like - and since EU member states continue having very diverse cultures and histories (and subsequently interests and identities) - also their policies continue looking very different. Let us be reminded of one example: Luxembourg views Cape Verde as a safe country of origin. This assessment is shared by only two EU member states, France and Malta. The decision to designate Cape Verde as safe is largely based on cultural and historical links between the two countries: Luxembourg has a large Portuguese community; Cape Verde is a former Portuguese colony; Cape Verde is also a target country for Luxembourgish development cooperation. Thus, as policy-makers and observers argue, it seems logical to declare the country as safe. The same can be argued for the UK having designated Jamaica, India or Pakistan (1996-2002) as safe countries of origin. Similar considerations can be assumed for other countries not studied in detail, such as the French decision to designate Mauritius as safe. Given these findings, working towards more convergence is laudable but will (presumably) only work up to a certain point. What, then, do these results mean for the role of policy coordination and the future of the Common European Asylum System, and EASO in particular? These questions are addressed in the next section.

\subsubsection{Policy coordination and the role of EASO}

Chapter 5 illustrated that COI cooperation primarily takes place at an informal level and works quite well between the countries involved. This is because they have a similar asylum history, a common understanding of problems at stake and possible solutions, equal ideas on procedures and linguistic/cultural affinities. With asylum policy becoming institutionalised in the EU framework, this well-functioning informal system comes under threat. Suddenly, there was a political interest (on part of the Commission) in country of origin information and COI cooperation; and there were new EU member states that - in the process of having to comply with the asylum acquis - were also in need of COI expertise. This has led to new COI cooperation fora emerging; and old fora becoming formalised.

Whereas informal COI cooperation previously filled gaps where no formal institution was in place or where the formal institution had not dealt with (see chapter 5); it now accommodates formal institutions. It is argued that formal COI cooperation is necessary for informal cooperation continuing to work. The main reason is that the lessexperienced countries lack the necessary conditions (mainly established COI units) for climbing on the bandwagon of a well-functioning (informal) COI cooperation system. Incorporating these EU member states into the existing informal COI exchange would potentially undermine the system simply because they would not be able to play to the rules - one of them being to equally give and take information (section 5.4.1): '... there 
are a lot of countries who bring, who have something to offer, and we don't get that much back from other countries, because of the enormous differences in experience and time that we are already working on this issue (interview 8).'

Also with more countries joining COI cooperation, the community is not as close anymore. Confidentiality and trust get lost because they are 'newcomers' and because (language) similarities vanish:

\footnotetext{
It is different if I call my colleague in Romania, because they have a completely different way of looking at things and I am not sure of the information that I will give to him or her will stay with him or her (interview 8).
}

With Eurasil[...] it becomes a bit more formal: you have translations and you have people sitting at the table [...] and you have of course now a Commission; and it is all more political in the sense of officepolicies; it is much more ... countries don't say as much as they would in an informal setting (interview 3).

We thus see that the well-functioning informal system of COI cooperation could not just simply incorporate new countries. This was also acknowledged by the old member states - in particular Germany and the Netherlands - who were key in setting up the new asylum agency (interview 25; interview 42; Angenendt and Parkes 2010). ${ }^{168}$

There are a number of external pressure factors requiring new member states and those with less-developed COI services (mainly the Southern and Eastern European ones) to participate in COI cooperation: they have to invest in national asylum structures in order to comply with the EU asylum acquis. Because most of them have an EU external border, they also face now much higher numbers of asylum seekers. These numbers require them to build up own expertise on country of origin information. Eventually, also the power shifts at the EU level, in particular the increasing role played by regional courts (Vedsted-Hansen 2010), requires countries to properly make use of $\mathrm{COI}$ in the refugee status determination process.

Given that these new countries have no (or not a comprehensive) COI collection themselves, they will heavily rely on the new formal structures, and EASO in particular. For some countries, such as Greece, Malta, Italy, Spain or the Slovak Republic, the Asylum Support Office might actually become some kind of a substitute to a national COI unit. This has been argued by interview partners who observed that countries stopped investing in national asylum infrastructure once it became clear that EASO would take a major role in COI exchange (interview 8). This reliance on EASO will also increase the agency's legitimacy. Being asked whether Malta (as a country with a poorly-developed COI collection system) will make use of the first COI report compiled by EASO (related to Afghanistan: EASO 2012c), an observer noted:

${ }^{168}$ Also the first director of the European Asylum Support Office is from the Netherlands. 
There is no way you can call that [people working with the Maltese Refugee Commissioner] a COI expert; in Malta we don't have the expertise; so I think the EASO document (on Afghanistan) will be for the government a key tool to use (interview 27).

The same question - whether or not to use the first reports produced by EASO - was posed to a German representative. He frankly denied seeing yet the added value of those reports for his (very well-equipped) COI unit (interview 35). This example from Germany also reminds us that their expectation regarding what to get out of COI cooperation are very different than those of new member states. Rather than being in need of basic, all-encompassing information on the countries of origin, they look for confidential, ad-hoc information to complement own data collection. And this need continues being primarily fulfilled by informal coordination, be it between two countries or within the IGC. Being asked whether IGC still make sense after the EU has put so much focus on developing own COI cooperation fora, one interviewee stressed:

We are one of the countries who think that despite all the beefing up of EU cooperation, there is still added value to organisations like the IGC, which is not smaller [...] but much more hands-on and practical and useful (interview 3).

And again, an internal paper evaluating twenty years IGC activity stressed that ' $[t]$ he continuity [of IGC] is the reliance on informality and confidentiality, the two critical aspects of the process that underpins the IGC approach to issues' (HJA 2005, p.3). The, largely unaltered, informal structure of IGC exists since the 1980s. As Brie and Stölting (2012) argue, informal institutions can resist the tendency towards formalisation because actors aim to avoid public scrutiny and justification. Analysis showed that these are precisely the reasons for countries to continue taking part in IGC, and in informal asylum policy coordination in general.

\subsection{The normative dimension}

The title of the thesis refers not only to 'common standards' but also to the idea of introducing such standards 'via the backdoor'. The latter relates to the very nature of the decision-making processes studied in this analysis. Their non-transparency, informality and confidentiality raise some profound normative questions. They relate to two aspects: the decision-making process regarding safe country of origin policies, and the very process of coordinating country of origin information and COI-related policies. Both are discussed below. 


\subsubsection{Safe country of origin policies}

The analysis of safe country of origin policies in the EU-27 (chapter 2) also included a comprehensive overview of criticism related to these policies. Since their very first introduction in the early 1990s, governments face criticism regarding the inherent danger of risking non-refoulement. Applying the SCO notion potentially results in sending people back to countries where they fear persecution (UNHCR 2010a, p.65). In fact, this argument was made many times for Roma being sent back to Serbia (see for example Waringo 2013). Another point of criticism relates to the assumption that one has at its disposal enough verified information to make such a safety assessment for an entire country (Byrne and Shacknove 1996; Goodwin-Gill 1992). Furthermore, the political susceptibility of such policy measures was repeatedly stressed (UNHCR 2010a, p.66; Byrne and Shacknove 1996, p.223; Martenson and McCarthy 1998). This point of criticism became very much confirmed during data analysis. Decisions on whether or not to designate countries as safe were closely tied to foreign policy and/or economic considerations: close ties with the Portuguese community led Luxembourg to designate Cape Verde as safe; or in almost all countries the designation of Serbia is justified with its candidate status. One further point of criticism, however, is worth discussing in more detail, namely the process of policy-making as such.

One of the earliest scholarly discussions on safe country of origin policies stems from 1992. By then, only Switzerland and Belgium had actually introduced SCO policies but agreement on the London Resolutions was in sight. Already at this point in time, Guy Goodwin-Gill (1992) stressed one of the, if not the major issue with SCO policies: 'Who then is to say that countries are safe? And by whose standards? Secret men in secret rooms reading secret memos? No (p.249).' Sadly, his comment has never been as topical as in 2014, more than 20 years later. My analysis showed that safe country of origin policies have become a common means to accelerate procedures of certain unwanted asylum seekers. In fact, in some countries it had become a means to accelerate the majority of asylum seekers. Almost all EU member states now pursue such policies. In many cases, this might have come at the expense of the principle of non-refoulement. This is even more worrying as these policies are pursued outside the EU policy-making process. If formal (national) lists of safe countries exist, it is often entirely unclear how they came into existence. It is also unclear which information sources they are relied upon (UNCHR 2010a, p.69). Country reports are confidential and only released to the public after many years. The situation is even worse when the lists exist but are confidential, or when the SCO notion is applied on a case-by-case basis, which seems to be common practice in several EU member states (UNCHR 2010a, p.66). Not only does it contradict European law, it also raises profound issues of legitimacy and accountability. It makes it impossible to understand the decision-making process for observers, including NGOs and international organisations. UNHCR notes that there is 'an apparent lack 
of regulation, transparency and accountability in the process by which countries are designated as safe countries of origin' (UNHCR 2010a, p.69).

The non-transparency of the decision-making process also manifested itself in the difficulties encountered by the author while collecting data on such policies in all EU member states. Given the increasing importance of these policy measures, something needs to change. The author aligns with UNHCR (2010a) suggesting that safe country of origin lists, and the information sources relied upon in making a designation, should be publicly available. In fact, more transparency is not required for after these measures have been agreed upon, but early in the process since the current analysis also highlighted few possibilities for NGOs to actually influence the policy-making process.

\subsubsection{Cooperation on country of origin information}

Also the process of policy coordination has to be viewed with much skepticism regarding its democratic value. Again, looking at the actual policy field, this criticism is not new. Already in 1996, the European Parliament criticised the work of the Council working group CIREA, which was explicitly set up by the member states to informally coordinate COI and COI-related policy decision (see section 5.4.2):

The CIREA's agenda, discussions and documents are confidential and not therefore accessible to the public, NGOs, etc. Consequently, it is not clear what information from what body is included [in the joint country reports] or how this information is assessed. This often puts asylum-seekers and their legal advisers at a disadvantage, given that they are unable to react to facts of which they are unaware. This is deemed inconsistent with the principle of 'equality of arms' (European Parliament 1996, p.24).

The analysis showed that informal COI cooperation is not a matter of the past but continues to play an important role in today's asylum governance system. In fact, the majority of Northern and Western European member states rely almost entirely on informal COI cooperation (as opposed to formal COI cooperation). This certainly raises normative concerns (for a general discussion on the normative issues of informal governance, see Reh 2012).

One issue is the relation between informality and convergence of policies. Essentially, it has been stressed that informal negotiations between governments allow policy decisions to be coordinated, and thus enhance the likelihood of policy convergence. This argument has, for example, been stressed by Thouez and Channac (2006) as well as Koppenfels (2001). They study so-called Regional Consultative Processes, which is also some form of informal policy coordination - for example in the framework of IGC (see section 5.4.2) but also the Budapest Process or the Puebla Process. These exchanges are informal and non-binding by nature and would, arguably, contribute to the harmonisation of migration practices and policies in specific regions (be it Europe or South America). Whereas this might be the case, a sensible argumentation should not neglect the accountability and legitimacy issues attached to these informal and confidential process- 
es. Just as in the examples studied in this thesis, policy coordination serves to pre-cook policy decisions at the domestic level, and thus limits or even impedes the possibility of influence for other actors, including nongovernmental organisations.

However, issues of accountability and legitimacy are actually not only related to the informal exchange of country of origin information. We see that within the formalised framework of EASO, transparency is not a matter of interest: COI exchange within EASO is exclusively limited to states. There is hardly any role for NGOs, and there is little transparency about what is going on within EASO (interview 27; Carrera et al. 2013). ${ }^{169}$ This relates, not entirely but to a large extent, to the agency's work on COI.

\subsection{Research agenda}

What then should future research focus on? The analysis contributed to the understanding of a new mode of governance, namely new intergovernmentalism (Bickerton et al. forthcoming; Putter 2012a). What Bickerton et al. (forthcoming) claim is that a distinctive form of European integration has evolved. It essentially relates to policy coordination between EU member states without transferring power to supranational institutions. They propose a research agenda to which the current study contributes both theoretically (chapter 3) and empirically (chapter 5). However, many issues on this research agenda remain open, and this openness became reinforced through the analysis conducted. Four issues in particular are worth to mention.

First, the role of supranational actors in policy coordination: the analysis showed that the European Commission plays a prominent role in formalising the cooperation between national asylum administrations, including the setup of the European Asylum Support Office (section 5.5). This suggests that the preferences of supranational institutions are not necessarily geared towards an ever-close union (Bickerton et al. forthcoming, p.10). For now, it seems as if the European Parliament plays no or hardly any role, at least not in the field of asylum policy coordination as analysed. The role of both the Parliament and the Commission in the newly created agency remains unclear. In theory (or law), there is no role. In practice, this analysis showed that the Commission takes a rather prominent part in facilitating COI cooperation. With the agency having started to work properly only in the last two years, there is more research necessary on the (power-) relationship between member states and supranational institutions.

Second, policy coordination as such needs to be further specified. In the present analysis, the reader had to content oneself with the absence or presence of asylum policy

\footnotetext{
${ }^{169}$ Comte (2010) describes the reluctance of member states to initially set up a so-called Consultative Forum through which civil society could participate in EASO's activities. Eventually, such a forum was established. However, its added value is, also among NGOs, contested. One source that frequently criticises the nonavailability of information on the agency's activities is the Malta-based NGO aditus via its blog EASO Monitor (http://easomonitor.blogspot.nl).
} 
coordination. For example, it was noted that such coordination takes place within the informal Council working group CIREA; or that it takes place bilaterally between two countries speaking the same language. However, there was no possibility to discuss in more detail what precisely policy coordination entails. To return to the example of Mr. Bavol and Mr. Franz: does policy coordination between the German and the Austrian asylum administrations simply mean an information exchange between Mr. Franz and his counterpart in the Austrian authority related to the situation of Roma living in the outskirts of Belgrade? Or does policy coordination mean that the German and Austrian authorities aim to avoid policy differences regarding their general treatment of asylum seekers from Serbia? These are two very different things but have, in this thesis, both been subsumed under the label of policy coordination. Specifying the differences would significantly contribute to the understanding of this policy mode. It could, for example, be achieved by relying on the policy coordination scale developed by Metcalfe (1994). His scale provides a method of differentiating features of inter-organisational relationships. They form a logical sequence of components of coordination capacity. Thus, he goes further than saying coordination is an all or nothing matter but defines nine stages in the coordination process. While Metcalve's (1994) focus is on intra-governmental coordination (among ministries of one country), applying the scale to intergovernmental coordination could reveal interesting insights.

Third, the effects of policy coordination on domestic policy-making processes need to be further studied. This relates not exclusively but in particular to the possible effect of policy convergence. It has been stressed in this thesis that policy convergence is only possible up to a certain extent. Beyond that point, divergence will remain because policies are always motivated by national considerations, and countries differ a lot - no matter whether one views this from a rational choice or a social constructivist point of view. From the rational side, countries of origin of asylum seekers vary greatly across EU member states - and deterring these asylum seekers will always ask for countryspecific rather than Europe-wide (policy) solutions. From the social constructivist point of view, national identities are very diverse and - since they play a crucial part in shaping policy - also policies will continue being very different from each other.

Finally, coming to the compatibility of the two logics of actions, more empirical analysis is necessary. There are now some prominent proponents of the commensurability of these perspectives, and they suggest various ways how to combine the two (section 8.2.4). Also here, the present analysis contributed to the discussion by illustrating one example of combining the logic of consequences and the logic of appropriateness. However, we miss more empirical analysis demonstrating this compatibility, and in particular the conditions under which they are in what way compatible. 


\subsection{The human story revisited}

We are always critical towards asylum policy and asylum policy-making. There are endless papers showing how wrong our current system is, how inhumanely we treat asylum seekers and how - in fact - they are constantly exposed to non-refoulement. By any means, this criticism is justified and necessary.

What, however, this analysis highlighted is that there is more than just $a$ policymaker or a government deciding on a certain policy. In fact, there is a huge machinery of asylum administration connected to it - at least in some countries. Where there is none, asylum seekers are in a sorry state. Where there is one, these asylum administrations are the result of an ever-increasing flow of people (presumably) being in need of protection, and hoping for a better life somewhere else. Persons like Mr. Franz, who work in these administrations, are on a daily basis confronted with these hopes and needs. He makes far-reaching decisions on whether or not an applicant can stay in the country where he applied for protection. Such decisions are based on a complicated set of rules negotiated by governments some 70 years ago, and constantly refined since then.

If one wants to know what the basic international rules for refugee protection are, it is possible to simply look them up (UNHCR 1951). If one wants to know how many and what kind of protection statuses are given to people asking for asylum, one can also easily find such statistics (Eurostat). However, there is a large black box between international refugee law, on the one hand, and eventual recognition rates on the other. There is hardly any analysis on how people like Mr. Franz, his colleagues and his supervisors take decisions. Also, little is known about how asylum policy decisions are actually taken both within national ministries and the national asylum administrations. We also hardly know whether and in how far these decisions are influenced by what is done in other countries. This thesis aimed to shed light on these political and, especially, administrative processes. Rather than simply observing that countries engage in a race to the bottom, as is often done, this thesis looked at four EU member states in detail, analysing how and why asylum policy takes certain shapes. In doing so, the thesis contributed towards uncovering such policy-making processes, and thus provides room for both further academic research and advocacy action. 


\section{List of References}

Alink, F., Boin, A., \& T' Hart, P. (2001). Institutional crises and reforms in policy sectors: the case of asylum policy in Europe. Journal of European Public Policy, 8(2), 286-306.

Amnesty International UK (2004). 'Safe countries' list and other policy proposals risk discrimination and human rights abuse. Press release. Retrieved on 22 July 2014, from http://www.amnesty.org.uk/pressreleases/eu-asylum-safe-countries-list-and-other-policy-proposals-risk-discrimination-and.

Amnesty International (1993). Press statement of 8 January 1993: Skandalöse Vorschläge des Bundesinnenministeriums für Liste "verfolgungsfreier" Staaten. (document in possession of the author)

Angenendt, S., \& Parkes, R. (2010). A New Impulse for EU Asylum Policy? The Potential of the European Asylum Support Office. SWP Comments. Stiftung Wissenschaft und Politik, 21.

Aronoff, M. J. (2001). Political Culture. In D. L. Sills (Ed.), International Encyclopedia of the Social Sciences (Vol. 17, pp. 11640-11644). New York: Macmillan.

BAMF (n.d.). D-A-CH Kooperation Asylwesen Deutschland-Österreich-Schweiz. Nuremberg: Bundesamt für Migration und Flüchtlinge.

BBC (2001). Pakistani immigrants hopeful after court ruling. 18 May 2001. BBC. Retrieved on 27 November 2012, from http://news.bbc.co.uk/2/hi/south_asia/1336657.stm

Bennett, C., \& Howlett, M. (1992). The Lessons of Learning: Reconciling Theories of Policy Learning and Policy Change. Policy Sciences, 25, 275-294.

Berry, J. M. (2002). Validity and Reliability Issues in Elite Interviewing. Political Science and Politics, 35(4), 679-682.

Bickerton, C., Hodson, D., \& Puetter, U. (forthcoming). The New Intergovernmentalism: European Integration in the Post-Maastricht Era. Journal of Common Market Studies.

Bloch, A. (2000). A New Era or More of the Same? Asylum Policy in the UK. Journal of Refugee Studies, 13(1), 29-42.

Boerzel, T., \& Risse, T. (2003). Conceptualizing the Domestic Impact of Europe. In C. M. R. K. Featherstone (Ed.), The Politics of Europeanization (pp. 57-80). Oxford: OUP.

Boerzel, T. A., \& Risse, T. (2000). When Europe Hits Home: Europeanization and Domestic Change. European Integration Online Papers, 4(15).

Bogner, A., \& Menz, W. (2009). The Theory-Generating Expert Interview: Epistemological Interest, Forms of Knowledge, Interaction. In A. Bogner, B. Littig \& W. Menz (Eds.), Interviewing Experts (pp. 81-97). Basingstoke: Palgrave Macmillan.

Borrás, S., \& Jacobsson, K. (2004). The open method of co-ordination and new governance patterns in the EU. Journal of European Public Policy, 11(2), 185-208.

Boswell, C. (2009). The Politcal Uses of Expert Knowledge. Immigration Policy and Social Research. Cambridge: Cambridge University Press.

Bundesministerium des Inneren (1996). Prüfung sicherer Herkunftsstaat: Senegal. Fortschreibung des Prüfberichts vom 1. Februar 1993 aus Anlass der vorläufigen Streichung Senegals aus der Liste sicherer Herkunftsstaaten durch Rechtsverordnung vom 27. März 1996.

Bundestag (2014). Gesetzesentwurf der Bundesregierung. Entwurf eines Gesetzes zur Einstufung weiterer Staaten als sichere Herkunftsstaaten und zur Erleichterung des Arbeitsmarktzugangs für Asylbewerber und geduldete Ausländer. Drucksache 18/1528. Berlin: Deutscher Bundestag.

Bundestag (2011). Antwort der Bundesregierung vom 18.08.2011 auf die kleine Anfrage der Abgeordneten Ulla Jepke, Sevim Dagdelen, Petra Pau, weiterer Abgeordneter und der Fraktion DIE LINKE, Drucksache 17/6810. Berlin: Deutscher Bundestag.

Bundestag (1996). Beschlussempfehlung und Bericht des Innenausschusses vom 26.06.1996 zu dem Antrag der Fraktion der SPD - Drucksache 13/3329 - Herausnahme von Ghana aus der Liste der sicheren Herkunftsstaaten, Drucksache 13/5075. Berlin: Deutscher Bundestag.

Bundestag (1993a). Discussion on the draft law amending articles 16 and 18 of the Basic Law, 4 March 1993, session 143. Berlin: Deutscher Bundestag. 
Bundestag (1993b). Hearing of experts. 55/71/8. Documentation of the open consultation with experts regarding the proposed changes of articles 16 and 18 GG. Berlin: Deutscher Bundestag. (in the possession of the author)

Bundestag (1993c). Discussion on the draft law amending articles 16 and 18 of the Basic Law, 26 May 1993 , session 160. Berlin: Deutscher Bundestag.

Bundestag (1993d). Bericht der Abgeordneten Wolfgang Zeitlmann, Erwin Marscheski, Gerd Wartenberg und Hans-Joachim Otto regarding discussion on the draft law amending articles 16 and 18 of the Basic Law. Drucksache 12/4984. Berlin: Deutscher Bundestag. (in the possession of the author)

Bundestag (1993e). Gesetzentwurf der Fraktionen der CDU/CSU, SPD und FDP. Entwurf eines Gesetzes zur Änderung des Grundgesetzes (Artikel 16 und 18). Drucksache 12/4152. Berlin: Deutscher Bundestag.

Bundesverfassungsgericht (2012), 18 July 2012. 1 BvL 10/10, 1 BvL 2/11.

Bundesverfassungsgericht (1996). 14 May 1996. 2BvR 1507/93.

Bunyan, T., \& Webber, F. (1995). Intergovernmental Cooperation on Immigration and Asylum. Brussels: Churches Commission for Migrants in Europe.

Byrne, R., Noll, G., \& Vedsted-Hansen, J. (2004). Understanding Refugee Law in an Enlarged European Union. EJIH, 15, 355-379.

Byrne, R., Noll, G., \& Vedsted-Hansen, J. (Eds.). (2002). New Asylum Countries? Migration Control and Refugee Protection in an Enlarged European Union. The Hague: Kluwer Law International.

Byrne, R., \& Shacknove, A. (1996). The Safe Country Notion in European Asylum Law. Harvard Human Rights Journal, 9, 185-228.

Calleya, S., \& Lutterbeck, D. (2008). Managing the Challenges of Irregular Immigration in Malta: Today Public Policy Institute.

Carrera, S., Hertog, L. d., \& Parkin, J. (2013). The Peculiar Nature of EU Home Affairs Agencies in Migration Control: Beyond Accountability versus Autonomy. European Journal of Migration and Law, 15(4), 337358.

Casciani, D. (2013). The UKBA's astonishingly troubled history. 26 March 2013. BBC News UK. Retrieved from http://www.bbc.co.uk/news/uk-21940901

Casciani, D. (2004). UN warns over EU asylum rules. 30 March 2004. BBC News. Retrieved 27 May 2014 from http://news.bbc.co.uk/2/hi/europe/3580665.stm

CDU, CSU and SPD (2013). Deutschlands Zukunft gestalten. Koalitionsvertrag zwischen CDU, CSU und SPD. 18. Legislaturperiode.

Checkel, J. T. (2010). Theoretical Synthesis in IR: Possibilities and Limits. Simons Papers in Security and Development, No. 6. Schools for International Studies. Simon Fraser University, Vancouver.

Checkel, J. T. (2001a). Why Comply? Social Learning and European Identity Change. International Organization, 55(3), 553-588.

Checkel, J. T. (2001b). Social Construction and European Integration. In T. Christiansen, K. E. Jorgensen \& A. Wiener (Eds.), The Social Construction of Europe (pp. 50-65). London: Sage.

Christiansen, T. \& Neuhold, C. (2013). Informal Politics in the EU. Journal of Common Market Studies 51(6), 1196-1206.

Christiansen, T., \& Neuhold, C. (Eds.). (2012). International Handbook on Informal Governance. Cheltenham: Edward Elgar.

Christiansen, T., Follesdal, A., \& Piattoni, S. (2003). Informal Governance in the European Union: an Introduction. In T. Christiansen \& S. Piattoni (Eds.), Informal Governance in the European Union (pp. 1-21). Cheltenham, UK: Edward Elgar.

Christiansen, T., \& Piattoni, S. (Eds.). (2003). Informal Governance in the European Union. Cheltenham, UK: Edward Elgar.

Citizenship and Immigration Canada (2008). Review of the Migration Policy Development Program. InterGovernmental Consultations on Asylum, Refugee and Migration Policies. Retrieved 21 October 2013, 2013, from http://www.cic.gc.ca/english/resources/evaluation/mpdp/key_success.asp

Collectif Rëfugiés Luxembourg (2007). Press statement of 16 May 2007 concerning the estbalishment of a national list of safe countries of origin. (in the possession of the author) 
Conseil d'Etat (2013), 4 March 2013. No 356490.

Constitutional Court of Belgium (1993), 4 March 1993. No 20/93. Retrieved 8 April 2014, from http://www.const-court.be/public/d/1993/1993-020d.pdf

Comte, F. (2010). A New Agency is Born in the European Union: The European Asylum Support Office. European Journal of Migration and Law, 12, 373-405.

Cooke, P. (2012, 12 July 2012). Detention Policy "Foments Racism". Times of Malta. Retrieved on 12 June 2014, from http://www.timesofmalta.com/articles/view/20120712/local/Detention-policy-foments- racism-. 428186

Costello, C. (2006). The European Asylum Procedures Directive in Legal Context. UNHCR - New Issues in Refugee Research Research Paper No. 134.

Costello, C. (2005). The Asylum Procedures Directive and the Proliferation of Safe Country Practices: Deterrence, Deflection and the Dismantling of International Protection. European Journal of Migration and Law, 7, 35-69.

Council of Europe (2005). Accelerated Asylum Procedures in the Council of Europe Member States: Committee on Migration, Refugees and Population.

Council of the European Union (2004). Report from the Presidency of the Council of the European Union (Netherlands) to the Asylum Working Party on 17 September on Minimum Common List of Safe Countries of Origin, 12118/1/04 REV 1. Brussels: JHA Council of the European Union.

Council of the European Union (2002). Declaration by the Ministers of Justice and Home Affairs of the Member States of the EU on Asylum. 15 October 2002.

Council of the European Union (1992a). Council Resolution of 30 November 1992 on Manifestly Unfounded Applications for Asylum ("London Resolution").

Council of the European Union (1992b). Council Conclusion of 30 November 1992 on countries in which there is generally no serious risk of persecution (London Resolution).

Court of Appeal (2001), 17 May 2001. C/2001/0291.

Cremer, H. (2013). Die Asyldebatte in Deutschland: 20 Jahre nach dem Asylkompromiss. Berlin: German Institute for Human Rights.

Cruz, A. (1999). Luxembourg. In S. Angenendt (Ed.), Asylum and Migration Policies in the European Union. Berlin: Europa Union Verlag.

Dalli, M. (2013). Pushbacks suspended as European Court demands explanation from Malta. 9 July 2013. Malta Today. Retrieved on 12 June 2014, from http://www.maltatoday.com.mt/-news/national/28246/pushbacks-suspended-as-european-court-demands-explanation-from-malta-20130709\#.U5lkqigjPhU

Danish Immigration Service (2013). Security and Protection in Mogadishu and South- Central Somalia. Joint report from the Danish Immigration Service's and the Norwegian Landinfo's fact finding mission to Nairobi, Kenya and Mogadishu, Somalia. Copenhagen.

Dolowitz, D. P., \& Marsh, D. (2000). Learning from Abroad: The Role of Policy Transfer in Contemporary Policy-Making. Governance, 13(1), 5-23.

Doughty Street Chambers (2006). Sri Lanka removed from "White List". Retrieved on 6 December 2012, from http://www.doughtystreet.co.uk/news/news_detail.cfm?iNewsID=193

EASO (2013). Asylum applicants from the Western Balkans. Comparative analysis of trends, push-pull factors and responses. Valetta: European Asylum Support Office.

EASO (2012a). Country of Origin Information Report Methodology. Valetta.

EASO (2012b). European Asylum Support Office to send Asylum Support Teams to Luxembourg. Press Release of 26 January 2012. Marsa: European Asylum Support Office.

EASO (2012c). Country of Origin Information report. Afghanistan. Taliban Strategies - Recruitment. Valetta: European Asylum Support Office.

EASO (2012d). Country of Origin Information report. Afghanistan. Insurgent strategies - intimidation and targeted violence against Afghans. Valetta: European Asylum Support Office. 
ECRE (2010). Comments from the European Council on Refugees and Exiles on the European Commission Proposal to recast the Asylum Procedures Directive: European Council on Refugees and Exiles, available at http://www.ecre.org/topics/areas-of- work/protection-in-europe/162.html, accessed July 2011

ELENA, European Legal Network on Asylum (2005). The application of the safe country of origin concept in Europe: ECRE, European Council of Refugees and Exiles.

EMN. (2010). Ad-Hoc Query on Storing COI in National Databases. Requested by the Finnish EMN NCP on 21st July 2010. Brussels: European Migration Network.

EMN Germany (2013). Annual Policy Report 2012: German National Contact Point for the European Migration Network. Retrieved on 22 January 2014, from http://www.bamf.de/SharedDocs/Anlagen/EN/Publikationen/EMN/Nationale-Berichte/emn-policy-report-2012germany.pdf?_blob=publicationFile

EMN Luxembourg (2012). Policy report on migration and asylum 2011: European Migration Network. National Contact Point Luxembourg.

EMN Luxembourg (2010). Policy Report on Migration and Asylum: European Migration Network, National Contact Point Luxembourg.

EMN Malta (2008). The Organisation of Asylum and Migration Policy in Malta: National Contact Point of the European Migration Network Malta

Engelmann, C. (2014a). Convergence Against the Odds: the Development of Safe Country of Origin Policies in EU Member States (1990-2013). European Journal of Migration and Law, 16(2), 249-302.

Engelmann, C. (2014b). Informelles Regieren in der europäischen Asylpolitik: der Austausch von Herkunftslandinformationen zwischen nationalen Asylbehörden. Zeitschrift für Vergleichende Politikwissenschaft, 8(1), 169-192.

European Commission (2011). European Refugee Fund 2011 Community Actions. List of Grants Awarded.: Commission of the European Communities.

European Commission (2009a). Commission Staff Working Document accompanying the Proposal for a Directive of the European Parliament and of the Council on Minimum Standards on Procedures in Member States for Grating and Withdrawing International Protection. Impact Assessment. SEC (2009) 1377: Commission of the European Communities.

European Commission (2009b). European Refugee Fund 2009 Community Actions. List of Grants Awarded. Brussels: Commission of the European Communities.

European Commission (2009c). Annexes to the Commission Staff Working Document accompanying the Proposal for a Directive of the European Parliament and of the Council on Minimum Standards on Procedures in Member States for Grating and Withdrawing International Protection. Impact Assessment. SEC (2009) 1376-part II. Brussels: Commission of the European Communities.

European Commission (2008a). European Refugee Fund 2008 Community Actions. List of Grants Awarded. Brussels: Commission of the European Communities.

European Commission (2008b). Communication from the Commission to the European Parliament, the Council, the European Economic and Social Committee and the Committee of Regions. Policy Plan on Asylum - an Integrated Aproach to Protection Across the EU. COM (2008) 360 final. Brussels: Commission of the European Communities.

European Commission (2006a). Communication from the Commission to the Council and the European Parliament on Strengthened Practical Cooperation - New Structures, New Approaches: Improving the Quality of Decision Making in the Common European Asylum System. COM (2006) 67 final. Brussels: Commission of the European Communities.

European Commission (2006b). Commission Staff Working Document. Annexes to the Communication from the Commission to the Council and the European Parliament on Strengthened Practical Cooperation New Structures, New Approaches: Improving the Quality of Decision Making in the Common European Asylum System. COM (2006) 67, SEC (2006) 189. Brussels: Commission of the European Communities.

European Commission (2002). The Law and Practice on Safe COuntry Principles Against the Background of the Common European Asylum System and the Goal of a Common Asylum Procedure. DG JAIA2/2002/04. Brussels: Commission of the European Communities. 
European Council (2009). The Stockholm Programme - An Open and Secure Europe Serving and Protecting Citizens, 2010/C 115/01. Brussels: Official Journal of the European Union.

European Council (1999). Tampere Programme. Brussels: Official Journal of the European Union.

European Council (1994). Second activity report on the Centre for Information, Discussion and Exchange on Asylum (Cirea). Brussels.

European Country of Origin Sponsorship (2010a). EU common guidelines on (Joint) Fact Finding Missions a practical tool to assist member states in organizing (joint) Fact Finding Missions.

European Country of Origin Sponsorship (2010b). ECS: Aims - Participating States - Tasks and Activities Contact Persons: Leaflet in possession of the author.

European Court of Justice (2011). Brahim Samba Diouf v. Ministre du Travail, de l'Emploi et de l'Immigration. Decision of 28 July 2011, Case C-69/10.

European Court of Justice (2010). Brahim Samba Diouf v Ministre du Travail, de l'Emploi et de l'Immigration. Reference for a preliminary ruling from the Tribunal administrative (Luxembourg) lodged on 5 February 2010, Case C-69/10.

European Court of Justice (2008). European Parliament v. Council of the European. Judgement of 6 August 2008, Case-133/06.

European Parliament (1996). Asylum in the European Union: The "Safe Country of Origin Principle": European Parliament Directorate General for Research.

Eurostat (2013). Asylum applicants and first instance decisions on asylum applicants: second quarter 2013: Eurostat $12 / 2013$.

Falzon, M. (2012). The immigrant detention policy. 8 July 2012. Times of Malta. Retrieved on 12 June 2014, from http://www.timesofmalta.com/articles/view/20120708/opinion/The- immigrant- detentionpolicy. 427591

Fassmann, H., \& Reeger, U. (2008). From Guest Worker Migration to a Country of Immigration. IDEA Working Paper. Retrieved on 27 May 2014, from http://www.idea6fp.uw.edu.pl/pliki/WP1_Austria.pdf

Frowein, J., \& Zimmermann, A. (1996). Die Asylrechtsreform des Jahres 1993 und das Bundesverfassungsgericht. Juristenzeitung, 15(16), 753-764.

Garrett, G., \& Tsebelis, G. (1996). An institutional critique of intergovernmentalism. International Organization, 50(2), 269-299.

George, A. L., \& Bennett, A. (2005). Case Studies and Theory Development in the Social Sciences. Cambridge, Massachusetts: MIT Press.

Gerring, J. (2007). Case Study Research. Cambridge: Cambridge University Press.

Gerring, J. (2004). What is a Case Study and What is it Good for? Americal Political Science Review, 98(2), 341354.

Goldmann, K. (2005). Appropriateness and Consequences: The Logic of Neo- Institutionalism. Governance, $18(1), 35-52$.

Goldstein, K. (2002). Getting in the Door: Sampling and Completing Elite Interviews. Political Science and Politics, 35(4), 669-672.

Goodwin-Gill, G., \& McAdam, J. (2007). The Refugee in International Law. Oxford: Oxford University Press.

Goodwin-Gill, G. S. (1992). Safe Country? Says Who? International Journal of Refugee Law, 4(2), 248-250.

Green, S. (2007). Divergent Traditions, Converging Responses: Immigration and Integration Policy in the UK and Germany. German Politics, 16(1), 95-115.

Guild, E., Carrera, S., Hertog, L. d., \& Parkin, J. (2011). Implementation of the EU Charter of Fundamental Rights and its Impact on EU Home Affairs Agencies: Frontex, Europol and the European Asylum Support Office. Study conducted for the European Parliament's Committee on Civil Liberties, Justice and Home Affairs. Brussels: European Parliament.

Guiraudon, V. (2000). European Integration and Migration Policy: Vertical Policy-making as Venue Shopping. Journal of Common Market Studies, 38(2), 251-271.

Haas, P. M. (1992). Introduction: Epistemic Communities and International Policy Coordination. International Organization, 46(1), 1-35. 
Hailbronner, K. (1993a). The Concept of 'Safe Country' and Expeditious Asylum Procedures: A Western European Perspective. International Journal of Refugee Law, 5(1), 31-65.

Hailbronner, K. (1993b). Stellungnahme zum Entwurf eines Gesetzes zur Änderung des Grundgesetzes (Art. 16 and 18), BT-Drs. 12/4152. (in the possession of the author)

Hallam Johnston \& Associates. (2005). Intergovernmental Consultations on Asylum, Refugee and Migration Policies. An Assessment of Twenty Years. Geneva: Intergovernmental Consultations on Asylum, Refugee and Migration Policies.

Heinhold, H. (1993). Stellungnahme zu den Vorschlägen zur Änderung des Asylgrundrechtes (Art 16 II 2 GG) sowie den beratenden Anträgen und Gesetzenentwürfen. (in the possession of the author)

Helmke, G., \& Levitsky, S. (2004). Informal Institutions and Comparative Politics: A Research Agenda. Perspectives on Politics, 2(4).

Hirczy, W. (1995). Explaining near-universal turnout: The case of Malta. European Journal of Political Research, 27, 255-272.

HoC, House of Commons (2007). Discussion on the draft Asylum (Designated States) Order 2007, 23 July 2007, Twelfth Delegated Legislation Committee.

HoC, House of Commons (2005a). Discussion on the draft Asylum (Designated States) Order 2005, 8 February 2005, Fifth Standing Committee on Delegated Legislation.

HoC, House of Commons (2005b). Discussion on the draft Asylum (Designated States) (No. 2) Order 2005, 24 November 2005, Fourth Standing Committee on Delegated Legislation.

HoC, House of Commons (2003). Discussion on the draft Asylum (Designated States) (No. 2) Order 2003, 7 July 2003, First Standing Committee on Delegated Legislation.

HoC, House of Commons (1996a). Discussion on the Asylum and Immigration Bill, 11-18 January 1996. Standing Committee D 1995-1996.

HoC, House of Commons (1996b). Discussion on the draft Asylum (Designated Countries of Destination and Designated Safe Third Countries) Order 1996, 15 October 1996.

HoL, House of Lords (2010). Discussion on the draft Asylum (Designated States) Order 2010, 9 February 2010, Grand Committee.

HoL, House of Lords (2007). Discussion on the draft Asylum (Designated States) Order 2007, 10 July 2007.

HoL, House of Lords (2005a). Discussion on the draft Asylum (Designated States) Order 2005, 4 February 2005.

HoL, House of Lords (2005b). Discussion on the draft Asylum (Designated States) (No. 2) Order, 24 November 2005.

HoL, House of Lords (2003a). Discussion on the draft (Asylum Designated States) Order 2003, 3 March 2003.

HoL, House of Lords (2003b). Discussion on the draft (Asylum Designated States) (No. 2) Order 2003, 4 July 2003

HoL, House of Lords (1996). Discussion on the draft Asylum (Designated Countries of Destination and Designated Safe Third Countries) Order 1996, 16 October 1996.

Holzinger, K., \& Knill, C. (2005). Causes and conditions of cross-national policy convergence. Journal of European Public Policy, 12(5), 775-796.

Home Office (2003). Country of origin information: a user and content evaluation. London: Home Office Research, Development and Statistics Directorate.

Hovy, B. (2001). Statistically Correct Asylum Data: Prospects and Limitations. UNHCR Working Paper No. 37: United Nations High Commissioner for Refugees.

Huysmans, J., \& Buonfino, A. (2008). Politics of Exception and Unease: Immigration, Asylum and Terrorism in Parliamentary Debates in the UK. Political Studies 56, 766- 788.

IAGCI (2013a). Minutes arising from the Independent Chief Inspector of the UKBA, Independent Advisory Group on Country Information (IAGCI) on 1 October 2013. London.

IAGCI (2013b). Reviews of Country Information Reports. Retrieved 15 July 2014, from http://icinspector.independent.gov.uk/country-information-reviews/reviews-of- country-informationreports/2013-reviews-of-country-information-reports/ 
ICMPD, International Centre for Migration Policy and Development (2006). Comparative study on country of origin information systems. Vienna.

IGC (2009). Asylum Procedures. Report on Policies and Practices in IGC participating States. Geneva: Intergovernmental Consultations on Migration, Asylum and Refugees.

Immergut, E. (1998). The Theoretical Core of New Institutionalism. Politics and Society, 26(1), 5-34.

IND (2008). Common EU Guidelines for Processing Country of Origin Information (COI): Office for Country Information and Language Analysis et al. ARGO Project funded by the European Commission.

Independent Chief Inspector to the UKBA (2011). The use of country of origin information in deciding asylum applications: A thematic inspection. London.

Jachtenfuchs, M. (2002). Deepening and Widening Integration Theory. Journal of European Public Policy, 9(4), 650-657.

Jesuit Refugee Service. (n.d.). Comments on Bill to Amend Refugees Act. Valetta.

Justaert, A., \& Keukeleire, S. (2012). Informal Governance and Networks in EU Foreign Policy. In T. Christiansen \& C. Neuhold (Eds.), International Handbook on Informal Governance (pp. 433-456). Cheltenham: Edward Elgar.

Joint Committee on Human Rights, HoL and HoC (2002). Nationality, Immigration and Asylum Bill: Further Report, Twenty-third Report of Session 2001-2002. HL Paper 176, HC 1255.

Joly, D. (1994). The Porous Dam: European Harmonization on Asylum in the Nineties. International Journal of Refugee Law, 6, 159-193.

Kaunert, C., \& Leonard, S. (2012). The development of the EU asylum policy: venue- shopping in perspective. Journal of European Public Policy, ?(?), 1-18.

Kaunert, C. (2009). Liberty vs. Security? EU Asylum Policy and the European Commission. Journal of Contemporary European Research, 5(2), 148-170.

Kinzer, S. (1991). A Wave of Attacks On Foreigners Stirs Shock in Germany. The New York Times. Retrieved on 8 November 2012, from http://www.nytimes.com/1991/10/01/world/a-wave-of-attacks-onforeigners-stirs- shock-in-germany.html

Kleine, M. (2013). Informal Governance in the European Union. How Governments Make International Organizations Work. Ithaca: Cornell University Press.

Knill, C. (2005). Introduction: Cross-national policy convergence: concepts, approaches and explanatory factors. Journal of European Public Policy, 12(5), 764-774.

Knill, C., \& Lenschow, A. (2005). Compliance, Competition and Communication: Different Approaches of European Governance and their Impact on National Institutions. Journal of Common Market Studies, 43(3), 583-606.

Von Koppenfels, A. K. (2001). Informal but effective: Regional consultative processes as a tool in managing migration. International Migration, 39(6), 61-84.

Kornelius, S. (1989). CDU beschliesst Verschärfung des Asylrechts. 14 September 1989. Süddeutsche Zeitung.

Kostakopoulou, T. (2000). The 'Protective Union': Change and Continuity in Migration Law and Policy in Post-Amsterdam Europe. Journal of Common Market Studies, 38(3), 497-518.

Kreienbrink, A. (2013). 60 Jahre Bundesamt für Migration und Flüchtlinge im Kontext der deutschen Migrationspolitik. Zeitschrift für Ausländerrecht und Ausländerpolitik, 11-12, 397-410.

Kreutz, D. (1992). An die sozialdemokratischen Bundestagsabgeordneten aus Köln bezüglich des Gesetzesentwurfs zur Neuregelung des Asylverfahrens. Landtag NRW. 5 February 1992. (document in possession of the author)

Lavenex, S. (2010). Justice and Home Affairs: Communitarization With Hesitation. In H. Wallace, M. A. Pollack \& A. R. Young (Eds.), Policy-Making in the European Union (6 ed., pp. 457-480). Oxford: OUP.

Lavenex, S. (2008). Asylum Policy. In P. G. Maarten P. Vink (Ed.), Europeanization. New Research Agendas (pp. 309-320). New York: Palgrave Macmillan.

Lavenex, S. (2006). Sifting up and out: The foreign policy of European immigration control. West European Politics, 29(2), 329-350. 
Lavenex, S. (2001). The Europeanization of Refugee Policy: Normative Challenges and Institutional Legacies. Journal of Common Market Studies, 39(5), 851-874.

Lavenex, S. (1999). Safe Third Countries. Extending the EU Asylum and Immigration Policies to Central and Eastern Europe. Budapest: Central European University Press.

Lavenex, S., \& Wallace, W. (2005). Justice and home affairs: towards a 'European Public Order'? In M. A. P. William Wallace; Helen Wallace (Ed.), Policy-Making in the European Union (5 ed., pp. 457-480). New York, US: OUP.

Lijphart, A. (1971). Comparative Politics and the Comparative Method. The American Political Science Review, 65(3), 682-693.

Lutterbeck, D. (2009). Small Frontier Island: Malta and the Challenge of Irregular Immigration. Mediterranean Quarterly, 20(1), 120-144.

Luxemburger Wort (2011). Asylum office to close temporarily. 3 October 2011. Luxemburger Wort. Retrieved on 24 January 2014, from http://www.wort.lu/en/view/asylum-office-to-close-temporarily4f60c4c7e4b047833b93b146

Mainwaring, C. (2012a). Constructing a Crisis: the Role of Immigration Detention in Malta. Population, Space and Place, 18, 687-700.

Mainwaring, C. (2012b). Resisting Distalization? Malta and Cyprus' Influence on EU Migration and Asylum Policies. Refugee Survey Quarterly, 31(4), 38-66.

March, J. G., \& Olsen, J. O. (2009). The Logic of Appropriateness. Arena Working Paper. Center for European Studies. University of Oslo, 4.

March, J. G., \& Olsen, J. P. (1998). The Institutional Dynamics of International Political Orders. International Organization, 52(4), 943-969.

March, J., \& Simon, H. (1993). Organizations (2 ed.). Cambridge, MA: Blackwell.

March, J. G., \& Olsen, J. P. (1989). Rediscovering institutions: the organizational basis of politics. New York: Macmillan.

Marcussen, M., Risse, T., Engelmann-Martin, D., Knopf, H. J., \& Roscher, K. (2001). Constructing Europe? The Evolution of Nation-State Identities. In T. Christiansen, K. E. Jorgensen \& A. Wiener (Eds.), The Social Construction of Europe (pp. 101-120). London: Sage Publications.

Martenson, H., \& McCarthy, J. (1998). 'In General, No Serious Risk of Persecution': Safe Country of Origin Practices in Nine European States. Journal of Refugee Studies, 11(3), 304-325.

Marx, R. (2008). Kommentar zum Asylverfahrensgesetz (Vol. 7): Luchterhand.

Metcalfe, L. (1994). International Policy Co-Ordination and Public Management Reform. International Review of Administrative Sciences, 60, 271-290.

Ministry for Justice and Home Affairs (2005). Irregular Immigrants, Refugees and Integration. Ministry for Justice and Home Affairs of Malta, Ministry for Family and Social Solidarity of Malta. Policy Document.

Monar, J. (2006). Cooperation the Justice and Home Affairs Domain: Characteristics, Constraints and Progress. European Integration, 28(5), 495-509.

Monar, J. (2003). The Area of Freedom, Security and Justice after the 2004 Enlargement. The International Spectator, 38(1), 33-50.

Monar, J. (2001). The dynamics of Justice and Home Affairs: laboratories, driving factors and costs. Journal of Common Market Studies, 39(4), 747-764.

Monheim, G. (1993). Wer Gewalt sät - von Brandstiftern und Biedermeiern. Documentary of the West German Broadcasting (WDR), 44 min. Retrieved on 17 June 2014, from http://lichtenhagen.net/index.php/hintergrund

Moravscik, A. (1993). Preferences and Power in the European Community: A Liberal Intergovernmentalist Approach. Journal of Common Market Studies, 31(4), 473-524.

Nagy, B. (2002). Hungary. In R. Byrne, G. Noll \& J. Vedsted-Hansen (Eds.), New Asylum Countries? Migration Control and Refugee Protection in an Enlarged European Union (pp. 138-199). The Hague: Kluwer Law International. 
Neumayer, E. (2005). Asylum Recognition Rates in Western Europe. Their Determinants, Variation and Lack of Convergence. Journal of Conflict Resolution, 49(1), 43-66.

Noll, G. (2000). Negotiating Asylum: The EU Acquis, Extraterritorial Protection and the Common Market of Deflection. The Hague, Boston, London: Martinus Nijhoff Publishers.

Oakley, S. (2007). Accelerated Procedures for Asylum in the European Union. Fairness versus Efficiency. Sussex Migration Working Paper No. 43.

ODYSSEUS (2006). Comparative Overview of the Implementation of the Directive 2003/9 of 27 January 2003 Laying Down Minimum Standards for the Reception of Asylum Seekers in the EU Member States.

Oel, M., \& Rapp-Lücke, J. (2008). Preparing Decision-Making on the Political Level in the EU-27 Plus: the Example of European Home Affairs. Working Paper Series on EU Internal Security Governance. Working Paper No 11. The Securint Collection.

Oelgemöller, C. (2011). Informal Plurilateralism: The Impossibility of Multilateralism in the Steering of Migration. British Journal of Politcs and International Relations, 13, 110- 126.

Olesen, J. W., \& Olsen, J. (2012). Danish Fact Finding MIssions and Refugee Status Determination. The Researcher, $x(\mathrm{x}), 7-9$.

Peers, S. (2013). The Second Phase of the Common European Asylum System: A Brave New World - or Lipstick on a Pig? : Statewatch.

Penisson, L. (2012). Aiming at Convergence: The EU Common Country of Origin Information Portal. The Researcher, 7(1), 16-17.

Pollack, M. A., Wallace, H., \& Young, A. R. (2010). EU Policy-Making in Challenging Times: Adversity, Adaptability, and Resilience. In H. Wallace, A. P. Mark \& A. R. Young (Eds.), Policy-Making in the European Union (Vol. 6, pp. 481-502). Oxford: OUP.

Pollak, J., \& Slominski, P. (2009). Experimentalist but not Accountable Governance? The Role of Frontex in Managing the EU's External Borders. West European Politics, 32(5), 904-924.

PoM, Parliament of Malta (2008). Discussion on the Refugees (Amendment) Bill of 2004. Second Reading (Plenary), 2 and 3 June 2014. Valetta.

PoM, Parliament of Malta (2005a). Discussion on the Refugees (Amendment Bill of 2005, Second Reading (Plenary), 5 October 2005.Valetta.

PoM, Parliament of Malta (2005b). Discussion on the Refugees (Amendment Bill of 2005, Second Reading (Plenary), 10 October 2005.Valetta.

PoM, Parliament of Malta (2005c). Discussion on the Refugees (Amendment Bill of 2005, Committee Stage (Standing Committee for Consideration of Bills), Meeting 60, 2 November 2005.Valetta.

PoM, Parliament of Malta (2004a). Discussion on the Refugees (Amendment) Bill of 2004, Second Reading (Plenary), 12 May 2004.Valetta.

PoM, Parliament of Malta (2004b). Discussion on the Refugees (Amendment) Bill of 2004, Second Reading (Plenary), 17 May 2004.Valetta.

PoM, Parliament of Malta (2004c). Discussion on the Refugees (Amendment) Bill of 2004, Committee Stage (Standing Committee for Consideration of Bills), Meeting 28, 20 July 2005.Valetta.

PoM, Parliament of Malta (2000). Discussion on the Refugees Bill, Second Reading (Plenary), 19 January-1 February 2000.Valetta.

Post, D., \& Niemann, A. (2007). The Europeanisation of German Asylum Policy and the "Germanisation"of European Asylum Policy: the Case of the "Safe Third Country" Concept. Paper presented at the European Union Studies Association.

Prasad, R. (2002). The asylum lottery. 25 January 2002. The Guardian. Retrieved on 12 June 2014, from http://www.guardian.co.uk/uk/2002/jan/25/immigration.socialsciences

Preu $\beta$, U. (1993). Vorläufige Stellungnahme zu den Gesetzenentwürfen Bt-Drs. 12/4152, 12/3235 ... für die Öffentliche Anhörung des Innen- und Rechtsausschusses des Deutschen Bundestages am 11. März 1993 in Bonn. (in the possession of the author)

Pro Asyl (2014). Einordnung von Serbien, Mazedonien, Bosnien und Herzegowina als "sichere Herkunftsländer"? Stellungnahme zum Referentenentwurf eines Gesetzes zur Änderung des Asylverfahrensgesetzes". Frankfurt am Main. 
Puetter, U. (2012a). The new intergovernmentalism in EU governance. In H. Zimmermann \& A. Dürr (Eds.), Key Controversies in European Integration (pp. 56-62). Basingstoke: Palgrave Macmillan.

Puetter, U. (2012b). Europe's deliberative intergovernmentalism: the role of the Council and the European Council in EU economic governance. Journal of European Public Policy, 19(2), 161-178.

Puetter, U. (2004). Governing Informally: the Role of the Eurogroup in EMU and the Stability and Growth Pact. Journal of European Public Policy, 11(5), 854-870.

Puetter, U. (2003). Informal Circles of Ministers: A Way Out of the EU's Institutional Dilemmas. European Law Journal, 9(1), 109-124.

Putnam, R. D. (1988). Diplomacy and domestic politics: the logic of two-level games. International Organization, 42(3), 427-460.

Radaelli, C. M. (2000). Whither Europeanization? Concept stretching and substantive change. European Integration Online Papers, 4(8).

Reh, C. (2012). Informal Politics: the Normative Challenge. In T. Christiansen \& C. Neuhold (Eds.), International Handbook on Informal Governance (pp. 65-84). Cheltenham: Edward Elgar.

Reslow, N. (2013). Partnering for Mobility: Three-Level Games in EU External Migration Policy. PhD thesis defended in September 2013 at the University of Maastricht, the Netherlands.

Rijpma, J. J. (2010). Justice and Home Affairs Agencies: Governing the Area of Freedom, Security and Justice after Lisbon. Paper presented at the ECPR Fifth Pan-European Conference, Porto 24-26 June 2010.

Ripoll-Servent, A., \& Trauner, F. (2013). Governing the Area of Freedom, Security and Justice: The role of supranational institutions in asylum policy. Paper presented at the ECPR General Conference 2013.

Ripoll-Servent, A. (2011). Co-decision in the European Parliament: Comparing Rationalist and Constructivist Explanations of the Returns Directive. Journal of Contemporary European Research, 7(1), 3-22.

Rohlfing, I. (2012). Case Studies and Causal Inference. An Integrative Framework. Basingstoke: Palgrave Macmillan.

Rose, R. (1991). What is Lesson-Drawing? Journal of Public Policy, 11(1), 3-30.

Statewatch (2004). EU divided over list of "safe countries of origin" - Statewatch calls for the list to be scrapped. Retrieved 27 May 2014, from http://www.statewatch.org/news/2004/sep/safe-countries.pdf

Statewatch (2003). The worst law yet: the Nationality, Immigration and Asylum Act 2002. Retrieved on 26 November, from http://database.statewatch.org/article.asp?aid=6669

Statewatch (2002). EU Ministers declare applicant countries "safe" to send back asylum- seekers. Retrieved 4 June 2012, from http://www.statewatch.org/news/2002/oct/05safe.htm

Statewatch (1997). Key texts on justice and home affairs, 1976-1993.

Statewatch (n.d.), EU law on asylum procedures: An assault on human rights?, available at http://www.statewatch.org/news/2003/nov/04asylum.htm, accessed 5 August 2011

Steinberg, R. (1993). Anhörung Gemeinsame Verfassungskommission. 11. März 1993. (in the possession of the author)

Stewart, E. (2004). Deficiencies in UK Asylum Data: Practical and Theoretical Challenges. Journal of Refugee Studies, 17(1), 29-49.

Stone, D. (2001). Learning Lessons, Policy Transfer and the International Diffusion of Policy Ideas. CSGR Working Paper no. 69/01. Retrieved from http://wrap.warwick.ac.uk/2056/1/WRAP_Stone_wp6901.pdf

Tatenhove, J. v., Mak, J., \& Liefferink, D. (2006). The Inter-play between Formal and Informal Practises. Perspectives on European Politics and Society, 7(1), 8-24.

TDI (2010). TDI Tools for Practical Cooperation on Data, Asylum, Resettlement and Return. Brussels: Temporary Desk Iraq. (in possession of the author)

Thielemann, E. (2006). The Effectiveness of Governments' Attempts to Control Unwanted Migration. In C. A. Parsons \& T. M. Smeeding (Eds.), Immigration and the Transformation of Europe (pp. 442-472). Cambridge: Cambridge University Press.

Thielemann, E. (2001). The 'Soft' Europeanisation of Migration Policy: European Integration and Domestic Change. Paper presented at the prepared for ECSA Seventh Biennial International Conference. 
Thielemann, E., \& El-Enany, N. (2009). Beyond Fortress Europe? How European Cooperation Strengthens Refugee Protection. Paper prepared for the European Union Studies Association's 11th Biennial International Conference, Marina De Rey, Los Angeles, April 23-25, 2009.

Thielemann, E., \& Zaun, N. (2013). Escaping Populism - Safeguarding Human Rights: The European Union as a Venue for Non-Majoritarian Policy-Making in the Area of Refugee Protection. Paper presented at the ECPR General Conference 2013.

Thouez, C., \& Channac, F. (2006). Shaping International Migration Policy: The Role of Regional Consultative Processes. West European Politics, 29(2), 370-387.

Times of Malta (2013). Court upholds judgement against forced repatriation of migrants. 3 July 2013. Times of Malta. Retrieved on 25 September 2014, from http://www.timesofmalta.com/articles/view/20130703/local/court-upholds-judgement- against-forced-repatriation-of-migrants.476467

Times of Malta (2012a). Bishop say migrant's killing raises serious questions - suggest review of detention policy. 5 July 2012. Times of Malta. Retrieved on 12 June 2014, from http://www.timesofmalta.com/articles/view/20120705/local/bishops-says-migrants-killing-raises-serious-questions.427282

Times of Malta (2012b). Carm Mifsud Bonnici resigns after losing vote of confidence. 20 May 2012. Times of Malta. Retrieved on 12 June 2014, from http://www.timesofmalta.com/articles/view/20120530/local/flash-franco- debono. 422058

Ucarer, E. (2001). From the Sidelines to Center Stage: Sidekick No more? The European Commission in Justice and Home Affairs. European Integration Online Papers, 5(5). Retrieved from http://eiop.or.at/eiop/pdf/2001-005.pdf

UNHCR (2010a). Improving Asylum Procedures: Comparative Analysis and Recommendations for Law and Practice. Key Findings and Recommendations.

UNHCR (2010b). Improving Asylum Procedures: Comparative Analysis and Recommendations for Law and Practice. Detailed Research on Key Asylum Procedures Directive Provisions.

UNHCR (2004). Country of Origin Information: Towards Enhanced International Cooperation. Geneva: UN High Commissioner for Refugees.

UNHCR (2003). Background Note on the Protection of Asylum Seekers and Refugees in Malta.

UNHCR (1991). Background Note on the Safe Country Concept and Refugee Status. Retrieved from http://www.unhcr.org/refworld/docid/3ae68ccec.html

UNHCR (1983). The Problem of Manifestly Unfounded or Abusive Applications for Refugee Status or Asylum. Executive Committee Conclusion No. 30. Retrieved on 27 May, from http://www.unhcr.org/refworld/docid/3ae68c6118.html

UNHCR (1967). Protocol Relating to the Status of Refugees. Geneva.

UNHCR (1951). Convention Relating to the Status of Refugees. Geneva.

Vedsted-Hansen, J. (2012). Common EU Standards on Asylum - Optional Harmonisation and Exclusive Procedures? In E. Guild \& P. Minderhoud (Eds.), The First Decade of EU Migration and Asylum Law (pp. 255-271). Leiden: Martinus Nijhoff.

Vedsted-Hansen, J. (2010). The European Convention on Human Rights, Counter-Terrorism, and Refugee Protection. Refugee Survey Quarterly, 29(4), 189-206.

Veenendaal, W. (2013). Politics and Democracy in Microstates. A Comparative Analysis of the Effects of Size on Contestation and Inclusiveness. PhD manuscript defended in April 2013 at the University of Leiden, The Netherlands.

Velluti, S. (2007). What European Union Strategy for Integrating Migrants? The Role of OMC Soft Mechanisms in the Development of an EU Immigration Policy. European Journal of Migration and Law, 9, 5382.

Versluis, E., Keulen, M. v., \& Stephenson, P. (2011). Analyzing the European Union Policy Process. Hamphire: Palgrave Macmillan.

Vink, M. P. (2010). European Integration and Domestic Immigration Policies: Convergence, Causality and Counterfactuals. In A. Luedtke (Ed.), Migrants and Minorities: The European Response (pp. 37-60). Cambridge: Cambridge Scholars Publishing. 
Vink, M. P. (2002). Negative and Positive Integration in European Immigration Policies. European Integration Online Papers, 6(13).

Vink, M. P. (2001). The Europeanization of Domestic Asylum Policy: National Executive Power and Two-Level Games. Paper presented at the ECSA Seventh Biennial International Conference.

Vink, M.P., \& Engelmann, C. (2012). Informal European Asylum Governance in an International Context. In

T. Christiansen \& C. Neuhold (Eds.), International Handbook on Informal Governance (pp. 690-718). Cheltenham: Edward Elgar.

Vink, M. P., \& Graziano, P. (2008). Challenges of a New Research Agenda. In P. Graziano \& M. P. Vink (Eds.), Europeanization. new Research Agenda (pp. 3-22). Basingstoke: Palgrave Macmillan.

Vink, M.P., \& Meijerink, F. (2003). Asylum application and recognition rates in EU member states 1982-2001: a quantitative analysis. Journal of Refugee Studies, 16(3), 297- 315.

Wallace, H. (2010). An Institutional Anatomy and Five Policy Modes. In H. Wallace, M. A. Pollack \& A.R. Young (Eds.), Policy-Making in the European Union (Vol. 6, pp. 69- 104). Oxford: OUP.

Waringo, K. (2013). Serbien - ein sicherer Herkunftsstaat. Eine Auswertung von Quellen zur Menschenrechtssituation. Frankfurt am Main: Pro Asyl

Wartenberg, G. (1993). An die Mitglieder der SPD-Bundestagsfraktion. Vorlage für die Sitzung des Fraktionsvorstands am 1./2.2.1993 betrifft: einfach-gesetzliche Umsetzung des Parteienkompromisses vom 6.12.1992 zu Asyl/Zuwanderung. (in the possession of the author)

Wolff, S., \& Mounier, G. (2012). A Kaleidoscopic View on the External Dimension of Justice and Home Affairs. European Foreign Affairs Review, 1(2), 143-162.

Yin, R. K. (2009). Case Study Research. Design and Methods (4 ed. Vol. 5). Los Angeles: Sage.

Legislative texts of countries selected as case studies

Germany

- Basic Law of 1949 (as last amended in 2012).

- Asylum Procedures Act of 1982 (as last amended in 2013).

The UK

- The Asylum (Designated States) Order 2010 (2010).

- $\quad$ The Asylum (Deignated States) Order 2007.

- The Asylum (Designated States) (Amendment) (No. 2) Order 2006 (2006).

- The Asylum (Designated States) (Amendment) Order 2006 (2006).

- The Asylum (Designated States) (Amendment) Order 2005 (2005).

- $\quad$ The Asylum (Designated States) (No. 2) Order 2005 (2005).

- $\quad$ The Asylum (Designated States) Order 2005 (2005).

- The Asylum (Designated States) (No. 2) Order 2003 (2003).

- The Asylum (Designated States) Order 2003 (2003).

- Nationality, Immigration and Asylum Act 2002, chapter 41, part 5, section 94(4).

- The Asylum (Designated Countries of Destination and Designated Safe Third Countries) Order 1996 (1996).

- $\quad$ Asylum and Immigration Act 1993 (as amended 1996), chapter 49(1).

Luxembourg

- Règlement grand-ducal du 19 juin 2013 modifiant le règlement grand-ducal du 21 décembre 2007 fixant une liste de pays d'origine sûrs au sens de la loi modifiée du 5 mai 2006 relative au droit d'asile et à des formes complémentaires de protection 
- $\quad$ Règlement grand-ducal du ler avril 2011 modifiant le règlement grand-ducal du 21 décembre 2007 fixant une liste de pays d'origine sûrs au sens de la loi modifiée du 5 mai 2006 relative au droit d'asile et à des formes complémentaires de protection.

- Règlement grand-ducal du 21 décembre 2007 fixant une liste de pays d'origine sûrs au sens de la loi modifiée du 5 mai 2006 relative au droit d'asile et à des forms complémentaires de protection, p. 4541

- Loi du 5 May 2006 relative au droit d'asile et à des formes complémentaires de protection 2006

Malta

- $\quad$ Refugees Act of 2000 (as last amended by Act VII of 2008), chapter 420. 


\section{Annex I: List of interviews and email communication}

\begin{tabular}{|c|c|c|}
\hline $\begin{array}{l}\text { Number of } \\
\text { interview }\end{array}$ & $\begin{array}{l}\text { Day interview } \\
\text { was conducted }\end{array}$ & $\begin{array}{l}\text { Place of } \\
\text { interview }\end{array}$ \\
\hline 1 & 27 July 2010 & Brussels \\
\hline 2 & 27 July 2010 & Brussels \\
\hline 3 & 19 August 2010 & Brussels \\
\hline 4 & 1 April 2010 & Vienna \\
\hline 5 & 1 April 2010 & Vienna \\
\hline 6 & 1 April 2010 & Vienna \\
\hline 7 & 1 April 2010 & Vienna \\
\hline 8 & 10 August 2011 & The Hague \\
\hline 9 & 10 August 2011 & The Hague \\
\hline 10 & 21 September 2011 & Luxembourg \\
\hline 11 & 21 September 2011 & Luxembourg \\
\hline 12 & 22 September 2011 & Luxembourg \\
\hline 13 & 23 September 2011 & Luxembourg \\
\hline 14 & 26 September 2011 & Luxembourg \\
\hline 15 & 27 September 2011 & Luxembourg \\
\hline 16 & 27 September 2011 & Luxembourg \\
\hline 17 & 24 November 2011 & Maastricht \\
\hline 18 & 18 January 2012 & Geneva (by phone) \\
\hline 19 & 19 March 2012 & London \\
\hline 20 & 22 March 2012 & London \\
\hline 21 & 23 March 2012 & London \\
\hline 22 & 23 March 2012 & London \\
\hline 23 & 26 March 2012 & London \\
\hline 24 & 13 April 2012 & London (by phone) \\
\hline 25 & 23 April 2012 & London (by phone) \\
\hline 26 & 3 May 2012 & Valetta \\
\hline 27 & 3 May 2012 & Valetta \\
\hline 28 & 4 May 2012 & Valetta \\
\hline 29 & 4 May 2012 & Valetta \\
\hline
\end{tabular}




\begin{tabular}{lll}
\hline $\begin{array}{l}\text { Number of } \\
\text { interview }\end{array}$ & $\begin{array}{l}\text { Day interview } \\
\text { was conducted }\end{array}$ & $\begin{array}{l}\text { Place of } \\
\text { interview }\end{array}$ \\
\hline 30 & 8 May 2012 & Valetta \\
31 & 8 May 2012 & Valetta \\
32 & 9 May 2012 & Valetta \\
33 & 9 May 2012 & Valetta \\
34 & 9 May 2012 & Valetta \\
35 & 1 June 2012 & Nuremberg (by phone) \\
36 & 14 June 2012 & Nuremberg \\
37 & 14 June 2012 & Nuremberg \\
38 & 20 June 2012 & Berlin \\
39 & 21 June 2012 2012 & Berlin \\
40 & 21 June 2012 & Berlin \\
41 & 25 June 2012 & Berlin \\
42 & 16 July 2012 & Brussels \\
\hline
\end{tabular}

\begin{tabular}{lll}
\hline $\begin{array}{l}\text { Number of email } \\
\text { communication }\end{array}$ & Day information received & Country concerned \\
\hline 1 & 02 June 2011 & Bulgaria \\
2 & 06 June 2011 & Bulgaria \\
3 & 18 May 2011 & Czech Republic \\
4 & 01 June 2011 & Hungary \\
5 & 10 August 2011 & Latvia \\
6 & 27 April 2011 & The Netherlands \\
\hline
\end{tabular}




\section{Annex II: Provisions from Directive 2013/32/EU relating to the SCO notion}

Art. 31 (examination procedure)

(8) Member States may provide that an examination procedure in accordance with the basic principles and guar antees of Chapter II be accelerated and/or conducted at the border or in transit zones in accordance with Article 43 if: [...]

(b) the applicant is from a safe country of origin within the meaning of this Directive;

Art. 36 (the concept of safe country of origin)

1. A third country designated as a safe country of origin in accordance with this Directive may, after an individual examination of the application, be considered as a safe country of origin for a particular applicant only if:

(a) he or she has the nationality of that country; or

(b) he or she is a stateless person and was formerly habitually resident in that country,

and he or she has not submitted any serious grounds for considering the country not to be a safe country of origin in his or her particular circumstances and in terms of his or her qualification as a beneficiary of international protection in accordance with Directive 2011/95/EU.

2. Member States shall lay down in national legislation further rules and modalities for the application of the safe country of origin concept.

Article 37 (national designation of third countries as safe countries of origin)

1. Member States may retain or introduce legislation that allows, in accordance with Annex I, for the national designation of safe countries of origin for the purposes of examining applications for international protection.

2. Member States shall regularly review the situation in third countries designated as safe countries of origin in accordance with this Article.

3. The assessment of whether a country is a safe country of origin in accordance with this Article shall be based on a range of sources of information, including in particular information

from other Member States, EASO, UNHCR, the Council of Europe and other relevant international organisations.

4. Member States shall notify to the Commission the countries that are designated as safe countries of origin in accordance with this Article.

Annex I to the Directive (designation of safe countries of origin for the purposes of Article 37(1))

A country is considered as a safe country of origin where, on the basis of the legal situation, the application of the law within a democratic system and the general political circumstances, it can be shown that there is generally and consistently no persecution as defined in Article 9 of Directive 2011/95/EU, no torture or inhuman or degrading treatment or punishment and no threat by reason of indiscriminate violence in situations of international or internal armed conflict.

In making this assessment, account shall be taken, inter alia, of the extent to which protection is provided against persecution or mistreatment by:

(a) the relevant laws and regulations of the country and the manner in which they are applied;

(b) observance of the rights and freedoms laid down in the European Convention for the Protection of Human Rights and Fundamental Freedoms and/or the International Covenant for Civil and Political Rights and/or the United Nations Convention against Torture, in particular the rights from which derogation cannot be made under Article 15(2) of the said European Convention;

(c) respect for the non-refoulement principle in accordance with the Geneva Convention;

(d) provision for a system of effective remedies against violations of those rights and freedoms. 


\section{Annex III: National provisions regulating the safe country of origin notion in the four countries selected}

\section{Germany}

Article 16a of the Basic Law (right to asylum)

(3) By a law requiring the consent of the Bundesrat, states may be specified in which, on the basis of their laws, enforcement practices, and general political conditions, it can be safely concluded that neither political persecution nor inhuman or degrading punishment or treatment exists. It shall be presumed that a foreigner from such a state is not persecuted, unless he presents evidence justifying the conclusion that, contrary to this presumption, he is persecuted on political grounds.

(4) In the cases specified by paragraph (3) of this Article and in other cases that are plainly unfounded or considered to be plainly unfounded, the implementation of measures to terminate an applicant's stay may be suspended by a court only if serious doubts exist as to their legality; the scope of review may be limited, and tardy objections may be disregarded. Details shall be determined by a law.

Section 29a of the Asylum Procedures Act (safe country of origin)

(1) The asylum application of any foreigner from a country within the meaning of Article 16a (3) first sentence of the Basic Law (safe country of origin) shall be turned down as being manifestly unfounded, unless the facts or evidence produced by the foreigner give reason to believe that he faces political persecution in his country of origin in spite of the general situation there.

(2) In addition to the Member States of the European Union, safe countries of origin are those listed in Appendix II.

(3) The Federal Government shall resolve by statutory ordinance without the consent of the Bundesrat that a country listed in Appendix II is no longer deemed a safe country of origin if changes in its legal or political situation give reason to believe that the requirements mentioned in Article 16a (3) first sentence of the Basic Law have ceased to exist. The ordinance shall expire no later than six months after it has entered into force.

The UK

Section 94 of the Nationality, Immigration and Asylum Act (Appeal from within United Kingdom: unfounded human rights or asylum claim)

(1)This section applies to an appeal under section 82(1) where the appellant has made an asylum claim or a human rights claim (or both).

(1A)A person may not bring an appeal against an immigration decision of a kind specified in section $82(2)(\mathrm{c})$, (d) or (e) in reliance on section 92(2) if the Secretary of State certifies that the claim or claims mentioned in subsection (1) above is or are clearly unfounded.]

(2)A person may not bring an appeal to which this section applies [in reliance on section 92(4)(a)] if the Secretary of State certifies that the claim or claims mentioned in subsection (1) is or are clearly unfounded.

(3)If the Secretary of State is satisfied that an asylum claimant or human rights claimant is entitled to reside in a State listed in subsection (4) he shall certify the claim under subsection (2) unless satisfied that it is not clearly unfounded.

(4)Those States are-

(k)the Republic of Albania,

(n)Jamaica,

(o)Macedonia,

(p)the Republic of Moldova, and

(s)Bolivia,

(t)Brazil,

(u)Ecuador,

(w)South Africa, and

(x)Ukraine. 
(y)India.

(z)Mongolia,

(aa)Ghana (in respect of men),

(bb)Nigeria (in respect of men).

(cc)Bosnia-Herzegovina,

(dd)Gambia (in respect of men),

(ee)Kenya (in respect of men),

(ff)Liberia (in respect of men),

(gg)Malawi (in respect of men),

(hh)Mali (in respect of men),

(ii)Mauritius,

(jj)Montenegro,

(kk)Peru,

(ll)Serbia,

Sierra Leone (in respect of men).

(5)The Secretary of State may by order add a State, or part of a State, to the list in subsection (4) if satisfied that-

(a)there is in general in that State or part no serious risk of persecution of persons entitled to reside in that State or part, and

(b)removal to that State or part of persons entitled to reside there will not in general contravene the United Kingdom's obligations under the Human Rights Convention.

(5A)If the Secretary of State is satisfied that the statements in subsection (5) (a) and (b) are true of a State or part of a State in relation to a description of person, an order under subsection (5) may add the State or part to the list in subsection (4) in respect of that description of person.

(5B)Where a State or part of a State is added to the list in subsection (4) in respect of a description of person, subsection (3) shall have effect in relation to a claimant only if the Secretary of State is satisfied that he is within that description (as well as being satisfied that he is entitled to reside in the State or part).

(5C)A description for the purposes of subsection (5A) may refer to-

(a)gender,

(b)language,

(c)race,

(d)religion,

(e)nationality,

(f)membership of a social or other group,

(g)political opinion, or

(h)any other attribute or circumstance that the Secretary of State thinks appropriate.

(5D)In deciding whether the statements in subsection (5) (a) and (b) are true of a State or part of a State, the Secretary of State -

(a)shall have regard to all the circumstances of the State or part (including its laws and how they are applied), and

(b)shall have regard to information from any appropriate source (including other member States and international organisations).]]

(6)The Secretary of State may by order amend the list in subsection (4) so as to omit a State or part added under subsection (5); and the omission may be-

(a)general, or

(b)effected so that the State or part remains listed in respect of a description of person.

(6A)Subsection (3) shall not apply in relation to an asylum claimant or human rights claimant who-

(a)is the subject of a certificate under section 2 or 70 of the Extradition Act 2003 (c. 41),

(b)is in custody pursuant to arrest under section 5 of that Act,

(c)is the subject of a provisional warrant under section 73 of that Act, 
(d)is the subject of an authority to proceed under section 7 of the Extradition Act 1989 (c. 33) or an order under paragraph 4(2) of Schedule 1 to that Act, or

(e)is the subject of a provisional warrant under section 8 of that Act or of a warrant under paragraph 5(1)(b) of Schedule 1 to that Act.]

(7)A person may not bring an appeal to which this section applies in reliance on section 92(4) if the Secretary of State certifies that-

(a)it is proposed to remove the person to a country of which he is not a national or citizen, and

(b)there is no reason to believe that the person's rights under the Human Rights Convention will be breached in that country.

(8)In determining whether a person in relation to whom a certificate has been issued under subsection (7) may be removed from the United Kingdom, the country specified in the certificate is to be regarded as-

(a)a place where a person's life and liberty is not threatened by reason of his race, religion, nationality, membership of a particular social group, or political opinion, and

(b)a place from which a person will not be sent to another country otherwise than in accordance with the Refugee Convention.

(9)Where a person in relation to whom a certificate is issued under this section subsequently brings an appeal under section 82(1) while outside the United Kingdom, the appeal shall be considered as if he had not been removed from the United Kingdom.

\section{Luxembourg}

Art. 20 and 21 of the Law on the Right of Asylum and to Complementary Forms of Protection

Art. 20

(1) Le ministre peut statuer sur le bien-fondé de la demande de protection internationale dans le cadre d'une procédure accélérée dans les cas suivants:

c) le demandeur provient d'un pays d'origine sûr au sens de l'article 21 de la présente loi;

Art. 21.

(1) Un pays peut être désigné comme pays d'origine sûr pour les besoins de l'examen de la demande de protection internationale.

(2) Un pays qui est désigné comme pays d'origine sûr conformément aux paragraphes (3) et (4) du présent article peut uniquement, après examen individuel de la demande de protection internationale, être considéré comme étant un pays d'origine sûr pour un demandeur, s'il possède la nationalité de ce pays ou s'il avait précédemment sa residence habituelle dans ce pays, et que le demandeur n'a soumis aucune raison valable permettant de penser qu'il ne s'agit pas d'un pays d'origine sûr en raison de sa situation personnelle.

(3) Une demande de protection internationale est rejetée, sans préjudice du paragraphe (2) qui précède, lorsqu'un pays est désigné comme pays d'origine sûr soit par l'Union européenne, soit par règlement grandducal.

(4) Un règlement grand-ducal pourra désigner un pays comme pays d'origine sûr s'il est établi qu'il n'y existe généralement et de façon constante pas de persécution au sens de la Convention de Genève. Les critères suivants seront pris en considération pour la désignation d'un pays comme pays d'origine sûr:

a) l'observation des droits et libertés prévus par la Convention européenne de sauvegarde des droits de l'homme

et des libertés fondamentales, le Pacte international des droits civils et politiques ou la Convention des Nations Unies contre la torture et autres peines ou traitements cruels, inhumains ou dégradants;

b) le respect du principe de non-refoulement prévu par la Convention de Genève;

c) la prévision d'un système de recours efficace contre les violations de ces droits et libertés

Malta

Articles 2(k) and 24 of the Refugees Act

Art.2: 
In this Act, unless the context otherwise requires - [...]"manifestly unfounded application" means an application $[\ldots]$

(k) when the applicant for asylum comes from a safe country of origin;

Art. 24:

(1) The application of any person in Malta seeking recognition of refugee status and who falls under any one of the following conditions, shall be inadmissible if: [...]

(i) is a national or citizen of any safe country of origin listed in the Schedule or, if he is not a national or citizen thereof, he has a right of residence therein.

(2) The provisions of article 22(2), (3), (4) and (5) shall apply mutatis mutandis to inadmissible applications.

(3) The Minister may by regulations amend the list of countries specified in the Schedule, provided that only countries which in his opinion are countries of safe origin may be listed in the said Schedule, sohowever that the Minister shall remove from the said Schedule any country which in his opinion is no longer a safe country of origin. 


\section{Nederlandstalige samenvatting}

\section{Gedeelde standaarden via achterkamertjes: De impact van Europese afstemming van asielbeleid op nationaal niveau}

In deze thesis wordt onderzoek gedaan naar het proces van asielbeleid maken in verscheidene EU lidstaten in het algemeen en het maken van beleid inzake veilige landen van herkomst in het bijzonder. Dit beleid illustreert het kerndilemma van tegenwoordige overheden: enerzijds hangen EU lidstaten het internationaal asielrecht aan door grondig te onderzoeken of het voor een vluchteling al dan niet veilig is om terug te keren naar het land van herkomst, terwijl er anderzijds wordt gedacht aan strategieën om asielaanvragen efficiënter te verwerken. Dit beleid illustreert ook de spanning tussen de nationale behoefte aan interstatelijke samenwerking aan de ene kant en terughoudendheid om gebonden te worden aan supranationale wetten en regels aan de andere kant. Hoewel er een minimum aan Europese regulering wat betreft een 'veilig land van herkomst' is geconstateerd, proberen lidstaten hier toch unilateraal naar te streven. Dit gebeurt niet zonder invloed van buitenaf: overheden kijken eerst naar andere overheden voordat ze een beleidsbeslissing maken. Hoewel er geen formeel Europees forum is waar beleid inzake veilig land van herkomst wordt bediscussieerd en besloten, vindt er wél informeel afstemming plaats tussen lidstaten. In dit onderzoek wordt beargumenteerd dat deze informele afstemming een belangrijke rol speelt in de nationale bepaling van beleid inzake veilig land van herkomst. Voor deze thesis resulteert dit in de volgende onderzoeksvraag: Wat is de rol van transnationale beleidsafstemming in het binnenlandse proces van Europese lidstaten bij het maken van asielbeleid?

\section{Beleid inzake veilige landen van herkomst}

Om te beginnen, voorziet hoofdstuk 2 in een analyse van de ontwikkeling van beleid inzake veilig land van herkomst in de $27 \mathrm{EU}$ lidstaten over een periode van 23 jaar. (1990-2013) Deze analyse betreft een significante bijdrage aan de reeds ontwikkelde discussie door een diepgaande dataset te bieden in een zowel ruimtelijke als tijdelijke bepaling. Deze dataset staat conclusies toe wat betreft de convergentie en divergentie van beleid inzake veilig land van herkomst tussen de verschillende EU lidstaten. Er wordt geconcludeerd dat er een verrassende mate van overeenkomst in dit beleid is tussen de EU lidstaten. Intuïtief lijkt dit voort te komen uit de generieke harmonisering tussen EU lidstaten. Dit is echter niet het geval. Er zijn gedeelde ideeën ontwikkeld op supranationaal niveau wat betreft een veilig land van herkomst; niettemin zijn deze 
ideeën slechts een minieme norm die een grote ruimte laten of en op welke wijze EU lidstaten dit beleid implementeren. Het betreft geen verplichting om deze notie toe te passen in het binnenlands recht van een EU lidstaat. Ondanks het gebrek aan bindend beleid is het verrassend te concluderen dat op twee landen na (Zweden en Italië) alle EU lidstaten de mogelijkheid hebben geïntroduceerd om een veilig land van herkomst aan te wijzen. De overeenkomsten in het beleid van de EU lidstaten stopt hier echter niet. Er is ook een toenemende mate van internationale overeenkomst aangaande het daadwerkelijk toekennen van het predicaat 'veilig' aan een land. De EU lidstaten die een lijst met veilige landen van herkomst hebben, hebben bijna allemaal de Westelijke Balkan als veilig bestempeld. Deze lidstaten zijn het er over eens dat de veiligheidssituatie in deze landen in het algemeen veilig genoeg is, waardoor asielzoekers die uit deze landen komen geen bescherming in een ander land nodig hebben. Dezelfde observaties zijn gedaan voor Ghana, Benin en Senegal. Echter, deze overeenkomst in beleid verbergt niet dat er veel verschillen in opvatting resteren. De analyse toont ook dat veel landen van herkomst door slechts één of twee EU lidstaten als veilig zijn gekenmerkt. De lijst met veilige landen van herkomst verschilt zeer binnen de EU. Tot slot leidt de analyse van beleid inzake veilig land van herkomst tot een aantal normatieve overwegingen. Sinds de inwerkingtreding van het beleid, gaat deze gepaard met hevige kritiek. Deze kritiek zet vraagtekens of het beleid in lijn is met de norm dat vluchtelingen beschermd moeten worden wanneer zij terugkeren naar landen waar hun leven en/of vrijheden worden bedreigd.

\section{Beleidsafstemming en samenwerking op het gebied van herkomstlandeninformatie.}

Hoe kunnen we, gezien de afwezigheid van algemene regels over het al dan niet toepassen van het 'veilig land van herkomst' idee en over welke landen als veilig kunnen worden bestempeld, een verklaring bieden voor de toenemende mate van overeenkomst wat betreft beleid inzake veilig land van herkomst? Het centrale argument van deze thesis is dat transnationale beleidsafstemming een belangrijke rol speelt voor het op nationaal niveau bepalen van beleid inzake veilig land van herkomst. Startpunt voor dit argument zijn hoofdstuk 3 (theoretisch kader) en hoofdstuk 5 (empirische analyse), welke zich richten op de term beleidsafstemming. De term wordt neergezet als horizontale coördinatie van beleid of beleidsrelevante informatie tussen personen welke betrokken zijn bij het maken van beleid, welke wordt bepaald door het informele, overleggende karakter en de afwezigheid van wettelijk bindende bepalingen. Het analytisch kader focust op drie aspecten van beleidsafstemming in het bijzonder: betrokken actoren bij beleidsafstemming (wie is betrokken); de functie van beleidsafstemming (waarom vindt het plaats); en de vorm van beleidsafstemming (hoe ziet het er uit en hoe werkt het?).

De empirische analyse van de afstemming van asielbeleid wordt uitgevoerd in hoofdstuk 5, door gebruik te maken van het voorbeeld van samenwerking op het gebied van herkomstlandeninformatie. Deze informatie is van cruciaal belang voor het bepalen van de status van elke individuele vluchteling, maar ook voor het aannemen van beleid 
voor een specifiek land, zoals beleid inzake veilig land van herkomst. Het verzamelen van herkomstlandeninformatie is een kerntaak van nationale instanties bezwaard met de uitvoering van asielbeleid en hun herkomstlandeninformatie afdelingen in het bijzonder. Deze thesis geeft een bijdrage aan de studie naar dergelijke instanties (en hun informatiesystemen) door als eerste een overzicht te geven van deze afdelingen binnen de 27 Europese lidstaten. Kijkend naar de opzet en het functioneren van deze afdelingen kan er geconcludeerd worden dat - in sommige landen - de samenwerking tussen landen en het verzamelen en interpreteren van herkomstlandeninformatie een kerntaak is van asielinstanties. Patronen van samenwerking op het gebied van herkomstlandeninformatie zijn veranderd van informele, door lidstaten zelf aangestuurde aangelegenheden (tijdens de jaren '90) naar een meer formeel proces waarin alle EU lidstaten betrokken zijn en de Europese Commissie een sleutelrol speelt (sinds 1999).

De focus van de analyse betreft (uitsluitend) de informele jaren van samenwerking. Vóór 1999 vond veel samenwerking op het gebied van herkomstlandeninformatie plaats op informele basis tussen een klein aantal landen. De noordelijke en westelijke Europese staten stemden hun herkomstlandeninformatie (en hieraan gerelateerd beleid) af in een aantal fora waarvan de volgende nader zijn bestudeerd: the Intergovernmental Consultations on Migration, Asylum and Refugees, the (European) Centre for Information, Discussion and Exchange on Asylum, en bilaterale uitwisseling van informatie tussen twee (of meer) lidstaten. Hoewel het bereik van deze fora erg verschillend is (mondiaal, Europees, sub-regionaal) zijn er veel overeenkomsten tussen de doelen, vormen en betrokken actoren. Er zijn een paar gelijkgestemde landen informeel betrokken bij dit overleg; zij doen dit vanwege het gebrek aan fora om op vertrouwelijke basis visies uit te wisselen en om beleidsoplossingen voor gedeelde problemen te ontwikkelen. De analyse toont ook aan dat samenwerking op het gebied van herkomstlandeninformatie in toenemende mate is geformaliseerd met de overeenkomst van het Tampere programma in 1999. Om te komen tot een gemeenschappelijk Europees asielbeleid, werd samenwerking op het gebied van herkomstlandeninformatie hoog op de politieke agenda van de lidstaten en de Europese Commissie geplaatst: samenwerking in bestaande fora werd geformaliseerd en gegroepeerd onder het net nieuw opgerichte European Asylum Support Office (EASO). Niet alleen lidstaten met een ontwikkeld asielsysteem waren deel van deze uitwisseling, de nieuwe geformaliseerde samenwerking op het gebied van herkomstlandeninformatie was specifiek gericht op lidstaten met minder ontwikkelde (of niet bestaande) systemen voor het verzamelen van herkomstlandeninformatie, de zuid- en oost Europese landen hierbij in het bijzonder.

$\mathrm{Na}$ het conceptualiseren, theoretiseren en het empirisch bestuderen van beleidsafstemming (en samenwerking op het gebied van herkomstlandeninformatie in het bijzonder), is het kijken naar de rol van beleidsafstemming in het nationale proces van beleid maken een volgende logische stap. Hoe gebruiken overheden de informatie die is verkregen uit deze informele afstemmingen? 
Om de finale en centrale vraag van dit onderzoeksproject te beantwoorden, zijn twee vormen van logica gebruikt die het menselijk gedrag interpreteren: "a logic of consequences" en "a logic of appropriateness". Beide vormen van logica en de bijbehorende mechanismen zijn geoperationaliseerd door voorwaarden te ontwikkelen, gebaseerd op literatuurstudie. De onderzoeksvraag is beantwoord door vergelijkende case studies uit te voeren. Vier landen zijn in detail bestudeerd: Duitsland, het Verenigd Koninkrijk, Malta en Luxemburg.

Hoofdstuk 6 analyseert het binnenlandse proces van beleid maken door te kijken naar actoren die handelen op basis van een kosten/baten analyse. Er wordt gesteld dat beleidsmakers deelnemen aan beleidsafstemming en verkregen informatie gebruiken om vooraf gestelde voorkeuren bevestigd te krijgen. Terwijl deze beleidsmakers mogelijk leren hoe andere landen hun (gelijk of afwijkend) beleid nastreven, veranderen hun initiële doelen niet. In die zin kan de "logic of consequences" zich op verschillende manieren manifesteren. De afstemming van asielbeleid kan hierin op meerdere manieren worden gebruikt: het kan helpen bij de rechtvaardiging van voorgenomen beleidsveranderingen op nationaal niveau (two-level games) of, meer generiek, leren beleidsmakers wat wordt gedaan in andere landen en nemen deze overwegingen mee in hun eigen, nationale situatie (simple learning). Voor zowel Duitsland als het Verenigd Koninkrijk kan het vaststellen van beleid inzake veilig land van herkomst uitgelegd worden door een kosten-baten analyse. ('Logic of consequences') In Duitsland hebben beleidsmakers de 'two-level game' succesvol gespeeld. Doordat men aan het eind van de jaren ' 80 niet in staat was op nationaal niveau het idee van veilig land van herkomst te introduceren, hebben Duitse beleidsmakers eerst een overeenkomst over veilige landen van herkomst veiliggesteld op Europees niveau (London Resolutions), voordat ze dit beleid hebben doorgevoerd naar nationaal niveau. De betrokkenheid van het Verenigd Koninkrijk in transnationale beleidsafstemming dient het nastreven van de eigen, vooraf afgestemde, voorkeuren van de Britse regering. Het vinden van manieren om asielzoekers van bepaalde landen af te schrikken en er zeker van zijn dat het Britse asielbeleid strikter overkomt dan het beleid van andere EU lidstaten, zijn altijd hoofddoelen geweest. Voor zowel Malta als Luxemburg is het bewijs minder gelastend, waardoor onduidelijkheden blijven.

In hoofdstuk 7 wordt het maken van beleid inzake veilig land van herkomst uitgelegd aan de hand van de "logic of appropriateness". Beleid inzake veilig land van herkomst werd een aanvaard middel om om te gaan met economische vluchtelingen (zoals door vele overheden beargumenteerd) en zorgde er voor dat vele landen, nieuwe EU lidstaten in het bijzonder, dit idee zonder veel nadenken hebben overgenomen. Hoewel de nieuwe EU lidstaten niet verplicht waren om het idee van veilig land van herkomst in hun nationale wetgeving op te nemen, deden zij dit toch. Zij deden dus dat wat als ge- 
schikt werd geacht, gezien de gegeven institutionele context. (i.e. de toekomstige toetreding tot de Europese Unie).

Hoofdstuk 7 toont ook aan dat de afstemming van asielbeleid gezien kan worden als een sociaal leerproces omdat het gelijkenis vertoond met vele aspecten van epistemische gemeenschappen. Actoren van de bestudeerde landen (Duitsland en Luxemburg in het bijzonder) zien de uitwisseling van informatie over herkomstlanden en de afstemming van beleid, als een gemeenschappelijke onderneming gedreven door gedeelde waarden en het idee van solidariteit. Voorkeuren worden gevormd (of aangepast) gedurende deze uitwisseling. Hierdoor treedt één van de voorwaarden, die noodzakelijk is voor sociaal leren - namelijk de betrokkenheid in epistemische gemeenschappen - op. Daarnaast zijn er verschillende voorwaarden op nationaal niveau geïdentificeerd waardoor sociaal leren (en dus gedrag dat voorkomt uit 'rules of appropirateness') waarschijnlijk op zal treden. Het is aangetoond dat - in het bijzonder in Malta en Luxemburg - beslissingen die genomen worden door beleidsmakers worden beïnvloed door hun institutionele, sociale en culturele context. Bijvoorbeeld: de manier waarop beleidsmakers hun eigen land zien ten opzichte van andere landen, helpt bij de verklaring waarom bepaalde landen van herkomst al dan niet als veilig zijn aangemerkt, maar ook bij het daadwerkelijke proces van beleid maken (naar wie moet worden gekeken). Deze ideeën over hoe asielbeleid gevormd dient te worden, zijn ingebed in instituties en in de cultuur van landen waarin beleid maken plaatsheeft. Echter, het verzamelde bewijs voor dit argument varieert. Er wordt aangenomen dat beleid maken op basis van 'rules of appropriateness' optreedt in alle vier de bestudeerde landen. Dit kon echter alleen worden vastgesteld voor Malta en Luxemburg en in mindere mate voor Duitsland. Het was voor het Verenigd Koninkrijk niet mogelijk om 'rules of appropriateness' te ontdekken gedurende de uitwisseling van informatie of tijdens het formeren van beleid. Dit kan een aanwijzing zijn dat deze overwegingen geen rol spelen. Het kan echter ook toe te wijzen zijn aan de gebruikte methodologie in dit onderzoek, die de voorkeur geeft aan een rationeel interpretatie van gebeurtenissen.

Concluderend kan worden vastgesteld dat beide vormen van logica een verklaring geven voor (een deel) van het proces van beleid maken in alle vier de landen. Het concluderende hoofdstuk (hoofdstuk 8) bediscussieert verscheidenen mogelijkheden over hoe deze twee vormen van logica zich tot elkaar verhouden. In plaats van ze wederzijds van elkaar uit te sluiten, wordt er aangetoond en beargumenteerd dat beide vormen van logica op kunnen treden, maar afhankelijk van de situatie waarin de beleidsmaker zich bevindt, één vorm van logica overheersend zal zijn. Beide vormen van logica zijn aanwezig en observeerbaar.

\section{De toekomst van één Europees asiel governance systeem.}

De resultaten van de analyse worden in het concluderende hoofdstuk 8 in de bredere context van Europees asiel governance geplaatst. Ondanks de toenemende formalise- 
ring, spelen informele afstemming van herkomstlandeninformatie en daaraan gerelateerd beleid een belangrijke rol. Daar waar het voorheen de gaten van een gebrek aan een formele institutie vulde of daar waar formele instituties die taak nog niet hadden opgepakt, staat het formele instituties tegenwoordig ter zijde. Formele afstemming van herkomstlandeninformatie is zelfs noodzakelijk voor het kunnen blijven functioneren van informele samenwerking. Belangrijkste reden hiervoor is dat minder ervaren landen in het opstellen van asielbeleid, een gebrek hebben aan de noodzakelijke voorwaarden (voornamelijk gevestigde herkomstlandeninformatie diensten) om mee te kunnen gaan in de vaart van goed functionerende (informele) samenwerkingsverbanden op het gebied van herkomstlandeninformatie. Het integreren van deze EU lidstaten in de bestaande, informele uitwisseling van informatie over herkomstlanden zou mogelijk het systeem ondermijnen omdat ze simpelweg niet in staat zijn het spel volgens de regels te spelen. Kortom: het informele systeem zal blijven bestaan; het nieuwe formele systeem zal voldoen in de behoefte van nieuwe lidstaten en de lidstaten met minder ontwikkelde diensten op het gebied van informatie over het land van herkomst. Consequentie hiervan is dat deze landen zwaar zullen terugvallen op nieuwe formele structuren, bijvoorbeeld de EASO in het bijzonder. Voor landen als Griekenland, Malta, Italië, Spanje of Slowakije zal het 'Asylum Support Office' waarschijnlijk de nationale eenheid van herkomstlandeninformatie vervangen. Of dit inderdaad zal leiden tot gedeelde asielstandaarden binnen de EU, valt te bezien.

Tot slot refereert de titel van deze thesis niet alleen naar 'gedeelde standaarden' maar ook naar het idee dat dergelijke standaarden 'via de achterdeur' geïntroduceerd worden. Twee typen processen zijn gedetailleerd bestudeerd: het proces van het maken van besluiten op het gebied van veilige landen van herkomst en het proces van afstemming van herkomstlandeninformatie en het daaraan gerelateerde beleid. Beiden worden gekenmerkt door hun ondoorzichtigheid, informele karakter en vertrouwelijkheid, waardoor er vraagtekens kunnen worden gezet bij hun normativiteit. Er is maar weinig bekend over hoe beslissingen over asielbeleid daadwerkelijk worden genomen. Dit geldt voor zowel nationale ministeries als nationale instanties bezwaard met het uitvoeren van asielbeleid. We weten ook amper of en in hoeverre deze beslissingen worden beïnvloed door beleid van andere landen. Deze thesis richt zich er op helderheid te verschaffen in deze politieke processen in het algemeen en de bijbehorende administratieve processen in het bijzonder. In plaats van simpelweg vast te stellen dat landen een alsmaar strenger asielbeleid nastreven, zoals zo vaak is gedaan, kijkt deze thesis gedetailleerd naar vier specifieke EU lidstaten. Dit om te komen tot een analyse over hoe en waarom asielbeleid bepaalde vormen aanneemt. Door dit te doen, geeft deze thesis een bijdrage in het blootleggen van dergelijke processen van beleid maken. Hierdoor ontstaat meer ruimte voor verder academisch onderzoek en ruimte om actie te ondernemen op het gebied van het beïnvloeden van beleid. 


\section{Valorisation addendum}

The PhD thesis Common standards via the backdoor - the domestic impact of asylum policy coordination in the European Union investigates how governments of EU member states coordinate their asylum policies with each other, and in how far this coordination impacts the actual policy-making process at the domestic level. This appendix addresses the knowledge valorisation of the $\mathrm{PhD}$ project. According to the Dutch National Valorization Committee, knowledge valorisation refers to 'the process of creating value from knowledge, by making knowledge suitable and/or available for social (and/or economic) use and by making knowledge suitable for translation into competitive products, services, processes and new commercial activities. ${ }^{170}$ While I consider it important that $\mathrm{PhD}$ candidates are required to think about the societal relevance of their project, such considerations should not determine whether a $\mathrm{PhD}$ project is pursued and/or financed.

Throughout the thesis, it became clear that many decision-making processes happen behind closed doors: informal asylum policy coordination is by definition informal, and thus not accessible for anyone not belonging to the group. Such groups consist of officials and/or elected politicians but provide minimum or no access to observers, including NGOs. In the same vein, decisions on safe country of origin policies are taken behind closed doors and outside of public scrutiny. More than often, such policies are taken ad-hoc and are difficult to comprehend because there is no information available on which safety-assessments (of so-called safe countries of origin) are based. This is even more worrying if one considers the profound criticism accompanying these policy measures. My thesis is thus relevant for society because it uncovers such policy-making processes. In what follows, I will explain how I engaged with society, and more specifically what I have done to disseminate my knowledge to a broader, non-scientific audience.

\section{Informing the public debate}

With the $\mathrm{PhD}$ thesis, I aim contributing to a balanced public debate on asylum policy. The word 'balanced' is key here because, in my opinion, much of what is reported via local or national media, is biased. If relating to the events studied in this thesis, many newspaper reports and tv programs fall short of addressing the human rights-aspect of

\footnotetext{
${ }^{170}$ Maastricht University (2013), Regulation governing the attainment of doctoral degrees, appendix 4, p.51.
} 
asylum policy, and the international obligation of governments in that regard. By informing the public debate, I hope to contribute towards a more nuanced picture of the asylum matter in general, and of some issues in particular (such as Roma being under general suspicion to not be in need of international protection).

First, I conducted an interview with the German radio station dradio wissen: on 19 September 2014, the German government revised the asylum law related to the safe country of origin notion. While it had not touched the initial provision of 1992 (and subsequent designations of countries as safe in 1993 and 1996), in the coalition agreement of autumn 2013, the Christian-Democrats and the Social-Democrats decided designating three further countries of origin as safe: Bosnia-Herzegovina, Macedonia and Serbia. Given my visibility in the German asylum research community (I am a member of Netzwerk Flüchtlingsforschung), the German radio station dradio wissen asked me for an interview on this very revision. ${ }^{171}$ During the live interview, I was asked to explain the revision of the German asylum law that was about to be adopted on the very same day. I was also asked to give an insight into arguments of both sides, those proposing the designation of the three Western Balkan countries as safe, and those opposing. In addition, I was asked to put the German policy changes in a European context: have similar policies been adopted by other member states, and if yes, do the lists converge or diverge? Eventually, the interview did not only allow me to inform a broader public audience about the intended changes, but also to give my opinion on the issue. This, I considered of great value. Given the highly politicized debate on the matter, there are too few opportunities for researcher to present a balanced view on asylum issues. After the interview was conducted, I was able to spread it via my networks (via twitter (see further down), facebook and linkedin), and thus reaching not only academics but a generally politically interested audience.

Second, I use twitter to disseminate results of my thesis as well as contribute to the asylum policy debate in general: ${ }^{172}$ for example, I extensively commented on the abovementioned policy-making process, and discussions in the German Bundestag and Bundesrat in particular. Figure 9.1 provides an example of such a tweet:

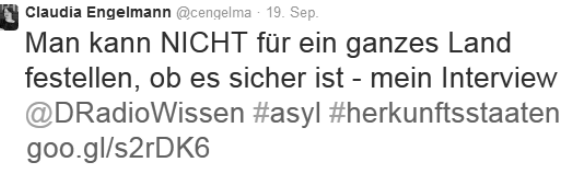

Figure 9.1: Example of tweet contributing to current asylum debate in Europe

\footnotetext{
${ }^{171}$ This is the link to the interview: http://ondemandmp3.dradio.de/file/dradio/2014/09/19/dradiowissen_asylrecht_gespraech_20140919_ac7e47a5.mp3 ${ }^{172}$ Via my twitter account https://twitter.com/cengelma
} 
Given that I extensively studied the processes leading to safe country of origin designations in Germany and other member states, it was a natural thing to follow up on these developments via twitter. Many of my comments have been retweeted.

I also commented on the role of Malta in the aftermath of the Lampedusa tragedy. When 200 migrants died in the Mediterranean Sea in October 2013, the Maltese government was accused of being complicit in not helping the migrants as well as not investigating the tragedy properly. Given that my research partly focused on Malta, I could contribute by pointing out the difficult situation in which Maltese policy-makers find themselves. However, I also critically stressed that such a difficult situation (no resources, external borders, no help from bigger member states) does not excuse the Maltese government from properly investigating the deaths of migrants at sea.

Third, I blog about the results of my research: the first blog post will be published in February 2015 as part of a network of asylum scholars in Germany (Netzwerk Flüchtlingsforschung). The blog explicitly aims at informing the wider public debate and making current asylum research accessible to media and the public. My post addresses safe country of origin policies in Europe in a comparative perspective. It primarily aims at informing NGOs for their advocacy work on SCO-related policy decisions. When governments intend to designate countries of origin as safe, they often do so with arguing that similar policies have been adopted elsewhere. My research shows that this similarity (regarding designations) is only partly true, and relates only to a small number of countries of origin.

I am currently planning a second blog post which will address the differences in collecting country of origin information across EU member states. It also aims at highlighting the big differences between national asylum administrations. While public opinion is always quick to judge on countries such as Malta, one tends to forget that the very limited resources those countries possess coupled with the large number of asylum seekers, very much determine (and limit) the possibilities of policy-makers from such countries. With informing about the differences between national asylum systems, I want to highlight the disproportionate burden hold by some (Malta, Luxembourg, or Belgium) and the relatively small burden hold by others (Germany in particular). With such a post, I aim to inform media and advocacy work of NGOs.

\section{Informing policy-makers}

Next to informing the public debate, I also aim at informing policy-makers. Several initiatives have been undertaken in this regard. I attended several events during which scholars and practitioners met to exchange their views on current topics. These events were no academic conferences but explicitly targeted towards fostering the exchange between scholars and practitioners. Most of these events took the format of scholars briefly presenting their current work followed by a discussion on its practical relevance for policy-makers. The events are listed below and one is explained in more detail. 
- 18-19 June 2012 (Berlin, Germany): conference on the future of the Dublin II Regulation with scholars and practitioners from various asylum-related fields (case officers, politicians, judges, NGO representatives)

- 15 May 2012 (The Hague, Netherlands): discussion between PhD candidates of Dutch universities and representatives from the Ministry of Interior and Kingdom Relations, Department of Migration Policy

- 5 March 2012 (Maastricht, Netherlands): discussion between migration scholars from Maastricht University and representatives from the Ministry of Interior and Kingdom Relations, Department of Migration Policy

- 20-21 October 2011 (The Hague, Netherlands): workshop with researchers from Dutch universities and pratictioners from various Dutch ministries on governance in the Area of Freedom, Security and Justice after the Lisbon Treaty

In what follows, my contribution during one event is further specified: on 15 Mai 2012, I was invited to present my research during the Art of the State - State of the Art discussion at the Dutch Ministry of Interior and Kingdom Relations. The event aimed at fostering dialogue between PhD candidates and ministry officials on the relevance of academic research for policy. The invitation explicitly focused on $\mathrm{PhD}$ candidates working in the field of asylum, migration and integration. Participating ministry officials were from the Department of Migration Policy. In what follows, a short summary of my project's valorization, as presented to Dutch ministry officials, is quoted:

The $\mathrm{PhD}$ project is relevant for public policy because it looks at a crucial aspect of both refugee status determination and asylum policy-making, namely country of origin information. The future of COI cooperation might be a side-by-side of EASO (its creation being very much pushed for by some states, including the Netherlands) and an informal COI exchange between asylum authorities of Northern and Western European member states already practiced for nearly 20 years. ${ }^{173}$

After the presentation, several ministry officials approached me individually to discuss the Dutch engagement in COI cooperation. My presentation and subsequent discussions made ministry officials aware of what their counterparts in other EU member states do (i.e. collecting COI in Germany; making COI-related policy decisions in Luxembourg) and thus related to the broader political implications of their daily work. Since them, I am connected with several of these people via linkedin and twitter, and there is thus a chance that they keep on following my work.

In sum, with the above-mentioned means of disseminating the results of my research, I intend to inform policy-makers about similar work (as theirs) being conducted in other countries; and NGOs about policy-making processes that are not easily accessi-

\footnotetext{
${ }^{173}$ Ministerie van Binnenlandse Zaken en Koninkrijksrelaties (2012). Art of the State - State of the Art. Asiel immigratie en integratieonderzoek. Samenvatting van PhD-onderzoek ter gelegenheid van de Promovendimiddag. 15 mei 2012. The Hague.
} 
ble. Most importantly, I aim to contribute to a balanced public debate in the field of asylum policy. 



\section{About the author}

Claudia Engelmann (Leipzig, 1982) studied International Human Rights Law at Oxford University, and graduated in 2010. She also holds an MA degree in German Literature, Political Science and Law from the University of Konstanz (2007). She also spent one semester at the University of Stockholm on the Erasmus Programme. During and after her studies, she worked for several organisations in the field of human rights and political education, including the German Institute for Human Rights (Berlin), the United Nations Association of Germany (Berlin) and the Conference of NGOs in Consultative Relationship with the UN (Geneva).

Since November 2009, Claudia has been a PhD candidate at Maastricht University. Her research focused on decision-making in the EU member states, and asylum policy in particular. The findings of her research have been published in the European Journal of Migration and Law and the Zeitschrift für Vergleichende Politikforschung. Claudia also co-authored a chapter in the International Handbook on Informal Governance. Besides her research, Claudia has been very active in teaching at the BA European studies. She served as a tutor for numerous courses, coordinated courses, gave lectures at both BA and MA level and initiated several workshops on research methods.

Currently, Claudia is a lecturer in European Public Policy at the Department of Political Science at Maastricht University. Beyond academia, she continues being involved in several political education projects. 

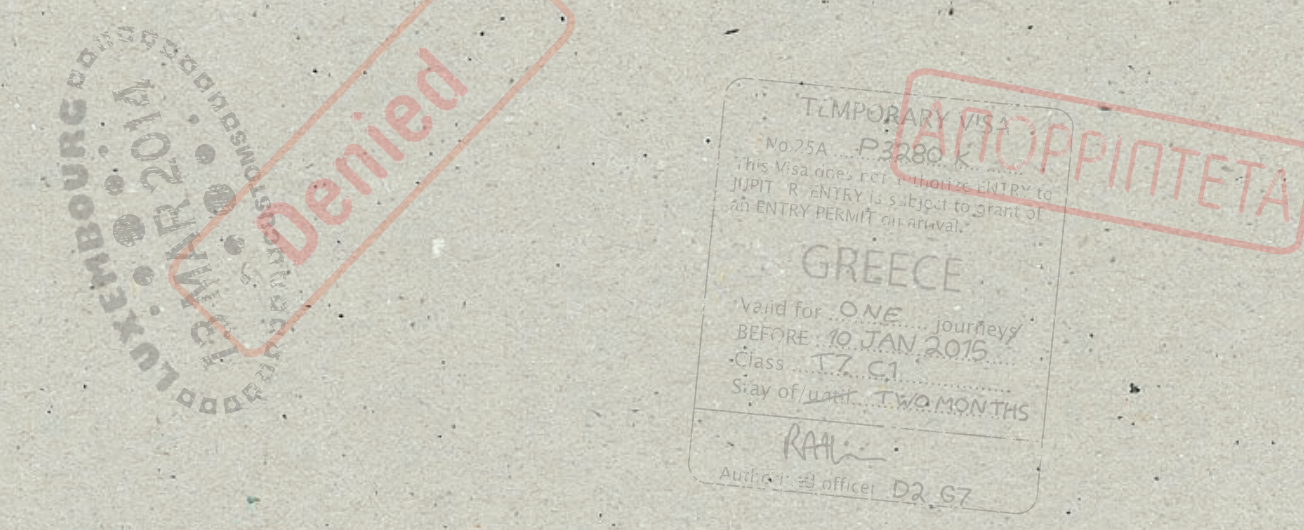

48
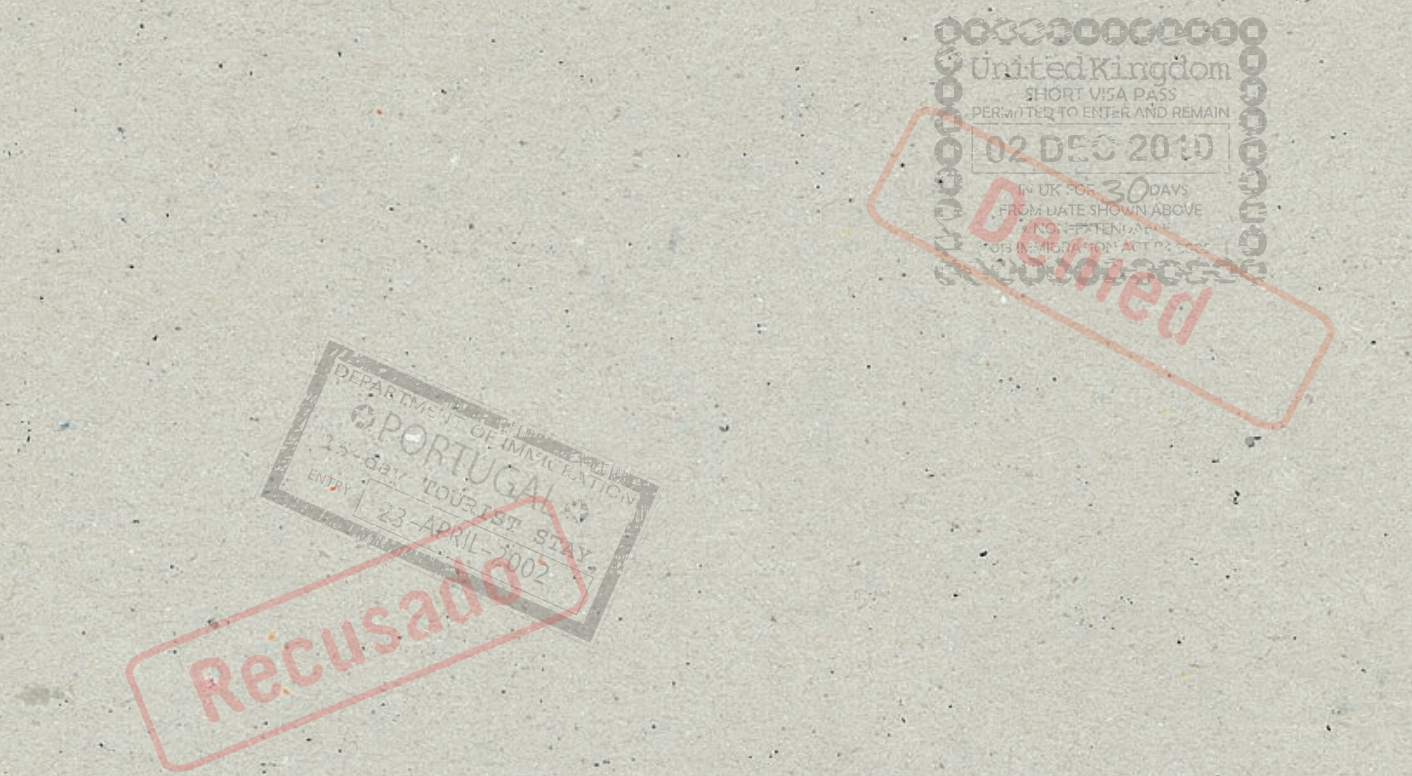